\title{
New Zealand weather extremes and climate-related events; a model-based assessment
}

Benjamin John Nistor

A thesis submitted to Victoria University of Wellington in fulfilment of the requirements for the degree of Master of Science in Physical Geography

School of Geography, Environment and Earth Sciences

Victoria University of Wellington, New Zealand

March 2018 


\section{ABSTRACT}

Extreme weather and climate-related events can have pronounced environmental, economic and societal impacts, yet large natural variability within Earth's constantly evolving climate system challenges the understanding of how these phenomena are changing. Increasingly powerful climate models have made it possible to study how certain factors, including anthropogenic forcings, have modified the likelihood and magnitude of extreme events.

This study examines climate observations, reanalysis fields and model output to assess how weather extremes and climate-related events have changed. Part 1 investigates the detection and attribution of surface climate changes in relation to ozone depletion. Part 2 uses probabilistic event attribution and storyline frameworks to evaluate the role of anthropogenic forcings in altering the risk of extreme 1-day rainfall (RX1D) events for Christchurch, New Zealand in light of an unprecedented rainfall event that occurred in March 2014.

Extremely large simulations of possible weather generated by the weather@home Australia-New Zealand (w@h ANZ) model found ozone forcings induced significant changes globally $(<3 \mathrm{hPa})$ in simulations of mean sea level pressure for 2013. A clear seasonal response was detected in the Southern Hemisphere $(\mathrm{SH})$ circulation that was consistent with prior studies. Ozone-induced changes to average monthly rainfall were not significant in New Zealand with large natural variability and the limitation of oneyear simulations challenging attribution to this climate forcing.

In Christchurch, model and observational data give evidence of human activity increasing the likelihood and magnitude $(+17 \%)$ of RX1D events despite significant drying trends for mean total rainfall $(-66 \%)$ in austral summer. For events similar to that observed during March 2014, the fraction of attributable risk (FAR) is estimated to be $27.4 \%$. This result was robust across different spatial averaging areas though is sensitive to the rainfall threshold examined. Unique meteorological conditions in combination with anomalously high sea surface temperatures (SSTs) in the tropical South Pacific were likely important to the occurrence of this extreme event. These results demonstrate how human influence can be detected in present-day weather and climate events. 


\section{ACKNOWLEDGEMENTS}

I would first like to acknowledge my supervisors, Prof. James Renwick and Dr Suzanne Rosier, for their immense support, guidance and critique during this research. This thesis would not have been possible without your input. A big thanks to James for his encouragement and accessibility, always ready to help find a solution or to share a unique opportunity, and Sue for her patience and attention to detail helping to ensure this research has been grounded in robust attribution science.

Many thanks also to Dr Trevor Carey-Smith who has been a tremendous help in navigating and reviewing the technical aspects of the statistical analyses. Thanks to Prof. Dave Frame in providing critical insights, feedback and oversight with this research. I would like to acknowledge Mitchell Black, Sarah Sparrow and the respective institutions involved with climateprediction.net for their work in setting up the Weather@home Australia-New Zealand project upon which this research has been based. Thanks also go to the many members of the public who have helped to process the large datasets in this distributed computing research. I would also like to thank Stephen Stuart, Damien Irving and Aleksandr Beliaev for their guidance in handling, processing and analysing the huge datasets involved in this research.

I am grateful to Victoria University of Wellington and Scholarships New Zealand for awarding me the scholarships to pursue this research. Additionally, to NIWA and the Deep South National Science Challenge for the resources they have contributed, alongside the Meteorological Society of New Zealand, Australian Meteorological and Oceanographic Society, and Australian Research Council for Climate System Science in supporting my attendance of workshops and conferences.

A heartfelt thanks to my flatmates for seeing me through the ups and downs, the late nights and celebrations; to my friends and office mates who have supported me with latenight antics, laughter, chocolate, exercise breaks, ice-cream and more; Zahra Islam for her awesome assistance proofreading, as well as Ricardo Delgado and Karsten Lorentz for the adventures - this year would not have been the same without you guys! Finally, a huge thank you to my parents for their unwavering support. Your constant encouragement and backing in all my pursuits helped make this possible. 


\section{CONTENTS}

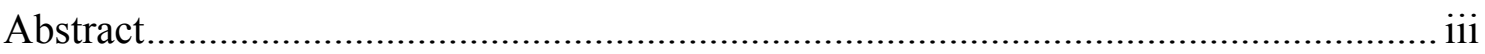

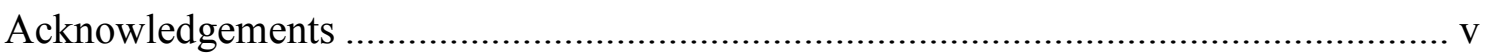

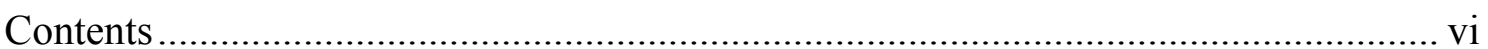

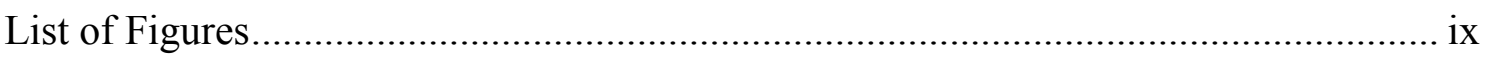

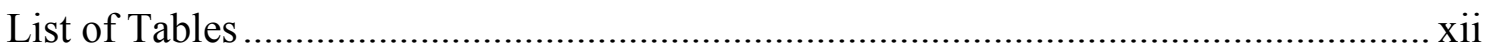

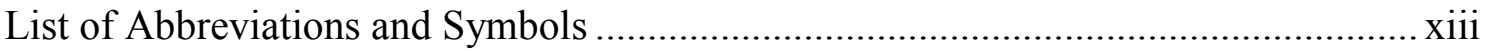

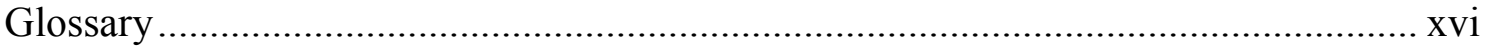

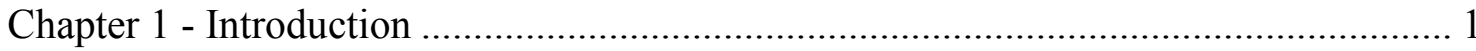

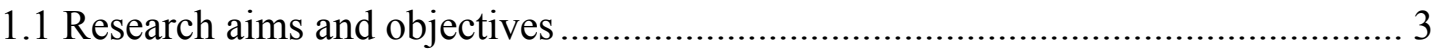

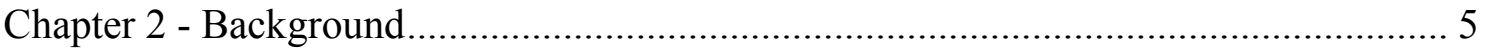

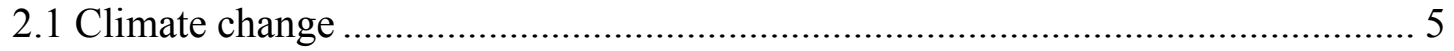

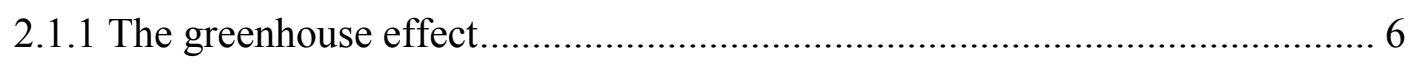

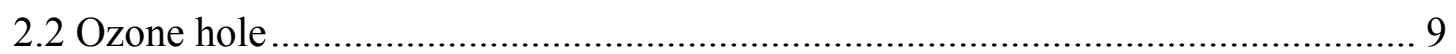

2.2.1 Southern Annular Mode _........................................................................ 12

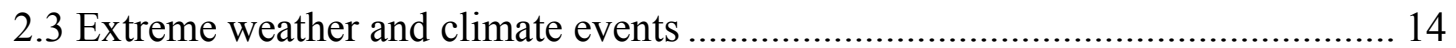

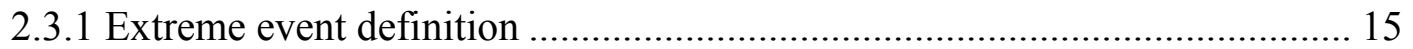

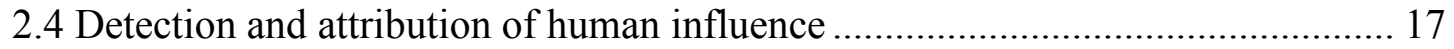

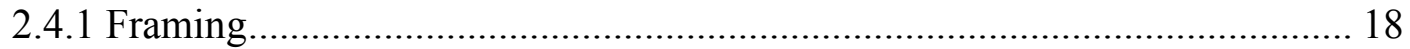

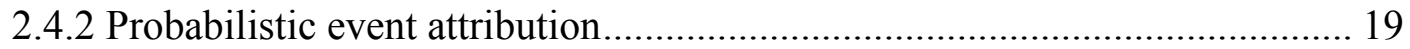

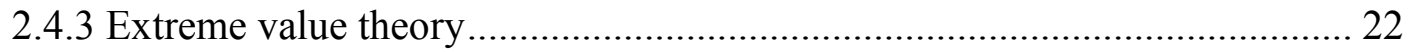

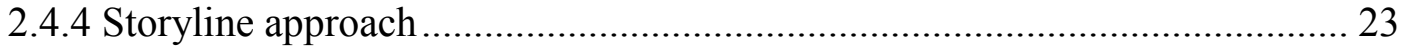

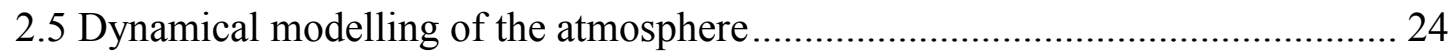

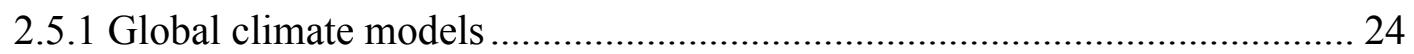

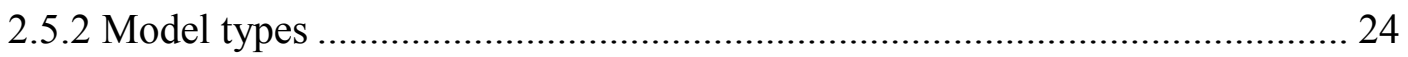


2.5.3 Weather@home

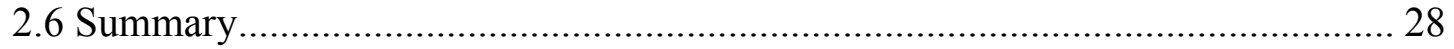

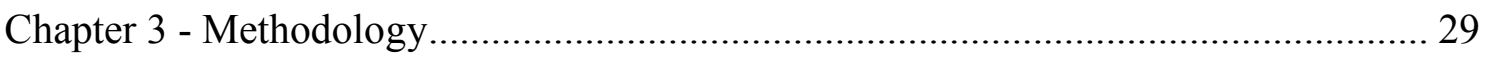

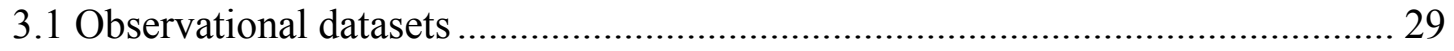

3.2 Weather@home model description ..................................................................... 29

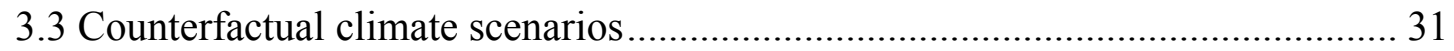

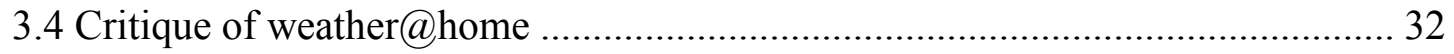

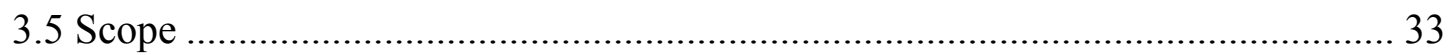

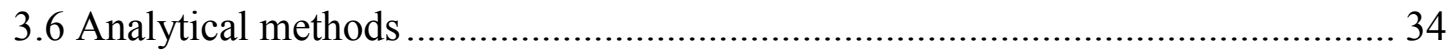

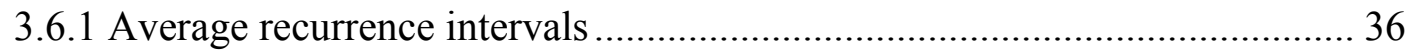

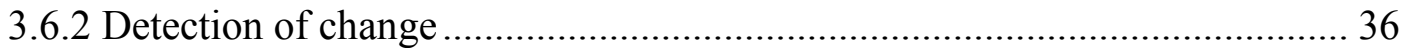

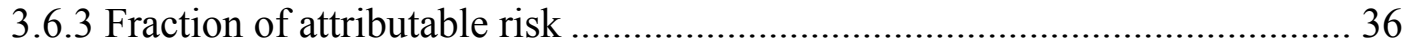

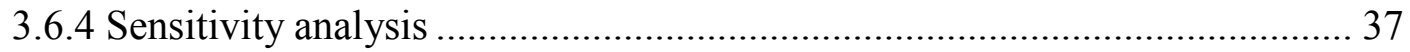

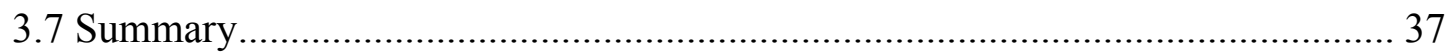

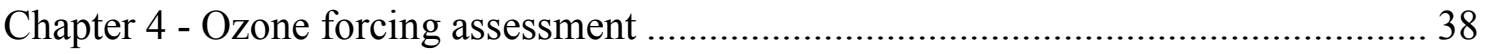

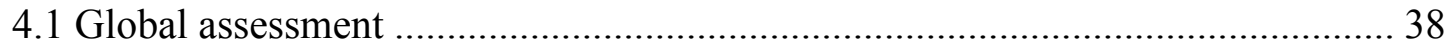

4.2 Westerly winds and the Southern Annular Mode............................................. 43

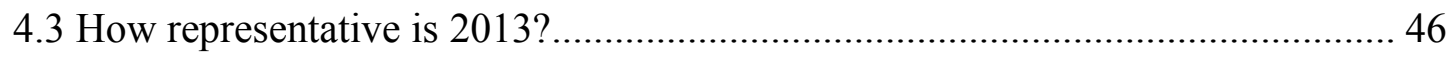

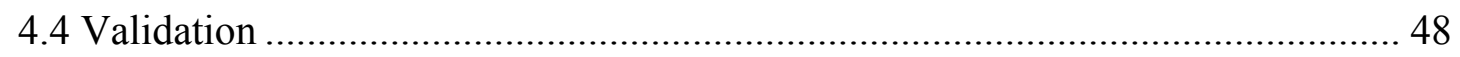

4.5 New Zealand surface climate changes........................................................... 50

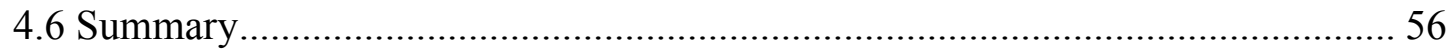

Chapter 5 - Extreme one-day rainfall in March 2014 for Christchurch ......................... 57

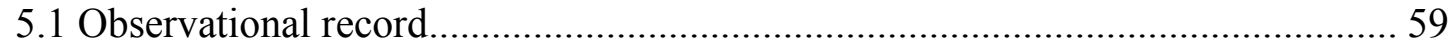

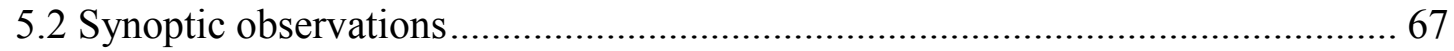

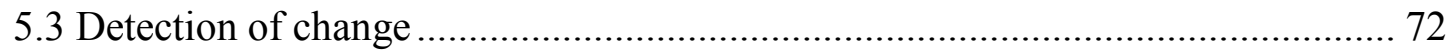

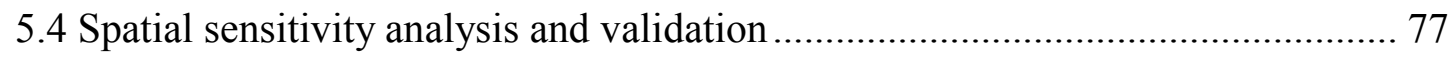

5.5 To what degree was this event influenced by global climate change? ................. 85 
5.6 Assigning the fraction of attributable risk 91

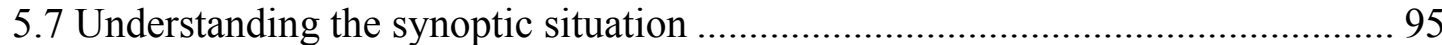

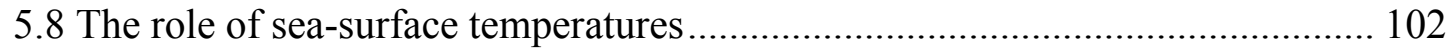

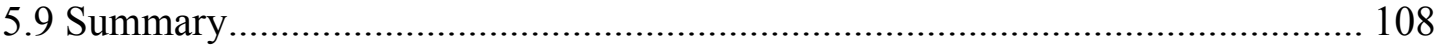

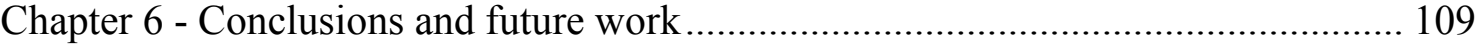

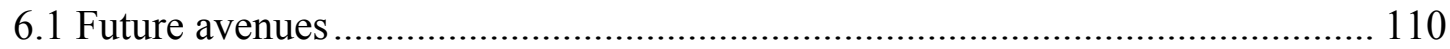

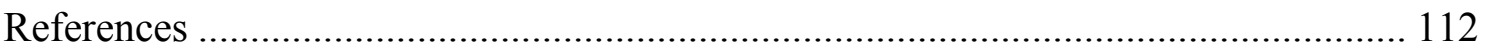

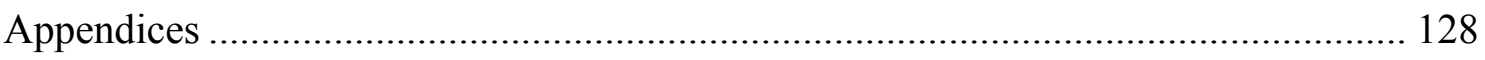

Appendix A: Mean sea level pressure anomalies for 2013 ..................................... 128

Appendix B: 1986 South Canterbury flood ............................................................ 129 


\section{LIST OF FIGURES}

Figure 2.1: Energy forms and transformations in the atmosphere ................................ 6

Figure 2.2: A simplified illustration of the greenhouse effect........................................ 7

Figure 2.3: Atmospheric windows in the electromagnetic spectrum ............................ 7

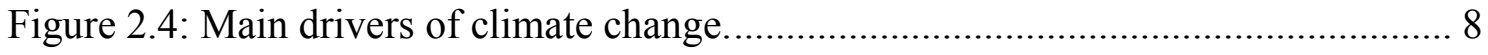

Figure 2.5: Southern Hemisphere tropospheric climate impacts of Antarctic ozone

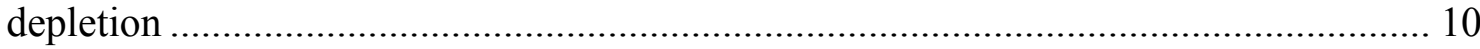

Figure 2.6: SAM response to ozone and greenhouse gas forced experiments ............... 11

Figure 2.7: DJF zonal mean change in precipitation for 1979-2000 ............................ 13

Figure 2.8: Depiction of temperature and precipitation extremes ............................... 16

Figure 2.9: Estimation of the fraction of risk for an extreme precipitation event

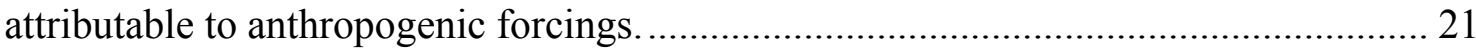

Figure 2.10: W@h ANZ regional model domain and elevation representation............. 27

Figure 4.1: Ozone hole analysis (A-O) monthly MSLP anomalies for 2013 ................ 40

Figure 4.2: Climate change analysis (A-N) monthly MSLP anomalies for 2013 ........ 41

Figure 4.3: Distribution of global MSLP anomaly z-scores for the climate change (A-N)

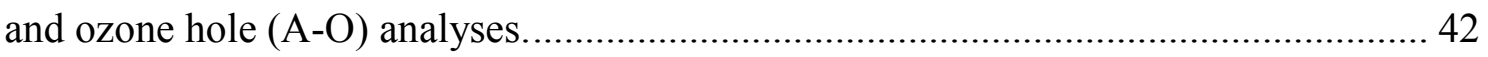

Figure 4.4: Distribution of z-scores for MSLP anomaly between $35^{\circ} \mathrm{S}$ and $65^{\circ} \mathrm{S}$ for the

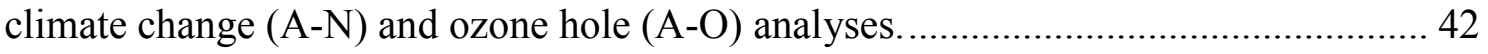

Figure 4.5: Zonally averaged MSLP anomalies by month in 2013 for the ozone hole analysis (A-O) 43

Figure 4.6: Zonally averaged mean westerly wind anomalies for 2013 at $850 \mathrm{hPa}$ for the ozone hole analysis (A-O)

Figure 4.7: Pseudo-SAM index for 2013 in the ALL (A), NAT (N) and ALL_NAT_O3 (O) climate forcing scenarios 46

Figure 4.8: October 2013 MSLP compared to 1979-2017 climatology ........................ 47

Figure 4.9: November 2013 MSLP compared to 1979-2017 climatology.................... 48

Figure 4.10: W@h bias in mean monthly MSLP for 2013 ........................................ 49

Figure 4.11: W@h bias in the westerly component of wind at $850 \mathrm{hPa}$ for 2013 ......... 50

Figure 4.12: Monthly precipitation anomaly in the ozone hole analysis (A-O) for 2013

Figure 4.13: South Island of New Zealand as represented by the w@h ANZ model.... 52 
Figure 4.14: Histogram comparing of November daily precipitation for the West Coast under the ALL (A) and ALL_NAT_O3 (O) forcings scenarios

Figure 4.15: Monthly westerly wind anomaly at $850 \mathrm{hPa}$ in the 2013 ozone hole analysis (A-O). 55

Figure 5.1: Hourly total rainfall in Riccarton from $2^{\text {nd }}-7^{\text {th }}$ March 2014. 57

Figure 5.2: Interpolated Christchurch flood depths for $5^{\text {th }}$ March 2014. 58

Figure 5.3: Rainfall stations located within $50 \mathrm{~km}$ of Christchurch's central business district. 60

Figure 5.4: VCSN $24 \mathrm{hr}$ precipitation from $3^{\text {rd }}$ March $-5^{\text {th }}$ March 2014. 63

Figure 5.5: VCSN total precipitation for the Canterbury region on $4^{\text {th }}$ March 2014 64

Figure 5.6: Time series of annual and March RX1D rainfall for Christchurch Gardens weather station. 64

Figure 5.7: Extreme value distributions for Christchurch Gardens March RX1D rainfall.

Figure 5.8: Extreme value distributions for Christchurch Gardens annual 1-day maximum rainfall 66

Figure 5.9: Synoptic circulation over New Zealand at UTC 1200 for the $2^{\text {nd }}-5^{\text {th }}$ March 2014. 68

Figure 5.10: Track of tropical cyclone Kofi. 69

Figure 5.11: Vertical integral of water vapour at UTC 1200 on $4^{\text {th }}$ March 2014.......... 70

Figure 5.12: Total precipitation for $12 \mathrm{hrs}$ preceding UTC 1200 on $4^{\text {th }}$ March 2014 ... 70 Figure 5.13: HYSPLIT $96 \mathrm{hr}$ back trajectory analysis from Christchurch .................... 71

Figure 5.14: SST anomalies for March 2014 from 1981-2010 average........................ 72

Figure 5.15: DJF precipitation distribution for events $\geq 1 \mathrm{~mm}$ observed at Christchurch Gardens for the periods 1899-1957 and 1959-2017. 74

Figure 5.16: Top three RX1D rainfall events annually for DJF at Christchurch Gardens for the periods 1899-1957 and 1959-2017. 74

Figure 5.17: MAM precipitation distribution for events $\geq 1 \mathrm{~mm}$ observed at Christchurch Gardens for the periods 1899-1957 and 1959-2017 75

Figure 5.18: Top three RX1D rainfall events annually for MAM at Christchurch Gardens for the periods 1899-1957 and 1959-2017. 76 Figure 5.19: W@h ANZ model representation of the South Island indicating the analysis domains 78 
Figure 5.20: W@h ANZ extent for Chch1, Chch4, Chch9_land and Chch9 in relation to topographic relief.

Figure 5.21: Quantile-quantile plot of March RX1D for Christchurch Gardens and w@h ANZ

Figure 5.22: Quantile-quantile plot of March RX1D in Christchurch from VCSN and w@h ANZ.. 82

Figure 5.23: VCSN March RX1D time series for 1972-2017 83

Figure 5.24: Extreme value distributions for VCSN Chch1 March 1-day maximum rainfall 84

Figure 5.25: Chch1 simulated RX1D return period estimates 87

Figure 5.26: Chch4 simulated RX1D return period estimates.................................... 88

Figure 5.27: Chch9 simulated RX1D return period estimates...................................... 89

Figure 5.28: Chch9L simulated RX1D return period estimates 90

Figure 5.29: Fraction of attributable risk (FAR) for March 2014 maximum 1-day total precipitation thresholds

Figure 5.30: Distribution of March 2014 maximum 1-day rainfalls for ALL and NAT forcings in Chch1 and Chch4

Figure 5.31: Simulated precipitation and synoptic circulation for ALL forcings first and second largest Chch1 RX1D events 96

Figure 5.32: Simulated precipitation and synoptic circulation for ALL forcings third and fourth largest Chch1 RX1D events.

Figure 5.33: Simulated precipitation and synoptic circulation for NAT forcings first and second largest Chch1 RX1D events. 98

Figure 5.34: Simulated precipitation and synoptic circulation for NAT forcings third and fourth largest Chch1 RX1D events 99

Figure 5.35: Reanalysis total column water vapour time-series for Christchurch $\left(43.5^{\circ} \mathrm{S}\right.$, $\left.172.5^{\circ} \mathrm{E}\right)$ in March 2014.

Figure 5.36: Domains for Fiji, Tonga, Chatham Islands, east of Christchurch and south of Christchurch in SST analysis 104

Figure 5.37: February SST anomalies for south of Christchurch.............................. 105

Figure 5.38: February SST anomalies for Chatham Islands...................................... 105

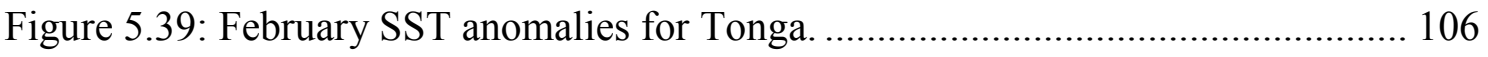

Figure 5.40: Time series of the Oceanic Niño Index $\left({ }^{\circ} \mathrm{C}\right)$ from 1950 to $2017 \ldots \ldots \ldots \ldots . . .107$ 


\section{LIST OF TABLES}

Table 2.1: Extreme precipitation indices

Table 3.1: Details on the ALL (A), NAT (N) and ALL_NAT_O3 (O) scenario ensembles.

Table 4.1: Rainfall on the West Coast for ALL (A), ALL_NAT_O3 (O) and NAT (N) scenarios

Table 5.1: Total daily precipitation on $5^{\text {th }}$ March for Christchurch weather stations..... 59

Table 5.2: Average recurrence interval (ARI) of historical heavy total rainfall events for Christchurch Gardens.

Table 5.3: Change in extreme rainfall events that exceed the $98^{\text {th }}$ percentile $(34.9 \mathrm{~mm})$ at Christchurch Gardens between 1899-1957 and 1959-2017 by season.

Table 5.4: Average recurrence interval (ARI) of historical heavy rainfall events for VCSN spatial domains; Chch1, Chch4 and Chch9L. 83

Table 5.5: Descriptors of the top ten simulated 1-day rainfall events in the ALL and NAT forcing ensembles for Chch1 and Chch4. 


\section{LIST OF ABBREVIATIONS AND SYMBOLS}

ALL: The historical ('all forcing') climate scenario that has been impacted by anthropogenic forcings, natural forcings and internal variability

ANZ: $\quad$ Australia New Zealand

AR: $\quad$ Atmospheric River

ARI: $\quad$ Average Recurrence Interval

BAMS: $\quad$ Bulletin of the American Meteorological Society

BOINC: $\quad$ Berkeley Open Infrastructure for Network Computing

CDO: $\quad$ Climate Data Operators

CliDB: $\quad$ National Climate Database

CMIP5: $\quad$ Coupled Model Intercomparison Project Phase 5

DJF: $\quad$ December, January, February

ENSO: $\quad$ El Niño Southern Oscillation

ETC: $\quad$ Ex-tropical Cyclone

ETCCDI: Expert Team on Climate Change Detection and Indices

EVT: $\quad$ Extreme Value Theory

FAR: $\quad$ Fraction of Attributable Risk

GCM: $\quad$ Global Climate Model

GEV: $\quad$ Generalised Extreme Value

GHG: $\quad$ Greenhouse Gas

GLO: $\quad$ Generalised Logistic 
GPCP: Global Precipitation Climatology Project

HadAM3P: Hadley Centre Atmospheric General Circulation Model 3P

HadRM3P: Regional configuration of HadAM3P

HYSPLIT: Hybrid Single Particle Lagrangian Integrated Trajectory Model

IPCC: $\quad$ Intergovernmental Panel on Climate Change

IR: $\quad$ Infrared Radiation

JJA: June, July, August

MAM: $\quad$ March, April, May

NASEM: National Academy of Science, Engineering and Medicine

NAT: The counterfactual ('natural') climate scenario that has only been impacted by natural forcings and internal variability

NCO: $\quad$ NetCDF Operators

NIWA: National Institute of Water and Atmospheric Research

NOAA: National Oceanic and Atmospheric Administration

NZ: $\quad$ New Zealand

NZLT: $\quad$ New Zealand Local Time

OLR: $\quad$ Outgoing Longwave Radiation

ONI: $\quad$ Oceanic Niño Index

P: $\quad$ Probability

$\mathrm{P}_{\mathrm{T}}: \quad$ Total Precipitation

PEA: $\quad$ Probabilistic Event Attribution

RCM: $\quad$ Regional Climate Model 
RCP: Representative Concentration Pathway

RX1D: Monthly Maximum 1-day Precipitation

SAM: $\quad$ Southern Annular Mode

SH: $\quad$ Southern Hemisphere

SON: $\quad$ September, October, November

SST: $\quad$ Sea Surface Temperature

SWR: $\quad$ Shortwave Radiation

TCWV: $\quad$ Total Column Water Vapour

VCSN: $\quad$ Virtual Climate Station Network

W@h ANZ: Weather@home Australia-New Zealand

WMO: World Meteorological Organisation 


\section{GLOSSARY}

Anthropogenic: Resulting from or produced by human activities.

Attribution: The process of evaluating the relative contributions of multiple causal factors to a change or event with an assignment of statistical confidence (Hegerl and Zwiers, 2011).

Conditioning: The process of limiting an attribution analysis to particular types of weather or climate situations. For example, an attribution study may assess whether human influence on the climate plays a role in a given type of event when El Niño "conditions" prevail.

Counterfactual: From the perspective of attribution studies, counterfactual refers to a hypothetical 'control' world that has only been impacted by natural forcings and internal variability. In practice it usually refers to the observed climatic conditions (e.g., a specific SST distribution) as they might have occurred had anthropogenic forcing been absent.

Detection: Detection of change is defined as the process of demonstrating that climate or a system affected by climate has changed in some defined statistical sense without providing a reason for that change (Hegerl and Zwiers, 2011).

Dynamic: Concerning the motion of bodies under the action of forces. In the context of event attribution, dynamics would include both large-scale circulation patterns, which can modulate temperature and precipitation extremes, and storms.

Ensemble: A collection of similar entities. In climate science, the term usually refers to a collection of simulations by a single model but with different initial conditions or to a set of simulations of similar design by different climate models.

External forcing: A forcing agent outside the climate system causing a change in the climate system. Volcanic eruptions, solar variations, and anthropogenic changes in the composition of the atmosphere and land use change are external forcings. 
Extreme event: An event that is rare at a particular place and time of year. Definitions of rare vary, but an extreme weather event would normally be as rare as or rarer than the 10th or 90th percentile of a probability density function estimated from observations.

Factual: From the perspective of attribution studies factual refers to the currently observed world as it exists in the context of climate change.

Fraction of Attributable Risk: The fraction of the likelihood of an event that is attributable to a specific causal factor.

Framing: The process of posing scientific questions that arise when an event occurs and establishing the context within which they are answered.

Internal variability: The technical term that is often used to describe the natural, unforced, chaotic variability that occurs continually in the climate system. It is a component of natural variability.

Natural variability: Internally (such as El Niño-Southern Oscillation) and externally (e.g. volcanic eruptions or changes in solar radiance) induced natural climate variability that occurs without anthropogenic forcing.

Return period: A return period (or average recurrence interval) is a commonly used metric of probability; for example, a 100-year return period means that in any given year, there is a 1 -in-100 chance of the threshold being reached.

Storm track: Regions of the mid-latitudes where storms most commonly occur. They tend to follow the dominant westerly winds.

Synoptic scale: The minimum horizontal spatial scale of weather systems (e.g. high and low pressure areas, fronts) (Sturman and Tapper, 2006).

Thermodynamic: Concerning heat and temperature, and their relation to energy and work. In the context of event attribution, thermodynamics would include behaviour related to the warming and increased moisture-holding capacity of the atmosphere.

These definitions are consistent with terminology used in reports by the Intergovernmental Panel on Climate Change (e.g., IPCC, 2013) and the United States National Academies of Sciences, Engineering and Medicine (NASEM, 2016). 


\section{CHAPTER 1 - INTRODUCTION}

The chaotic nature of weather and non-stationarity in our climate system are formidable scientific challenges to understanding extreme weather and climate-related events. These challenges come to the fore when evaluating how such events are changing or when attributing causality to specific climate drivers, including human-induced climate change (Sippel et al., 2015). As extreme weather and climate events can have pronounced impacts on the environment, economy and society, it is important that robust climate assessments are made that help ascertain climate risk and guide climate adaptation strategies (Dong et al., 2017).

Warming over the last century is unequivocal and has given rise to unprecedented changes in many aspects of our climate system (IPCC, 2013; Reisinger et al., 2014). In order to understand climate change risks, the contributions of multiple causal factors need to be understood in addition to providing an assignment of statistical confidence (Stott et al., 2016). The relative shortness of observational records in addition to limitations around data availability and quality, necessitate the use of complementary approaches to detect and interpret climate changes.

Event attribution quantifies how the risk of weather and climate-related events have changed in response to particular internal or external forcings (Allen, 2003; Stott et al., 2004; Pall et al., 2011; Black et al., 2016). As it is not possible to observe counterfactual 'natural' worlds without human influence on the climate, physically-based climate models are required to simulate how the weather and climate would have been (Stott $e t$ $a l ., 2016)$. Cause and effect can then be explored by assessing the response under different scenarios while ensuring the same prescribed boundary conditions (e.g. seasurface temperature and sea-ice extent).

Extreme weather events are inherently rare, making them difficult to analyse reliably (Guillod et al., 2017). Simulation-based approaches using global climate models (GCMs) allow for the generation of large ensembles of realisations from which the statistics of rare events can be evaluated. Large samples of the relevant climatic variable (e.g. precipitation, in investigating a flood event) are generated in ensembles with and without the climate forcings of interest. The distribution of the variable in each scenario can thus 
be constructed to obtain estimates of changing probability. Downscaling of GCM simulations by regional climate models (RCMs) then provides higher spatial and temporal resolution datasets to assist with the investigation of localised impacts associated with extremes.

One modelling system developed for event attribution studies of extreme weather events isweather@home Australia - New Zealand herein referred to as w@h ANZ. As a member of the climateprediction.net project,w@h ANZ utilises a network of volunteer distributed computing to generate very large ensembles of the HadRM3P regional climate model driven by the HadAM3P atmosphere-only global model (Massey et al., 2015). Since development,w@h ANZ has been successfully used for the attribution of many extreme weather events across the globe, including in New Zealand (e.g. Rosier et al., 2015).

Over the last century, anthropogenic forcings including increasing greenhouse gases (GHGs) and stratospheric ozone depletion have had a substantial influence on the surface climate of the Southern Hemisphere (SH; Thompson et al., 2011). Regions as far equatorward as the subtropics are thought to have experienced radiative and dynamical effects associated with the Antarctic ozone hole, while the signature of GHGs has been pervasive globally. During austral summer, the impact of the ozone hole is greatest with a strong resemblance to the positive phase of the Southern Annular Mode (SAM), the most prominent pattern of large-scale climate variability in the SH. This shift towards a high-index polarity of the SAM is generally associated with a poleward shift in the SH storm track (Gillet and Thompson, 2003; Polvani et al., 2011), an acceleration of the prevailing westerly winds for high latitudes $\left(\sim 55-70^{\circ} \mathrm{S}\right)$ and deceleration of prevailing westerly winds for the mid-latitudes $\left(\sim 35-50^{\circ} \mathrm{S}\right)$ (Thompson et al., 2011). As both the westerly wind belt and the associated storm track are important rainfall sources for SH mid-latitudes (Son et al., 2009), understanding the timing and magnitude of change is critical to predicting future precipitation in New Zealand (NZ). Furthermore, recovery of stratospheric ozone is expected to oppose anticipated changes in the SAM due to increasing GHGs (Arblaster et al., 2011), making it important to correctly assign the contributions of different anthropogenic climate forcings to inducing change.

Increasing GHG concentrations are also anticipated to increase maximum atmospheric moisture availability due to thermodynamic changes (Held and Soden, 2006; Seager et 
al., 2010) (Arblaster et al., 2011). In a warmer world the additional latent heat that can be released by this moisture may lead to more intense and more extreme weather (Shepherd, 2016). As such there is a strong interest in discerning if damaging events can be attributed to anthropogenic climate change (Pall et al., 2011). This has given rise to several methods and frameworks for evaluation of evolving climate conditions and extreme weather. In early March 2014, Christchurch, NZ was inundated by torrential rainfall during an extreme 1-day rainfall event (RX1D). This event is examined as a case study to assess if and how its properties may have changed as a result of GHG emissions. While specific weather and climate events cannot be solely attributed to a single cause, climate models such as those used in w@h ANZ make it possible to estimate how certain factors, including anthropogenic forcings, have modified the likelihood and magnitude of events (Dong et al., 2017).

\subsection{Research aims and objectives}

This thesis evaluates how anthropogenic forcings have contributed to modifying New Zealand's weather and climate usingweather@home ANZ regional climate simulations. The first component examines if surface climate changes can be detected and attributed to ozone depletion in the w@h ANZ model. This is achieved by:

a) Determination of anomalies in circulation and precipitation between factual and counterfactual climate change simulations for 2013, and between ozone hole and non-ozone hole 2013 simulations.

b) Establishment of the significance of changes solely due to ozone forcings.

c) Validation of the w@h ANZ simulations of large-scale circulation by comparison with ERA-Interim reanalysis fields.

d) Assessment of how representative the study period is of the long-term regional climatology.

e) Investigation of the SAM response to simulated changes in ozone forcings.

The second component investigates whether, and to what degree, there was an anthropogenic influence on extreme March 1-day rainfall in Christchurch as observed in 2014. The objectives addressed for this include: 
a) Contextualising the March 2014 extreme rainfall event within the observational and New Zealand Virtual Climate Station Network (VCSN) record.

b) Exploring how anthropogenic forcings have changed March rainfall events in Christchurch.

c) Determining the role of anthropogenic forcings in contributing to March 2014 extreme rainfall.

There is currently a limited understanding about the extent to which anthropogenic forcings, including stratospheric ozone depletion, have altered the surface climate and properties of extreme events. Improving our characterisation of the influence of anthropogenic forcings on the regional scale weather experienced in NZ will allow us to better attribute the occurrence of future extreme weather events and changes as they arise (Massey et al., 2015).

Theoretical ideas and concepts relating to anthropogenic climate forcings, extreme weather events, attribution science and dynamical modelling of the atmosphere are reviewed in the next chapter. The methodology, scope, data products and analytical techniques employed for this project are then described in Chapter 3. Chapter 4 presents and discusses the results of the assessment of ozone forcings, while Chapter 5 details findings pertaining to the extreme rainfall event in Christchurch in March 2014. The final chapter summarises the findings of this research and outlines potential avenues for future research. 


\section{CHAPTER 2 - BACKGROUND}

Anthropogenic climate change is one of the greatest challenges facing humanity in the $21^{\text {st }}$ century. The most recent assessment report released by the Intergovernmental Panel on Climate Change (IPCC) reiterated the 'clear' evidence of human influence on the climate system and documented that many extreme weather and climate events have observed changes since the 1950's (IPCC, 2013). Communities around the world are now having to manage the increasing risks, impacts and implications associated with climate change (Stott et al., 2016). An important tool used in assisting decision making and advancing understanding of the dynamical causes for extreme events are climate models. Incremental advances in climate modelling capability are permitting increasingly holistic attribution statements (Stott et al., 2016). This chapter provides background information about the anthropogenic influences on our climate system, documents previous work in the field of climate attribution science and explores the use of climate models to assist understanding of the atmosphere.

\subsection{Climate change}

The sun is the primary energy source for the Earth-atmosphere system and is fundamental to driving weather and climatological processes including airflow and precipitation (Sturman and Tapper, 2006). Solar energy is converted into various other forms of energy (Figure 2.1), notably thermal, potential and kinetic energy. Earth's surface temperature is sensitive to perturbations that give rise to a surplus or deficit of energy, known as climate or radiative forcings. Forcings are classified as either natural or anthropogenic, with the latter the result of human actions. These include GHG emissions, stratospheric ozone depletion and atmospheric pollutants. Unequivocal evidence indicates that anthropogenic activity since the industrial era (1750) has substantially altered Earth's energy balance (Stott et al., 2016). The IPCC in their Summary for Policymakers state "it is extremely likely ( $>95 \%$ likelihood) that more than half the observed increase in global average surface temperature from 1951 to 2010 was caused by anthropogenic increase in greenhouse gas concentrations and other anthropogenic forcings together" (IPCC, 2013 p.17). 


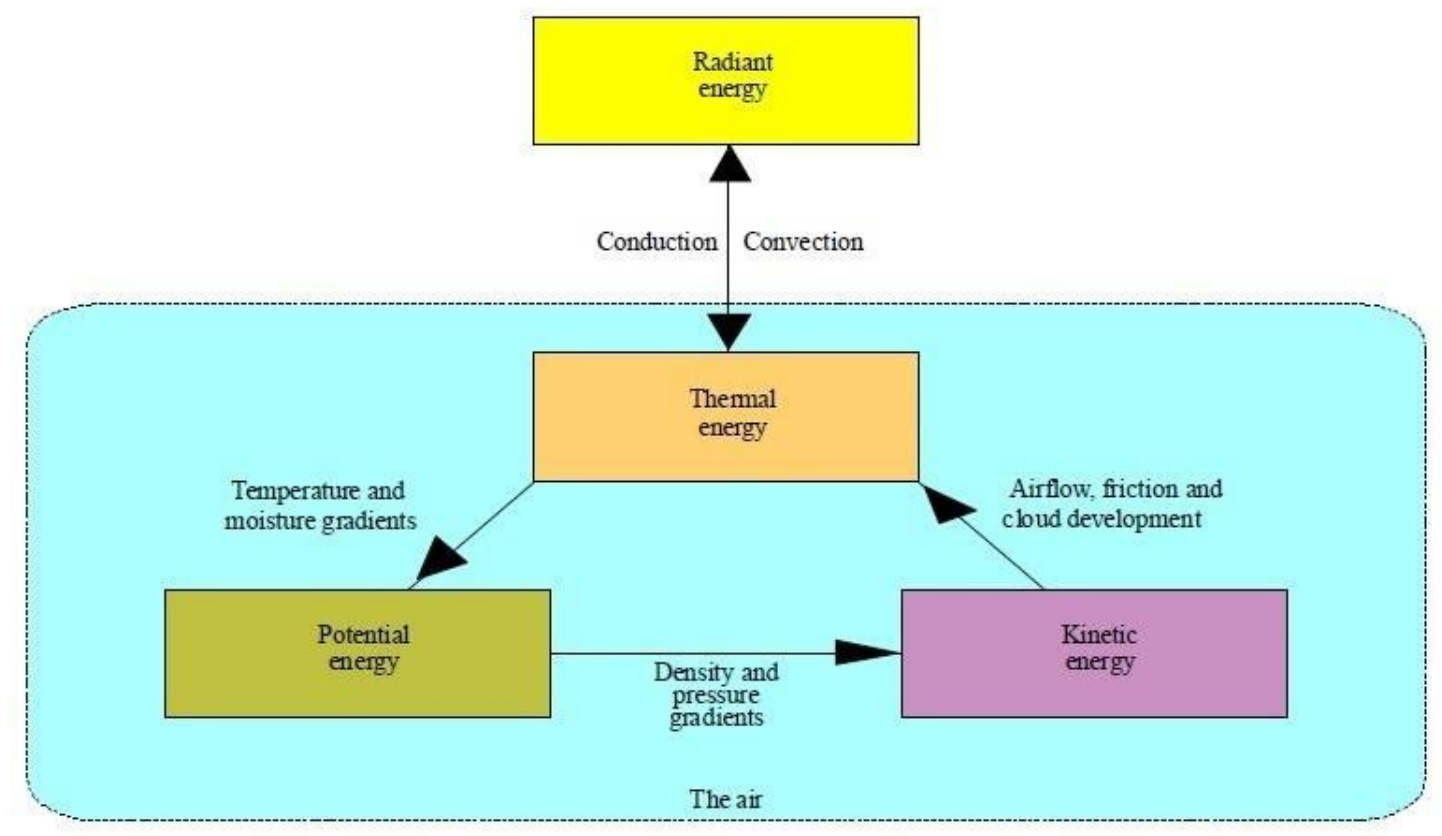

Figure 2.1: Energy forms and transformations in the atmosphere (Sturman and Tapper, 2006).

\subsubsection{The greenhouse effect}

The "greenhouse effect" (Figure 2.2) is the warming of Earth's surface and lower atmosphere due to molecules which absorb infrared radiation (IR; Sturman and Tapper, 2006). When incident to outgoing longwave radiation (OLR), certain IR active molecules including carbon dioxide $\left(\mathrm{CO}_{2}\right)$, methane $\left(\mathrm{CH}_{4}\right)$, water vapour and nitrous oxides $\left(\mathrm{NO}_{2}\right)$, undergo a change between rotational and vibrational states. Their change in dipole moment only occurs at discrete wavelengths corresponding to the size of the energy transition. As such, regions of the electromagnetic spectrum where the atmosphere allows the unimpeded passage of infrared radiation are labelled "atmospheric windows" (Figure 2.3). These "windows", however, can be closed much like in a greenhouse, by changing the composition of the atmosphere giving rise to enhanced heat retention. 


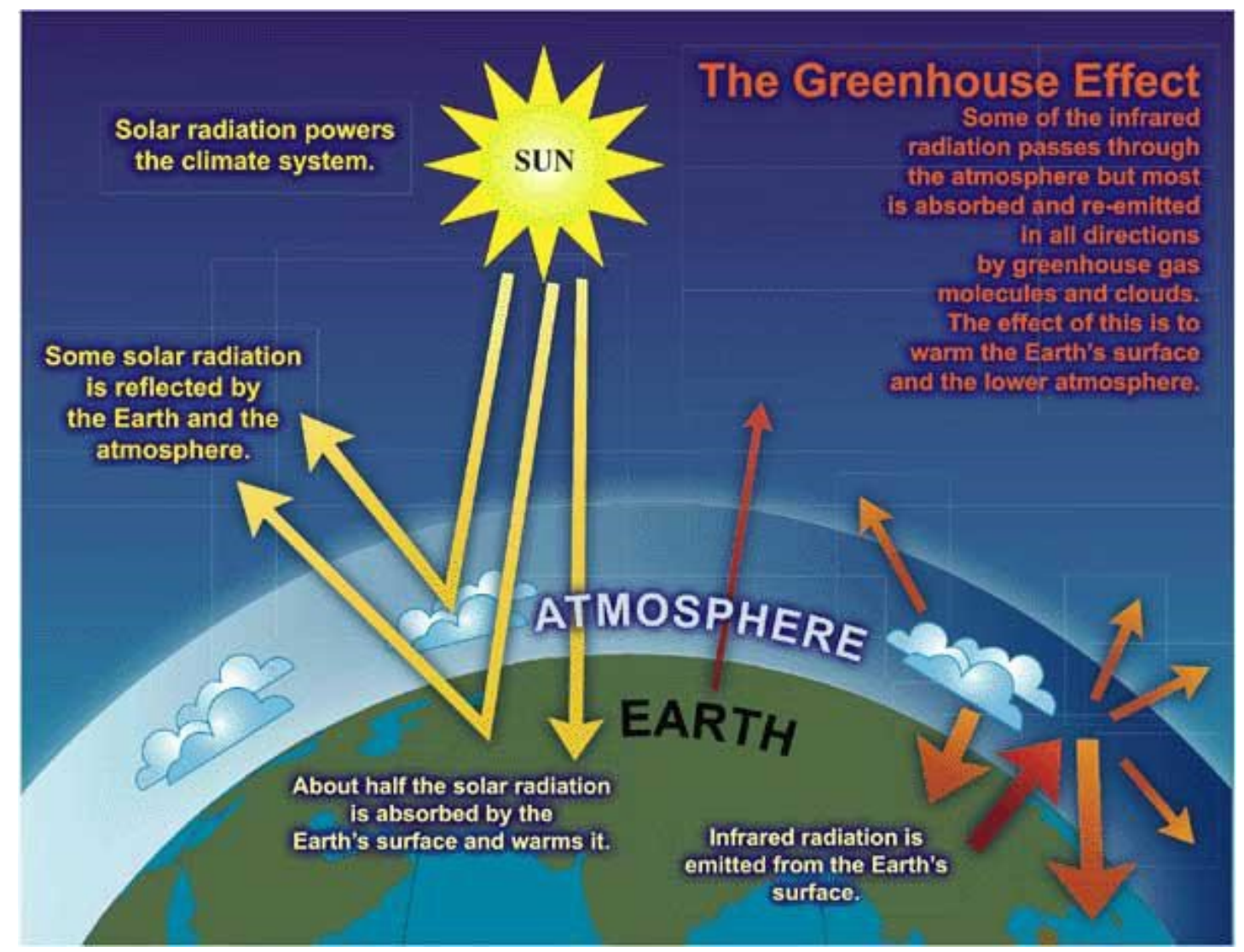

Figure 2.2: A simplified illustration of the greenhouse effect (Le Treut et al., 2007).

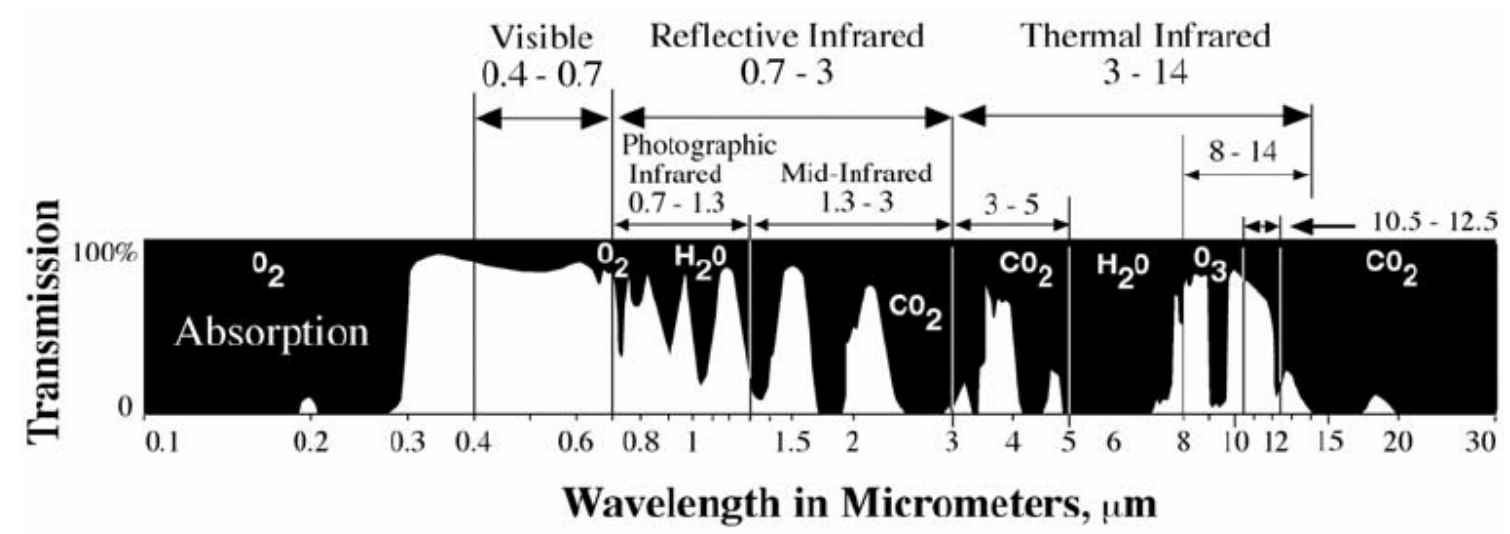

Figure 2.3: Atmospheric windows in the electromagnetic spectrum (Jensen, 2000).

Increasing concentrations of GHGs in the atmosphere reduce the size of the "windows" for energy to be radiated from Earth. As the atmosphere becomes more opaque to IR, OLR that would have been lost to space is instead absorbed by GHG molecules and a portion of this energy is re-emitted back to Earth's surface. This causes additional warming of Earth's surface and lower atmosphere known as the "enhanced greenhouse effect" until the balance of incoming shortwave radiation (SWR) and outgoing longwave radiation is restored at a new equilibrium temperature. 
Within Earth's climate system there are various temperature-induced feedbacks. One of the most fundamental feedbacks is the Clausius-Clapeyron relationship which relates rising temperatures to exponential increases in saturation vapour pressure, itself a powerful greenhouse gas (IPCC, 2012). Each 1-K increase in temperature is associated with an increase in atmospheric moisture content of approximately 7\% (Held and Soden, 2006).

Atmospheric concentrations of greenhouses gases; $\mathrm{CO}_{2}, \mathrm{CH}_{4}$ and $\mathrm{NO}_{2}$, have also increased significantly since 1750 due to human activity (IPCC, 2013). In 2017 the concentrations of these GHGs were 404 ppm (44\% increase), $1845 \mathrm{ppb}$ ( $155 \%$ increase), $329 \mathrm{ppb}$ (22\%) respectively (IPCC, 2013; ESRL, 2017). Over the period 1880-2012, globally averaged warming of $0.85^{\circ} \mathrm{C}$ has been observed and global surface temperature change, relative to $1850-1900$, is likely to exceed $1.5^{\circ} \mathrm{C}$ by 2100 with additional warming anticipated beyond this (IPCC, 2013). However, the feedbacks for numerous other climate system interactions are yet to be fully understood (Figure 2.4).

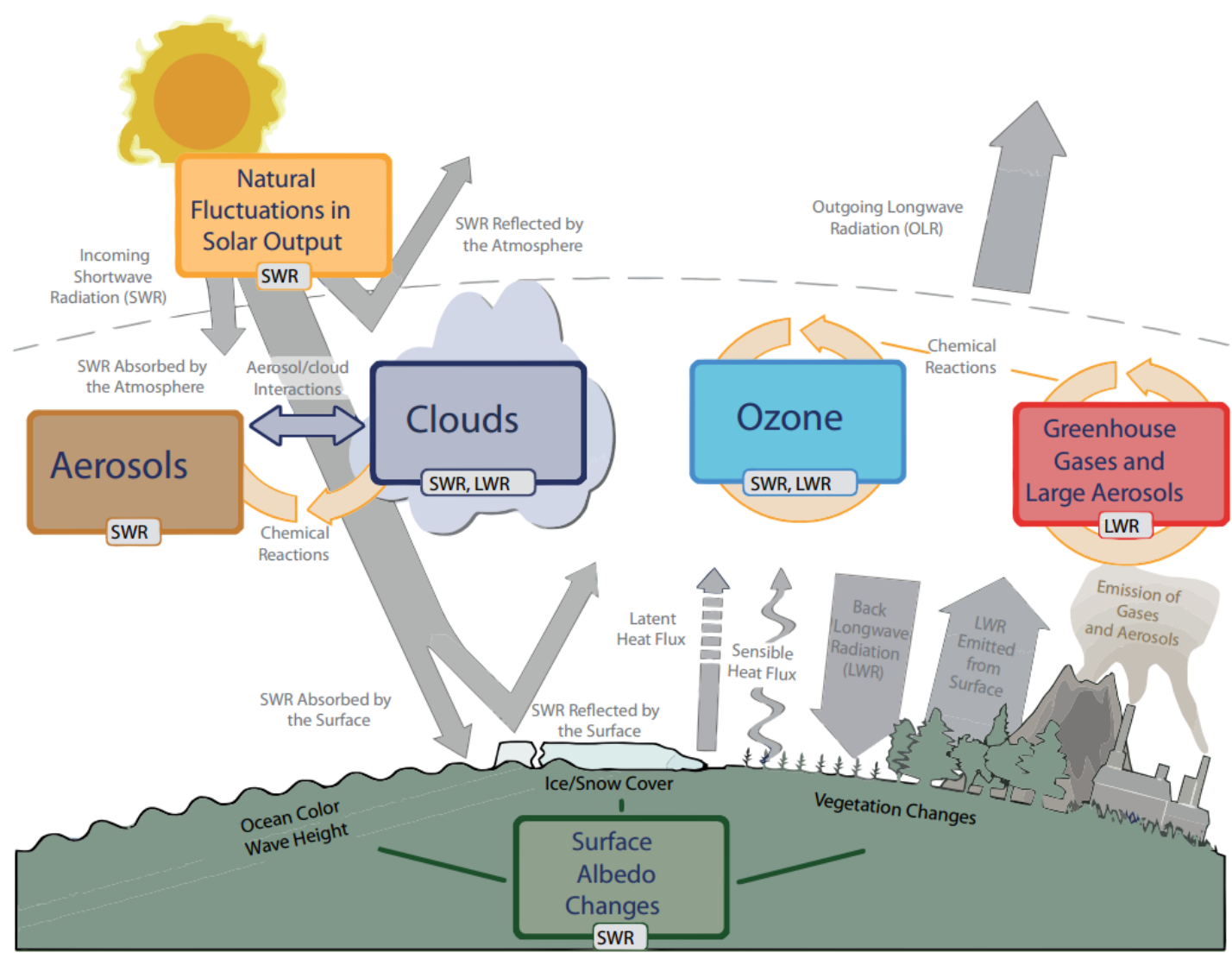

Figure 2.4: Main drivers of climate change depicting the radiative balance between incoming shortwave radiation (SWR) and outgoing longwave radiation (OLR) (Cubasch et al., 2013). 


\subsection{Ozone hole}

While anthropogenic emissions of GHGs drive widespread surface climate change, ozone forcings have greater impacts on SH circulation (Polvani et al., 2011). Since the 1970s, stratospheric ozone concentrations decreased $\sim 3-4 \%$ globally due to human activity (WMO, 2014). During the same period the Antarctic observed dramatic ozone depletion, with austral spring total column ozone losses of approximately 50\% (Previdi and Polvani, 2014). Since 2000 there has, however, been a trend towards a very modest $1 \%$ per decade recovery of stratospheric ozone concentrations (WMO, 2014). The return of sunlight in spring to the cold Antarctic stratosphere, in combination with photochemical processes, give rise to a unique set of conditions such that ozone-depleting substances become highly effective at bringing about rapid ozone destruction (Thompson et al., 2011). As an annual phenomenon, the 'ozone hole' exhibits strong seasonality, quickly developing in September/October followed by a recovery which coincides with the collapse of the stratospheric vortex in November/December (Solomon, 1999). For the lower stratosphere, where roughly $90 \%$ of atmospheric ozone is found (Thompson et al., 2011), marked radiative cooling occurs due to less incoming solar radiation being absorbed (Randel et al., 2009). The resulting change in meridional temperature gradient alters the vertical wind shear (Thompson et al., 2011), accelerating the stratospheric polar vortex during October-December. Changes in polar stratospheric geopotential height ( $\mathrm{Z}$ ) persist through January (Waugh et al., 1999; Thompson and Solomon, 2002) and project into the troposphere, affecting the mid-latitude circulation down to the Earth's surface (Thompson and Solomon, 2002; Gillet and Thompson, 2003).

Studies have linked Antarctic ozone losses to pronounced changes in surface climate with a prominent signature of ozone depletion during the austral summer (Thompson et al., 2011). A key indicator has been the poleward displacement of the SH westerly jet (Fogt et al., 2009) as illustrated in Figure 2.5. This gives rise to a poleward shift of SH midlatitude storms (Grise et al., 2014) alongside continued strengthening and poleward contraction of the Southern Ocean westerly wind belt (Mayewski et al., 2015), both of which play a pivotal role in determining summertime moisture availability. Understanding of the mechanisms which couple changes in the stratosphere to variability in tropospheric circulation and shifts in jet position is still the subject of active research 
(Polvani et al., 2011; Thompson et al., 2011). Radiative (Grise et al., 2009) and dynamical (Haynes et al., 1991; Song and Robinson 2004; Thompson et al., 2006; Orr et al., 2012) mechanisms have been proposed to explain the strong coupling of stratospheric and tropospheric circulation (Thompson and Wallace, 2000; Thompson et al., 2005) for which a lag in tropospheric response means spring ozone loss is observed most clearly in austral summer (Bandoro et al., 2014). Antarctic ozone depletion and upper-tropospheric warming from increased GHG concentrations both act to increase the meridional temperature gradient in the lower stratosphere and strengthen the $\mathrm{SH}$ westerly jet. As the ozone hole recovers these two factors will oppose each other (Figure 2.6; Thompson et al., 2011) making it important to correctly apportion the role of different anthropogenic climate forcings (Polvani et al., 2011).

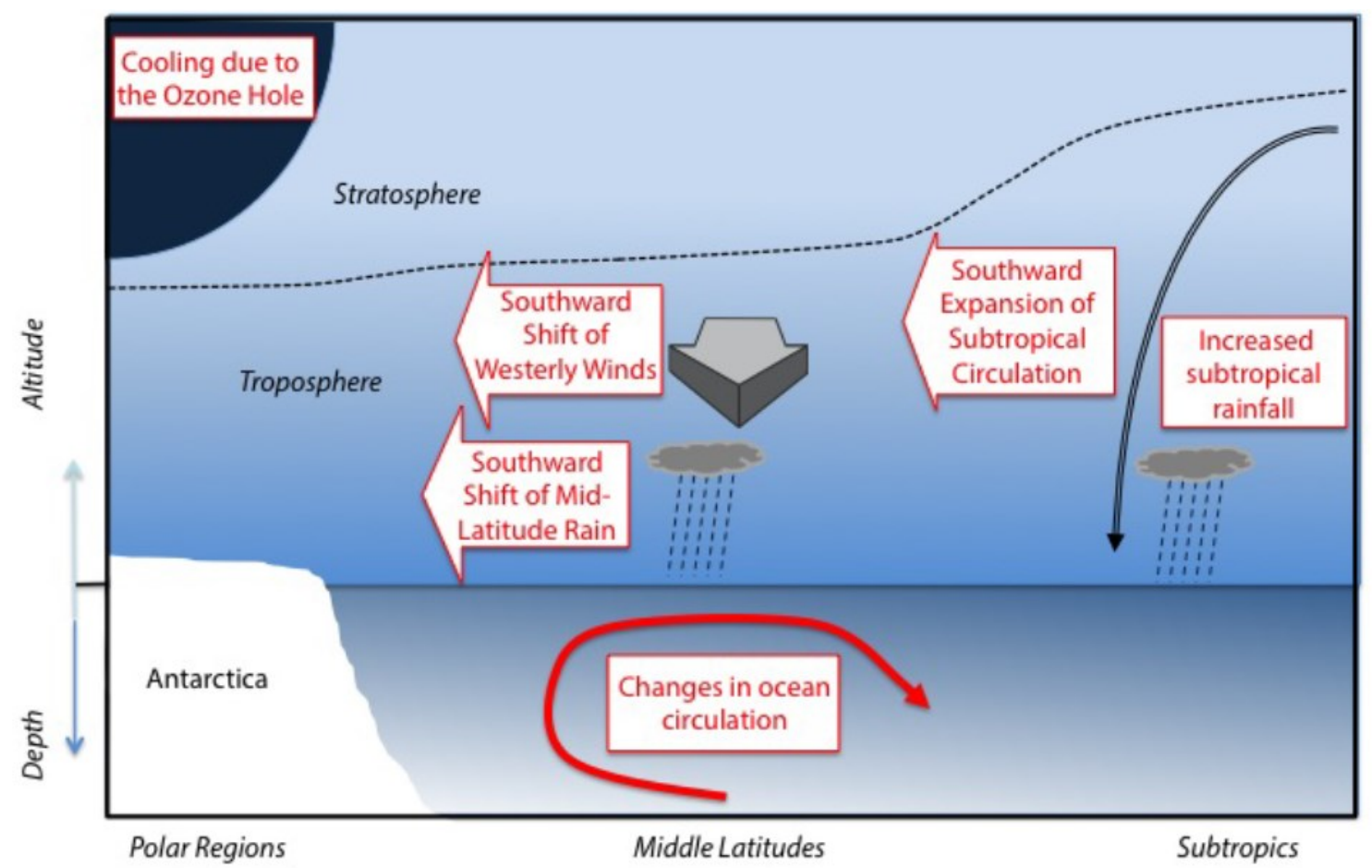

Figure 2.5: Illustration of the Southern Hemisphere tropospheric climate impacts of Antarctic ozone depletion (WMO, 2014, p. 4.43). 


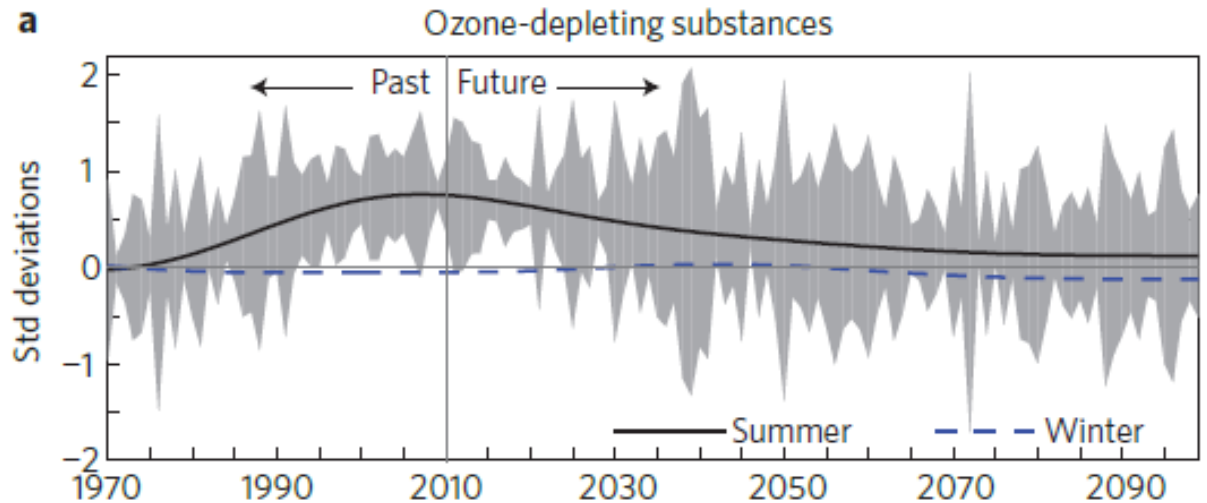

b

Greenhouse gases

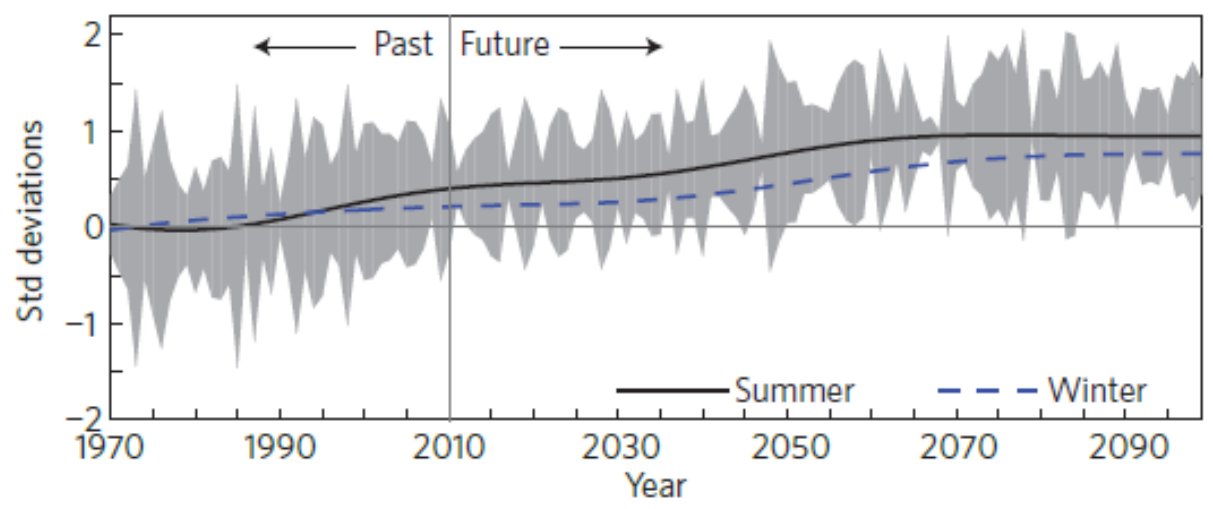

Figure 2.6: Southern Annular Mode response to experiments (McLandress et al., 2011) forced with time-varying ozone-depleting substances and greenhouse gases (Thompson et al., 2011). a) Forcing with ozone-depleting substances. b) Forcing with greenhouse gases. Past forcings are based on observational estimates and future forcings are based on the predictions outlined by McLandress et al. (2011).

Circulation in the mid- to high-latitudes of the $\mathrm{SH}$ has changed markedly over the last few decades with associate impacts on precipitation, ocean circulation and wind belts (Kang et al., 2011; Figure 2.5; WMO, 2014). Stratospheric ozone depletion is a key driver of climate trends for the SH during the austral summer (Arblaster and Meehl, 2006; Polvani et al., 2011, Gillet, et al., 2013) yet large natural variability has challenged the detection of changes within simulations of circulation due to the small signal-to-noise ratios (Trenberth et al., 2015). The Working Group 1 contribution to the IPCC Fifth Assessment report stated it likely ( $>66 \%$ likelihood) that human influence has altered patterns of sea level pressure globally (Bindoff et al., 2013). Studies using "large" 40 member ensembles have shown the notable changes in atmospheric circulation are not robust and change considerably between runs and model (Deser et al., 2012; Deser et al., 2014). As natural climate variability will continue to be superimposed on ozone and GHG forced climate changes, discerning and attributing changes from "climate noise" (Madden, 1976, Feldstein, 2000) is a worthy undertaking. 


\subsubsection{Southern Annular Mode}

Observed increases in geopotential height over the mid-latitudes and decreased geopotential height over Antarctica closely resemble a shift towards a high-index polarity of the SAM, the leading mode of extratropical circulation variability in the $\mathrm{SH}$ (Thompson and Wallace, 2000). As a largely zonally-symmetric mode of variability centred near $50^{\circ} \mathrm{S}$, the phase of SAM modulates much of the weather experienced throughout the mid-latitudes of the SH. Changes in the SAM to positive phase are associated with climate impacts across the SH including an acceleration of the prevailing westerly winds over high latitudes $\left(\sim 55-70^{\circ} \mathrm{S}\right)$ and deceleration over mid-latitudes $(\sim 35$ $50^{\circ} \mathrm{S}$ ) (Thompson et al., 2011). In concert, the Hadley cell has expanded poleward (Hendon et al., 2014; Lim et al., 2016). For the mid-latitudes, the anomalous summertime flows in response to the ozone hole give rise to increases in orographically-induced precipitation and lower than average temperatures on the eastern side of topographic features including the Southern Alps of NZ and the Great Dividing Range of south-eastern Australia (Renwick and Thompson, 2006; Ummenhofer et al., 2009; Thompson et al., 2011). Corresponding decreases in precipitation and higher than normal temperatures are observed west of the Southern Alps of NZ and over the western half of Tasmania. Ummenhofer et al. (2009) found SAM to contribute up to $80 \%$ of observed declines in December - February (DJF) precipitation for wide parts of the North Island and western parts of the South Island during the late twentieth-century. Entwined with westerly wind changes and the SAM are shifts in the SH storm track which makes an important contribution to summertime rainfall.

The SH storm track is generally located on the poleward side of the westerly jet (Purich and Son, 2012). The poleward-shifted storm track resulting from changes in jet position has been associated with less precipitation in the mid-latitudes $\left(\sim 45^{\circ} \mathrm{S}\right)$ and increased precipitation in the high latitudes $\left(\sim 60^{\circ} \mathrm{S}\right)$ (Gillet and Thompson, 2003; Son et al., 2009; Polvani et al., 2011). More recently, a positive trend in austral summer precipitation between $15-35^{\circ} \mathrm{S}$ has been related to ozone depletion and the poleward jet shift demonstrating the extent of ozone influences on SH processes (Kang et al., 2011; Figure 2.7; Previdi and Polvani, 2014). Modelling by Kang et al. (2013) also suggested the frequency and intensity of extreme precipitation in austral summer to increase due to ozone loss, though a decrease was modelled for SH mid-latitudes. 


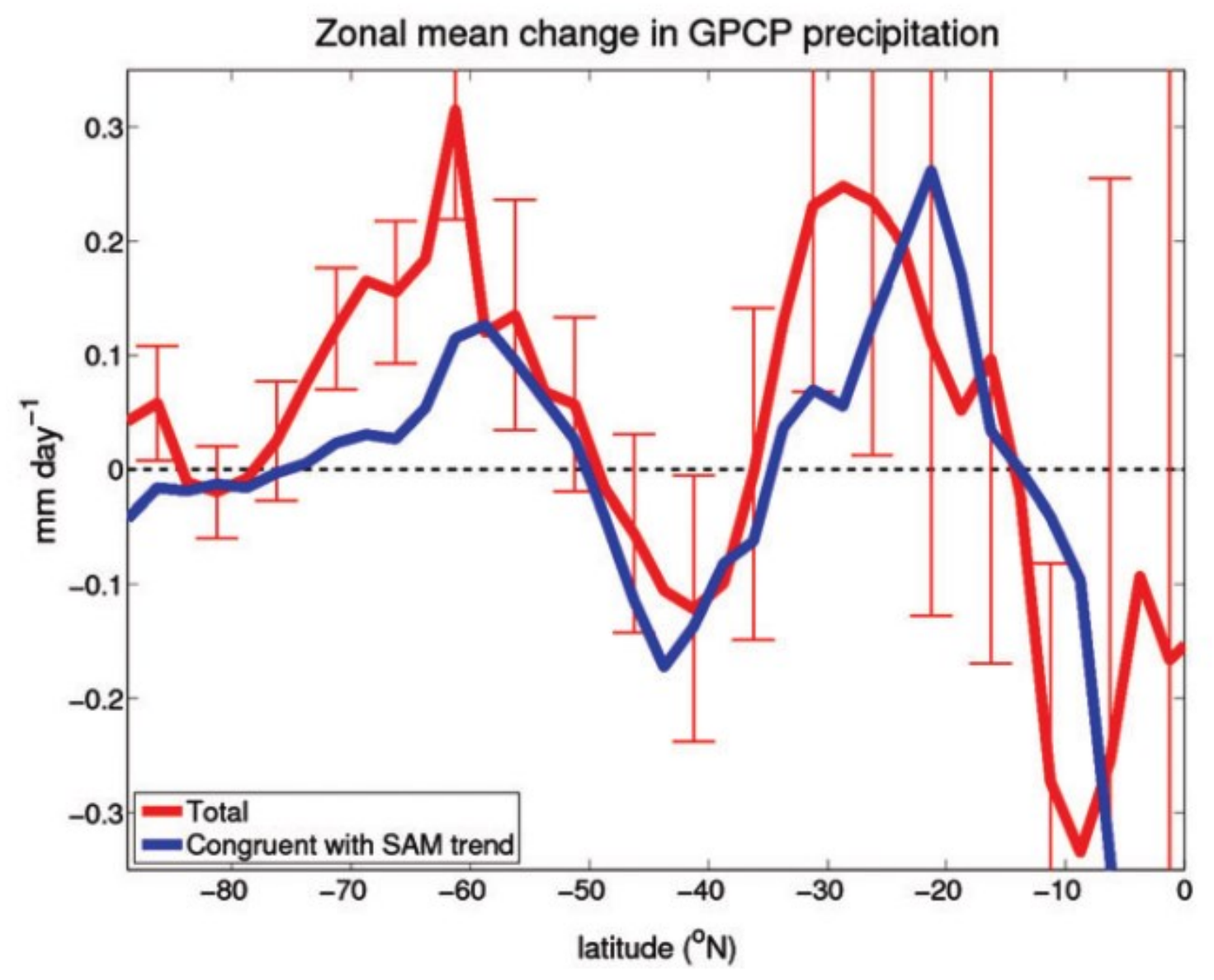

Figure 2.7: DJF zonal mean change in precipitation for 1979-2000 from the Global Precipitation Climatology Project (GPCP) (Previdi and Polvani, 2014).

For the $\mathrm{SH}$, future surface climate change is anticipated to be driven by two opposing forces, increasing GHGs and stratospheric ozone recovery (Arblaster et al., 2011; Watson et al., 2012). Positive trends are anticipated for the SAM to the end of the $21^{\text {st }}$ century under the representative concentration pathway 8.5 scenario but when a weaker GHG forcing scenario is used this trend is otherwise countered by the dominance of ozone recovery (Lim et al., 2016). These changes would further decrease rainfall in the SH midlatitudes and increase rainfall in the high latitudes, most prominently during winter as ozone recovery is confined to austral spring and early summer. Subtropical rainfall meanwhile will likely show strong seasonality with increasing summertime rainfall and reductions during winter ( $\operatorname{Lim}$ et al., 2016). Without changes in the SAM, Lim et al. (2016) suggest the subtropics would experience a decrease in precipitation while the midhigh latitudes will experience an increase, of which a large proportion can be accounted for by global warming and the Clausius-Clapeyron effect where the maximum atmospheric moisture availability increases by approximately $7 \%$ per degree of warming 
(Held and Soden, 2006). Subsequently, it is important to evaluate regional change on a case by case basis, particularly for extreme weather events where there is strong interest in attributing damaging weather-related events to anthropogenic climate change (Pall et al., 2011).

\subsection{Extreme weather and climate events}

Extreme weather and climate events are some of the biggest stressors on natural and human systems (Easterling et al., 2000; IPCC, 2012). As climate change is a slow incremental alteration of average climate conditions, it is difficult to detect based on personal experience (Weber, 2010). Due to their marked impacts, changes in extreme weather events are more likely to be noticed (Weber, 2010; Harrington, 2017), making it important to robustly quantify the risk of these events for both current and future climates (Diffenbaugh et al., 2017).

Understanding natural variability and the influence of historical changes in extremes is central to detecting how climate change is changing extreme weather and climate events (IPCC, 2014; Rosenzweig et al., 2008). While trends in the frequency and magnitude of extremes have been identified (Easterling et al., 2000; IPCC, 2012), continued warming is anticipated to cause widespread emergence of unprecedented events (Diffenbaugh and Scherer, 2011; King et al., 2016). Due to thermodynamic processes, the additional atmospheric moisture in a warmer world can provide greater latent heat release to facilitate more intense storms and more extreme weather (Shepherd, 2016).

For the hydrological cycle, anticipated changes resulting from anthropogenic climate change are commonly simplified to the "wet get wetter and dry get drier" (Seager et al., 2010). In other words, the already wet deep tropics and mid-latitudes are anticipated to get wetter, while arid and semiarid regions in the subtropics will likely get drier (Held and Soden, 2006; Chou et al., 2009). Dry length spells are anticipated to be longer (Giorgi et al., 2011) and when it rains, it will rain harder because of increased atmospheric moisture (Trenberth et al., 2014). Observed changes in precipitation extremes are less spatially coherent and statistically significant when compared to observed changes in temperature extremes (Alexander et al., 2006; Bindoff et al., 2013). Significant trends to 
larger precipitation extremes occur for a greater fraction of Earth's surface than those toward smaller precipitation extremes (Alexander et al., 2006) providing medium confidence that anthropogenic forcing contributed to the global-scale intensification of heavy precipitation (Bindoff et al., 2013). Though there is a need for extreme precipitation event studies to better understand and resolve the multiple meteorological factors to reduce uncertainty and better ascertain causality and attribution (Otto et al., (2015).

\subsubsection{Extreme event definition}

Many aspects of climate analysis can be evaluated on the basis of monthly means. By contrast extremes (Figure 2.8), which are the tails of a distribution, need to be assessed using high temporal and spatial resolution data to prevent much of the characteristic information being smoothed over (Zhang et al., 2011). Two important features that distinguish extreme indices include: a) how the distribution was defined, and b) the positioning of the index threshold at the tail of the distribution. Traditional examination of extremes is a balance between sample size and rarity of the event with many extreme indices being based on 'moderate extremes', or events that occur on at least an annual basis (Zhang et al., 2011). 


\section{What is an extreme?}
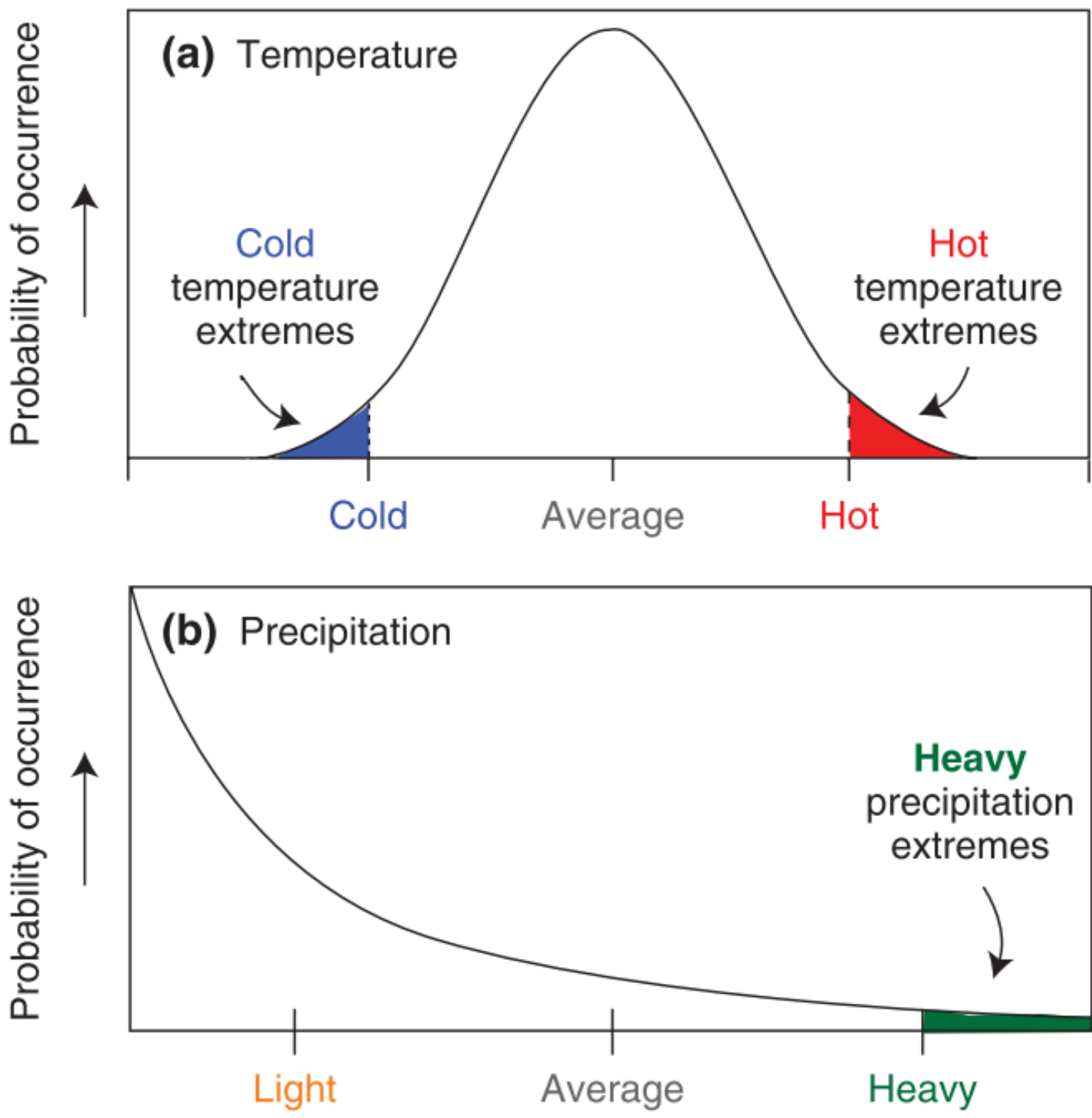

Figure 2.8: Stylised representations of temperature and precipitation extremes using probability distributions. Extremes are denoted using shaded areas (Zhang et al., 2011).

To detect changes in climate extremes, a set of internationally agreed-upon indices were established by the Expert Team on Climate Change Detection and Indices (ETCCDI) (Peterson and Manton, 2008). This ensured the chosen indices were: statistically robust, well suited to perform across a wide range of climates and had a high signal-to-noise ratio (Zhang et al., 2011). It also safeguards that results can be compared consistently across different countries. As shown in Table 2.1, there are a variety of extreme precipitation indices including monthly or annual maxima, day-count indices and percentile thresholds. 
Table 2.1: Extreme precipitation indices recommended by the ETCCDI (Zhang et al., 2011).

\begin{tabular}{|c|c|c|c|}
\hline ID & Indicator Name & Indicator Definitions & Units \\
\hline RX1day & Max 1-day precipitation amount & Monthly maximum 1-day precipitation & $\mathrm{mm}$ \\
\hline RX5day & Max 5-day precipitation amount & Monthly maximum consecutive 5 -day precipitation & $\mathrm{mm}$ \\
\hline SDII & Simple daily intensity index & $\begin{array}{l}\text { The ratio of annual total precipitation to the number of wet } \\
\text { days ( } \geq 1 \mathrm{~mm} \text { ) }\end{array}$ & $\mathrm{mm} /$ day \\
\hline R10 & Number of heavy precipitation days & Annual count when precipitation $\geq 10 \mathrm{~mm}$ & days \\
\hline $\mathrm{R} 20$ & Number of very heavy precipitation days & Annual count when precipitation $\geq 20 \mathrm{~mm}$ & days \\
\hline CDD & Consecutive dry days & $\begin{array}{l}\text { Maximum number of consecutive days when precipitation } \\
\quad<1 \mathrm{~mm}\end{array}$ & days \\
\hline CWD & Consecutive wet days & $\begin{array}{l}\text { Maximum number of consecutive days when precipitation } \\
\geq 1 \mathrm{~mm}\end{array}$ & days \\
\hline R95p & Very wet days & Annual total precipitation from days $>95$ th percentile & $\mathrm{mm}$ \\
\hline R99p & Extremely wet days & Annual total precipitation from days $>99$ th percentile & $\mathrm{mm}$ \\
\hline PRCPTOT & Annual total wet-day precipitation & Annual total precipitation from days $\geq 1 \mathrm{~mm}$ & $\mathrm{~mm}$ \\
\hline
\end{tabular}

Precise definitions are given at http://ccema.seos.uvic.ca/ETCCDU/list_27_indices.html.

As extreme events have increased in many regions, efforts to understand the influence of global warming on individual events have also increased (Diffenbaugh et al., 2017). This has given rise to the development of a number of attribution methods as the climate community respond to the demands for timely appraisals of evolving climate conditions and extreme weather (Trenberth et al., 2015).

\subsection{Detection and attribution of human influence}

The purpose of attribution studies is to differentiate between changes driven by internal variability or by external forcings (NASEM, 2016). A change is detected in observations only if the probability of occurrence by chance due to internal variability is small (i.e. $p$ $<0.05$ ) (Stocker et al., 2010). Attribution seeks to assign a degree of statistical confidence to the causal factors of the change (e.g. anthropogenic forcings). This can be achieved in many ways (see Diffenbaugh et al., 2017) though the primary method is to compare observations to expected changes from physically based model simulations. Such simulations permit the observation of a counterfactual world without human influence and thus the estimation of anthropogenic influence and risk (Risser et al., 2017). While the methods used for detection and attribution continue to evolve, they have been repeatedly demonstrated to be robust to methodological variations (Allen and Stott, 2003; Hegerl and Zwiers, 2011; NASEM, 2016). 
Two broad classes of methodologies exist. Observational-only methods compare observations for a recent time period to a historical time period (e.g. early or mid- $20^{\text {th }}$ century) where anthropogenic influences are assumed to be weaker (NASEM, 2016). This approach can identify changes which are poorly simulated by climate models and where understanding of the response to forcings is incomplete. Observation-only methods rely on the assumption that the response to a forcing is instantaneous or that climate change and variability can be separated on the basis of timescale (Hegerl and Zwiers, 2011). Long observational data sets are, however, rarely available and may exhibit non-stationarity for the period of interest (NASEM, 2016). Hence it is often difficult to adequately quantify uncertainty using an observation-based approach.

The second class of methods use physically-based climate models. Model-based approaches translate changes in radiative forcing into climate responses based on physical understanding. Estimates of internal variability must be derived and separated out to distinguish the forced signal (Hegerl and Zwiers, 2011). Fingerprint methods compare observed changes with model simulations both with and without anthropogenic forcings (Stott et al., 2010). The landmark study of Stott et al. (2000) demonstrated observed changes in global surface air temperatures during the twentieth century could be reproduced only by climate models that included both anthropogenic and natural forcings. Models have however been identified to have challenges simulating extremes of precipitation in the tropics well (Kharin et al., 2007), with thermodynamic variables exhibiting stronger signal-to-noise ratios than dynamic variables (Deser et al., 2012). Furthermore, detection of changes due to external climate forcings becomes increasingly difficult at smaller scales due to a less discernible signal relative to noise (Angelil et al., 2014), though strengthening climate signals are anticipated to reduce the scales required for detection (Stott and Tett, 1998). In most cases, the choice of method employed is often a result of the resources available and the way an attribution question is framed (NASEM, 2016).

\subsubsection{Framing}

The framing of attribution questions has become a fundamental consideration in attribution studies, as the way an attribution question is posed can have a major bearing on results. The pioneering work of Otto et al. (2012) reconciled how two attribution studies of the 2010 Western Russia heat wave (Dole et al., 2011; Rahmstorf and Coumou, 
2011) can have what may first appear as opposite conclusions yet not contradict each other as explicitly stated by the latter study. Dole et al. (2011) reported the extreme heat event to be primarily of natural origin while Rahmsorf and Coumou (2011) had shown the event would not have occurred without anthropogenic warming. Otto et al. (2012) used probabilistic event attribution (PEA) to demonstrate that when the heatwave was framed in terms of magnitude it is mostly internally-generated by natural variability, meanwhile when framed using occurrence-probability, the event was mostly externallydriven due to anthropogenic forcings. These findings subsequently opened a new branch of inquiry seeking to address the sensitivity of attribution statements to methodology and data sources, which has proceeded to be a major research priority in event attribution studies (Stott et al., 2013; Titley et al., 2016; Angelil et al., 2017). PEA has proceeded to be used extensively by the climate science community (see the Bulletin of the American Meteorological Society (BAMS) Supplement - Explaining Extreme Events) to determine the impact of a factor on an event.

Typical event definitions are based on thresholds that may contain both a spatial and temporal dimension. Defining an event over a large area and long time scale reduces the natural variability and tends to give larger PEA metrics. Contrastingly, defining a class of events very specific to a location and over a short time period (i.e. close to the observed event) tends to give very low probabilities of occurrence, and limited future relevance given most extreme events rarely manifest in exactly the same manner (Trenberth et al., 2015). As such generalised statements of class-based events are normally formulated for which spatial or temporal details may differ from the observed event in question (Stott et al., 2016).

\subsubsection{Probabilistic event attribution}

The 'risk-based' approach was first introduced to the climate science community by Allen (2003) and applied to the European heat wave of 2003 (Stott et al., 2004). Drawing on the approach used in epidemiology to answer questions such as 'does smoking increase the likelihood of lung cancer?' the method of PEA instead sought to answer questions such as 'how has the likelihood of this event changed due to anthropogenic forcings?' This approach required the use of climate models to simulate current (ALL) and counterfactual climate (NAT) conditions assuming 'all other factors [aside from the forcing of interest] are equal' (Bindoff et al., 2013). Figure 2.9 illustrates the probability 
distribution for daily precipitation modelled under current climate conditions and for the counterfactual climate where only natural forcings are present. A defined threshold is used to compare the calculated probabilities, $P_{N A T}$ and $P_{A L L}$, for events of a given magnitude or larger which can then be used to calculate the Fraction of Attributable Risk metric (FAR; Allen, 2003).

$$
F A R=1-\frac{P_{N A T}}{P_{A L L}}
$$

Positive FAR values imply the event has become more common due to anthropogenic influence, whereas a negative FAR suggests the event would have been more common in the counterfactual natural climate. For example, if $P_{N A T}=0.01$ and $P_{A L L}=0.03$, then the risk of an extreme rainfall event has increased by a factor of three due to anthropogenic influence noting that the use of 'risk' within event attribution literature is focussed on event probability without considering damage or exposure (Black, 2017). The corresponding FAR value of 0.66 indicates that $66 \%$ of the risk of the extreme rainfall event is attributable to human activity. In both cases, these hypothetical results refer to event likelihood, not magnitude. Otto et al. (2015) suggest the FAR is insensitive to the threshold value (e.g. magnitude) used in the calculation. However, errors, potential forms of bias and uncertainties should be thoroughly assessed in any study using such metrics to attribute an event to anthropogenic climate change (Otto et al., 2012). 


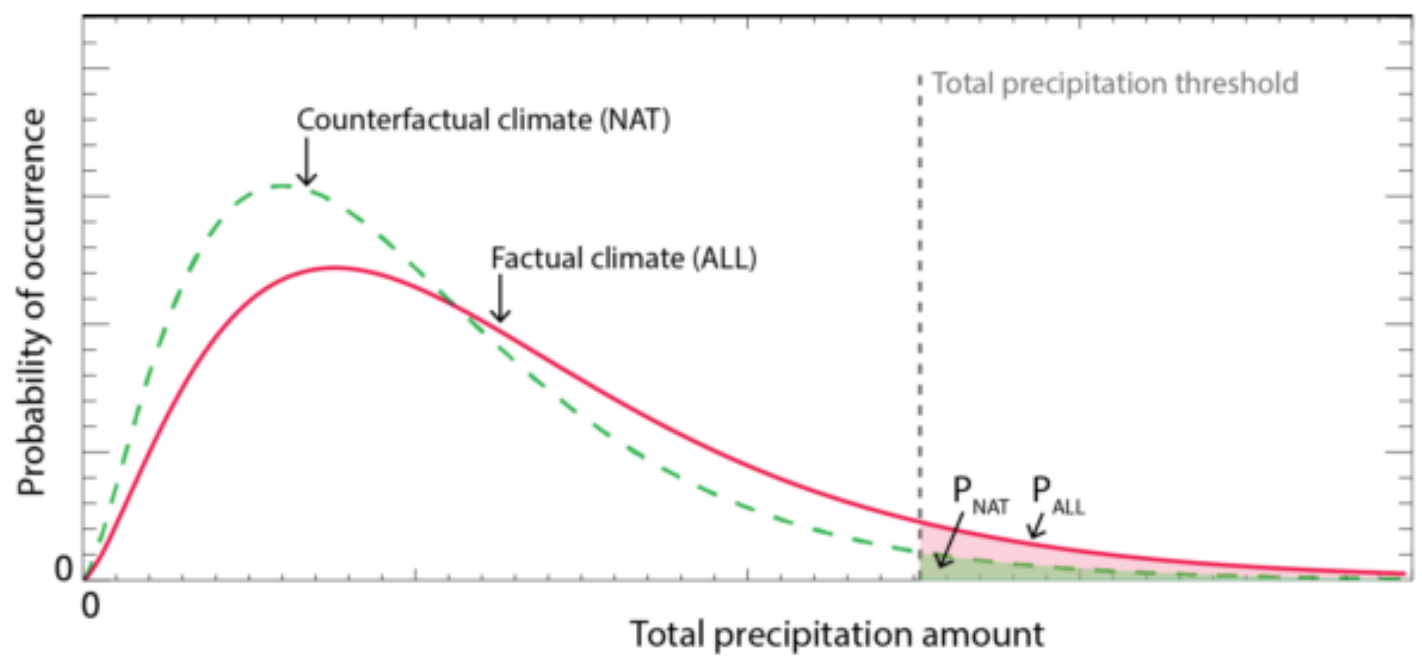

Figure 2.9: Schematic example of the estimation of the fraction of risk for an extreme precipitation event attributable to anthropogenic forcings. The factual (ALL) distribution is a probability distribution function of precipitation totals for the observed world while the counterfactual natural (NAT) distribution is for a hypothetical world with greenhouse gas concentrations at pre-industrial (1850) concentrations (Black, 2017).

Event attribution studies rely on the estimation of event probabilities and/or magnitudes. Christidis et al. (2013) have argued that robust attribution is only possible when the observed climatology is represented well with factual simulations corresponding closely to the observed climate, though most studies only quantify sampling uncertainty. Hawkins and Sutton (2009) propose other sources of uncertainty affect the estimate of event probability and magnitude in model analyses including:

- Boundary condition uncertainty: the fixed aspects of the climate model (i.e. land surface characteristics)

- Model uncertainty: the inability to fully represent the climate system

- Parametric uncertainty: the appropriate values for input parameters in the climate model

- Counterfactual boundary condition uncertainty: i.e. uncertainty for sea-surface temperatures (SSTs) that force the atmosphere-only model in a counterfactual scenario

- Conditioning uncertainty: conditioned results only correspond to the state of the system used in generating the simulation i.e. the SST state in atmosphere-only models. 
These sources of uncertainty are largely unavoidable and difficult to evaluate. This makes it important to not just evaluate the best estimate in an attribution study, but also the uncertainty associated with the estimate. As all models have biases in representing the climate system, some studies (NASEM, 2016; Angelil et al., 2017) suggest using multiple models and/or methods to reduce biases and firmly distinguish robust results from those that have high sensitivity.

\subsubsection{Extreme value theory}

To address many of the difficulties associated with the study of extreme events (e.g. limited observations, data availability, data quality), complementary methodologies have been developed to constrain changes in the odds of these events. Extreme value theory (EVT), as an alternate approach to PEA for interpreting model output, makes it possible to model and study the tails of probability distribution functions on the basis of mathematical theory (Coles, 2001). Parametric extreme value distributions are generated to make statistical statements and estimate return periods (Sippel et al., 2015). One of the most common approaches utilises the Generalised Extreme Value (GEV) distribution (Jenkinson, 1955) as below (Coles, 2001)

$$
P(x)=\exp \left(-\left[1+\xi \frac{x-\mu}{\sigma}\right]^{-(1 / \xi)}\right)
$$

where $\mu, \sigma, \xi$ denote the location, scale and shape parameter of the GEV distribution respectively. For the shape parameter $\xi=0, \xi<0, \xi>0$ the distribution type is Extreme Value Type 1, 2 or 3 (henceforth EV1, EV2 and EV3, respectively). When $\xi=$ 0 the distribution reduces to the Gumbel distribution (Gumbel, 1958) and takes the form

$$
P(x)=\exp \left\{-\exp \left(-\left[\frac{x-\mu}{\sigma}\right]\right)\right\}
$$

The $\xi<0(\mathrm{EV} 2)$ and $\xi>0$ (EV3) distributions are also commonly referred to as the Frechet distribution and Weibull distribution (Ailliot et al., 2011). An alternate distribution is the Generalised Logistic distribution (Greenwood, 1979)

$$
P(x)=\left\{1+\exp \left(-\left[\frac{x-\mu}{\sigma}\right]\right)\right\}^{-1}
$$

The parameters of such distributions have also previously been used for detection and attribution analysis (Zwiers et al., 2011) but are more commonly used in the 
determination of annual return periods for extreme events. In NZ, Griffiths et al. (2014) found $70 \%$ of rainfall sites follow an EV1 distribution, 27\% EV2 and 3\% EV3 though the distinctions between locations are sometimes minute. Combining large model ensembles with extreme value statistics can bring about benefits including reduced numbers of simulations required, and improved attribution statements of rare events (Sippel et al., 2015). While EVT does not yet provide a convenient way to account for spatial or temporal dependence in analyses of time series fields of extreme values (Zwiers et al., 2011), novel methodologies have been proposed to preserve physical consistency and multivariate structure (Sippel et al., 2016). Though if an event is truly extreme in the present climate, it also undoubtedly required some unusual meteorological conditions such that climate change is only a contributing factor (Shepherd, 2016).

\subsubsection{Storyline approach}

As climate change is an accepted fact (IPCC, 2013), an alternative framing to PEA or EVT is to examine the various factors contributing to the event as it unfolded (Shepherd, 2016), including the unique meteorological conditions. Trenberth et al. (2015) argue a more effective approach than the highly uncertain outcomes of probabilistic assessments is to investigate how various physical factors, including anomalous aspects of natural variability, contributed to the event. These factors, such as anomalous SSTs, may have been affected by known thermodynamic responses to climate change. In their study of four extreme climate events, they found anomalously high SSTs played a key role in providing moisture into storms, intensifying the storm and causing heavy rains. While this storyline approach can also be used to quantify the magnitude of anthropogenic influence (Hoerling et al., 2013), any result only pertains to that specific event and such studies do not address the potential change in likelihood (Shepherd, 2016). This does not dismiss the usefulness of this approach, especially if historical events are to be used as benchmarks for liability or planning purposes. Additionally, as the storyline approach is strongly anchored in physically-based mechanisms, confidence can be drawn from aspects of climate change that are well understood. 


\subsection{Dynamical modelling of the atmosphere}

Models of the atmosphere are an indispensable tool for testing how the climate system and the extreme event class in question is responding to changed forcings such as GHGs (Moise et al., 2015). Dynamical models are constructed from physical laws, including equations of motion and state, which determine the thermodynamics and fluid dynamics of Earth's oceans and atmosphere (Holton and Hakim, 2013). Increased understanding of processes within the climate system and greater computational power have given rise to increasingly sophisticated and realistic models. These have enabled larger ensembles of simulations to be generated and higher resolution outputs - both of which are pivotal to the study of extreme weather events. Depending on the type of extreme being assessed the specific model and configuration will also vary.

\subsubsection{Global climate models}

General circulation models or global climate models (GCMs) are an extension of weather forecasting models (Moise et al., 2015). GCMs are central to advancing our understanding of climate system response to forced change and to making future projections of Earth's climate. As the atmosphere is strongly influenced by multiple geophysical components including the ocean, cryosphere and biosphere, models of these components must be coupled to the atmosphere model to produce more realistic climate simulations over the long term.

The complexity of the Earth's climate system, in combination with finite computing power, means GCMs must be simplified abstractions of the real world. Spatial and temporal details of processes may only be partially represented while other processes may not be directly simulated at all (Moise et al., 2015). Furthermore, if large ensembles of simulations are required (as in event attribution studies) then the model must not be overly demanding on computing resources and so may be somewhat simplified compared to state-of-the-art models.

\subsubsection{Model types}

Coupled atmosphere-ocean-models and earth-system-models (ESM) are arguably some of the most comprehensive climate models available. While a coupled atmosphereocean-model includes representations of the atmosphere, oceans, ice and land, an ESM 
additionally incorporates biological and chemical processes including the cycling of carbon. Greater complexity requires greater computational capacity and usually means only smaller ensembles can be obtained and larger spatial scales can be simulated. As such, these models are ill-suited for studying most extremes. The large computational requirements largely come from the need for these models to maintain a fully-dynamic ocean. Consequently, the SSTs resolved by the model do not correspond to real SSTs observed in any given year (Black, 2017).

Atmosphere-only models avoid such conditions by resolving only atmosphere and land processes. SSTs and sea ice coverage are prescribed as lower boundary conditions which drive the atmosphere model (Black, 2017). An advantage of prescribing SSTs within an atmosphere-only model is that dynamical processes, particularly synoptic circulation regimes that can be related to the extreme event (Otto et al., 2012; Mitchell et al., 2016), may be better represented due to a reduction in biases associated with the ocean state.

As extreme events are by definition inherently rare, the sparse observation of their occurrence necessitates a number of modelling requirements including: 1) very large ensembles of climate model simulations to constrain estimates of sampling uncertainty and, 2) sufficient model resolution to realistically simulate extreme events given they typically occur at regional or local scale (Black, 2017). While conventional computing resources are challenged to undertake such demanding requirements, distributed computing has opened up new avenues for citizen science participation in running such models.

\subsubsection{Weather@home}

Distributed volunteer computing has revolutionised scientific research allowing previously infeasible research to be conducted by tapping into what equates to a global supercomputer (Anderson, 2004). Since the end of the $20^{\text {th }}$ century, climateprediction.net (Allen, 1999) has been using the personal computers of thousands of volunteers around the globe to quantify uncertainties in long-term climate predictions. More recently a subset of this project known as ‘weather@home' was developed to simulate weather on a medium resolution scale $(50 \mathrm{~km})$ such that attribution of extreme events could be conducted (Massey et al., 2015). As coarse resolution GCMs have a limited ability to reproduce the interactions of weather systems with local terrain and mesoscale processes, 
regional atmosphere models can be embedded within the global model to downscale simulations for a select domain (Black, 2017). Weather@home (w@h) utilises the climateprediction.net distributed network to compute very large ensembles of simulations from the HadRM3P regional climate model (Jones et al., 2004) that is driven by the HadAM3P atmosphere-only GCM (Pope et al., 2000). Forcings for the global model are applied at the lateral boundaries allowing the higher resolution $(50 \mathrm{~km})$ regional climate simulations to be obtained. While this is a relatively low resolution for an RCM, the ability of w@h to generate large ensembles is one of the best methodologies to account for the uncertainty associated with natural variability (Otto et al., 2015).

One of these RCMs is the weather@home Australia-New Zealand project which is run over the Australasian region (Figure 2.10). Validation work by Black et al. (2016) found the model capable of resolving many of the important climate features for Australia and $\mathrm{NZ}$, including the influence of ENSO in driving natural climate variability. This is not unsurprising given the model is forced by observed SSTs. While large-scale spatial patterns of temperature were modelled very well, Black et al. (2016) noted a systematic underestimation of maximum wintertime temperatures at almost every land grid point, including a prominent negative temperature bias for the NZ South Island western coastline in both summer and winter.

For precipitation,w@h ANZ captured the strong rainfall gradient across the Southern Alps, though tended to underestimate rainfall in both DJF and JJA seasons throughout ANZ. Over the entire 29-year simulation period (1985-2014), the mean precipitation rate bias in $\mathrm{NZ}$ was $-1.02 \mathrm{~mm} /$ day. Black et al. (2016) propose such biases can be corrected through a simple scaling and offset approach (e.g. Sippel and Otto, 2014), quantile mapping (Bergaoui et al., 2015), or a resampling-based bias correction (Sippel et al., 2016). Yet this does not address the systematic bias that must persist within the model parameterisation, physics or input. While they highlight the importance of SSTs on driving the climates of Australia and NZ, a key limitation of the model included the land surface data being fixed between both the factual and counterfactual scenario. Similarly, asw@h ANZ only uses a single atmospheric model, it is restricted to only being able to make attribution statements that pertain to the context of the specific model setup, with the dependence of the model on physical parameterisation yet to be assessed. 


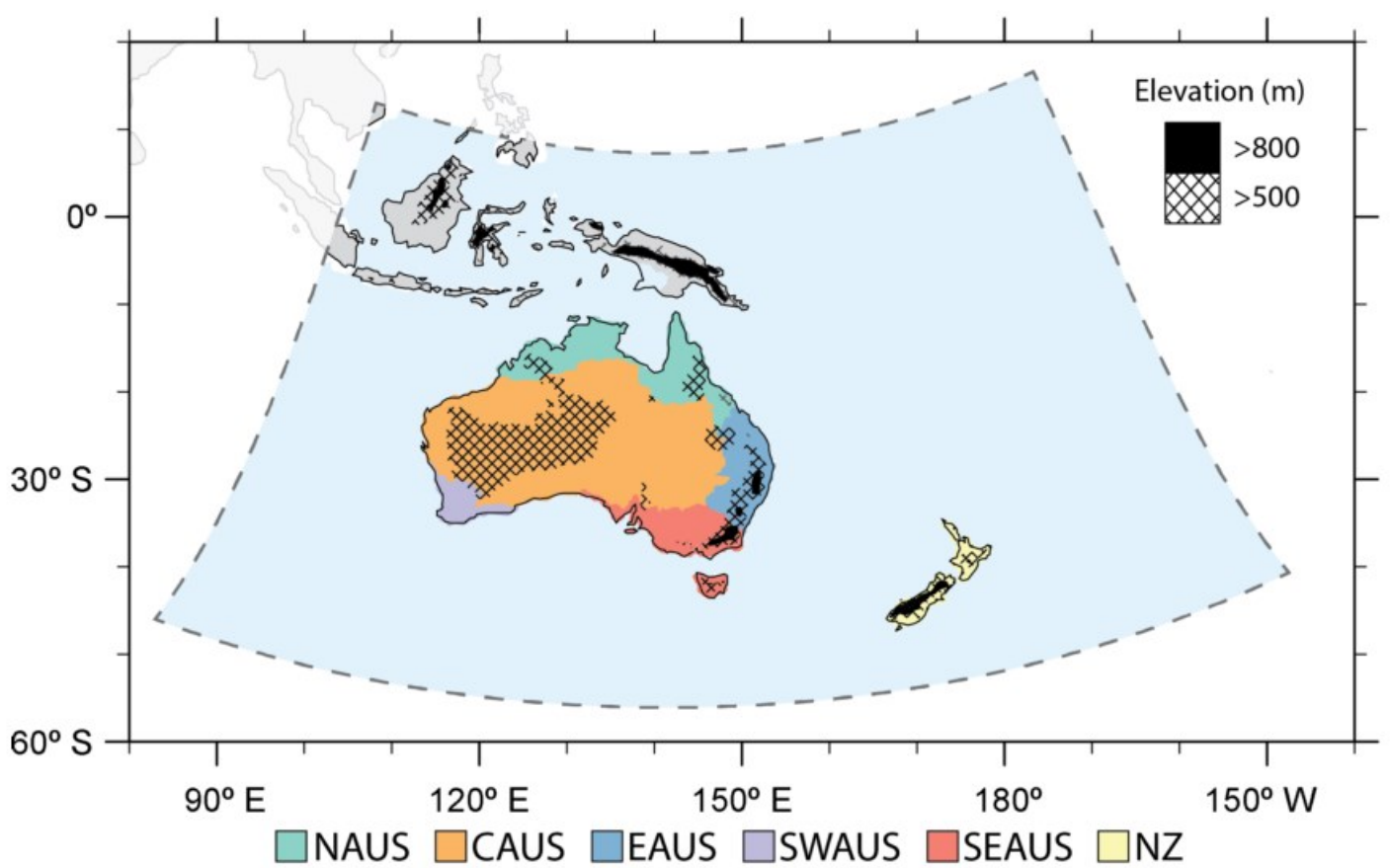

Figure 2.10: Domain and elevation of terrain used in the w@h ANZ model simulations. Land areas have been separated into six regions for evaluation: northern Australia (NAUS), central Australia (CAUS), eastern Australia (EAUS), southwest Australia (SWAUS), southeast Australia (SEAUS) and New Zealand (NZ) (Black et al., 2016).

Despite such restrictions, w@h ANZ makes an important contribution to advancing our knowledge of the role anthropogenic forcings are having in extreme weather events for Australasia. Studies have included assessment of heat events (Black et al., 2015; King et al., 2015), record low rainfall (Karoly et al., 2016), the role of ENSO (Black and Karoly, 2016), mean sea level pressure anomalies (Grose et al., 2015), and extreme rainfall (Rosier et al., 2015). A yet-to-be-released report commissioned by the New Zealand Treasury also used w@h ANZ to pioneer new research to estimate the cost of anthropogenic climate change. In this work Frame et al. (unpublished) conservatively estimated the attributable cost for these events to be $\$ 839.73$ million over 10 -years revealing the large climate change cost already being borne by society.

In w@h ANZ studies that examined circulation and precipitation, Rosier et al. (2015) found evidence of increased maximum 5-day precipitation (RX5D) for Northland, NZ due to anthropogenic forcings. Extreme events like the observed RX5D event were found to have a FAR of $47 \%$, with most of the simulated extreme precipitation events coinciding with anomalously high moisture fluxes from the subtropics. Likewise, King et al., 2016 found anthropogenic climate change in combination with the strong El Niño of 2015 to 
very likely have increased the chances of breaking previous low rainfall records in Tasmania by at least $39 \%$ and $18 \%$ for these respective factors.

This research utilises w@h ANZ output to evaluate and quantify how anthropogenic forcings have contributed to modifying NZ's weather and climate. Firstly, how has ozone depletion affected Southern Hemisphere extra-tropical circulation? Then, what percentage of the attributable risk can be related to human influence to influence for an extreme rainfall event in Christchurch, New Zealand?

\subsection{Summary}

- Anthropogenic activity is unequivocally changing patterns of weather and climate globally, based on well-understood physical mechanisms.

- Stratospheric ozone losses have contributed to significant changes in SH surface climate and circulation, most prominently during the austral summer mediated by the SAM.

- Large natural variability has challenged the detection and attribution of anthropogenically induced changes, particularly in regard to the dynamical (circulation) component of our climate system which is a key control on precipitation.

- A combination of short, disparate observational records in addition to extreme events being inherently rare have challenged detection of changes and trends in extremes, especially if using traditional approaches applied in climate analysis.

- Global climate models have made it possible to discern and attribute simulated changes to specified climate forcings using a PEA framework. The attribution study framing must be carefully considered due to having an important bearing on results.

- Distributed computing, employing the use of volunteered public computing capacity, has allowed for the generation of very large ensembles of simulations from which changes in extreme weather and events can be assessed. Weather@home is one of the leading climate models helping to address and answer concerns as to whether human influence on the climate has increased the frequency or magnitude of events. 


\section{CHAPTER 3 - METHODOLOGY}

This chapter first details the observational datasets used in this study. Thew@h ANZ model and the methodology used in its parameterisation is then described. A critique of the model is conducted before details are provided on the project scope and analytical methods employed.

\subsection{Observational datasets}

A number of observed and derived datasets are used, including; weather station observations as from New Zealand's National Climate Database (CliDB; accessible http://cliflo.niwa.co.nz), rainfall estimates for the period 1972-2017 from the Virtual Climate Station Network (VCSN; Tait et al., 2006) and ERA-Interim reanalysis data (Dee et al., 2011). Within VCSN, daily rainfall estimates ( 9 am -9 am total) for a $0.05 \times 0.05$ degree grid of terrestrial NZ are generated (11,491 grid points; Tait et al., 2012). This dataset is derived using a thin-plate smoothing spline interpolation based on measurements from approximately 600 sites across NZ, although this number varies with time (Tait et al., 2006). ERA-Interim provides a continuous global record for numerous climate variables from 1979 to the present. Simmonds et al. (2012) identify ERA-Interim as "one of the best reanalyses available to date" providing more robust assessments of the $\mathrm{SH}$ than competing global reanalyses products. The high temporal (every $6 \mathrm{hr}$ ) and spatial $\left(0.75^{\circ} \times 0.75^{\circ}\right.$ grid $)$ resolution of ERA-Interim for variables including mean sea level pressure $(\mathrm{Pa})$, total precipitation and $10 \mathrm{~m}$ wind make it well suited for this investigation. These data products in addition to the westerly $(\mathrm{u})$ wind component at $850 \mathrm{hPa}, 500 \mathrm{hPa}$ geopotential height and vertical integral of water vapour are used for global and regional comparisonwithw@h ANZ output.

\subsection{Weather@home model description}

Simulations withw@h ANZ are generated from the HadAM3P (Pope et al., 2000) and HadRM3P (Jones et al., 2004) atmosphere-only models, requiring forcings to be defined at the lower boundary. Specified boundary conditions include SSTs and sea ice fraction 
fields obtained from the UK Met Office Operational Sea Surface Temperature and Sea Ice Analysis dataset (Donlon et al., 2012). These are input as global, daily fields on the $1.25^{\circ}$ longitude $\times 1.875^{\circ}$ latitude HadAM3P grid (Massey et al., 2015). Atmospheric composition is prescribed in the model with greenhouse gases $\left(\mathrm{CO}_{2}, \mathrm{CH}_{4}\right.$ and $\left.\mathrm{N}_{2} \mathrm{O}\right)$, ozone, halocarbons, sulphur species and solar anomalies input following Coupled Model Intercomparison Project Phase 5 (CMIP5; Taylor et al., 2012) recommendations. After 2005, the concentrations of GHGs and emissions of aerosols specified in w@h follow the representative concentration pathway $(\mathrm{RCP}) 8.5$ scenario.

HadAM3P-HadRM3P solves dynamical, radiative and kinematic equations across 19 vertical levels. The global model HadAM3P has a 15-minute timestep using a regular longitude-latitude grid $\left(1.25^{\circ}\right.$ longitude $\times 1.875^{\circ}$ latitude $)$. The regional ANZ model configuration of HadRM3P has a 5-minute timestep using a rotated grid $\left(0.44^{\circ}\right.$ longitude $\times 0.44^{\circ}$ latitude) with an artificial North Pole at $60.31^{\circ} \mathrm{N}, 141.38^{\circ} \mathrm{E}$. This ensures each grid box in the nested region has approximately the same area. The nesting is onedirectional, with no feedback from the regional model to the global model. Further details of the HadAM3P-HadRM3P configuration are provided by Massey et al. (2015), Black et al. (2016) and Black (2017).

Weather@home's capability to generate very large ensembles is possible due to a globally distributed network of computing power. Members of the public volunteer unused capacity on their personal computers by signing up via the Berkeley Open Infrastructure for Network Computing (BOINC; Anderson, 2004) client software. The climate model setup is downloaded to the volunteer's computer so that individual work units can be received from the BOINC server and run when the computer is idle (Black, 2017). Each work unit contains the required configuration inputs for the climate model to run an experiment for one model year (December-November) of 360 days, under a prescribed climate scenario. To minimise file size for data transfer and storage, the output is postprocessed to retain only a selection of key meteorological variables with w@h ANZ final results returned to a server hosted in Hobart, Australia. On average each experiment takes a standard home computer approximately 4-5 days to complete. Through this procedure, a large number of simulations can be performed across a distributed network of computers, which is particularly useful when examining extreme events. 
A perturbation is applied to the initial conditions of each work unit to represent internal variability within the model (see Massey et al., 2015 or Black, 2017). A variety of starting conditions are then applied to the first month of the model integration to provide perturbation to starting conditions. These are based on control simulations from the previous year which contain different large-scale circulations and soil moisture amounts (Black, 2017).

\subsection{Counterfactual climate scenarios}

To quantify how human-induced stratospheric ozone depletion and anthropogenic climate change have altered $\mathrm{SH}$ circulation and the likelihood of extreme precipitation in NZ, large ensembles are required under three scenarios. Firstly, the current climate which has been altered by anthropogenic forcings (ALL; A). Additionally, two counterfactual climates. The natural (NAT; N) climate as it may have been without human influence on atmospheric composition, and a current climate with natural ozone (ALL_NATURAL_O3; O) as might have been without human-induced stratospheric ozone depletion. Thus, the $\mathrm{O}$ simulations have no ozone depletion but still contain GHG contributions.

For the counterfactual scenarios, different atmospheric composition, sea ice and SST specifications drive the model (Black, 2017). For the natural world, the atmosphere has prescribed pre-industrial (1850) levels of GHGs, ozone and aerosols. The sea ice extent corresponds to the year of maximum sea ice extent in each hemisphere while SSTs are modified to remove estimates of anthropogenic warming (Black, 2017). For the current climate with natural ozone, the setup for the lower boundary conditions including SST forcings are the same as for the current climate (ALL) but natural ozone concentrations are prescribed to 1959 concentrations. These ozone concentrations come from a control integration of the Hadley Centre Coupled Model version3 (HadCM3) whilst the 2013 ozone is from a model running the IPCC Special Report on Emissions Scenarios using the 'A2' projections scenario. Forcings common to all scenarios are the natural forcing factors including changes in volcanic aerosols and solar irradiance. Land surface types have been kept constant between the historical and counterfactual climate scenarios. 
As it is not possible to observe true climate conditions for a "world without humans", w@h ANZ utilises 10 different realisations of the counterfactual natural climate scenario. The set of realisations is derived from different estimates of human-induced SST warming as calculated from 10 available CMIP5 models and the multi-model mean (Taylor et al., 2012; Grose et al., 2015). The ensembles generated for the natural world are considerably larger, helping to quantify some of the uncertainty in the approximations of a world without anthropogenic influence (Black, 2017). Due to the time taken forw@h to reach a state of statistical equilibrium under the applied forcing, the results for December are ill-suited for analysis as 'model spin-up' carries into this month. Hence results for this month are excluded from the analysis.

\subsection{Critique of weather@home}

Whilew@h ANZ has previously been demonstrated to be capable of resolving many important climate features for the Australia and New Zealand regions (Black et al., 2016; Black, 2017), it is important to recognise some of the limitations of the system. Under the current model configuration simulations are always initialised on $1^{\text {st }}$ December in the previous year and run for 12 months. Asw@h ANZ must spin-up in response to the SST field and prescribed boundary conditions, the December results are unreliable and not included. This is problematic for assessing summertime phenomena in the SH (including drought and stratospheric ozone depletion) given December is a key month for which a response is likely to be observed. Land surface data (e.g. vegetation type and roughness) are also fixed between the climate scenarios despite documented climate feedbacks associated with land surface changes (Pitman et al., 2009; Pielke et al., 2011; De NobletDucoudre et al., 2012; Mahmood et al., 2014). While refinements proposed in weather@home2 (Guillod et al., 2017) will go some way to addressing these challenges, output from this improved model is not yet readily available for the ANZ domain.

A further challenge is that w@h ANZ is based on a single atmospheric model. Attribution statements from this study can be made only within the context of the specific model setup. The limited vertical resolution of 19 atmospheric levels also restricts the representation of stratospheric circulation (Pope et al., 2000). This is an issue when investigating the effects of stratospheric ozone depletion as the lower stratosphere is only 
represented by four levels. As such, any differences that are detected due to ozone change in w@h may only represent a portion of the true response. A further constraint of the $\mathrm{RCM}$ is the temporal and spatial resolution. The assessment of short-lived or highly localised events are hampered given data is only available at daily $50 \mathrm{~km}$ resolution. This is particularly challenging in the assessment of regions with large spatial heterogeneity which the model is unable to fully represent (e.g. mountain valleys, urban environments).

\subsection{Scope}

The first part of this research examines if surface climate changes can be detected and attributed to ozone depletion in the w@h ANZ model, using simulations for 2013. Emphasis is placed on examining the Southern Hemispheric effects of stratospheric ozone depletion and the climatological impacts for NZ, especially changes in precipitation.

The second part of the research investigates the anthropogenic influence on March RX1D rainfall in Christchurch. Observations are first examined to contextualise the event in question and to determine the event class to which it belongs. Historical observations are investigated to discern the event return period and if significant changes can be observed for the respective class of event. W@h ANZ simulations for 2014 are used to quantify and evaluate changes in event likelihood. Further detail regarding the temporal and spatial domains for this assessment and the respective sensitivity of results are outlined in Chapter 5.

Allw@h ANZ data products used in this research were copied from the server hosted at the Tasmanian Partnership for Advanced Computing in Hobart, Australia to NIWA's Fitzroy supercomputer where they were accessed for assessment purposes. 


\subsection{Analytical methods}

\section{Software}

The Climate Data Operators (CDO) library, developed by the Max-Planck Institute in Hamburg, Germany is used alongside the open-source NetCDF Operators (NCO) library (Zender, 2008) to manipulate and process the extensive w@h ANZ datasets. This is done via shell-command style interfaces including X-launch and Unix command line. The visual browser for netCDF format files, Ncview (Version 2.1.7, $\mathrm{http}: / /$ meteora.ucsd.edu/ pierce/ncview_home_page.html), is used to inspect data files while Panoply (Version 4.7, http://www.giss. nasa.gov/tools/panoply/) is used to plot geo-referenced data.

The programming language Python (Version 3.6) is the main interface for this project for data handling, analysis and generation of figures and is accessed via the Ipython and Spyder3 command shell environments. A number of supplementary packages are used to assist the analyses performed in Python including Matplotlib (Hunter, 2007), Scikitextremes and Bootstrapped. The Hybrid Single Particle Lagrangian Integrated Trajectory Model (HYSPLIT) developed by Australia's Bureau of Meteorology and the National Oceanic and Atmospheric Administration (NOAA) is used to compute air parcel backtrajectories (Draxler and Hess, 1998; Stein et al., 2015). The statistical packages Microsoft Office Excel (2013) and R (3.3.1) are used to conduct statistical analysis and graphically display data. Lastly, ESRI's ArcMap (Version 10.1) is used to explore spatial relations and generate maps utilising publicly-funded geospatial data obtained from Koordinates (https://koordinates.com/) and Land Information New Zealand (https://data.linz.govt.nz/data/).

\section{Data screening and aggregation}

Due to the large volume of w@h ANZ data, every file within each ensemble of simulations was screened to ensure it contained a complete record and was suitable for analysis. A number of criteria were specified including; the file contained 360 timesteps, all timesteps contained valid data and the total file size was $44,049 \mathrm{~KB}$. After applying these criteria at least $97.6 \%$ of files obtained from the server were retained (Table 3.1). CliDB daily observations for Christchurch Gardens from 02/01/1873 - 31/12/2017, 
having already been screened by NIWA to ensure data integrity, were $89.8 \%$ complete (89.0\% complete for March).

Simple arithmetic operations (i.e. addition, subtraction, division) were performed using $\mathrm{CDO}$ and $\mathrm{NCO}$ to aggregate and determine the mean conditions for each ensemble. Anomalies were then determined by subtracting the difference between the two mean states.

Table 3.1: The ALL (A), NAT (N) and ALL_NATURAL_O3 (O) scenario ensemble sizes (\% retained) for 2013 and 2014 for variables daily precipitation and mean sea level pressure (MSLP) at monthly global and daily regional resolutions.

\begin{tabular}{|c|c|c|c|c|}
\hline Year & Variable & ALL (A) & NAT (N) & ALL_NATURAL_O3 (O) \\
\hline \multirow{2}{*}{2013} & MSLP_mon & $6,218(100 \%)$ & $17,509(100 \%)$ & $5,944(100 \%)$ \\
\cline { 2 - 5 } & Precipitation & $6,088(97.8 \%)$ & $8,748(97.3 \%)$ & $980(98.0 \%)$ \\
\hline \multirow{2}{*}{2014} & MSLP_daily & $2,718(97.6 \%)$ & $5,526(98.5 \%)$ & $\mathrm{n} / \mathrm{a}$ \\
\cline { 2 - 5 } & Precipitation & $2,718(97.6 \%)$ & $5,525(98.5 \%)$ & $\mathrm{n} / \mathrm{a}$ \\
\hline
\end{tabular}

Statistical analysis

Statistical significance was determined for observed anomalies by calculation of a $\mathrm{z}$-score for each cell. These were calculated using CDO and NCO libraries to perform the operations in equation 3.1 (from Eq. 5.8, Wilks, 2006),

$$
z=\frac{\mu_{a}-\mu_{o}}{\left[\frac{s_{a}^{2}}{n_{a}}+\frac{s_{o}}{n_{o}}\right]^{1 / 2}}
$$

where $\mu$ is the mean of the distribution, $s$ is the variance of the population and $n$ is the number of simulations in the population, subscripts $a$ and $o$ represent the factual and counterfactual scenarios. As daily precipitation data is not normally distributed, medians are reported and non-parametric tests (Mann-Whitney (MW) and Kolmogorov-Smirnov (KS); Massey, 1951, Lillieflors, 1967) are utilised for testing significance of difference. The non-parametric KS test is well suited for such analysis due to being able to detect differences in the location and shape of two different distributions (King et al., 2015). In addition to these tests, the Anderson-Darling test (Stephens, 1974) is also used in assessing the performance of each parametric extreme value distributions due to giving more weight to the tails than the KS test, allowing for a more restrictive comparison of climate extremes (Diffenbaugh et al., 2017). 


\subsubsection{Average recurrence intervals}

Two approaches are utilised in estimating average recurrence intervals (ARIs) for the extreme precipitation event in Christchurch. The first approach,

$$
A R I=\frac{(N+1)}{R a n k}
$$

estimates the ARI based on the magnitude rank position of the event where $\mathrm{N}$ is the number of events (years) for the population. The second approach assesses three different parametric extreme value distributions (Gumbel, Generalised Extreme Value (GEV) and Generalised Logistic (GLO)) to ascertain which is most suitable for determining ARI. These were fit by using probability-weighted moments (Greenwood et al., 1979; Hosking et al., 1985; McKerchar and Pearson, 1989). As in prior studies of Christchurch rainfall (Griffiths and Pearson, 1993; Griffiths et al., 2009), the Gringorten (1963) plotting position has been used to simplify the inspection of the distribution.

\subsubsection{Detection of change}

In assessing change for extreme events in the historical observation record, there is a need for "complete" records (for our purposes $>99 \%$ complete). This is due to a missing record for an extreme event potentially having a large bearing on results given their occurrence is so infrequent. Christchurch Gardens, which is one of the longest records in NZ, has complete annual records dating back to 1899. This long-term observational record is divided into two 59-year windows (1899-1957 and 1959-2017) to determine if a significant change can be detected and the season when the change is occurring. To ensure both windows are the same size 1958 has been left out. This analysis is conducted using the annual and seasonal records examining three indices: extreme 1-day rainfall events (RX1D) larger than the $98^{\text {th }}$ percentile of rainfall events $\geq 1 \mathrm{~mm}$, all 1-day rainfall events $\geq 1 \mathrm{~mm}$ and the top three events annually.

\subsubsection{Fraction of attributable risk}

In the case of our Christchurch study, the components of the FAR (Equation 2.1) are based on a specified March precipitation threshold being exceeded in the two scenarios. This metric provides a means of expressing how much of the events current risk is due to anthropogenic GHG. 
Uncertainty in the calculation of return period and FAR is estimated using a bootstrap procedure (without replacement) 10,000 times on 50\% of subsamples from the complete simulated ensemble. Sampling without replacement is used to better preserve secondorder properties (i.e. variance) though, given the large dataset and number of resampled values, differences from utilising this approach are likely negligible (Bertail, 1997). The 10,000 bootstrapped estimates were then used to calculate $10^{\text {th }}$ and $90^{\text {th }}$ percentile return period and FAR estimates. Definitions of when anthropogenic influence can be detected for FAR estimates are consistent with those used in prior studies (King et al., 2016). If the $10^{\text {th }}$ percentile FAR value is greater than zero, a significant anthropogenic influence is detected (i.e. human-induced climate change very likely increased the likelihood of the extreme weather event). If the $10^{\text {th }}$ percentile FAR value is greater than 0.5 , a significant and substantial anthropogenic influence is detected (i.e. human-induced climate change very likely at least doubled the likelihood of the extreme weather event).

\subsubsection{Sensitivity analysis}

The sensitivity of results with regards to the choice of spatial domain and observational dataset was assessed to establish the uncertainty associated with framing choices. A key component of this analysis was ascertaining which spatial domain exhibited the smallest bias between simulated values and observations for the equivalent class of event. Quantile-quantile plots were used to determine if the two data sets belong to the same distribution in addition to the degree of correction required to accommodate discrepancies arising in modelled output.

\subsection{Summary}

Observational data sets, including reanalysis fields, are examined to validate output from w@h ANZ, contextualise RX1D rainfall for Christchurch in March 2014 and ascertain if significant changes can be detected. Simulations from w@h ANZ for three forcing scenarios are compared to determine the influence of ozone and anthropogenic forcings in altering patterns of circulation and precipitation, with a detailed enquiry for Christchurch to assess how the likelihood of RX1D rainfalls have changed due to human influence. The next two chapters describe and discuss the results of this analysis, first for the contribution of ozone forcings and secondly for extreme 1-day rainfall events in Christchurch like that observed in early March 2014. 


\section{CHAPTER 4 - OZONE FORCING ASSESSMENT}

Regional climate simulations generated by w@h ANZ for 2013 were examined to determine whether surface climate changes can be detected and attributed to ozone depletion. The relative contribution of ozone depletion to change was assessed by comparison of the anomalies between factual and counterfactual climate change simulations, and ozone hole and non-ozone hole simulations. From this, the contribution of ozone depletion to recent changes in our climate system may be better apportioned assisting understanding of present and future climate change risks.

\subsection{Global assessment}

One of the primary aims of this thesis is to examine if surface climate changes can be detected and attributed to ozone depletion in the w@h ANZ model. Anomalies in circulation and precipitation are determined by comparison of 2013 simulations for the ALL (A) and ALL_NATURAL_O3 (O) scenarios, which we refer to as the ozone hole analysis (A-O). Results from a global assessment of the monthly averaged values of mean sea level pressure (MSLP) indicate a strong seasonal response to stratospheric ozone depletion (Figure 4.1). The largest anomalies are primarily observed in the mid- to highlatitude SH regions with disparities over $2 \mathrm{hPa}$ observed near the Antarctic coastline during the austral summer. Equatorial regions and the Northern Hemisphere see smaller anomalies.

In 2013, a zonal wave three pattern is seen in the A-O MSLP anomalies during January and February (Figure 4.1). The strong anomalies dissipate for the austral winter with a zonal wave one pattern appearing later in the year. During late austral spring, a trough of negative pressure anomaly extends over NZ while the South Atlantic experiences a large positive anomaly. Despite the anomalies generally having small magnitude, they are significantly different from zero at the $95 \%$ level (based on a two-tailed t-test).

In contrast, the climate change analysis $(\mathrm{A}-\mathrm{N})$ has MSLP anomalies greater than $3 \mathrm{hPa}$ (Figure 4.2) with most regions across the globe having z-scores greater than plus or minus three, indicating statistical significance at the $99^{\text {th }}$ percentile. Figure 4.3 indicates a large 
majority of the anomalies in both analyses lie outside three standard deviations $\left(99^{\text {th }}\right.$ percentile) of monthly MSLP variability. The z-score distribution has a negative mean globally, indicating the global mean surface pressure response is primarily due to large high-latitude decreases in MSLP (Gillet and Stott, 2009). The mean shift in z-score for the climate change analysis is larger at -5.61 in addition to having wider variability (larger tails). When the scope is reduced to the region between $35^{\circ} \mathrm{S}$ and $65^{\circ} \mathrm{S}$, where the largest anomalies are observed, variability is reduced and the mean z-score for the climate change and ozone analysis are positioned at 2.5 and 2.25 respectively (Figure 4.4 ). In both the global and restricted SH cases, the climate change analysis sees larger variability and shifts in the mean z-score than the ozone hole analysis. This suggests that while ozone forcings are a critical component of change, the additional contribution from other GHGs amplify such changes.

Prior studies have suggested observed shifts in the mid-latitude jet and trends for the SAM index in DJF during the last 50 years are primarily in response to stratospheric ozone depletion. Lee and Feldstein (2013) stated that ozone depletion contributed approximately 50\% more than GHGs toward the jet shift in austral summer. This can also be seen in our results where the maximum MSLP anomaly increases between the ozone hole $(\mathrm{A}-\mathrm{O})$ and climate change $(\mathrm{A}-\mathrm{N})$ analyses by roughly a factor of two. This is despite scenarios A and O being forced with exactly the same SSTs which could have lessened the potential response (unlike $\mathrm{N}$ where the anthropogenic temperature component had been removed from SSTs). 

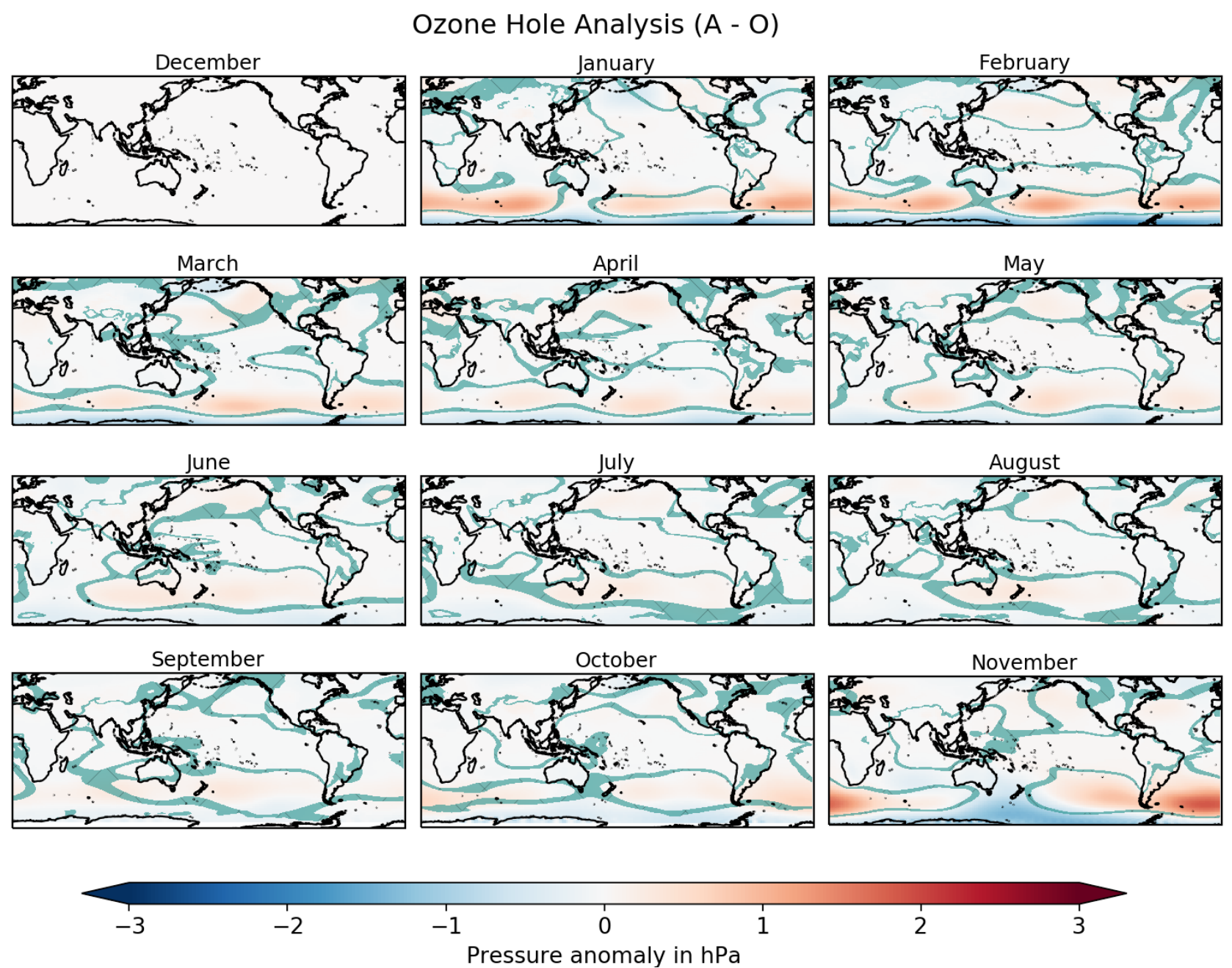

Figure 4.1: Ozone hole analysis (A-O) monthly mean sea level pressure anomalies (hPa) for 2013. Shaded areas indicate regions where z-score is $<2.0$ (i.e. 95 th percentile). Values for December have been set to zero due to distortion by model spin-up 
Climate Change Analysis (A - N)
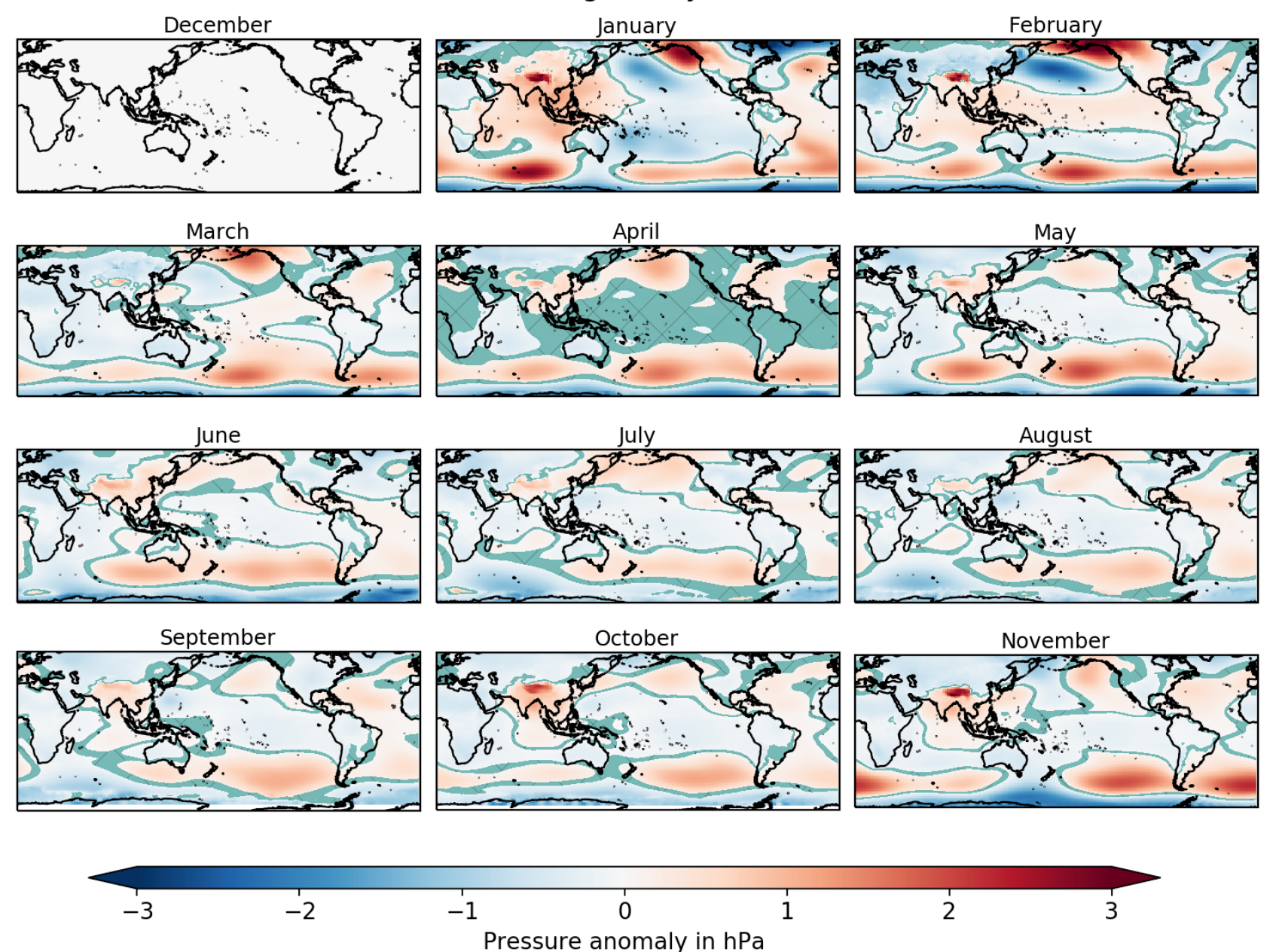

Figure 4.2: Climate change analysis (A-N) monthly mean sea level pressure anomalies (hPa) for 2013. Shaded areas indicate regions where the z-score $<2.0$ (i.e. 95 th percentile). Values for December have been set to zero due to distortion by model spin-up. 


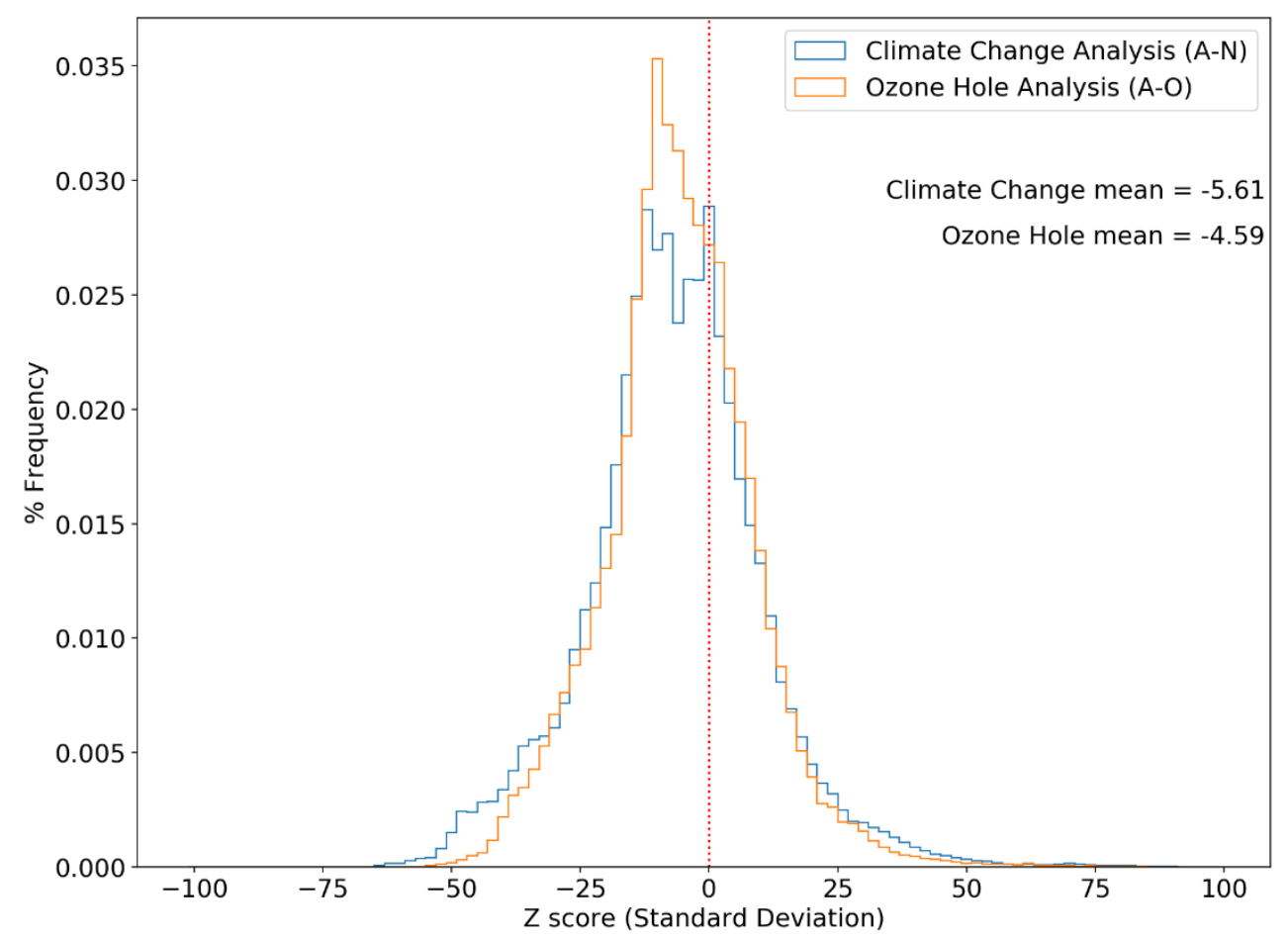

Figure 4.3: Distribution of global mean sea level pressure anomaly z-scores from JanuaryNovember 2013 for the climate change analysis (A-N) and ozone hole analysis (A-O). The red-dotted line indicates zero.

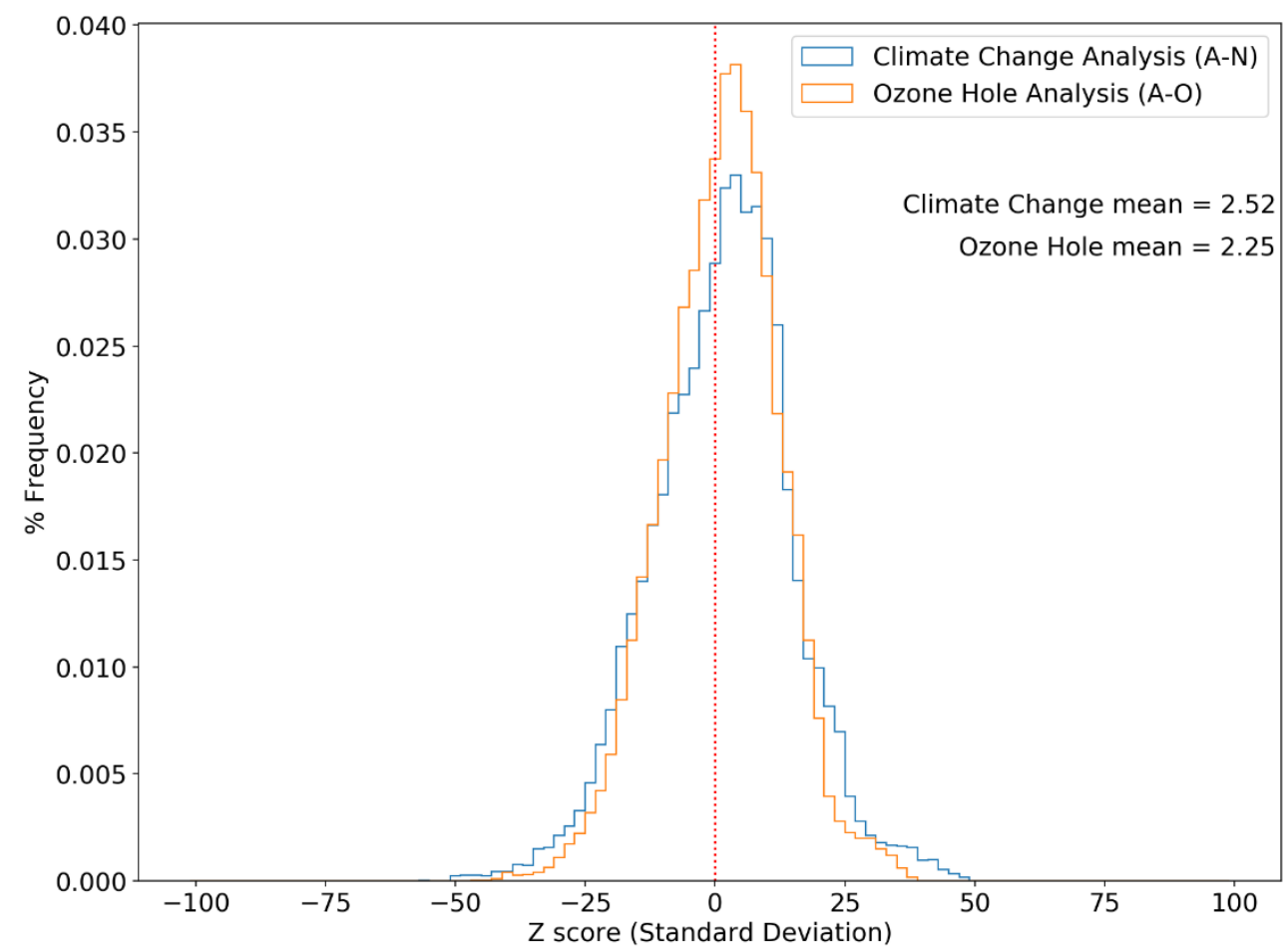

Figure 4.4: Distribution of z-score for mean sea level pressure anomaly between $35^{\circ} \mathrm{S}$ and $65^{\circ} \mathrm{S}$ from January-November 2013 for the climate change (A-N) and ozone hole (A-O) analyses. The red-dotted line indicates zero. 


\subsection{Westerly winds and the Southern Annular Mode}

When examined zonally, MSLP, as modelled by w@h ANZ, decreases at high latitudes in response to stratospheric ozone depletion with negative anomalies peaking at $75^{\circ} \mathrm{S}$ (Figure 4.5). In the mid-latitudes of the SH, positive MSLP anomalies reach their maxima at $50^{\circ} \mathrm{S}$. The enhanced pressure gradient between these latitudes affects the strength and position of the westerly winds. In w@h ANZ, the region $50-75^{\circ} \mathrm{S}$ sees increases of up to $1.0 \mathrm{~m} / \mathrm{s}$ in average westerly wind speed at $850 \mathrm{hPa}$, for which February has the greatest acceleration (Figure 4.6). The mid-latitudes between $30^{\circ} \mathrm{S}$ and $50^{\circ} \mathrm{S}$ meanwhile have an average decrease in westerly wind speed of $0.5 \mathrm{~m} / \mathrm{s}$, with the largest deceleration again in February. These MSLP and wind responses are suggestive of a positive SAM index in support of prior attribution studies and are consistent with the observed positive trend in the SAM found for austral summer in recent decades (Thompson et al., 2011; Abram et al., 2014).

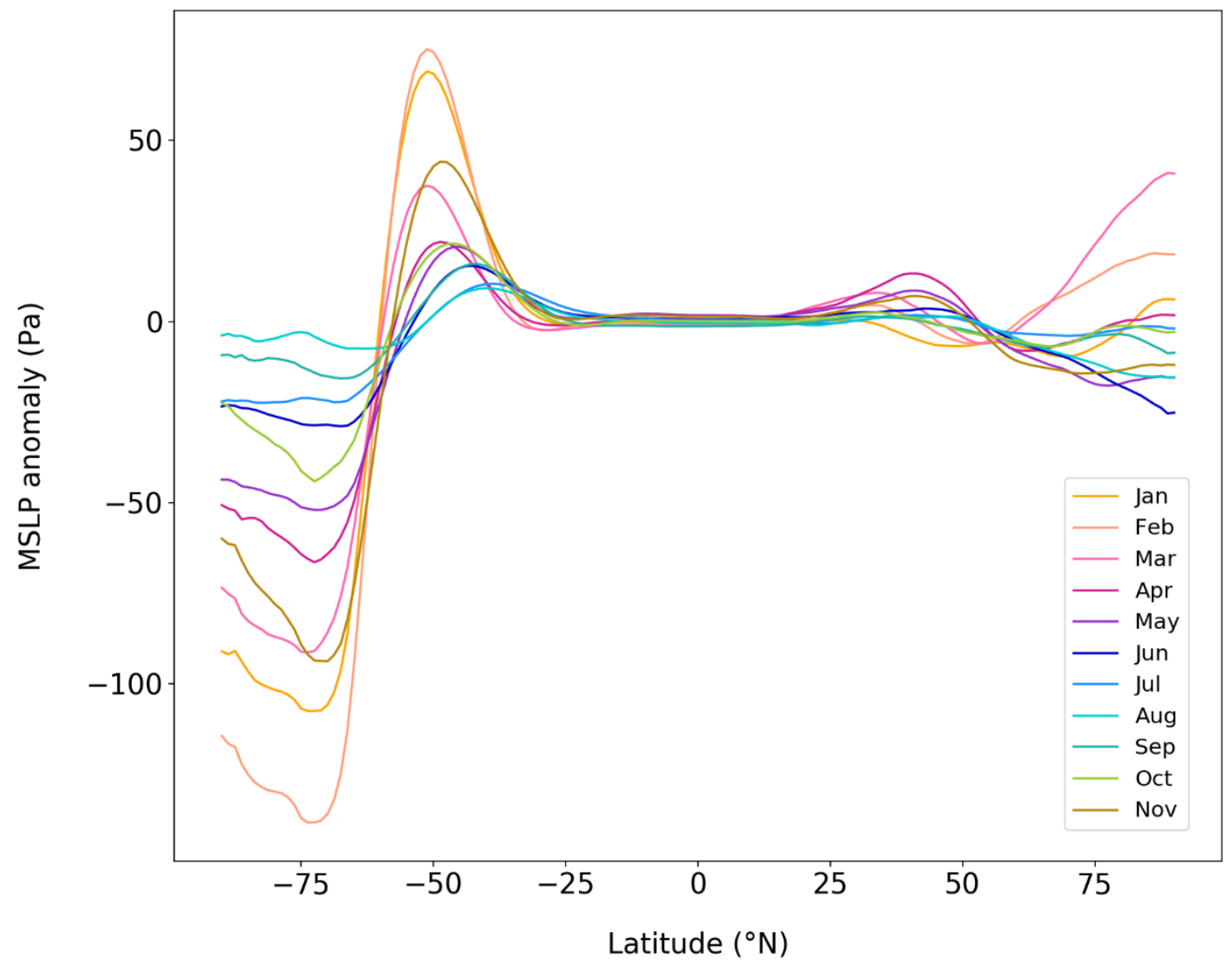

Figure 4.5: Zonally averaged mean sea level pressure anomalies (Pa) by month from January - November 2013 for the ozone hole analysis (A-O). 


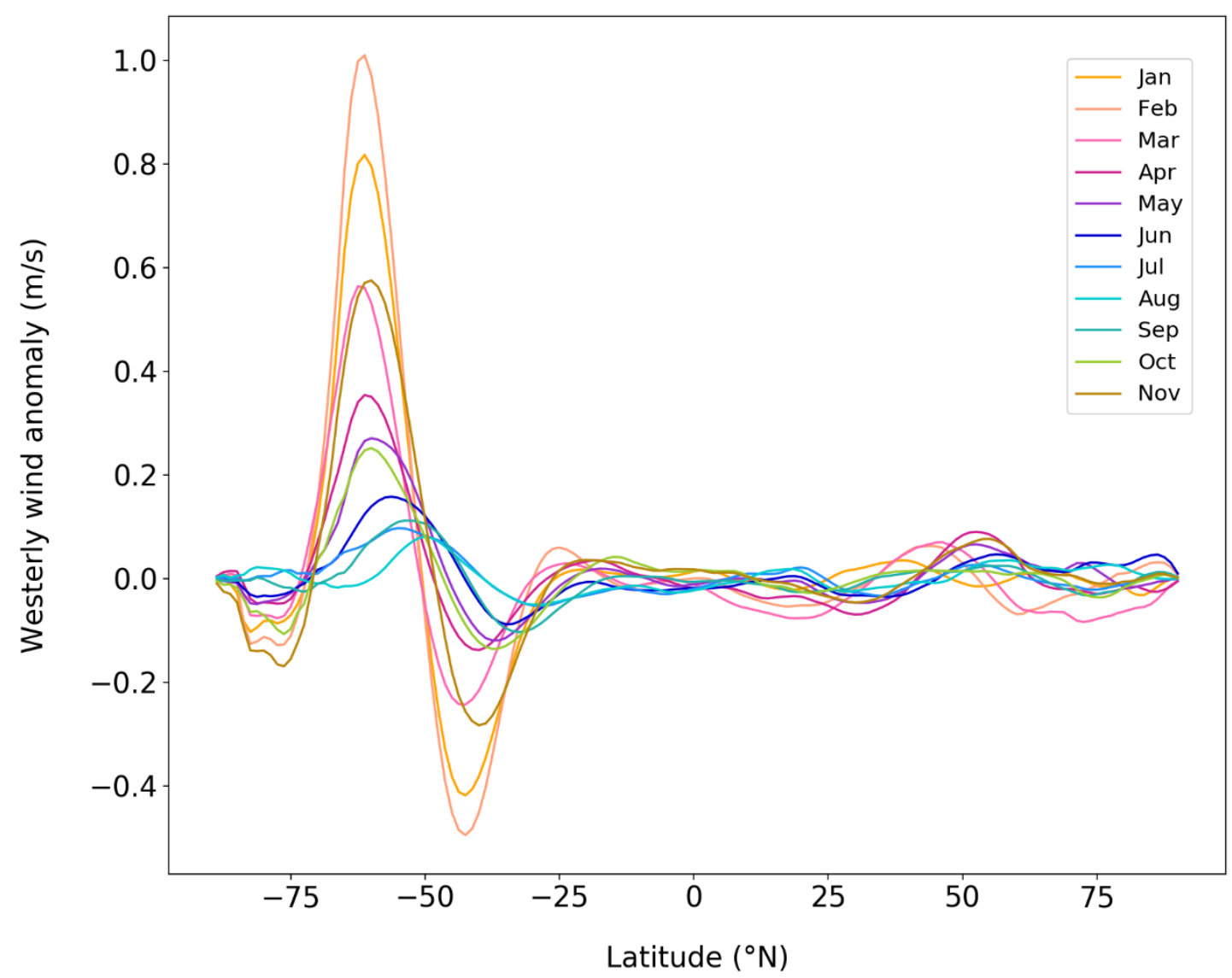

Figure 4.6: Zonally averaged mean westerly wind anomalies $(\mathrm{m} / \mathrm{s})$ at $850 \mathrm{hPa}$ by month from January - November 2013 for the ozone hole analysis (A-O).

The SAM index can be calculated in a number of different ways including Marshall's 12station index (Marshall, 2003) and the NOAA Climate Prediction Center's reanalysesbased Antarctic Oscillation Index (AOI; Gong and Wang, 1999). A pseudo-SAM index was developed in an attempt to replicate the steps used by NOAA in calculating the SAM. Zonal MSLP means at $40^{\circ} \mathrm{S}$ and $65^{\circ} \mathrm{S}$ were calculated before subtraction of the $65^{\circ} \mathrm{S}$ value from the $40^{\circ} \mathrm{S}$ value. The monthly values were then standardised by a linear scaling using the annual mean mslp difference $\mu$ before subtraction of one (i.e. $\mu / \mu$ ) to centre the index on zero.

$$
\text { Pseudo-SAM }=\frac{m s l p_{40}-m s l p_{65}}{\mu}-1
$$

This differs slightly to the standardisation used by NOAA where zonal means are standardised by the mean/standard deviation using the climatological period (1981-2010) however this length of data is not available for the ozone experiments fromw@h ANZ. 
Applying the pseudo-SAM index indicates a positive phase for this index in March and April, followed by a negative phase through the austral winter (Figure 4.7). The end of the year then sees a return to a strong positive phase. These are consistent between the three scenarios with the "NAT" scenario indicating a more negative pseudo-SAM index in austral autumn and winter. The lack of difference between the curves for $\mathrm{A}$ and $\mathrm{O}$ during April-June is consistent with the lack of ozone forcing during autumn and winter, though the difference between these two curves is generally small for most of the year in question. In November, the curves for $\mathrm{A}$ and $\mathrm{O}$ go in opposite directions relative to $\mathrm{N}$, suggesting ozone forcings (as encapsulated in A) give rise to a more positive SAM index while GHG alone $(\mathrm{O})$ perhaps lead to a more negative SAM index. This single year result differs to the findings of Gillet et al. (2013) who found MSLP trends for the period 19512011 to increase in the mid-latitudes for both ozone and GHG changes, consistent with a positive phase of the SAM.

Comparison with NOAA's SAM index indicates the shape of the pseudo-SAM index to be in poor agreement with large differences in both the timing and magnitude. This may be partially accounted for by the different standardisation procedure or model biases propagating into MSLP estimates, but is likely to be largely due to the model's internal variability not matching that observed in 2013. The low correlation (0.02) between the pseudo- and NOAA-SAM indices suggests that the model simulated monthly circulation variability does not match the observed sequence well. As SSTs are the only source of variability that is common to the w@h ANZ simulations and observational record, the lack of agreement between these indices suggests the limited role of SST in driving SAM variability. This supports the findings of Gupta and England (2006) who found the SAM to be mainly controlled by internal atmospheric mechanisms, though they did find lagged correlations whereby the oceans thermal inertia re-imprinted the SAM signature back to surface air temperatures. In light of this, it is worthwhile to evaluate how representative 2013 is against the long-term climatology and the performance of w@h ANZ with ERAInterim reanalysis data to better understand the limitations of the model. 


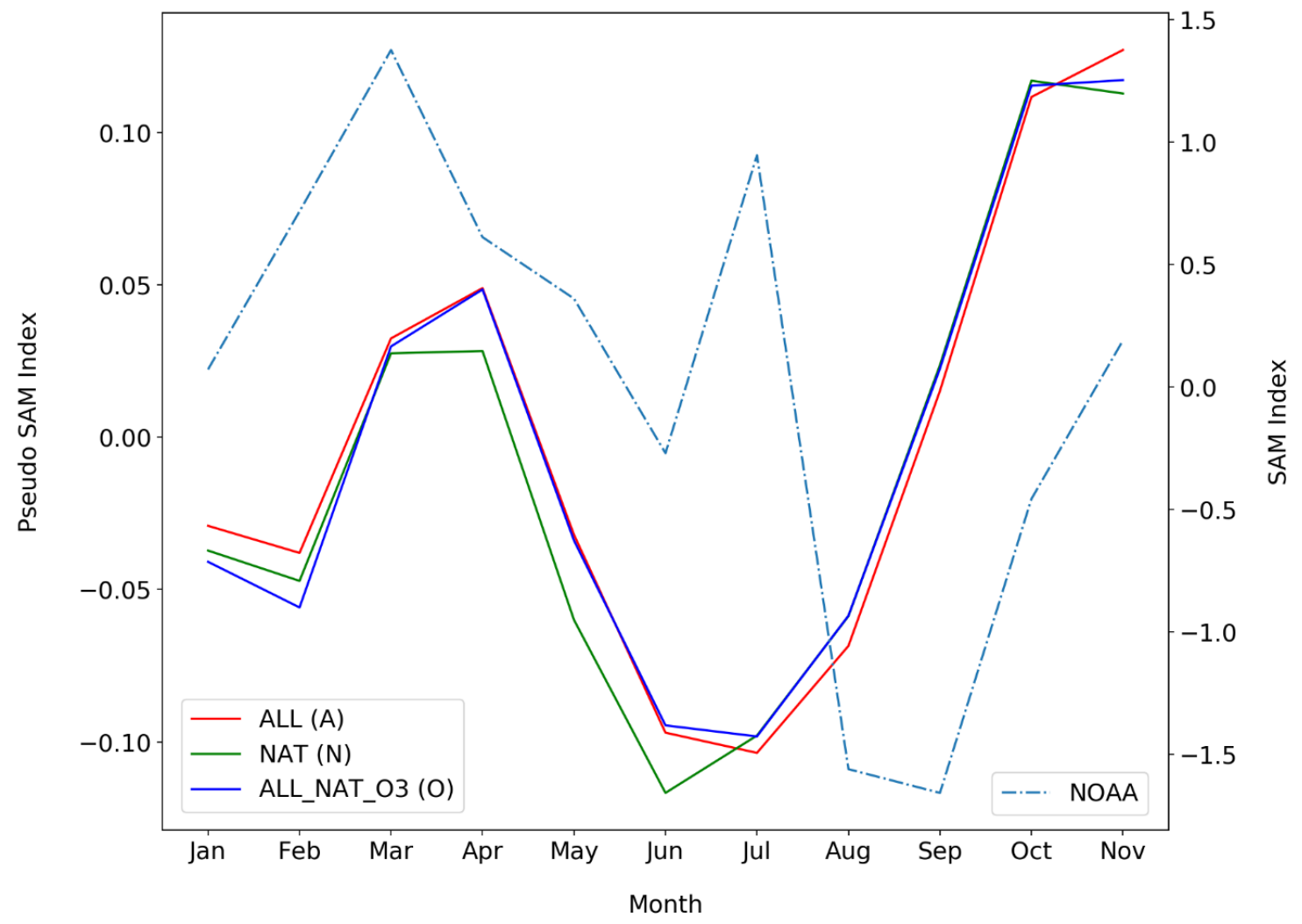

Figure 4.7: Pseudo-SAM index determined as the zonal mean sea level pressure difference between $40^{\circ} \mathrm{S}$ and $65^{\circ} \mathrm{S}$ normalised against the mean for the entire January - November period for the ALL (A), NAT (N) and ALL_NAT_O3 (O) climate forcing scenarios. These are compared to the NOAA SAM index (dashed line) for 2013 which is plot with respect to the right-hand axis.

\subsection{How representative is 2013 ?}

ERA-Interim reanalysis fields for 2013 were compared to the average over 1979-2017 to assess the representativeness of the year under investigation. Standardised anomalies were calculated by subtracting the climatological mean from each observation before dividing by the climatological standard deviation for the location. By and large, 2013 does not appear to be particularly anomalous with regard to MSLP with the largest anomalies occurring in the Northern Hemisphere (Appendix A).

For the NZ region, the largest anomalies from climatological average occurred in July and October. The negative anomaly southwest of NZ in October (Figure 4.8), and enhanced pressure gradient over the country would result in stronger than average westerly winds and more precipitation on the West Coast for October 2013 compared to 
the climatology. In contrast, an extensive positive anomaly to the south of Australia in November also influences the southern half of NZ, likely reducing westerly wind speeds for this month (Figure 4.9). While the unique characteristics of 2013 are important to keep in mind, a robust model such as w@h ANZ that is conditioned on SSTs should be able to accommodate seasonal variability which we now assess in a simple validation.

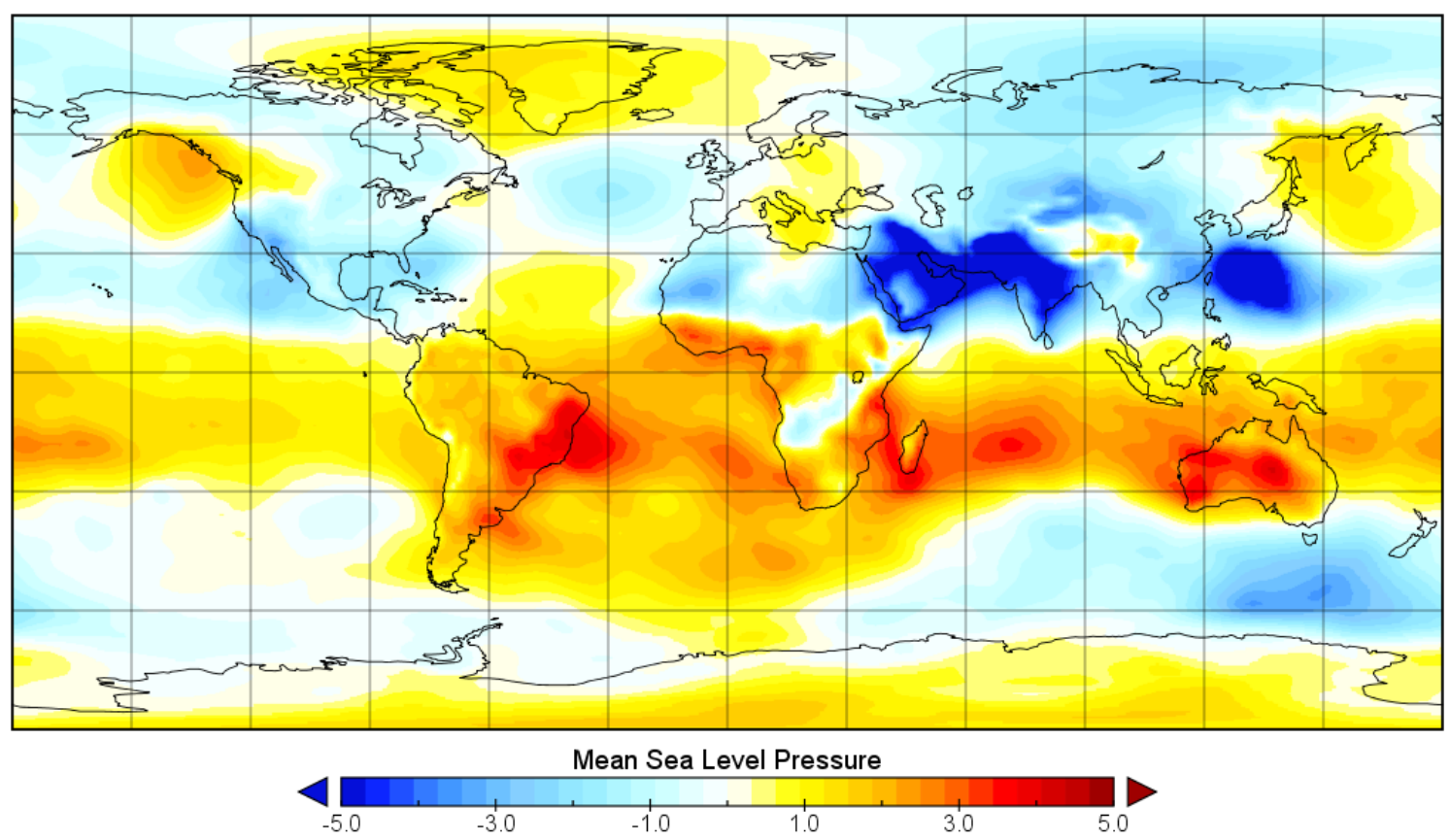

Figure 4.8: October 2013 MSLP compared to 1979-2017 climatology in ERA-Interim displaying standardised anomaly (dimensionless, units are standard deviations). 


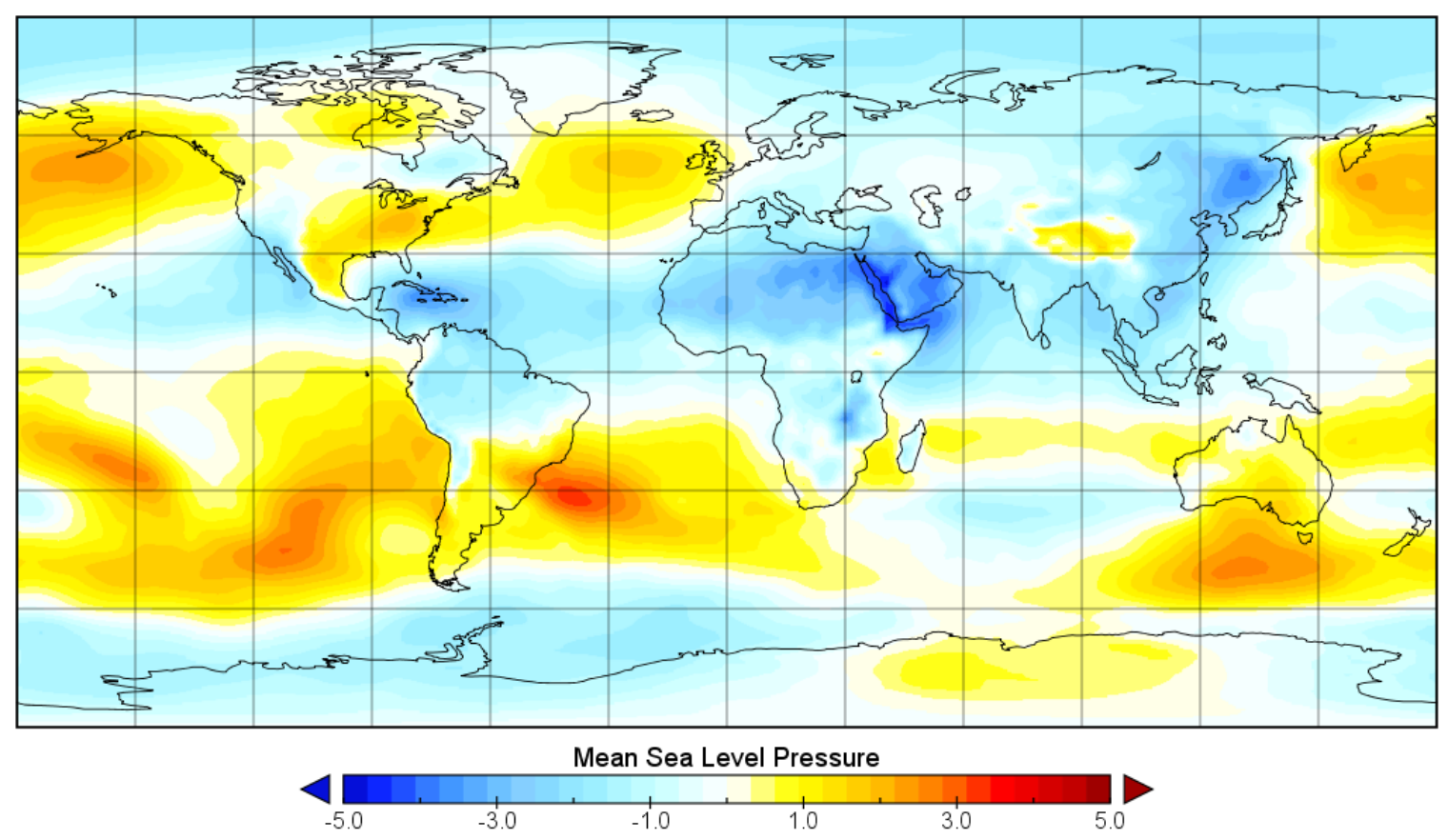

Figure 4.9: November 2013 MSLP compared to 1979-2017 climatology in ERA-Interim displaying standardised anomaly (dimensionless, units are standard deviations).

\subsection{Validation}

A simple validation of $\mathrm{w} @ \mathrm{~h}$ ANZ with ERA-Interim observations indicates several systematic biases. Antarctica has large discrepancies, with the model consistently underestimating MSLP by over $5 \mathrm{hPa}$ (Figure 4.10). This discrepancy is also observed for the Himalaya region from May until October, though the interpretation of MSLP in regions where the Earth's surface is much higher than mean sea level is questionable. In the mid-latitudes, MSLP appears to be often over-estimated. The combination of these biases in w@h ANZ would result in an over-prediction of westerly winds in the midhigh-latitudes at $850 \mathrm{hPa}$ (Figure 4.11) due to an inflated pressure gradient between midlatitude highs and Antarctic lows. Stronger westerly winds than reality would in turn likely contribute to an overestimate of precipitation on western coastlines in the SH. While this positive bias in westerly wind is observed in the SH mid-latitudes, globally the model underestimates westerly winds with a bias of $-0.2 \mathrm{~m} / \mathrm{s}$. 


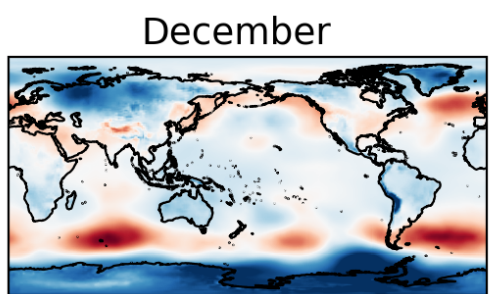

March
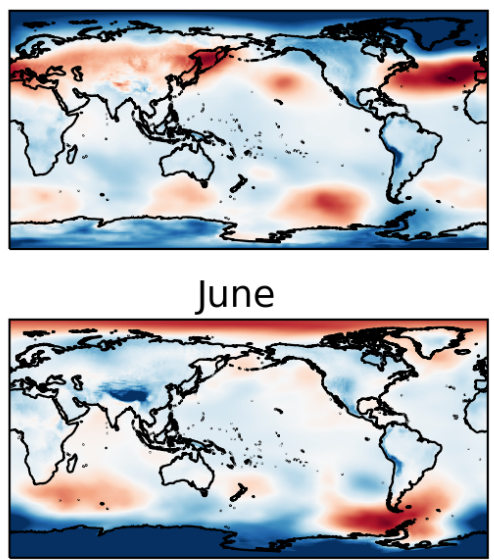

September

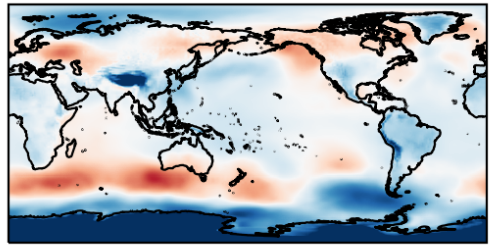

January

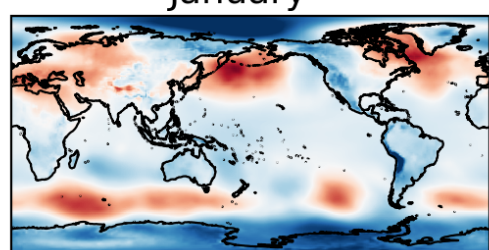

April
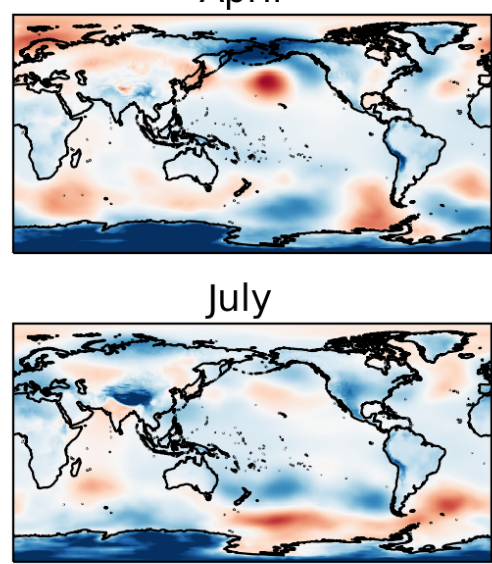

October

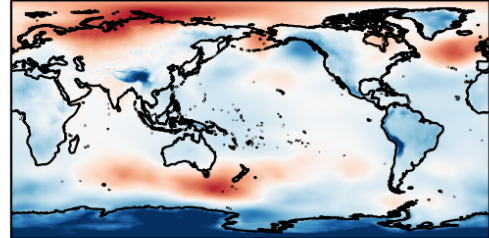

February

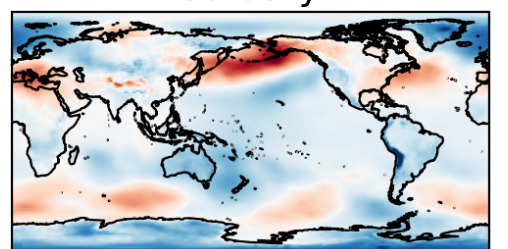

May

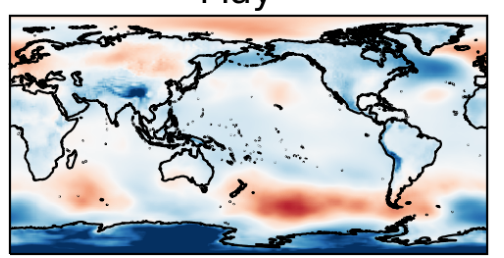

August

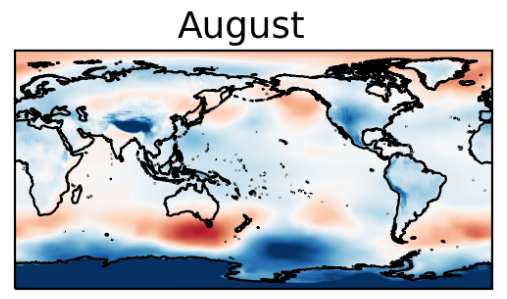

November

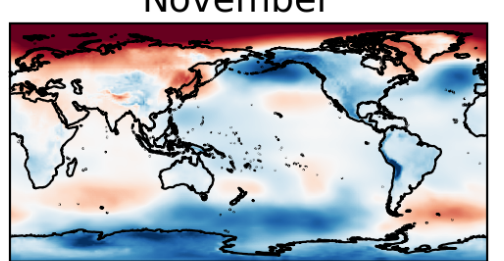

10

$\frac{0}{2}$
$\frac{1}{.}$
$\vdots$
$\frac{0}{0}$
$\frac{0}{0}$
$\frac{0}{0}$
$\frac{0}{\Sigma}$

$-10$

$-15$

Figure 4.10: Weather@home bias in mean monthly MSLP (hPa) for 2013. ALL (A) forcings minus ERA-Interim. Positive bias in MSLP indicated by warm colours. 


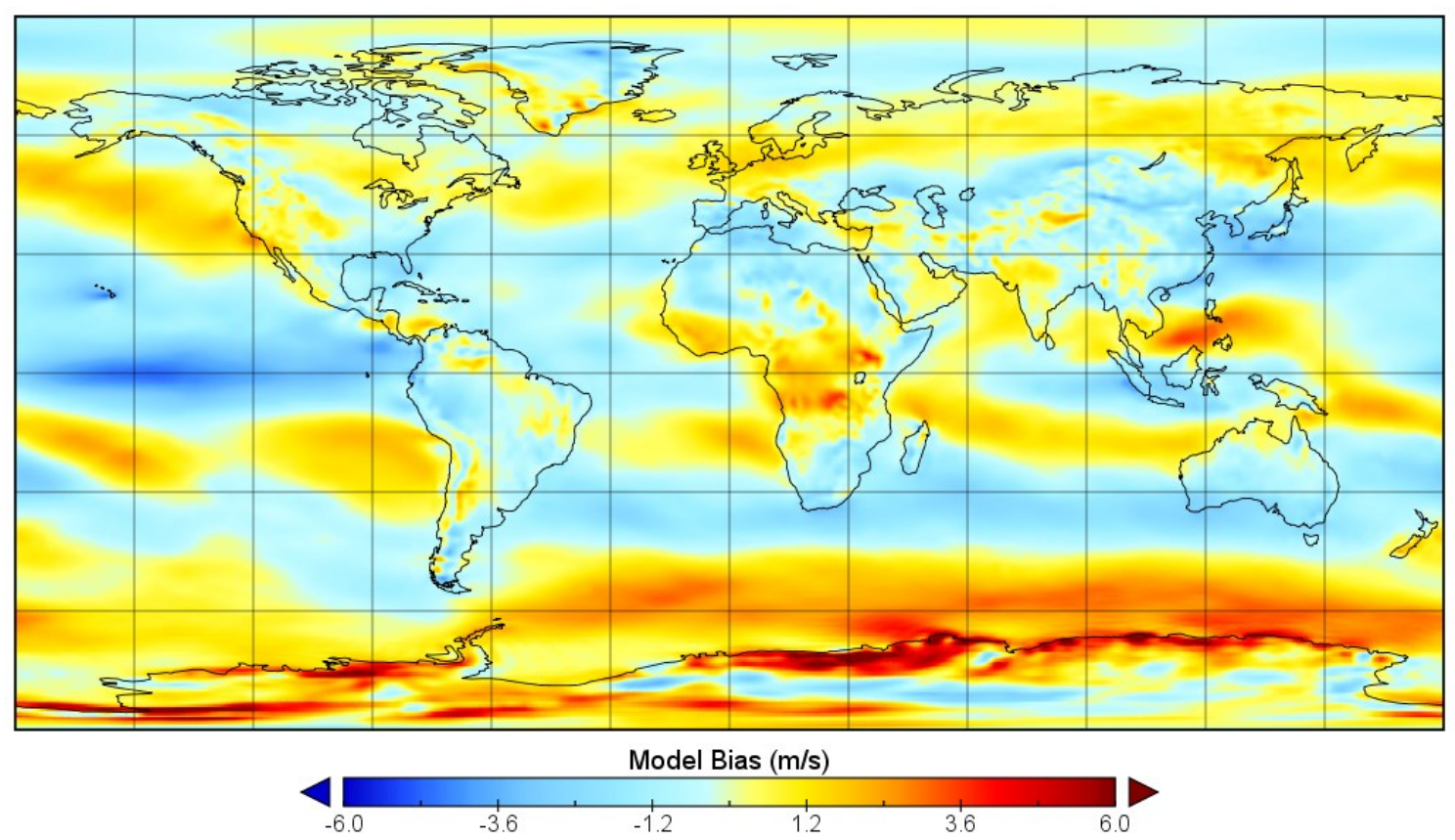

Figure 4.11: Weather@home bias in the westerly (u) component of wind at 850 hPa for January - November 2013 (ALL (A) forcings minus ERA-Interim). Positive westerly flow bias is indicated by warm colours.

Despite the tendency for w@h to overestimate the westerly wind (u) component at midhigh-latitudes in the $\mathrm{SH}$, meaningful comparison can still be made between simulations if we assume the inherent biases within the model are consistent and thus cancel out. This assumption permits us to understand how variables, such as $\mathrm{u}$ and precipitation, respond to stratospheric ozone depletion which we discuss further for the NZ region.

\subsection{New Zealand surface climate changes}

Precipitation anomalies in our ozone hole analysis (A-O) exhibit a high degree of temporal and spatial variability across NZ (Figure 4.12). The spatial variability for the South Island is largely due to the dominant topographic feature, the Southern Alps. The West Coast of the South Island, where annual rainfall totals are largest (Tait et al., 2006), sees the largest magnitude anomalies. Fromw@h ANZ, we see that in May-June 2013 the West Coast receives less precipitation in the ozone hole analysis with the magnitude of the precipitation anomaly up to $-16.6 \mathrm{~mm}$ per month. Despite the relatively large magnitude, these changes are not statistically significant. Furthermore, the change is 
much smaller in magnitude than $-50 \mathrm{~mm}$ per month change found for the West Coast by Ummenhofer et al. (2009) for a one SD positive SAM index. Conversely, for late winter and spring, the West Coast receives more daily precipitation. January and November on the West Coast observe modest increases in monthly mean precipitation up to $+46 \mathrm{~mm}$ per month which are significant at the $66^{\text {th }}$ percentile. In November, the positive pseudoSAM index is associated with increased precipitation anomalies over the NZ region, opposing the overall relationship between positive SAM and drying on the West Coast. This reiterates how a zonally-based index such as the SAM does not always account for regional variability.

The grid cells used to represent the West Coast (Figure 4.13) equate to roughly $1 / 3^{\text {rd }}$ of the 67 cells that comprise the model South Island. Median daily precipitation on the West Coast in 2013 had a net increase in the ozone hole analysis (A-O) with the greatest contribution to this increase during spring (Table 4.1). This coincides with when ozone forcings may be anticipated to have greatest effect. November exhibited a significantly different precipitation distribution when using a KS test, with the median increasing significantly from $10.62(\mathrm{O})$ to $11.80 \mathrm{~mm} /$ day (A) (Figure 4.14). The MW test indicates August exhibited a significant increase $(p=0.038)$ in median precipitation from 10.71 to $11.08 \mathrm{~mm} /$ day while June has a small $(p=0.089)$ decrease in median daily precipitation from 10.61 to $10.58 \mathrm{~mm} /$ day. 


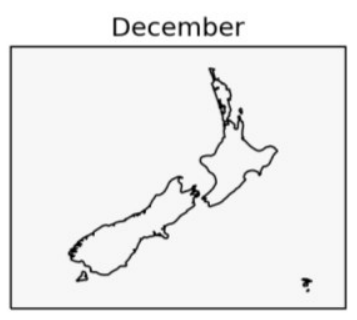

March

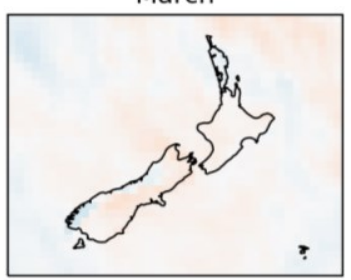

June

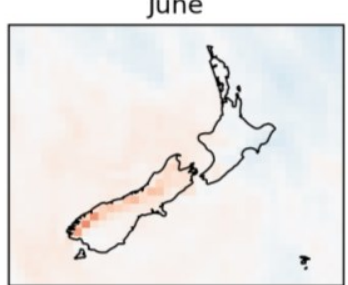

September

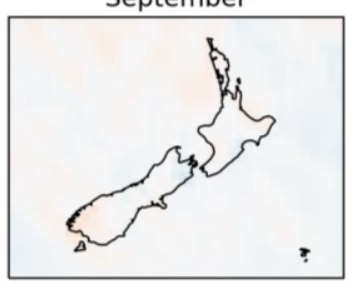

$-30$
January

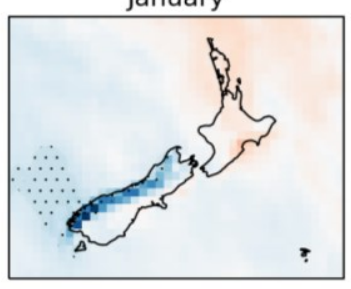

April

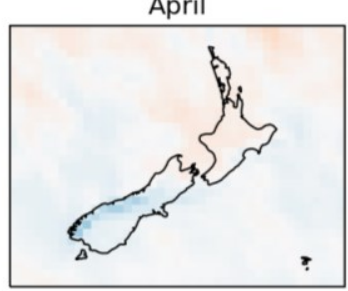

July

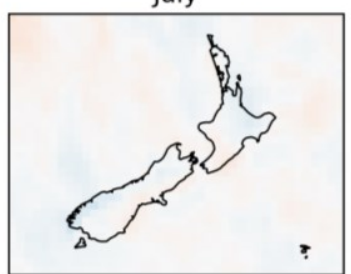

October

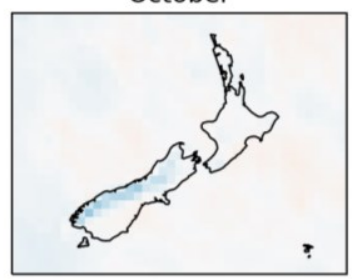

February

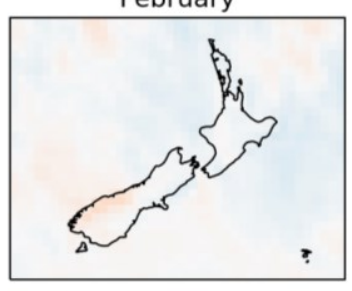

May

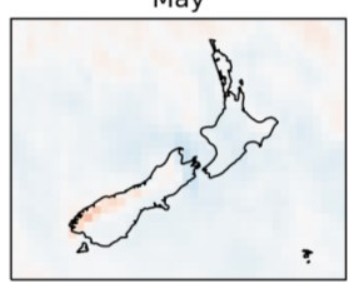

August

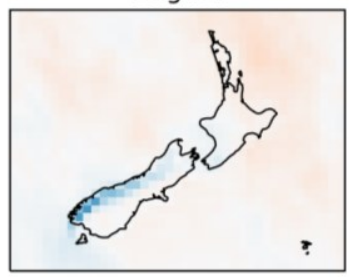

November

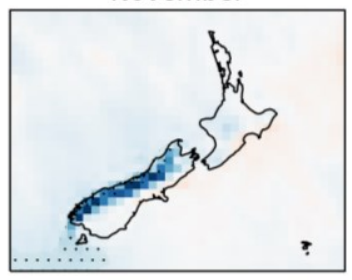

20

30

Precipitation anomaly in $\mathrm{mm} / \mathrm{month}$

Figure 4.12: Monthly precipitation anomaly in the ozone hole analysis (A-O) for 2013, stippling indicates significance at 66 th percentile and no data is presented for December.

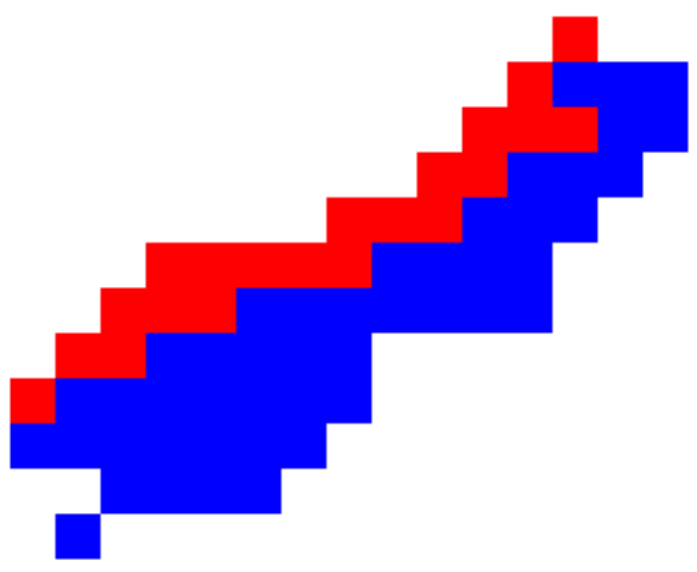

Figure 4.13: South Island of New Zealand as represented by the w@h ANZ model configuration with the West Coast cells $(n=21)$ represented in red. 
Table 4.1: Median daily precipitation ( $\mathrm{mm} /$ day) and the median annual total rainfall $(\mathrm{mm})$ on the West Coast for different scenarios; ALL (A), ALL_NAT_O3 (O) and NAT (N).

\begin{tabular}{|c|r|r|r|}
\hline & \multicolumn{4}{|c|}{ Median Daily Precipitation $(\mathbf{m m} / \mathbf{d a y})$} \\
\hline Month & $\mathbf{A}$ & $\mathbf{O}$ & $\mathbf{N}$ \\
\hline Dec & $\mathrm{n} / \mathrm{a}$ & $\mathrm{n} / \mathrm{a}$ & $\mathrm{n} / \mathbf{a}$ \\
\hline Jan & 6.31 & 5.87 & 6.87 \\
\hline Feb & 6.67 & 6.71 & 6.83 \\
\hline Mar & 7.98 & 8.02 & 8.22 \\
\hline Apr & 10.31 & 9.94 & 10.47 \\
\hline May & 9.89 & 9.99 & 9.99 \\
\hline Jun & 10.58 & 10.61 & 10.45 \\
\hline Jul & 10.68 & 10.56 & 10.42 \\
\hline Aug & 11.08 & 10.71 & 10.95 \\
\hline Sep & 12.55 & 12.59 & 12.33 \\
\hline Oct & 13.97 & 13.53 & 13.69 \\
\hline Nov & 11.80 & 10.62 & 11.29 \\
\hline Annual Total $(\mathrm{mm})$ & 3165.3 & 3098.4 & 3139.2 \\
\hline
\end{tabular}

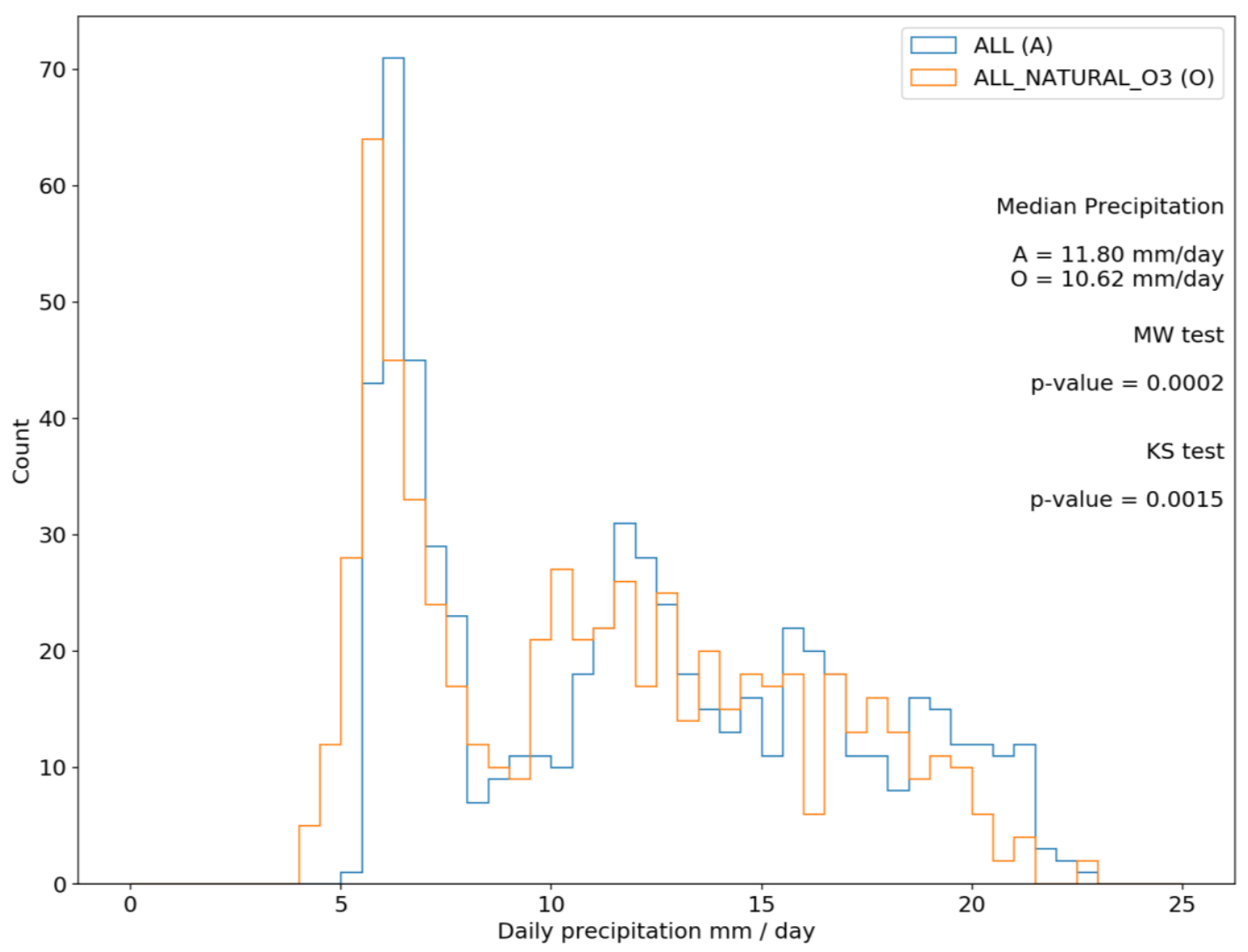

Figure 4.14: Histogram and statistical results comparing daily precipitation for the West Coast under the ALL (A) and ALL_NAT_O3 (O) forcings in November. 
In the $\mathrm{O}$ scenario when ozone forcings are set at 'natural' concentrations, total median daily precipitation on the West Coast has a small decrease relative to $\mathrm{N}$, while the all forcings (A) scenario has a small increase (Table 4.1). If these results were representative of decadal-scale changes, they suggest that summer months in the western parts of the South Island are generally wetter due to ozone depletion while winter is generally drier albeit with a smaller signal. Such a result is opposite to the late twentieth century (19792006) precipitation trends for NZ (Ummenhofer et al., 2009). We conclude that modelled internal variability over-rode the ozone depletion signal for this one-year experiment.

The transitional seasons, autumn and spring, exhibit mixed precipitation responses, though November is significantly wetter. February has a significant change in precipitation in the anthropogenic climate change simulations, although the decrease in median daily precipitation from 6.83 to $6.67 \mathrm{~mm}$ /day is not statistically significant ( $p=$ 0.105 ) for a MW test. To understand the context for these changes it is important to consider changes in the regional wind regime given much of NZ's rainfall arises from the storm track and westerly wind belt (Ummenhofer and England, 2007).

For the first half of 2013, A-O differences show weakened westerly winds (Figure 4.15). From June onwards, westerly wind enhancement propagates up and over the country with November showing spatially extensive enhancement of up to $0.42 \mathrm{~m} / \mathrm{s}$. While the stronger westerly winds modelled during November support enhanced precipitation, January's observation of higher precipitation despite reduced westerly winds is less intuitive. This may be due to the meridional (v) component of the wind bringing moisture from the Tasman Sea to the north which interacts with the topographical features. Without data regarding the $\mathrm{v}$ component of wind vectors this cannot be validated, though it would be an interesting avenue for further enquiry. However, the drier West Coast seen in February, when there is anomalous easterly airflow, reiterates the importance of westerly winds to South Island rainfall spatial variability. 


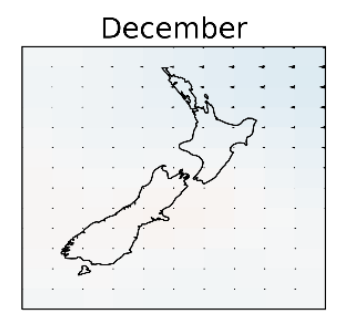

March

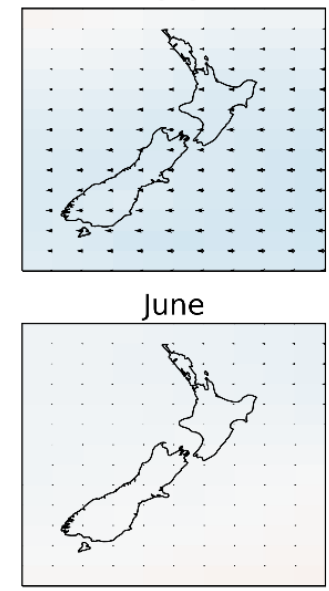

September

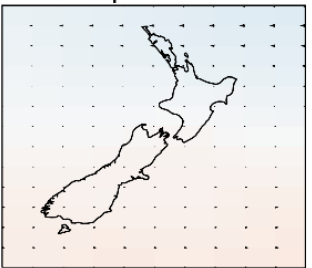

January

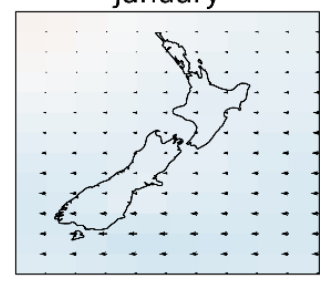

April

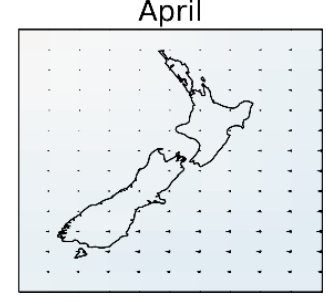

July

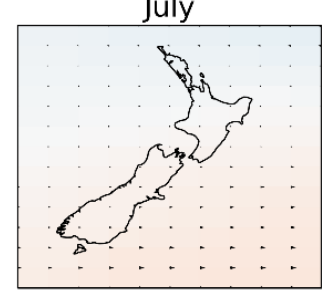

October

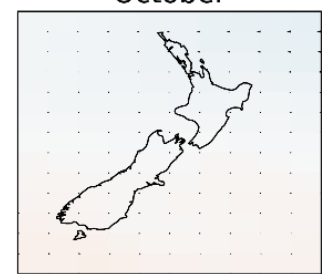

February

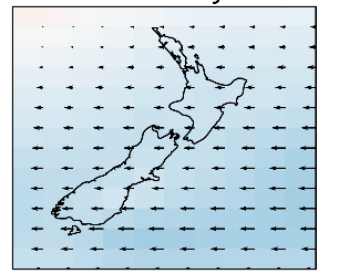

May

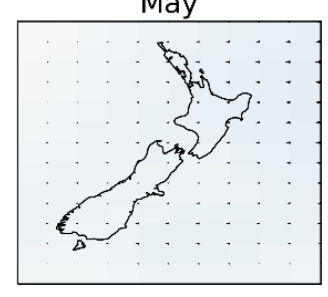

August

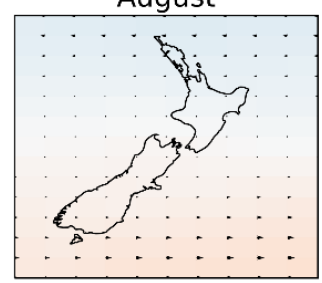

November

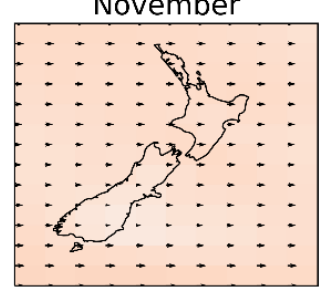

1.5

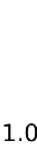

1.0

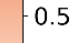

0.5

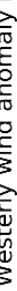

Figure 4.15: Monthly westerly wind anomaly in the ozone hole analysis (A-O) at $850 \mathrm{hPa}$ in 2013. Positive westerly flow anomaly is indicated by warm colours.

Increased MSLP for SH high-latitudes reported earlier in this Chapter (Section 4.1) aligns with the ozone response and increase in SAM index documented for DJF (Polvani et al., 2011; Gillett et al., 2013). For the first half of 2013 the NOAA SAM was predominantly in a positive phase before changing to negative phase for late winter and spring (Figure 4.7). As the westerly wind belt was positioned poleward for the start of the year, which A-O simulations suggest to be partially due to ozone forcings (Figure 4.15), the West Coast experiences reduced westerly winds and precipitation. Conversely, during the negative phase of SAM from June onwards, westerly winds are more equatorward and are thus stronger than normal for most of the country, contributing to the positive precipitation anomalies observed on the West Coast. It is surprising that the pseudo-SAM index does not show better agreement with the A-O strengthened mid- high-latitude westerlies $\left(50-70^{\circ} \mathrm{S}\right)$ and weaker westerlies in mid-latitudes $\left(30-50^{\circ} \mathrm{S}\right)$. Yet despite this, 
these results reconfirm how the ozone hole is strongly implicated in the position of the westerly wind anomalies.

A restriction of only having one year's worth of simulations has been the inability to study inter-annual/decadal trends in climate variables or to average out the effects of internal variability in simulations. Comparing whole decades would help minimise the influence of large-scale teleconnections (e.g. the SAM) by smoothing inter-annual variability of such oscillations (Otto et al., 2015). Future research may look to assess the role of ozone forcings integrated over a longer period (i.e. 1985 till present as performed for GHGs by Black et al., 2016) which may help generate more useful outputs regarding changing climate patterns and apportioning the role of ozone forcings. This may include improving the representation of the stratosphere in addition to exploring factors that contribute to discrepancies of the w@h ANZ model with observations.

\subsection{Summary}

This chapter demonstrated that w@h ANZ is capable of resolving and detecting significant changes in circulation and precipitation both for the NZ region and globally. Ozone related changes in MSLP were significant for most of the Earth with the most prominent changes in monthly MSLP $(<3 \mathrm{hPa})$ observed in the $\mathrm{SH}$ during the austral summer. At high latitudes, SH westerly winds are up to $1.0 \mathrm{~m} / \mathrm{s}$ stronger than otherwise due to ozone forcings while for the SH mid-latitudes, westerly winds are generally weaker. This corroborates the late $20^{\text {th }}$ century trend in the SAM index towards its positive phase and increasingly drier conditions observed for much of NZ's South Island (Ummenhofer et al., 2009). The seasonal anomalies in rainfall in response to ozone forcings for 2013 contradict our existing understanding, despite 2013 being fairly representative of the climatological average in the NZ region. This is thought to be due to challenges stemming from large natural variability in circulation dynamics and indices such as the SAM. Future analysis would benefit from having multi-year simulations to average out natural variability thus assisting with the identification and apportioning of ozone-induced change. An interesting use of w@h ANZ's current capability would be to assess how extremes in 2013 responded to ozone forcings in isolation following similar procedures to the next chapter, where attribution analysis is conducted for a 2014 extreme rainfall event in Christchurch. 


\section{CHAPTER 5 - EXTREME ONE-DAY RAINFALL IN MARCH 2014 FOR CHRISTCHURCH}

On the $4^{\text {th }}$ and $5^{\text {th }}$ March 2014, Christchurch, NZ experienced torrential rainfall over a period of 30 hours (Figure 5.1). Resulting damages are estimated to have cost NZD \$22.5 million in insurance claims with more than 100 homes inundated with water (NIWA, 2014; RNZ, 2014). These homes were primarily located in the suburbs of Richmond, St Albans and Mairehau to the north-east of the CBD (Figure 5.2). Over 94\% of the rainfall associated with this event was received within the $24 \mathrm{hr}$ window (New Zealand Local Time (NZLT) 0900-0900) for which daily rainfall observations are available back to 1873. As such, this short duration event is herein evaluated as a one-day rainfall event (RX1D).

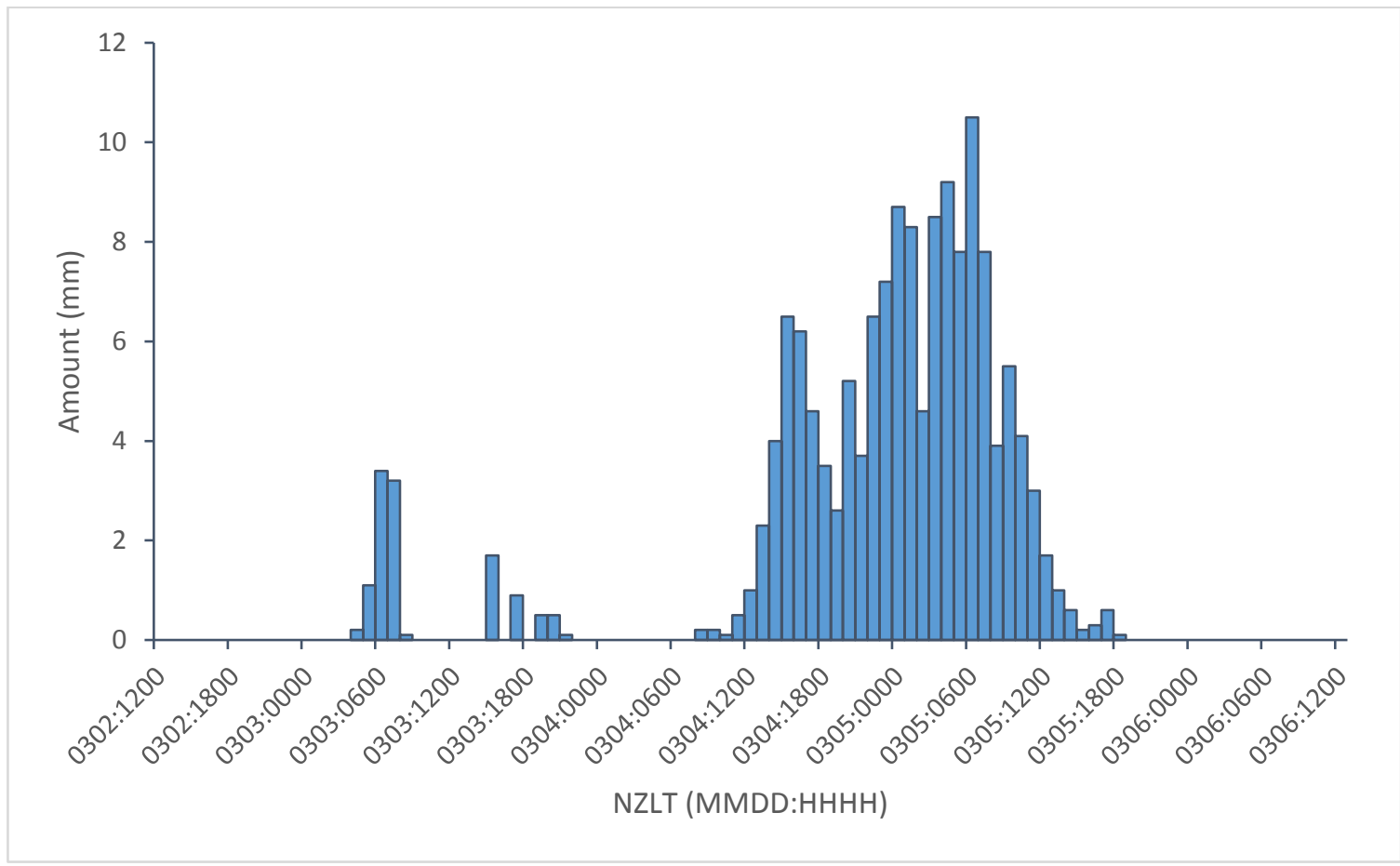

Figure 5.1: Hourly total rainfall at Kyle Street electronic weather station in Riccarton from $2^{\text {nd }}-7^{\text {th }}$ March 2014. From this record, $132.7 \mathrm{~mm}$ was measured from NZLT 0900-0900, while $140.7 \mathrm{~mm}$ was received from $4^{\text {th }}$ March NZLT $0800-5^{\text {th }}$ March NZLT 1900. 


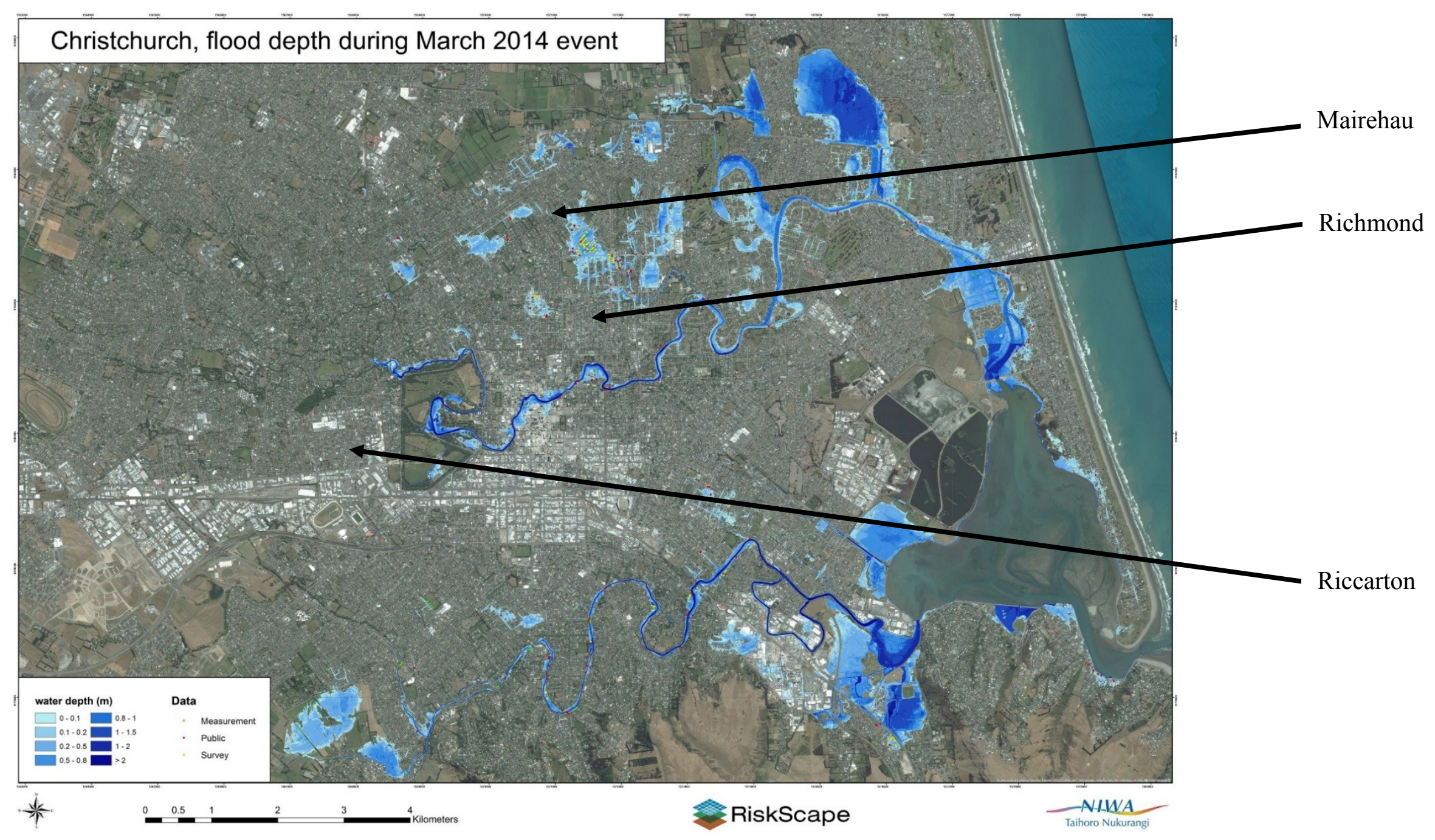

Figure 5.2: Interpolated flood depths (m) based on citizen science data collection, for $5^{\text {th }}$ March 2014 flood in Christchurch, New Zealand. Darker blues indicate greater water inundation (Le Coz et al., 2016). 


\subsection{Observational record}

A number of observational records are available for contextualising this extreme precipitation event. These include measurements from NIWA's Christchurch weather stations accessed via CliDB, and high resolution $0.05^{\circ} \times 0.05^{\circ}$ latitude/longitude observations derived from NZ weather stations via the Virtual Climate Station Network (VCSN; Tait et al., 2006). As primary observations, weather stations provide an indication of the conditions for a given point at a given time. The spatial coverage is however haphazard (Figure 5.3), and some weather stations provide hourly observations while others provide only total daily rainfall observations. Further challenges arise due to the differing lengths and completeness of the rainfall record as illustrated for a selection of sites in Table 5.1. In contrast, VCSN estimates, while available at high spatial resolution, are only generated from 1972 and do not have sub-daily data offered.

Table 5.1: Total daily precipitation observations on $5^{\text {th }}$ March for Christchurch weather stations from CliDB. Total rainfall ( $\mathrm{mm}$ ) observed for 24 hours prior to 9 am and rank position for extreme 1-day rainfall (RX1D) and extreme 3-day rainfall (RX3D). Completeness of daily record (\%) are as reported in CliDB summary.

\begin{tabular}{|c|c|c|c|c|c|c|c|}
\hline $\begin{array}{c}\text { Weather } \\
\text { Station }\end{array}$ & Start-date & End-date & $\begin{array}{c}\text { Complete } \\
\mathbf{( \% )}\end{array}$ & $\begin{array}{c}\text { 5th } \\
\text { Mar } \\
\mathbf{2 0 1 4} \\
\mathbf{( m m )}\end{array}$ & $\begin{array}{c}\text { RX1D } \\
\text { Rank }\end{array}$ & $\begin{array}{c}\text { 4-6th } \\
\text { March } \\
\mathbf{2 0 1 4} \\
\text { (mm) }\end{array}$ & $\begin{array}{c}\text { RX3D } \\
\text { Rank }\end{array}$ \\
\hline $\begin{array}{c}\text { Christchurch } \\
\text { Gardens }\end{array}$ & $1 / 01 / 1873$ & $01 / 11 / 2017$ & 90 & 130.0 & 1 & 144.9 & 6 \\
\hline $\begin{array}{c}\text { Kyle Street, } \\
\text { Riccarton }\end{array}$ & $1 / 06 / 1998$ & $31 / 05 / 2017$ & 100 & 133.0 & 1 & 177.4 & 1 \\
\hline Shirley & $1 / 01 / 1940$ & $31 / 03 / 2017$ & 100 & 113.0 & 2 & 139.6 & 4 \\
\hline \begin{tabular}{c} 
Lyttelton \\
\hline Christchurch \\
Aero
\end{tabular} & $1 / 03 / 1961$ & $13 / 09 / 2015$ & 60 & 152.8 & 3 & 171.2 & 7 \\
\hline
\end{tabular}




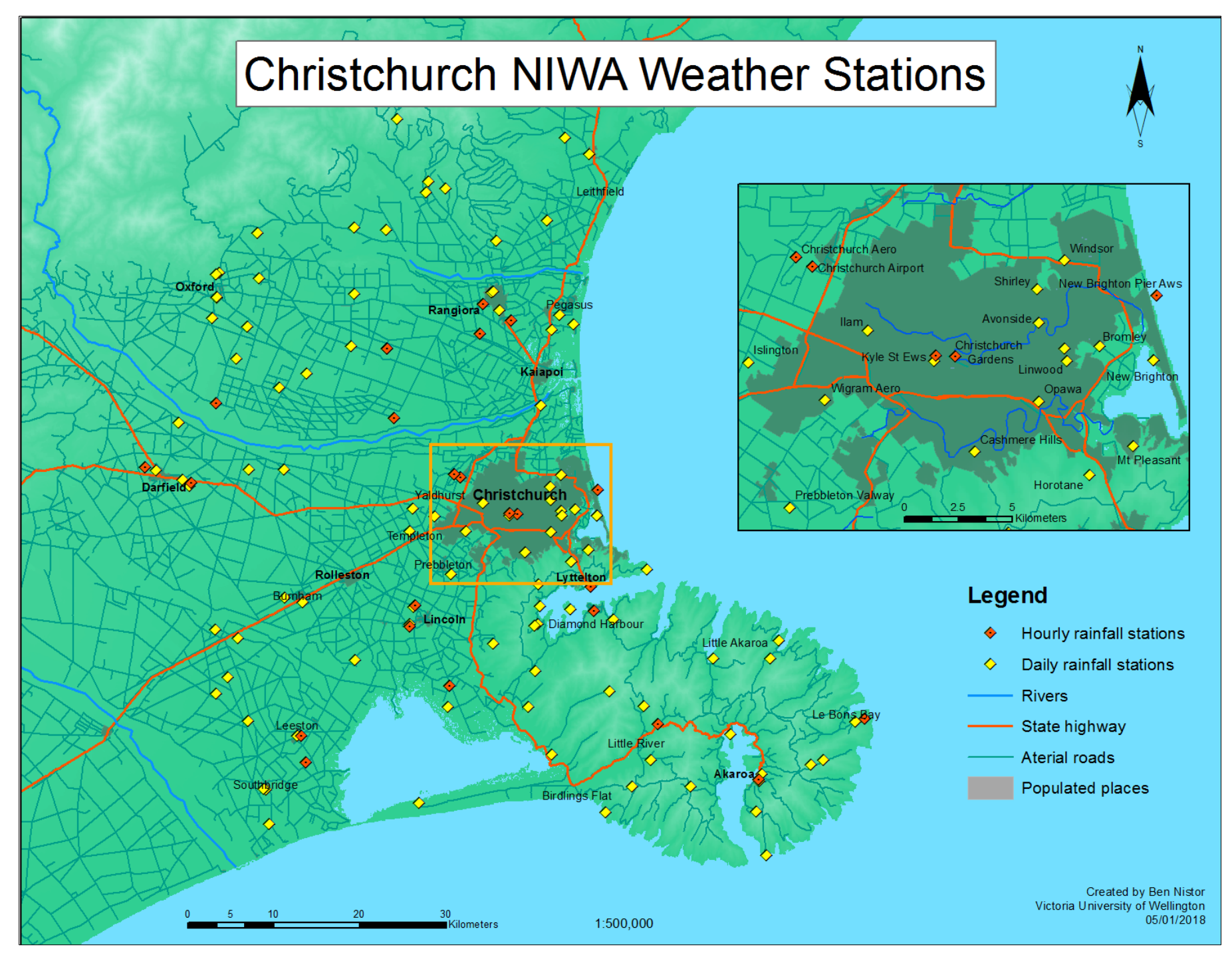

Figure 5.3: Rainfall stations located within $50 \mathrm{~km}$ of Christchurch's central business district as available via CliDB. 
Preliminary observation of the event using VCSN data reveals the spatial extent and timing of the heavy precipitation. On the $2^{\text {nd }}$ and $3^{\text {rd }}$ March 2014, small volumes of rainfall are estimated to have occurred in the greater Christchurch region (Figure 5.4). A large increase in total daily rainfall is seen on the $4^{\text {th }}$ March, the day corresponding to the extreme event, with the greatest amount of rainfall centred over coastal mid- and northCanterbury. Across Christchurch city, there is a clear east-west gradient in precipitation distribution with eastern suburbs receiving up to $150 \mathrm{~mm}$ within $24 \mathrm{hrs}$, nearly double that observed in the west for the corresponding period (Figure 5.5). The following day, total daily rainfall is less than $25 \mathrm{~mm}$ for greater Christchurch, with high rainfalls centred over Kaikoura to the north (Figure 5.4).

Christchurch Gardens, located in the central city botanic gardens, contains the longest record of observations in Christchurch, and one of the longest in NZ. These date back to 1873 and provide a relatively complete series (90\%) of observations (Table 5.1). Figure 5.6 indicates the $130 \mathrm{~mm}$ March 2014 event to be the largest ever RX1D event since records began at this site. The more recently installed Kyle Street weather station $0.9 \mathrm{~km}$ to the west recorded a comparable amount of precipitation at $133 \mathrm{~mm}$, meanwhile Shirley, one of the suburbs where flooding was most extensive, received $113 \mathrm{~mm}$ of rainfall making this the $2^{\text {nd }}$ largest $\mathrm{RX} 1 \mathrm{D}$ event in its 77 -year record.

Both the Generalised Logistic (GLO; Coles, 2001) and Generalised Extreme Value (GEV; Jenkinson, 1955) distributions are able to estimate the average recurrence interval (ARI) for Christchurch Gardens March maximum RX1D well (Figure 5.7). The Anderson-Darling test p-value for the GLO distribution (0.879) and Generalised Extreme Value (GEV) distribution (0.716) indicate both these distributions fit the data well - with a stronger fit for GLO. However, GEV has been used extensively in earlier studies of Christchurch rainfall and is a more common standard distribution (Griffiths and Pearson, 1993; Pearson and Henderson, 1998; Griffiths et al., 2009; Griffiths et al., 2014). In light of this, and previous findings of the Christchurch Gardens rain gauge exhibiting EV1 (Griffiths et al., 2009) and EV2 (Pearson and Henderson, 1998) type distributions (depending on the length of the record examined), this study also employs a GEV distribution.

A Gringorten plot of March RX1D for Christchurch Gardens indicates the $130 \mathrm{~mm} 2014$ event to have March ARI of 1-in-303 years thus placing in the $99.7^{\text {th }}$ percentile with $5^{\text {th }}$ 
and $95^{\text {th }}$ confidence intervals of 1 -in-75 and 1-in-1226 years (Figure 5.7). Meanwhile, if considered in terms of the annual records the associated RX1D return period is 1-in-76 years $(32,185)$ and RX3D is 1 -in-26 years $(15,47)$. The March 2014 event has the longest ARI out of all observed March and annual RX1D events (Table 5.2) while being positioned as an outlier for the distribution (Figure $5.7 \& 5.8$ ).

Table 5.2: Average recurrence interval (ARI) of historical heavy total rainfall events $\left(\mathrm{P}_{\mathrm{T}}\right)$ for Christchurch Gardens from fitting a Generalised Extreme Value distribution to March RX1D, annual RX1D and annual RX3D (see Figure $5.7 \& 5.8$ ).

\begin{tabular}{|c|c|c|c|c|c|c|}
\hline & \multicolumn{2}{|c|}{ March RX1D } & \multicolumn{2}{|c|}{ RX1D } & \multicolumn{2}{c|}{ RX3D } \\
\hline Year & $\mathrm{P}_{\mathrm{T}}(\mathrm{mm})$ & ARI $(\mathrm{yrs})$ & $\mathrm{P}_{\mathrm{T}}(\mathrm{mm})$ & ARI $(\mathrm{yrs})$ & $\mathrm{P}_{\mathrm{T}}(\mathrm{mm})$ & ARI $(\mathrm{yrs})$ \\
\hline $\mathbf{1 8 9 4}$ & n/a & n/a & 101.6 & 28 & 184.7 & 98 \\
\hline $\mathbf{1 9 0 9}$ & 80.3 & 69 & 80.3 & 12 & 144.5 & 26 \\
\hline $\mathbf{1 9 2 5}$ & 13.2 & 2 & 119.6 & 54 & 142.7 & 25 \\
\hline $\mathbf{1 9 6 8}$ & 27.2 & 5 & 81.3 & 12 & 156.3 & 39 \\
\hline $\mathbf{1 9 7 4}$ & 14.8 & 2 & 124.2 & 63 & 149.4 & 31 \\
\hline $\mathbf{1 9 7 5}$ & 87.4 & 89 & 87.4 & 16 & 113.8 & 9 \\
\hline $\mathbf{2 0 1 4}$ & 130.0 & 303 & 130.0 & 76 & 144.9 & 26 \\
\hline
\end{tabular}



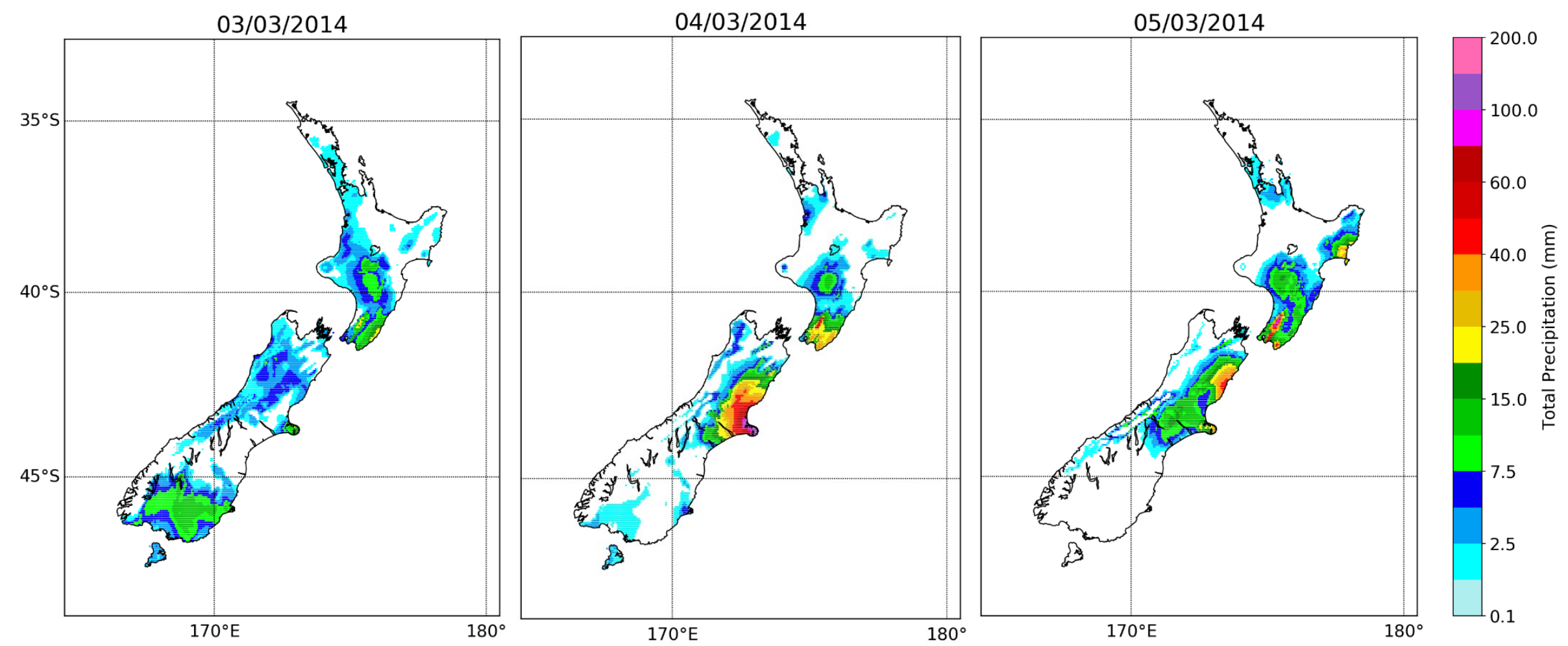

Figure 5.4: Virtual Climate Station Network 24 hr precipitation (NZLT 9 am -9 am total) from $3^{\text {rd }}$ March $-5^{\text {th }}$ March 2014. 


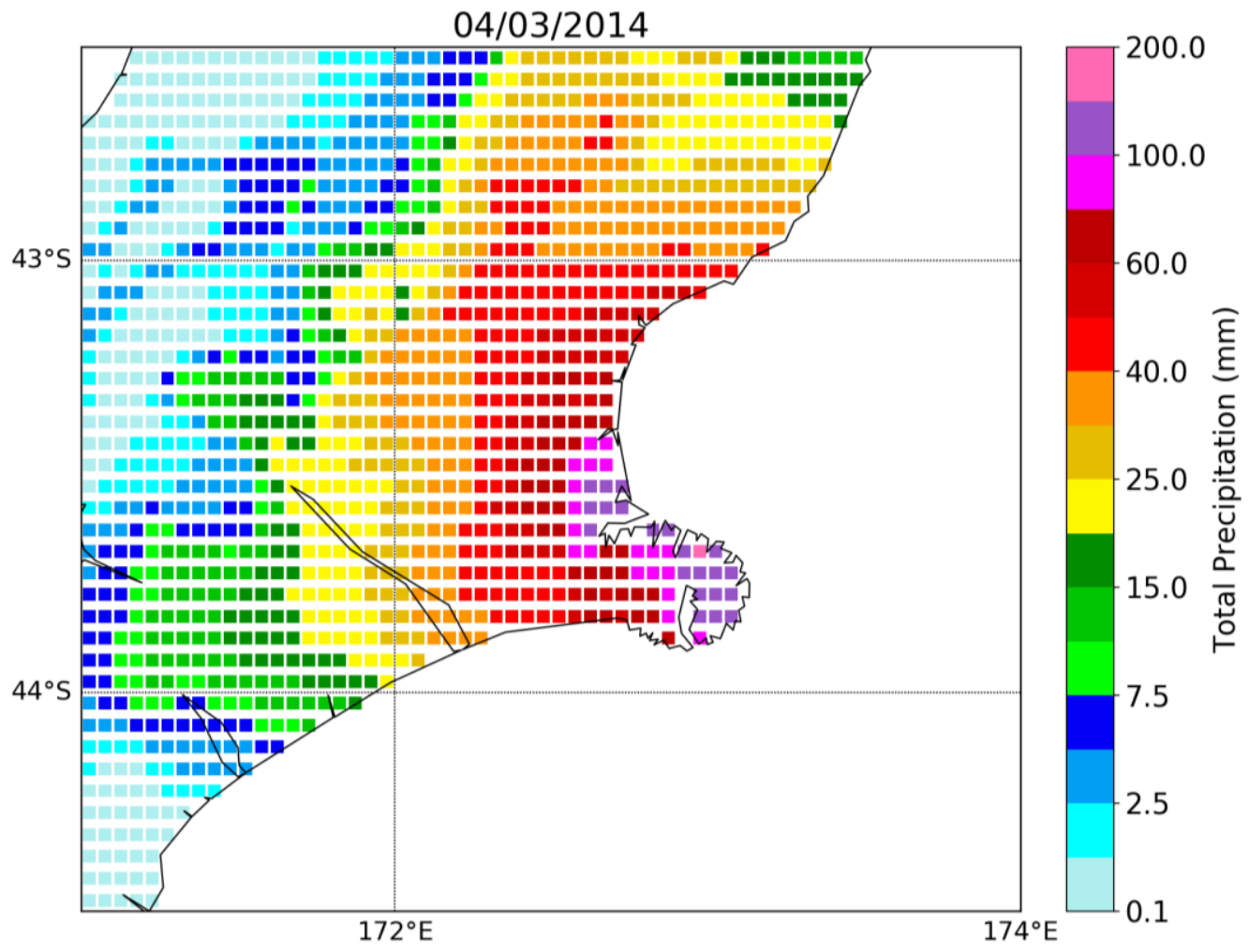

Figure 5.5: Total precipitation $(\mathrm{mm})$ for the Canterbury region on $4^{\text {th }}$ March 2014 as determined by the Virtual Climate Station Network spatial interpolation.

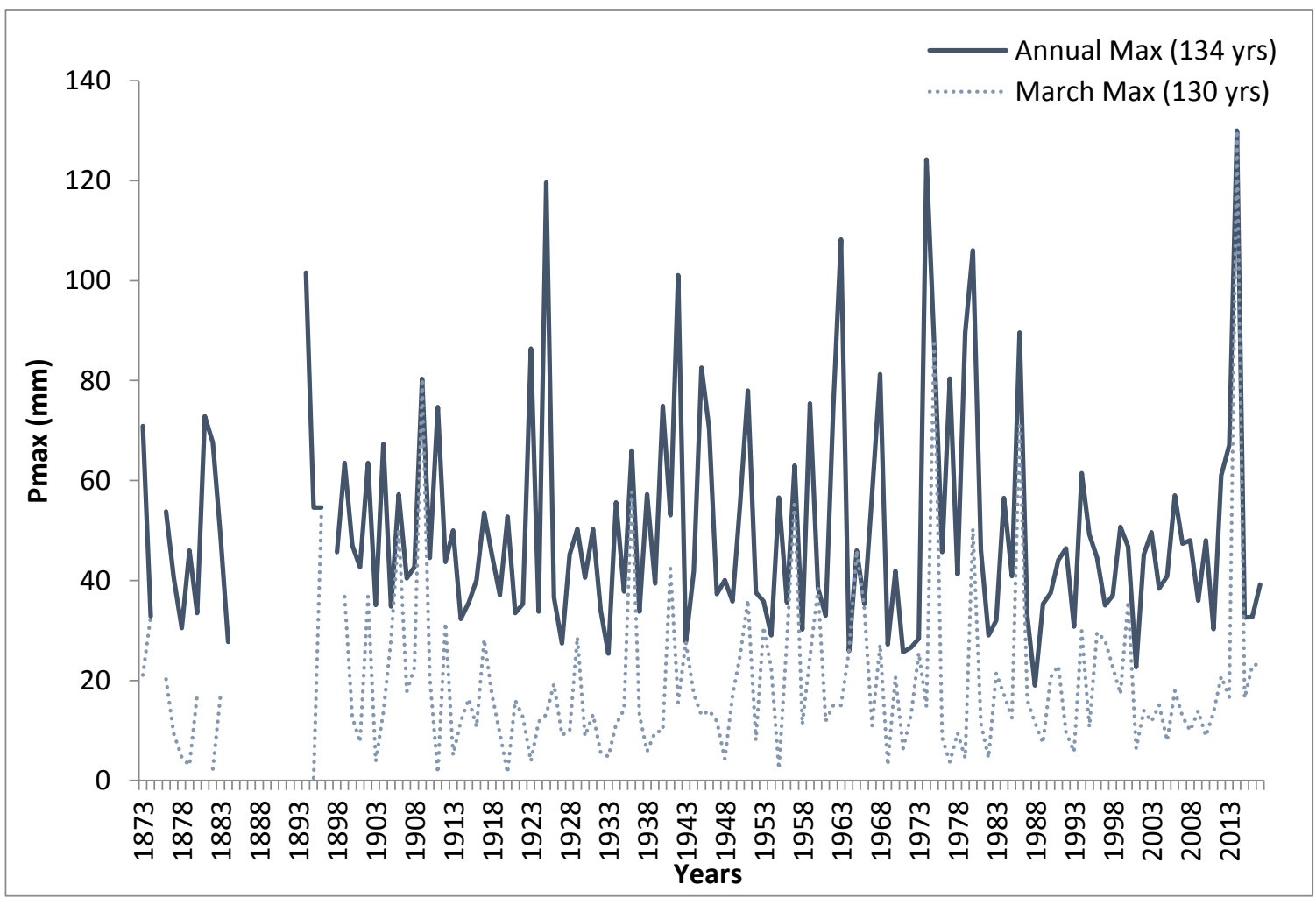

Figure 5.6: Time series of annual (line) and March (dots) daily precipitation maxima for Christchurch Gardens weather station from 1873 until 2017. 


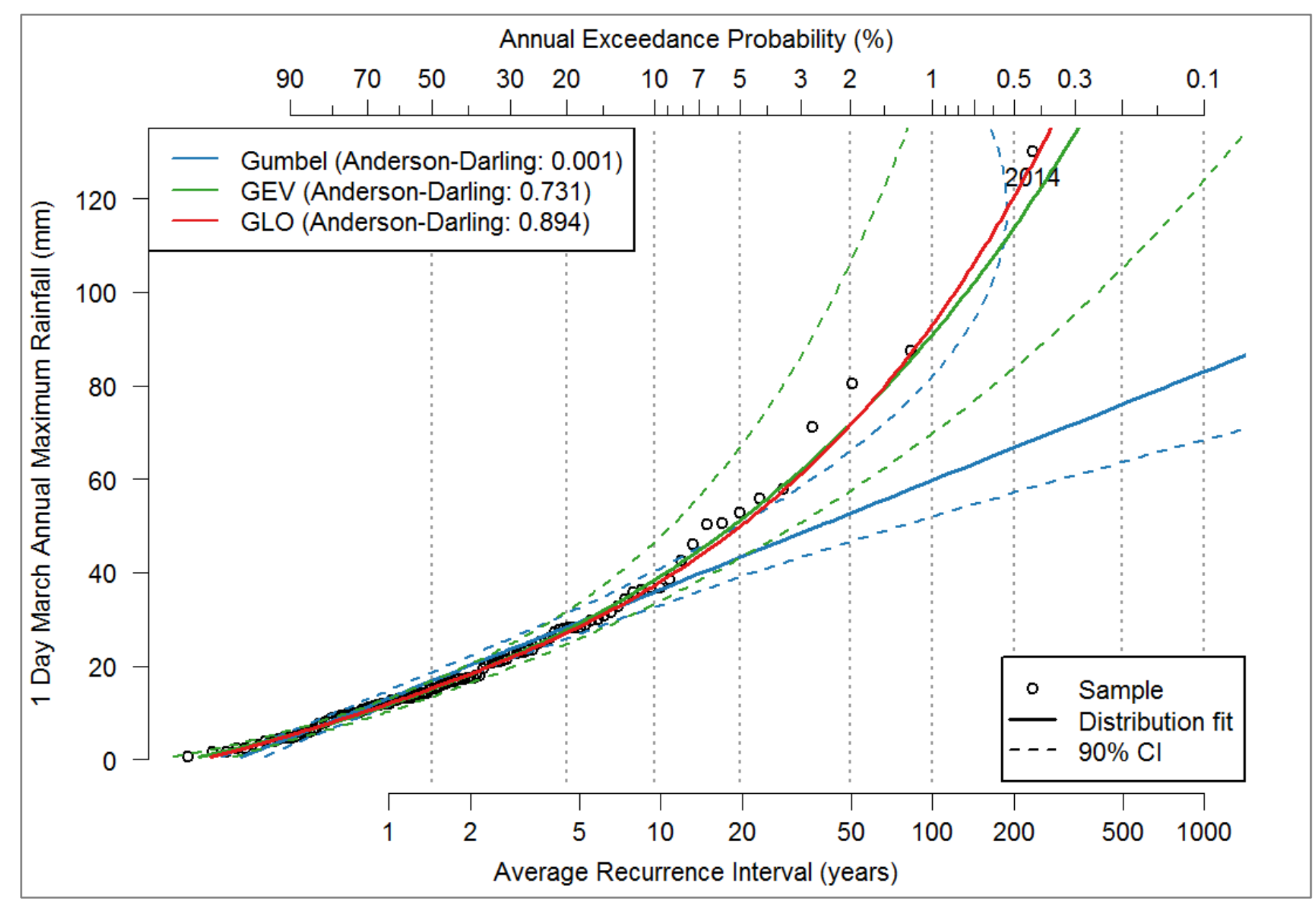

Figure 5.7: Extreme value Gumbel (blue), Generalised Extreme Value (red) and Generalised Logarithmic (green) distributions with 90\% confidence intervals (plotting $5^{\text {th }}$ and $95^{\text {th }}$ percentiles) for Christchurch Gardens March 1-day maximum rainfall. Anderson-Darling p-values are reported for how well each distribution fits the population of samples. 


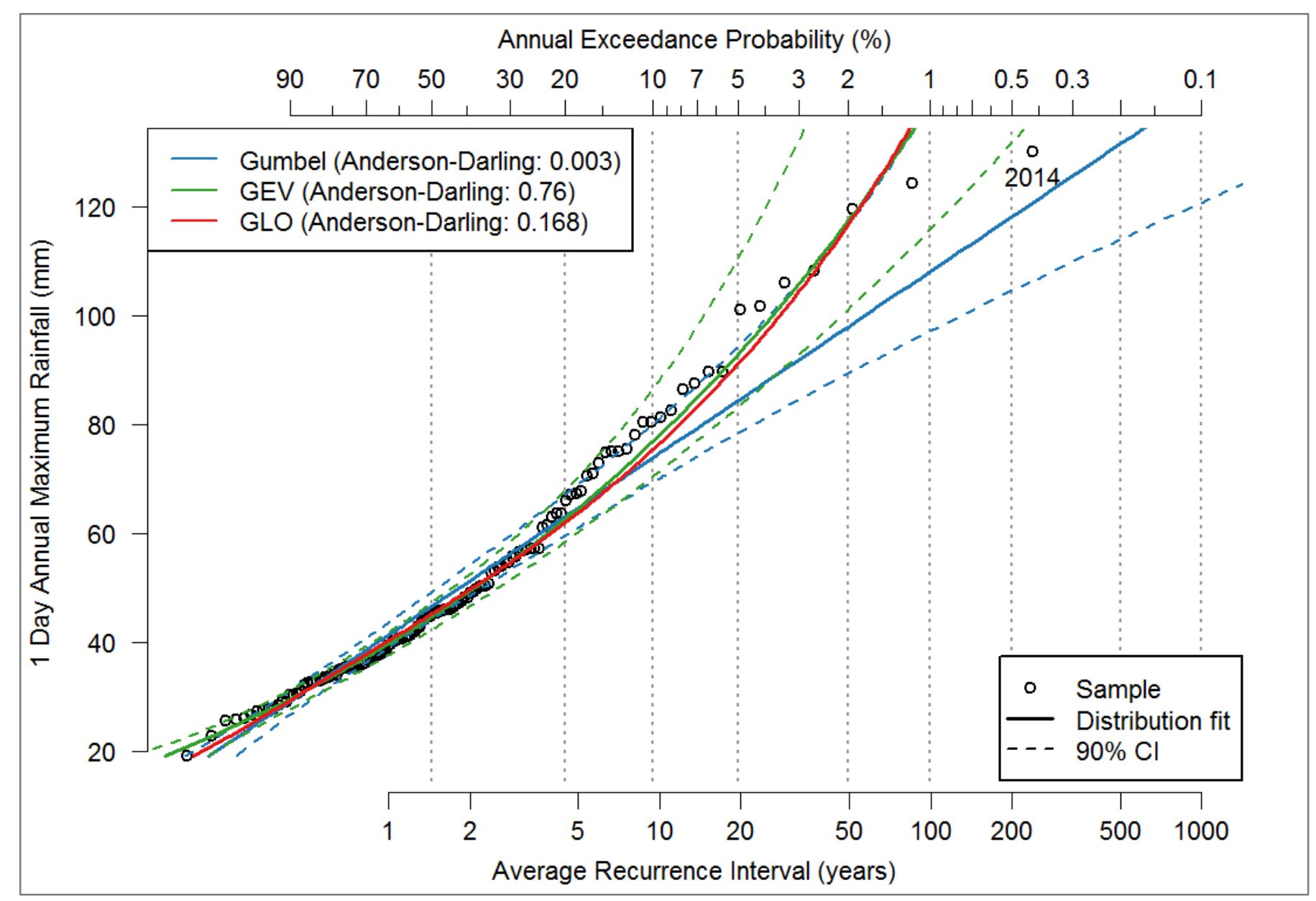

Figure 5.8: Extreme value Gumbel (blue), Generalised Extreme Value (red) and Generalised Logarithmic (green) distributions with 90\% confidence intervals (plotting $5^{\text {th }}$ and $95^{\text {th }}$ percentiles) for Christchurch Gardens annual 1-day maximum rainfall. Anderson-Darling p-values are reported for how well each distribution fits the population of samples. 


\subsection{Synoptic observations}

A deep low originating south of $\mathrm{NZ}$ was a key player in the heavy precipitation event (Figure 5.9). This storm travelled northwards off the east coast of the South Island and coupled with ex-tropical cyclone Kofi (Figure 5.10) to bring strong, moisture-laden onshore winds. While the airflow is from the south-east, the vertical integral of water vapour and precipitation, as assessed by ERA-Interim, reveal this to be an extension of a moisture-laden air mass that extends to the tropics (Figure 5.11 and 5.12). However, multi-level back trajectory analysis using the period of heaviest rainfall in Christchurch as the destination does not indicate the air parcel to have tropical origins (Figure 5.13) instead, they largely derive from the Southern Ocean to the south of NZ. Multiple other back trajectory analyses performed to terminate on dates $3^{\text {rd }}-7^{\text {th }}$ March 2014 at a variety of locations (Oamaru, Chatham Islands, Castlepoint, Gisborne and Whangarei) found no tropical origin for their respective air parcels. At increasing height, the air parcels appear to spend a larger component of time to the east of the South Island. This may be assisting the air mass to entrain moisture, especially if the body of water is warm. While March SSTs to the east are approximately $1{ }^{\circ} \mathrm{C}$ above climatological average, SSTs to the northwest and south are slightly below average (Figure 5.14). 

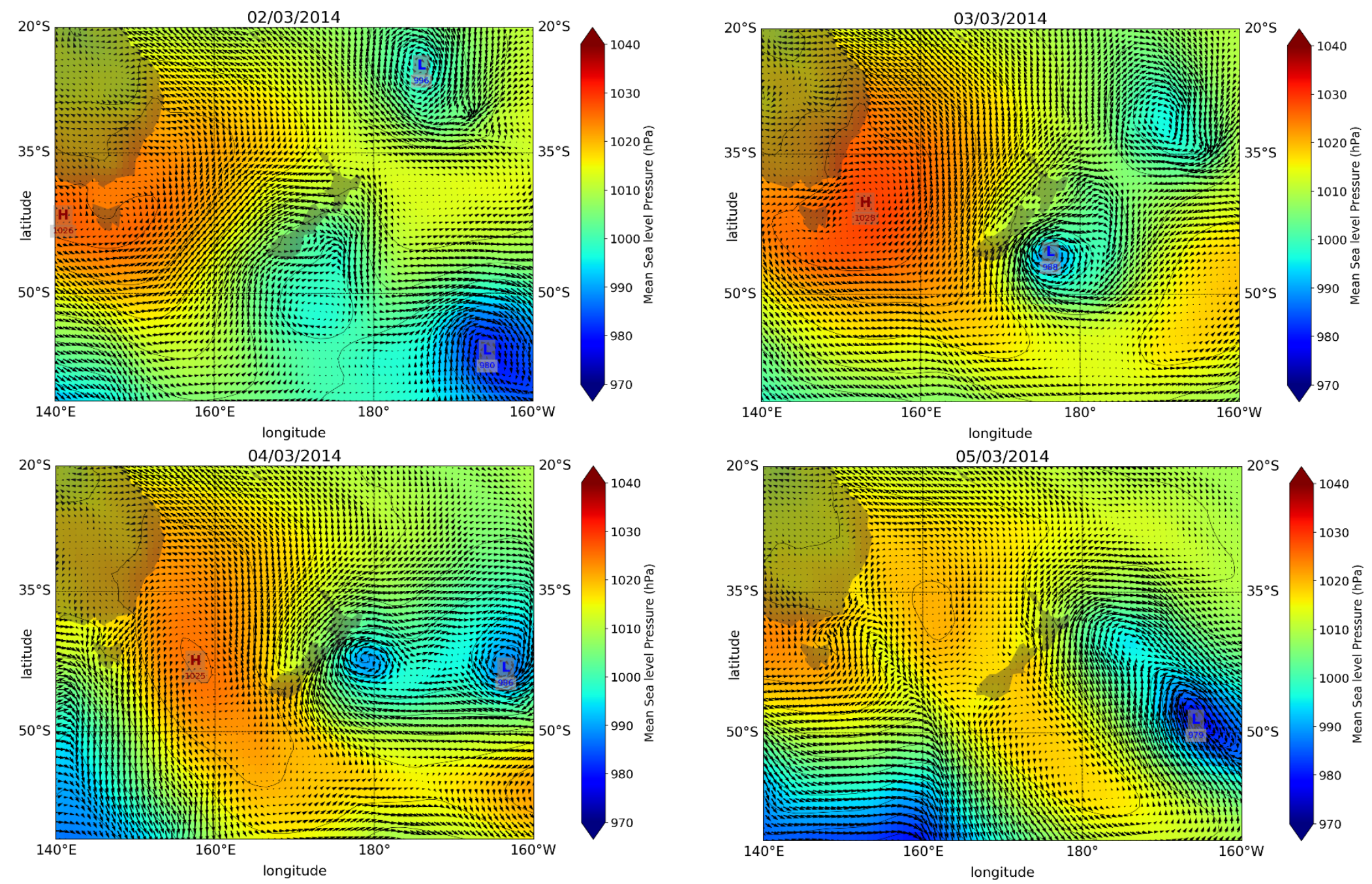

Figure 5.9: Synoptic circulation over New Zealand at UTC 1200 from ERA-Interim mean sea level pressure (hPa) and $10 \mathrm{~m}$ wind vectors (length of arrow corresponds to wind speed) for the $2^{\text {nd }}, 3^{\text {rd }}, 4^{\text {th }}$ and $5^{\text {th }}$ March 2014. 


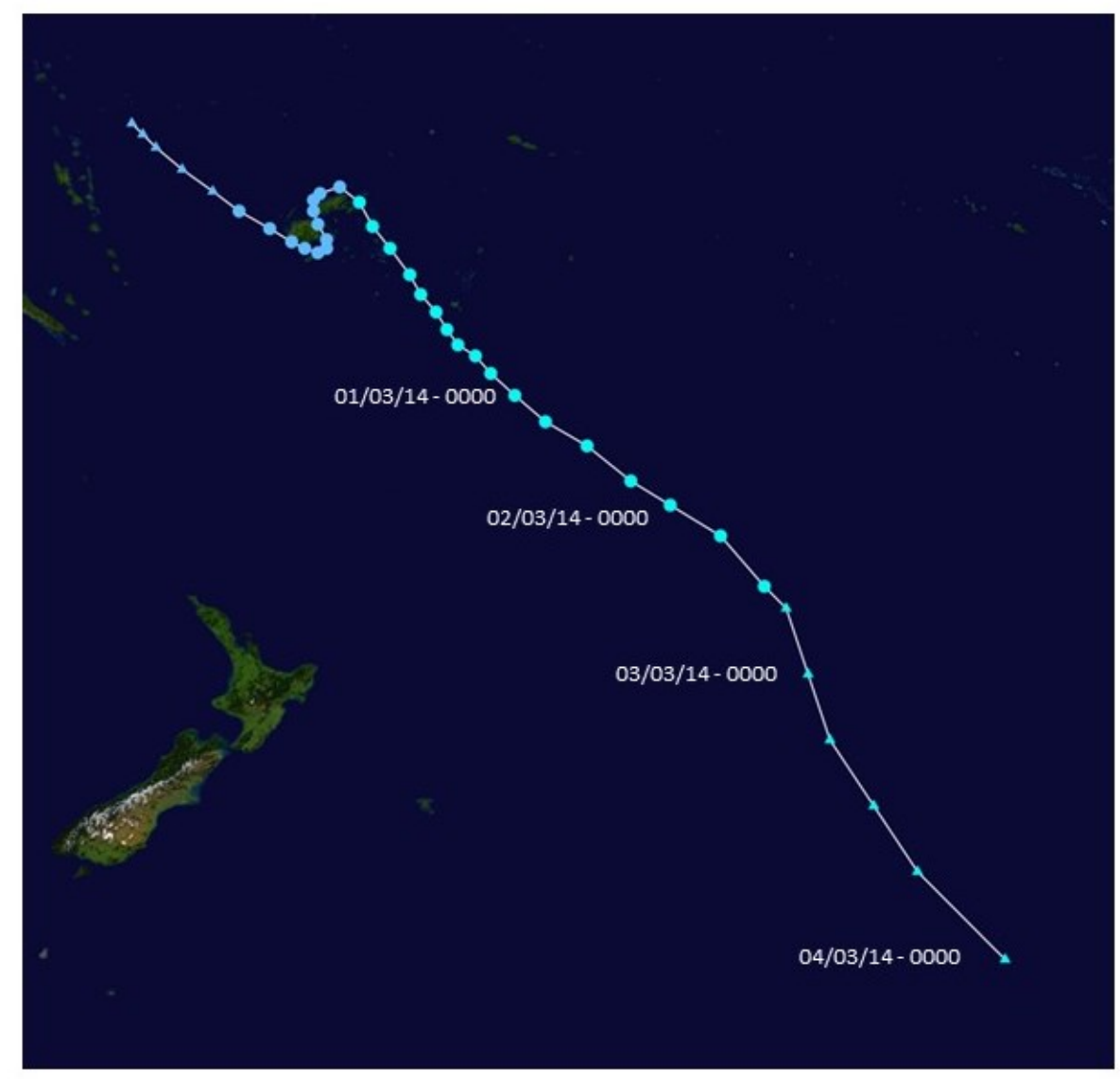

Figure 5.10: Track of tropical cyclone Kofi (dd/mm/yy - hhhh in UTC) which transitioned to an ex-tropical cyclone on March $3^{\text {rd }} 2014$ (http://www.usno.navy.mil/NOOC/nmfc$\mathrm{ph} / \mathrm{RSS} / \mathrm{jtwc} / \mathrm{jtwc} \cdot \mathrm{html})$. 


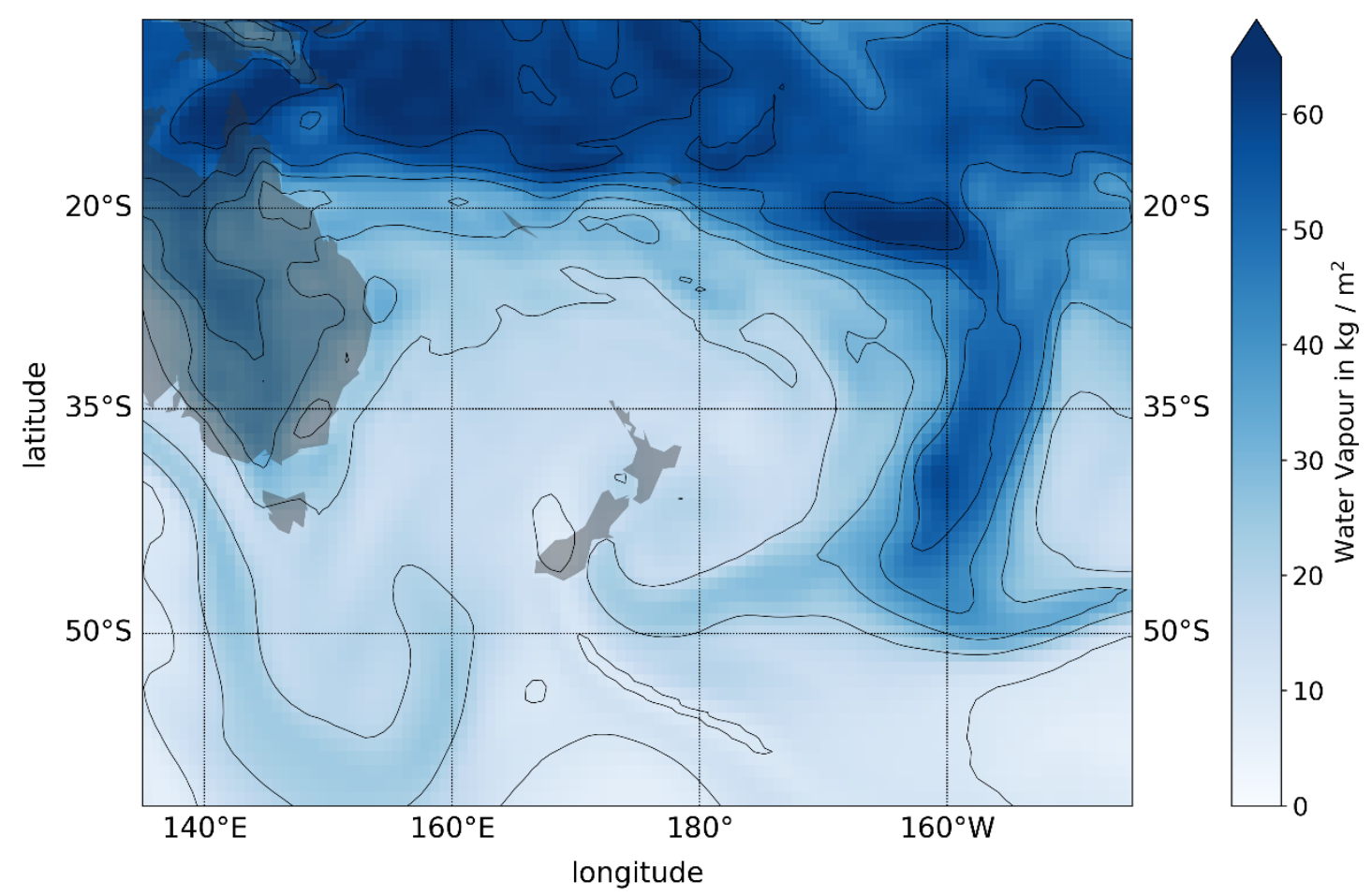

Figure 5.11: ERA-Interim vertical integral of water vapour $\left(\mathrm{kg} \mathrm{m}^{-2}\right)$ at UTC 1200 on $4^{\text {th }}$ March 2014.

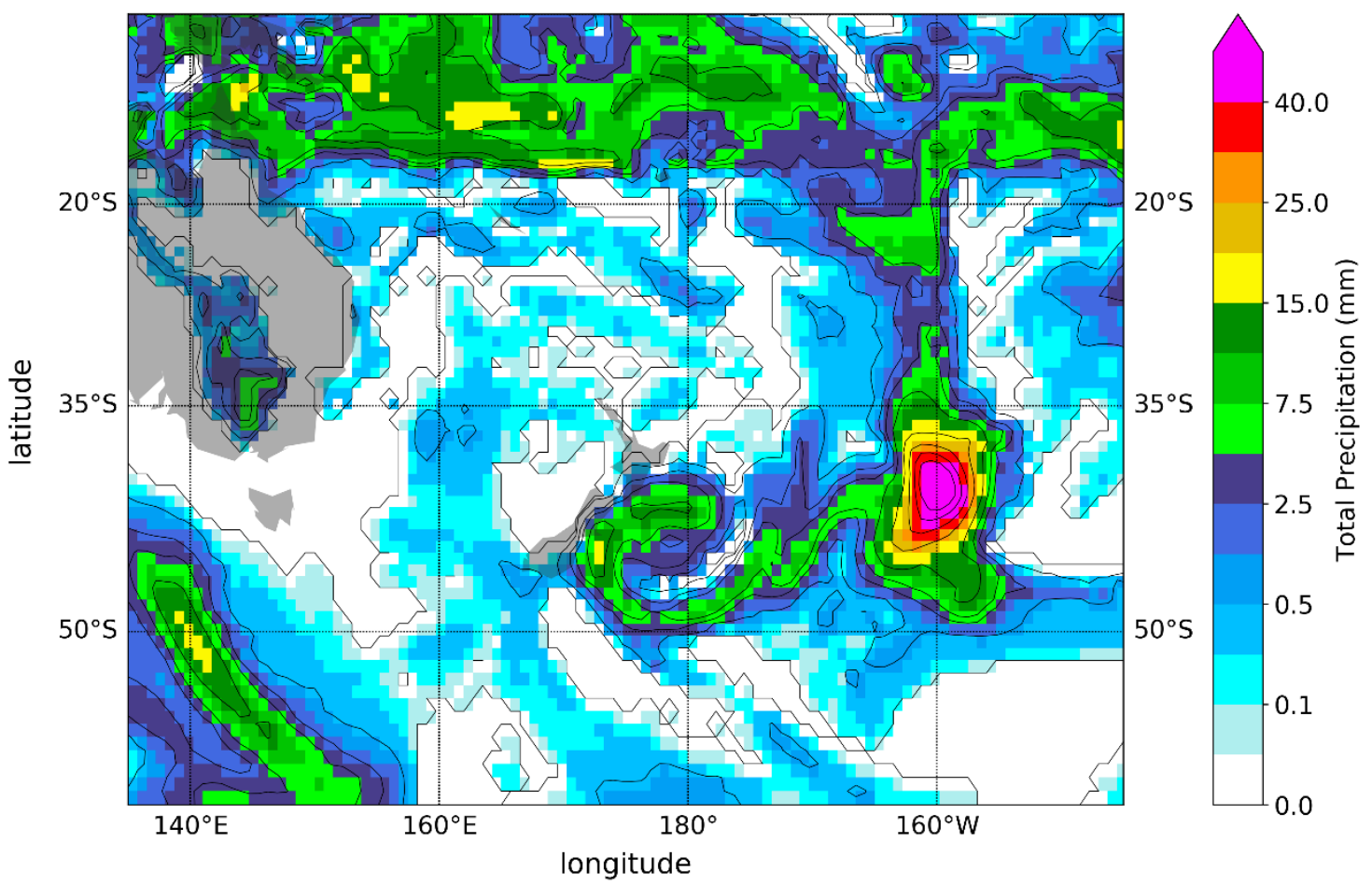

Figure 5.12: ERA-Interim total precipitation $(\mathrm{mm})$ for $12 \mathrm{hrs}$ preceding UTC 1200 on the $4^{\text {th }}$ March 2014. 


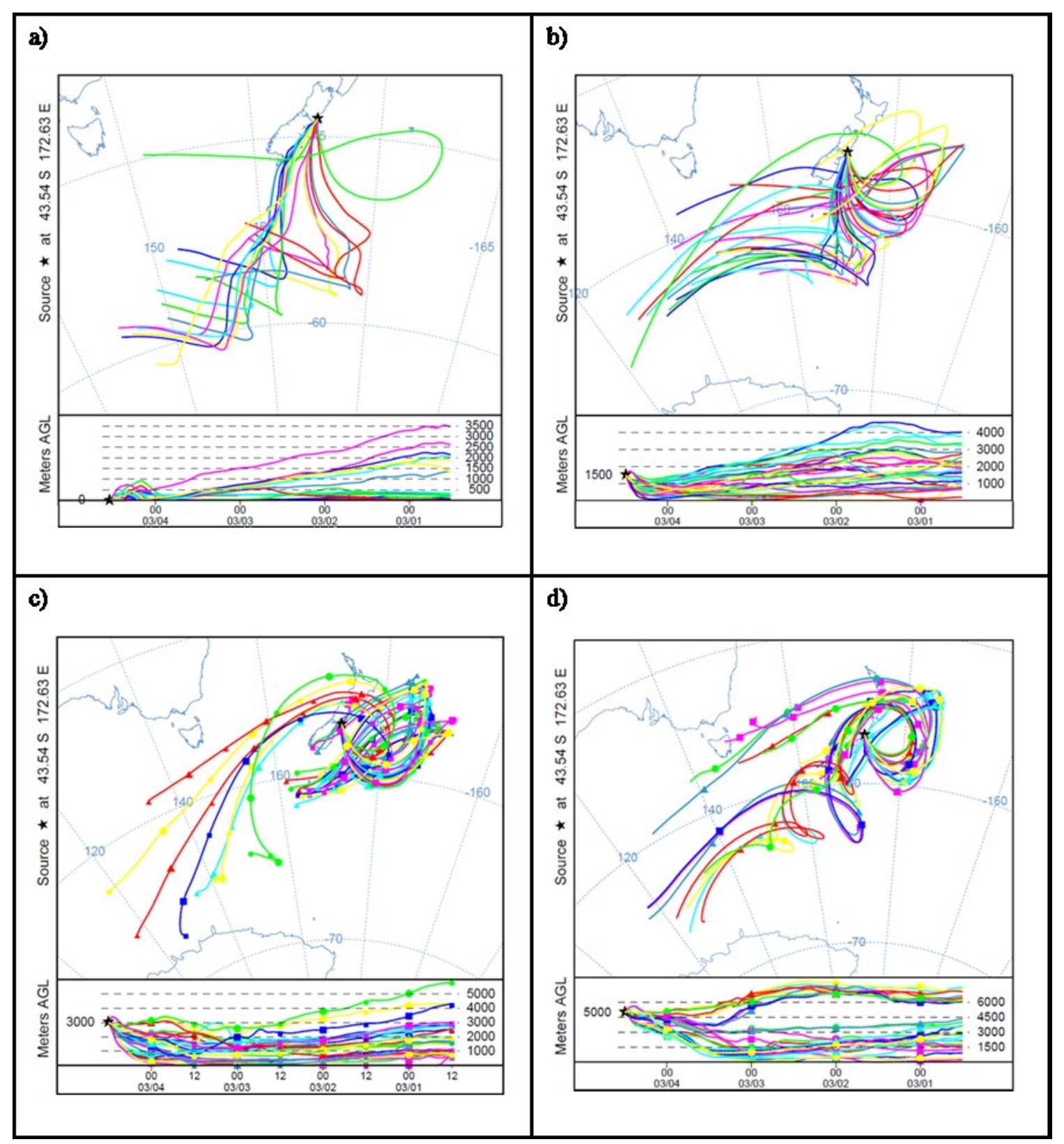

Figure 5.13: HYSPLIT (Draxler and Hess, 1998; Stein et al., 2015) 96 hr back trajectory analysis for elevations (m above ground level); a) $0 \mathrm{~m}$, b) $1500 \mathrm{~m}$, c) $3000 \mathrm{~m}$ and d) $5000 \mathrm{~m}$ from Christchurch endpoint at UTC 1200 on $4^{\text {th }}$ March, 2014. 


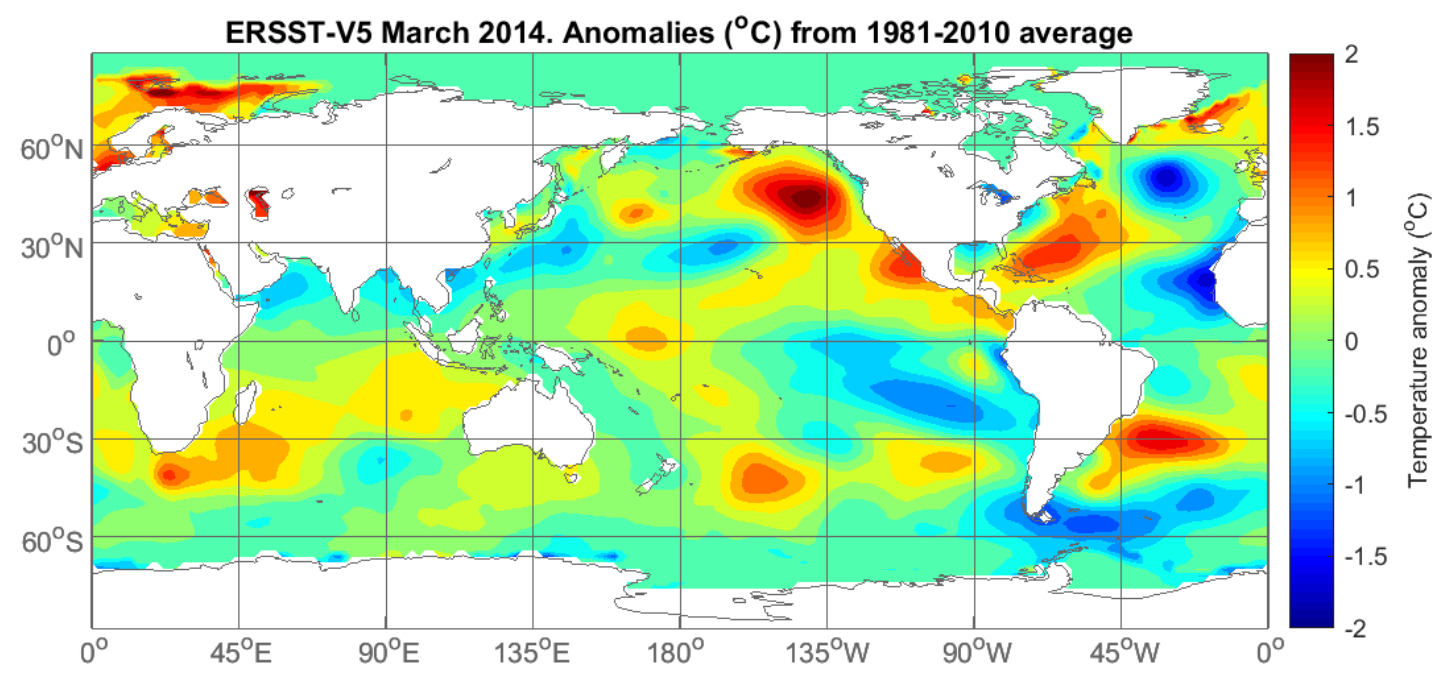

Figure 5.14: Sea-surface temperature anomalies for March 2014 from 1981-2010 average.

\subsection{Detection of change}

Unlike clear trends in temperature records, changes in extreme precipitation events are much less consistent and spatially coherent (Alexander et al., 2006; Bindoff et al., 2013). Before utilising climate model output to address the role of anthropogenic forcings in the Christchurch extreme rainfall event, the historical observational record is first examined to see if any significant changes can be detected for extreme rainfall events in Christchurch.

In most assessments of climatological trends, the median or mean of a distribution can be compared reliably without the need for "complete" data records (for our purposes $>99 \%$ complete). However, assessments of trends in extreme events do require complete records given the focus on quantifying how the tail of a distribution is changing, for which a missing record can have a large bearing on the result. While Christchurch Gardens precipitation observations are available from as early as 1873 , complete annual records are only reported on a regular basis from 1899. As such, the following analysis divides the observational window into two equal sized 59-year windows 1899-1957 (99.4\% complete), which we consider to be our natural (n) reference period, and 1959-2017 (99.6\% complete) which we consider to be the anthropogenically (a) influenced period. A 59-year period is used as opposed to a shorter baseline to reduce the potential influences of multi-decadal variability to ensure the findings are more robust. 
For all RX1D events between 1899 and 2017 greater than or equal to $1 \mathrm{~mm}$, the $98^{\text {th }}$ percentile is found to be $34.9 \mathrm{~mm}$. The frequency of events which exceed this threshold decreases between the two respective periods from 111 to 90 (Table 5.3). When divided by season, the largest change occurs in DJF with a $66 \%$ decrease in extreme rainfall events. The other seasons, however, do not observe such a pronounced change. In DJF, the distribution of rainfall events $\geq 1 \mathrm{~mm}$ has changed significantly $(\mathrm{KS} \mathrm{p}$-value $=0.001)$ with a significant decrease in the median daily precipitation from $4.1 \mathrm{~mm} /$ day to 3.4 $\mathrm{mm} /$ day $(\mathrm{MW} \mathrm{p}$-value $=0.005$; Figure 5.15). These results indicate Christchurch is now significantly drier in DJF, in addition to rainfall events being less frequent. Meanwhile, the three largest RX1D rainfall events annually for DJF are found to be significantly wetter, increasing $17 \%$ from $15 \mathrm{~mm}$ /day to $17.5 \mathrm{~mm}$ /day (Figure 5.16), even though high rainfall events are decreasing in frequency as described above.

Table 5.3: Change in extreme rainfall events that exceed the $98^{\text {th }}$ percentile $(34.9 \mathrm{~mm})$ at Christchurch Gardens between 1899-1957 and 1959-2017 by season.

\begin{tabular}{|c|c|c|c|}
\hline Season & $\begin{array}{c}\text { Number of } \\
\text { occurrences } \\
\mathbf{1 8 9 9 - 1 9 5 7}\end{array}$ & $\begin{array}{c}\text { Number of } \\
\text { occurrences } \\
\mathbf{1 9 5 9 - 2 0 1 7}\end{array}$ & \% change \\
\hline DJF & 29 & 10 & -65.5 \\
\hline MAM & 39 & 34 & -14.7 \\
\hline JJA & 25 & 31 & +24.0 \\
\hline SON & 18 & 15 & -16.7 \\
\hline Annual & 111 & 90 & -18.9 \\
\hline
\end{tabular}




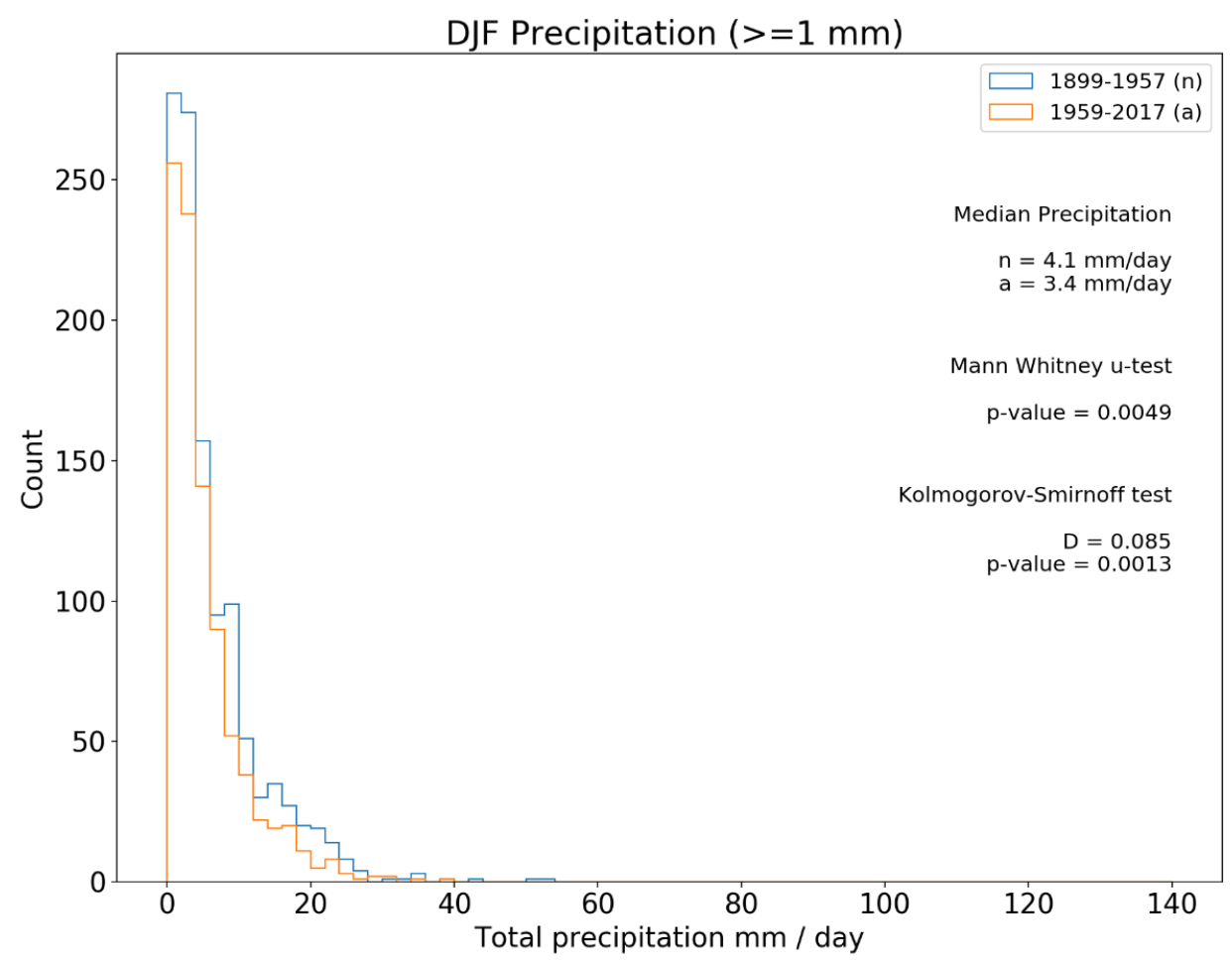

Figure 5.15: December, January, February (DJF) precipitation distribution for events $\geq 1 \mathrm{~mm}$ observed at Christchurch Gardens for the periods 1899-1957 (n) and 1959-2017 (a). The median precipitation for each distribution is reported alongside the p-value result from a Mann-Whitney u-test and Kolmogorov-Smirnoff test.

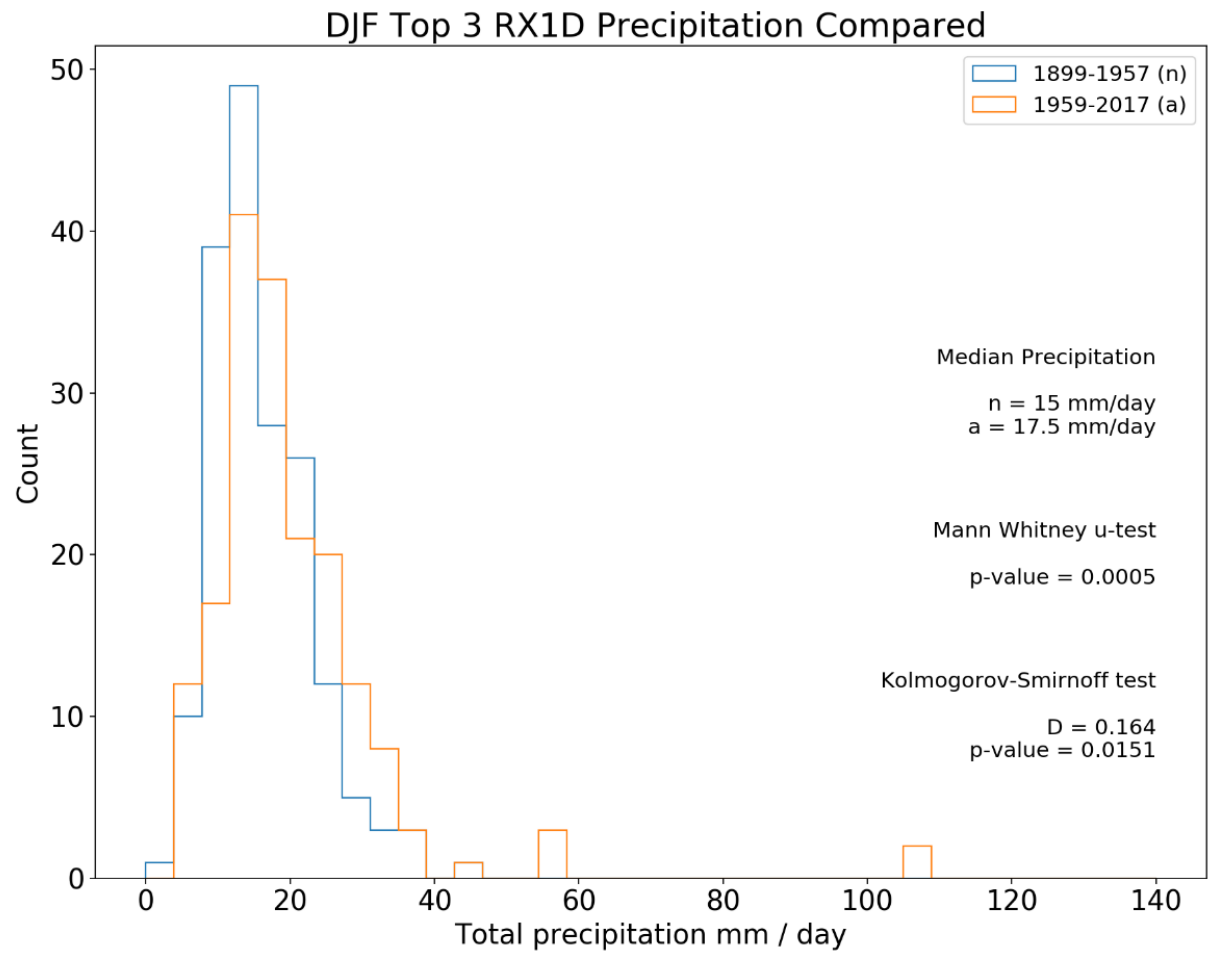

Figure 5.16: Top three RX1D rainfall events annually for December, January, February (DJF) at Christchurch Gardens for the periods 1899-1957 (n) and 1959-2017 (a). The median precipitation for each distribution is reported alongside the p-value result from a MannWhitney u-test and Kolmogorov-Smirnoff test. 
The MAM period during which the 2014 event is placed, reports a smaller decrease in extreme rainfall events $(>34.9 \mathrm{~mm}$ ) between the two periods of only $-15 \%$ (Table 5.3 ). The population distribution of rainfall events during MAM had a small but significant increase of $0.3 \mathrm{~mm} /$ day (Figure 5.17). While the median of the most extreme annual MAM rainfall events increases by almost $2 \mathrm{~mm}$ /day, these changes are not statistically significant at the $95^{\text {th }}$ percentile (Figure 5.18).

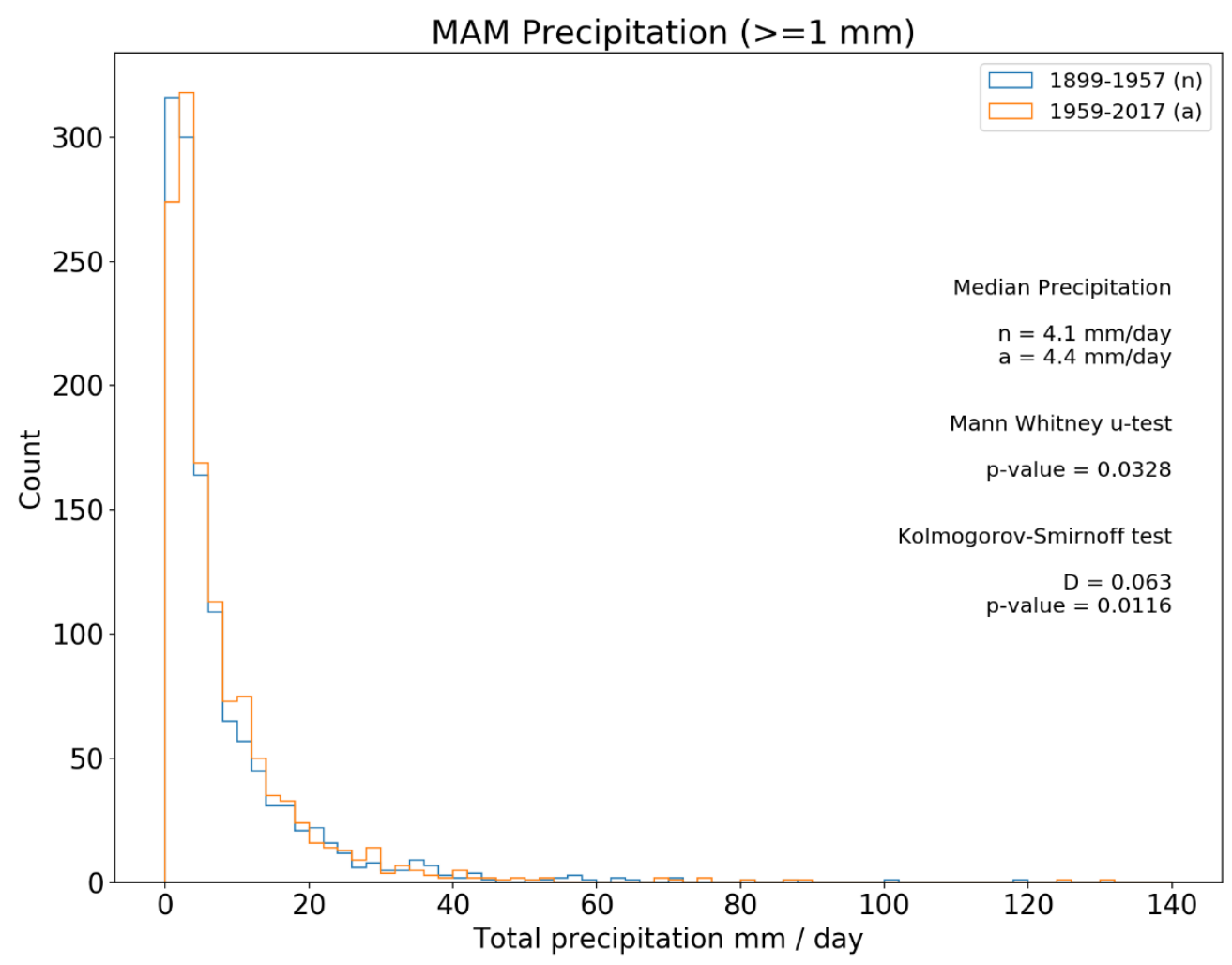

Figure 5.17: March, April, May (MAM) precipitation distribution for events $\geq 1 \mathrm{~mm}$ observed at Christchurch Gardens for the periods 1899-1957 (n) and 1959-2017 (a). The median precipitation for each distribution is reported alongside the $\mathrm{p}$-value result from a MannWhitney u-test and Kolmogorov-Smirnoff test. 


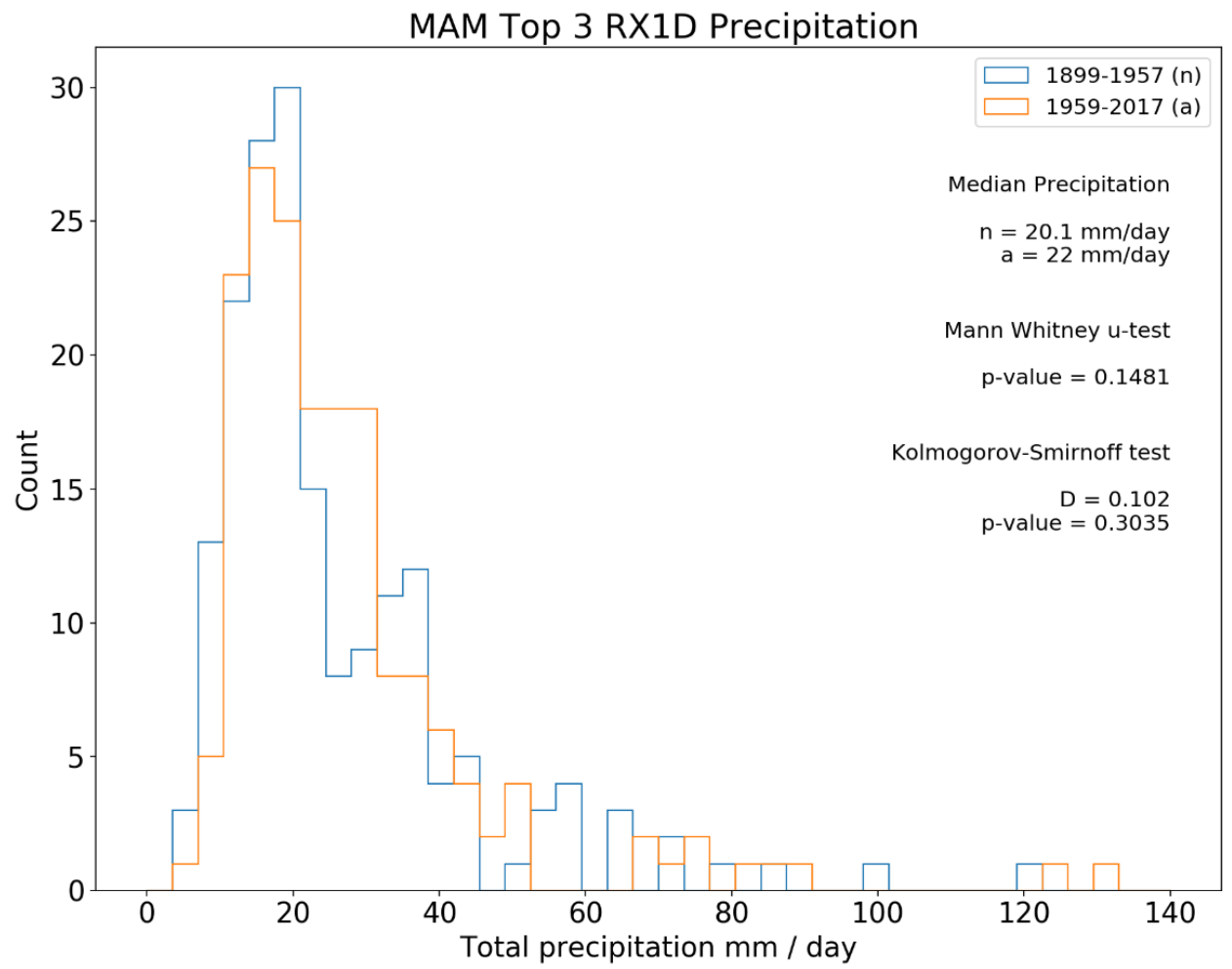

Figure 5.18: Top three RX1D rainfall events annually for March, April, May (MAM) at Christchurch Gardens for the periods 1899-1957 (n) and 1959-2017 (a). The median precipitation for each distribution is reported alongside the $\mathrm{p}$-value result from a MannWhitney u-test and Kolmogorov-Smirnoff test.

The significant drying observed for Christchurch in DJF is consistent with the multimodel trends for historical changes associated with ozone and GHG forcings (Figure 2.7; Previdi and Polvani, 2014). Mid-latitude drying during austral summer has primarily been associated with the poleward displacement of the westerly wind belt and the associated storm track (Son et al., 2009). Furthermore, Purich and Son (2012) found decreased precipitation in the mid-latitudes has largely been due to changes in the light precipitation ( $1-10 \mathrm{~mm} /$ day). The finding of extreme rainfall events getting wetter does differ to earlier work on NZ and Christchurch extreme rainfall events (Griffths et al., 2009; Griffiths et al., 2014), where no evidence was found to support a significant trend or change in annual daily maxima for long-term rainfall records.

Future projections indicate the frequency of extreme precipitation to increase for much of the South Island (Mullan et al., 2016). Such a change is not, however, found to be significant for Canterbury, which may be due to the opposing contribution from anticipated ozone recovery manifesting differently throughout NZ (See Chapter 4). Likewise, Purich and Son (2012) suggest extreme precipitation changes in the extra- 
tropics to be more sensitive to thermodynamic processes at the surface than the dynamical response to ozone change.

While no significant trends in extreme rainfall events are observed in the historical MAM record,w@h ANZ can be used to assess how anthropogenic forcings may have changed March extreme rainfall events and their role in this extreme 2014 event. The most appropriate spatial criterion for such an assessment must be first established, given the model is relatively coarse at $50 \mathrm{~km}$ resolution. The following details a sensitivity analysis of results fromw@h ANZ to alterations in the spatial domain.

\subsection{Spatial sensitivity analysis and validation}

An important consideration in the development of an attribution study is the choice of spatial extent to be examined (Stocker et al., 2010). As precipitation is a continuous random variable with high temporal variability, we assess the sensitivity of the model when four different spatial areas are examined (Figure 5.19). The high degree of relief heterogeneity within the South Island (Figure 5.20), irregular coastline of our study area and irregular boundaries for rainfall (Figure 5.5) provide further weight to the necessity of a sensitivity assessment, given the simplification and averaging that occurs within a 50 km spatial resolution climate model such as w@h ANZ. Typically, events are defined over a large area and long-time scales to reduce natural variability and give larger FARs (Stott et al., 2016). Three of the extents used in this assessment are land only (Chch1, Chch4, Chch9_land) with the numeral contained within the label indicating the number of grid boxes which are averaged across (i.e. 1, 4 and 9 grid boxes). Chch9 (Figure 5.19d), centred on the cell for Christchurch, contains five cells located over the ocean for which no VCSN data is available, thus it has a very similar representation to Chch4 within VCSN. 
a)

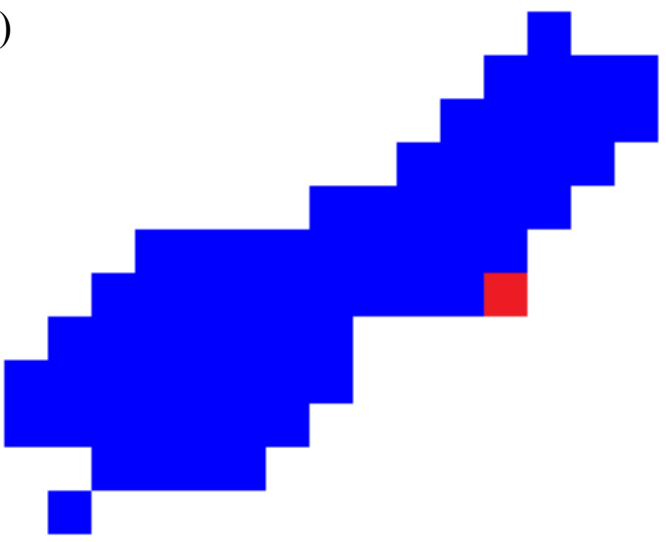

c)

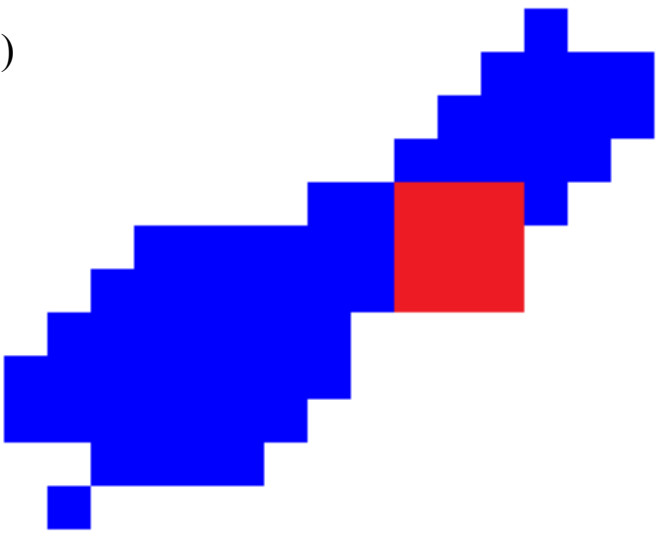

b)
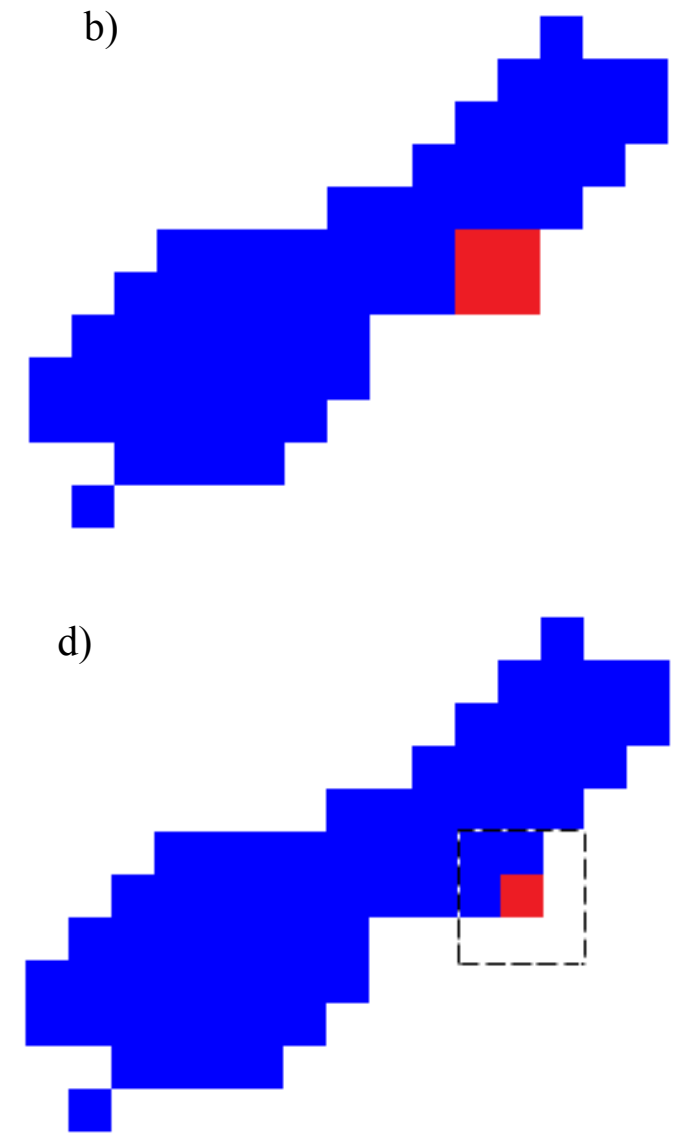

Figure 5.19: Weather@home ANZ model representation of the South Island with highlighted cells indicating the domains for a) Chch1, b) Chch4, c) Chch9_land and d) Chch9 (within the frame of the dashed line). 


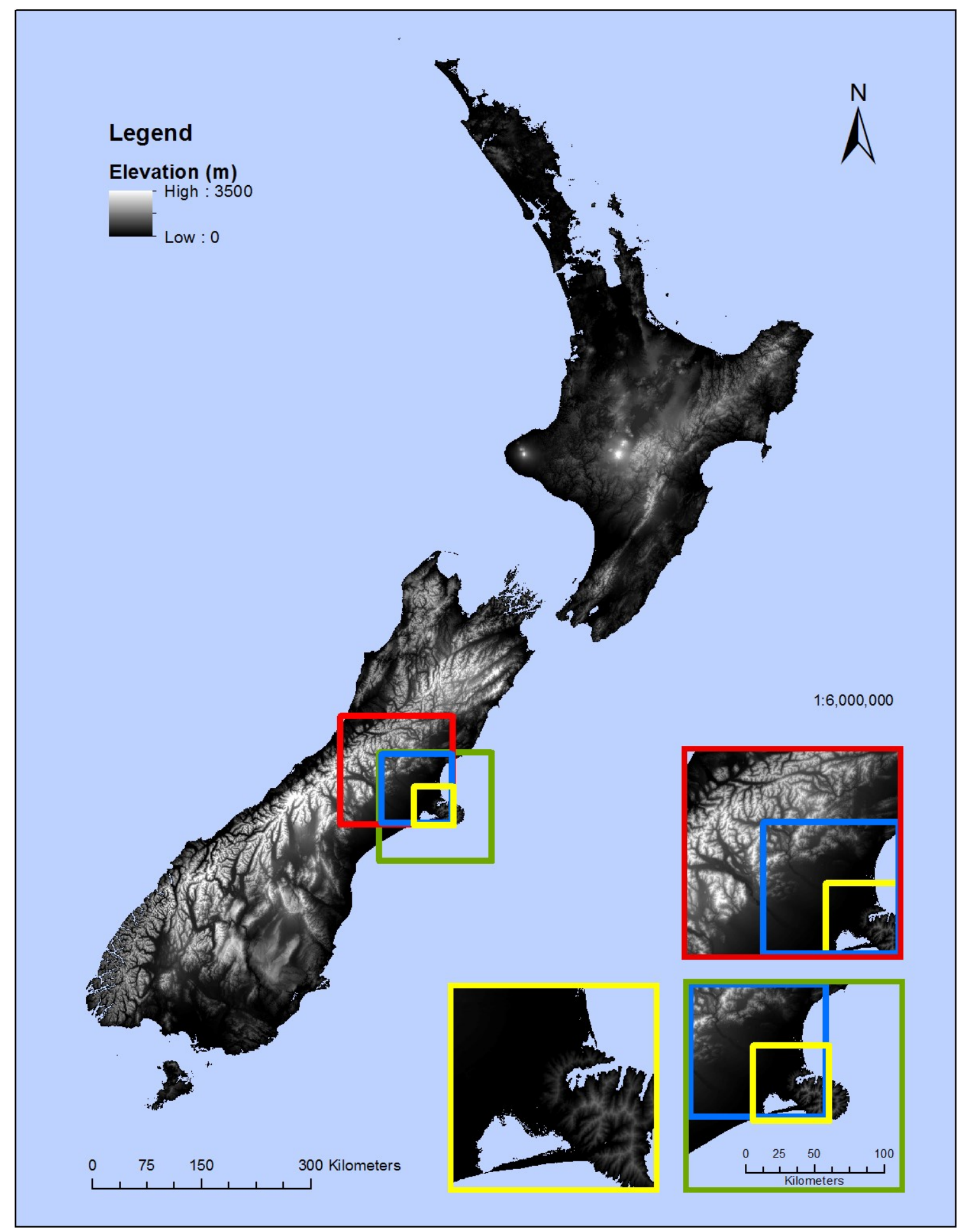

Figure 5.20: Weather@home ANZ extent for Chch1 (yellow), Chch4 (blue), Chch9_land (red) and Chch9 (green) in relation to topographic relief. 
Comparison of observations withw@h ANZ simulation output can be performed using a quantile-quantile plot to determine if the two data sets belong to the same distribution and the degree of correction required for modelled output. This is achieved by determining the Gringorten plotting position (a rank based adjustment) for each observation (x-axis) and equivalent Gringorten position for the w@h ANZ data series. A limitation of this approach is that distribution-dependent plotting positions can be subject to bias when studying the most extreme value for a data series and estimating quantiles (Cunnane, 1978; Arnell et al., 1986). While the Gringorten estimator is distribution-dependent, Cook (2011) reiterated its validity in extreme value analysis and excellent ability to provide valid estimates of plotting positions.

Maximum March daily rainfall for Christchurch Gardens compared withw@h ANZ (Figure 5.21) indicates the Chch1 domain to generally have the smallest departure from a 1:1 perfect correlation with a root-mean-square-error (RMSE) of 4.58, closely followed by Chch9. The larger RMSE for Chch4, which has the same land grid points as Chch9, may be due to the ocean points reducing the magnitude of the maxima. The overprediction of maximum March daily rainfalls for Chch4 and Chch9_land could be due to these domains including the model's representation of the Southern Alps, giving a higher mean elevation and average precipitation.

At high daily rainfalls (>60 mm) for Christchurch Gardens weather station,w@h ANZ for Chch1 under-predicts the maximum March one-day rainfall (Figure 5.21). The straight line in Figure 5.21 is the linear fit between both distributions. Chch4 and Chch9_land show good agreement in this year, yet also depart at extreme magnitude events $(>100 \mathrm{~mm})$. As the model is averaged over a much greater domain than the single point for Christchurch Gardens, the degree to which we can validatew@h ANZ using this data is limited. However, it does give us the potential to account for the bias between observations at Christchurch Gardens and w@h ANZ simulated output. The dashed yellow lines in Figure 5.21 shows how the $130 \mathrm{~mm}$ observation at Christchurch Gardens corresponds to $94.16 \mathrm{~mm}$ in w@h ANZ. To further investigate the validity of the simulated output, we also comparew@h ANZ with VCSN data that has been averaged for the equivalent spatial extent. 


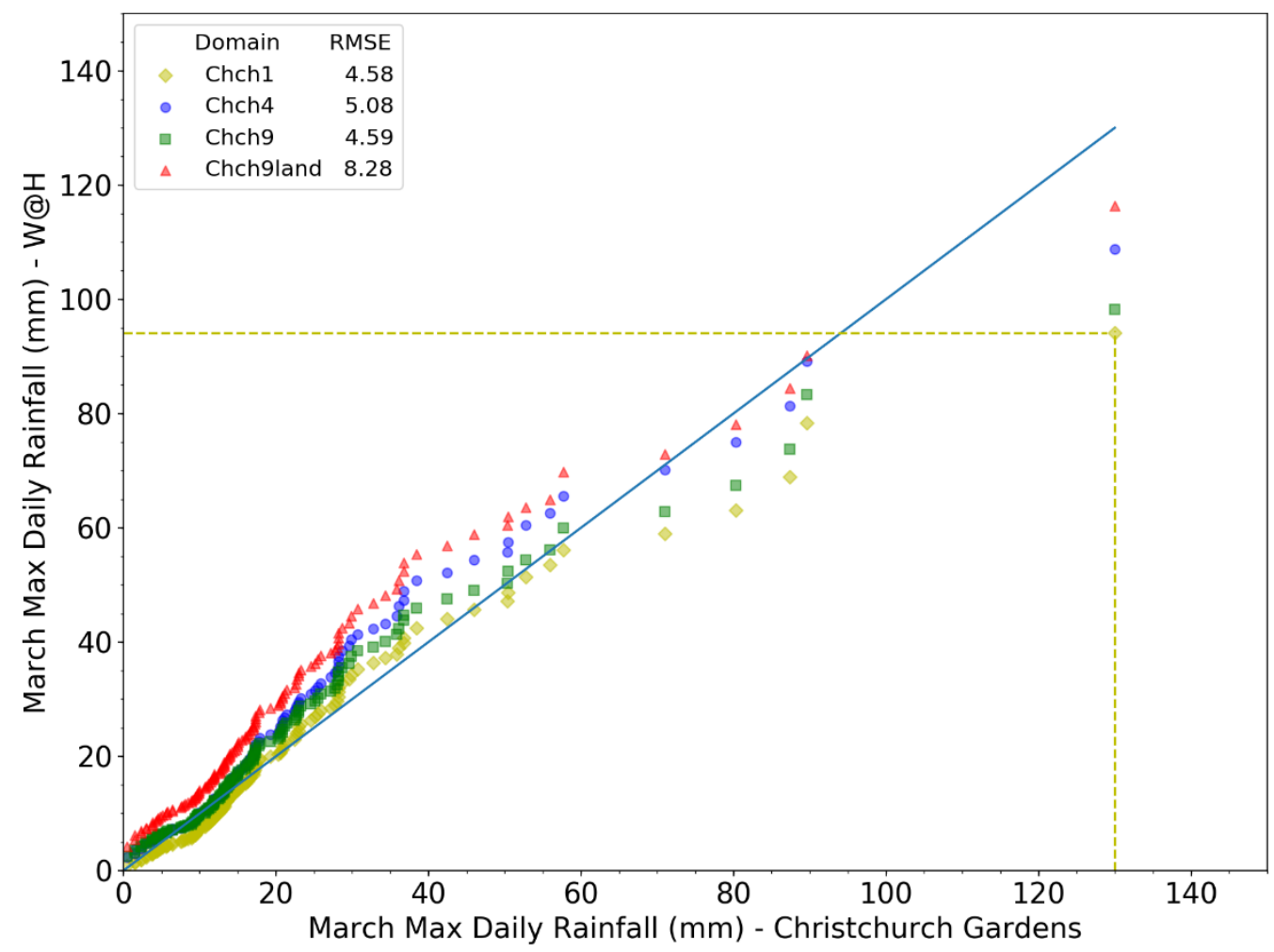

Figure 5.21: Quantile-quantile plot of March maximum RX1D for Christchurch Gardens (CliDB) and w@h ANZ using Gringorten plotting positions on each axis for determining equivalent rainfall. Root-mean-square-error (RMSE) determined for each data series based on deviation from a perfect correlation. The yellow dashed line indicates the bias correction to ascertain the "equivalent" rainfall to the early March 2014 event as simulated in w@h ANZ.

Despite VCSN data only being available from 1972, the higher spatial resolution of this data set permits a more robust comparison and thus validation for w@h ANZ extreme rainfall simulations in Christchurch. The best agreement of the model with VCSN data occurs for the Chch1 domain with a RMSE of 3.72 (Figure 5.22). Chch4 and Chch9 are the next best performing domains with most of the residual error originating above 30 mm / day where deviations are more apparent. At high VCSN rainfalls,w@h ANZ tends to over-predict rainfall across all the domains, with large deviations particularly apparent for Chch9_land. This illustrates the difficulty for coarse GCM-based models to capture complex spatial heterogeneity such as that arising from the Southern Alps. Recognising that the VCSN interpolation smooths out the extremes of the station records, this feature may be partly responsible for part of the discrepancy. For this reason it is not unexpected thatw@h ANZ extreme rainfall simulations are now appearing to over-predict extreme rainfall events. Despite this, we can ascertain that the early March 2014 RX1D $69.1 \mathrm{~mm}$ VCSN event corresponds to a 77.9mm inw@h ANZ. 


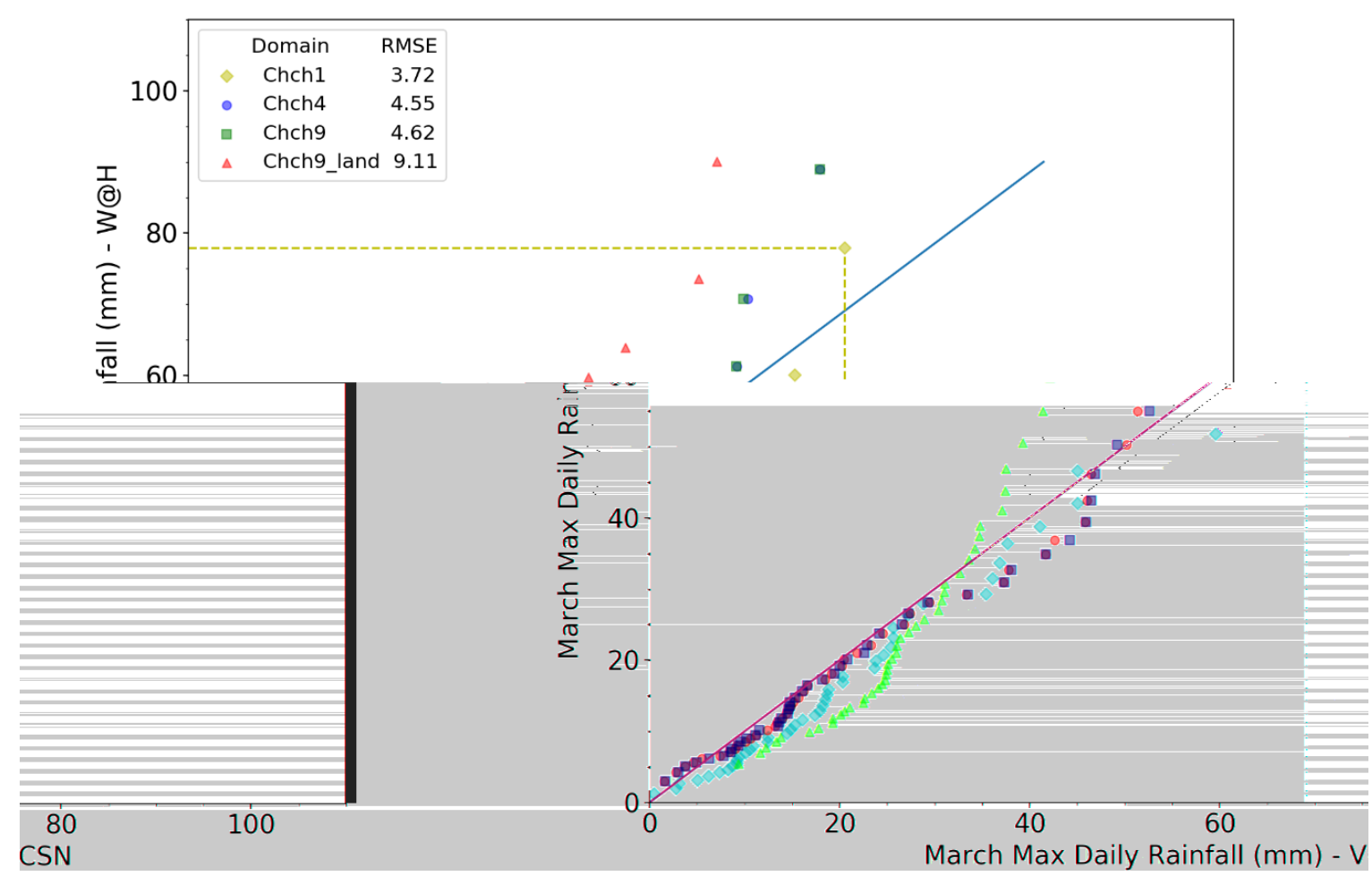

Figure 5.22: Quantile-quantile plot of March maximum 1-day precipitation in Christchurch from VCSN averaged over the equivalent spatial domain as weather@home ANZ. 46 data points matched using Gringorten plotting positions on each axis. Note: the VCSN "observational' values are not true observations but were derived from spatial interpolation (see Tait et al., 2006) and have differing positions on the x-axis due to being determined across different domains. Root-mean-square-error (RMSE) determined for each data series based on deviation from a perfect correlation. The yellow dashed line indicates the bias correction to ascertain the "equivalent" rainfall to the early March 2014 event as simulated in w@h ANZ.

VCSN data indicates the $4^{\text {th }}$ March 2014 precipitation event when examined for the Chch1 domain, to be the largest historic March 1-day rainfall (Figure 5.23) at $69.1 \mathrm{~mm}$ (after averaging across all grid boxes contained within this domain). For this domain, the March average recurrence interval from fitting a GEV distribution is estimated to be a 1in-46 year event, thus placing in the 97.8 percentile with $5^{\text {th }}$ and $95^{\text {th }}$ confidence intervals of 1-in-14 years and 1-in-159 years (Figure 5.24). While notably less than the 1-in-300 years estimated from the longer Christchurch Gardens weather station record, the confidence intervals for these two estimates of ARI for this event still overlap supporting that the two data sets are not drawn from different populations. When the domain under examination is expanded to Chch4 $(42.7 \mathrm{~mm})$ and Chch9_land $(24.95 \mathrm{~mm})$ the magnitude of the precipitation maxima and associated ARI decrease to 1-in-8 years and 1-in-1.7 years respectively (Table 5.4), demonstrating the localised nature of this rainfall event (see Figure 5.5). This contrasts with $12^{\text {th }}$ March 1986 extreme rainfall which was spatially 
extensive, causing the event to be observed across all domains with approximately the same magnitude (Figure 5.23, see Appendix B).

In summary, the Chch1 domain offers the greatest agreement of w@h ANZ simulations to both CliDB and VCSN data sets. The larger spatial domains (i.e. Chch4 and Chch9) disguise the extremity of this localised event and increasingly extend into the more heterogeneous landscapes of the Southern Alps which bring differing model challenges. For these reasons we use Chch1 as our primary region for assessment. The $69.1 \mathrm{~mm}$ event from VCSN (bias corrected to 77.9 mm in w@h ANZ) for the Chch1 domain is used preferentially to Christchurch Gardens $130 \mathrm{~mm}$ ( $94.2 \mathrm{~mm}$ bias corrected) event as it is more representative of the climate model resolution.

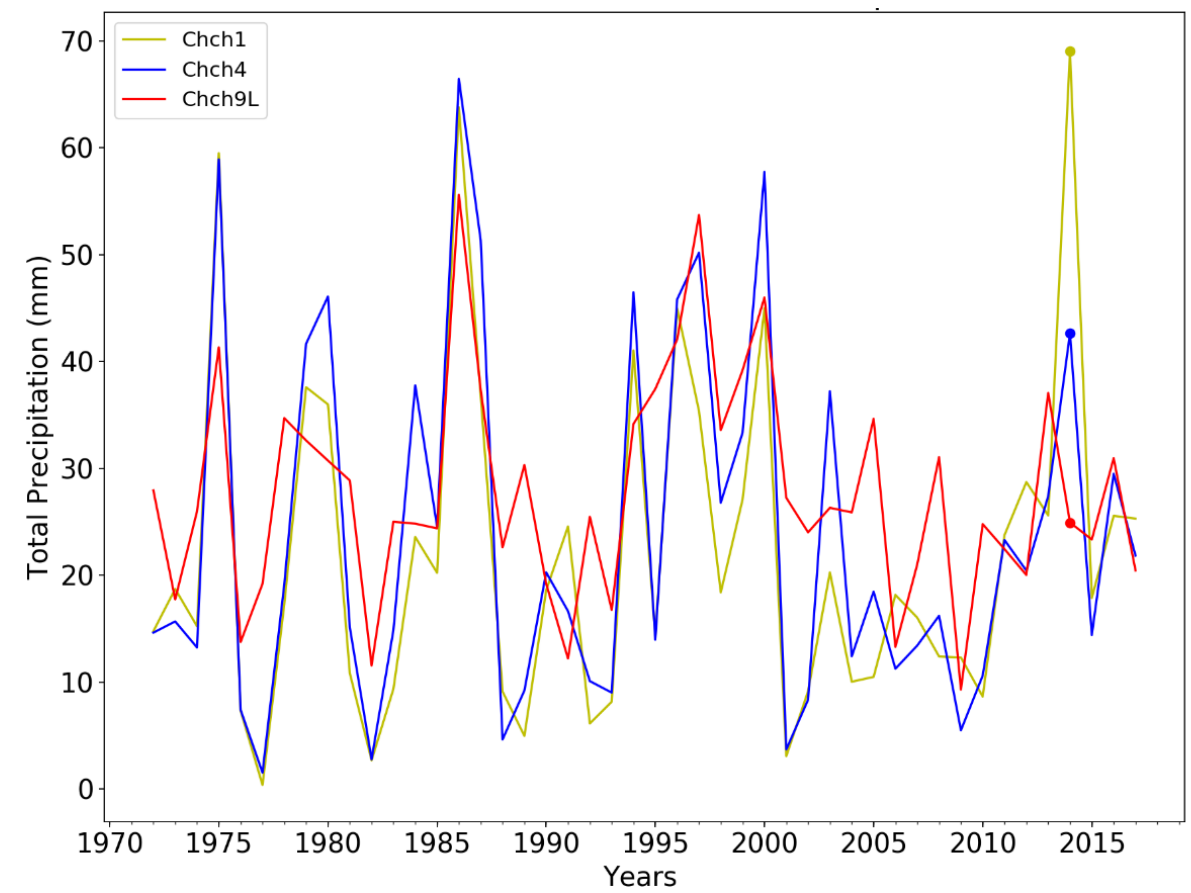

Figure 5.23: VCSN March maximum 1-day rainfall time series from 1972-2017 after spatial averaging for the spatial domains; Chch1 (yellow), Chch4 (blue) and Chch9L (red).

Table 5.4: Average recurrence interval (ARI) of historical heavy rainfall events $\left(\mathrm{P}_{\mathrm{T}}\right)$ from fitting a Generalised Extreme Value distribution for VCSN spatial domains; Chch1, Chch4 and Chch9L.

\begin{tabular}{|r|r|r|r|r|r|r|}
\hline & \multicolumn{2}{|c|}{ Chch1 } & \multicolumn{2}{c|}{ Chch4 } & \multicolumn{2}{c|}{ Chch9L } \\
\hline Year & $\mathrm{P}_{\mathrm{T}}(\mathrm{mm})$ & ARI (yrs) & $\mathrm{P}_{\mathrm{T}}(\mathrm{mm})$ & \multicolumn{1}{c|}{ ARI (yrs) } & \multicolumn{1}{c|}{$\mathrm{P}_{\mathrm{T}}(\mathrm{mm})$} & \multicolumn{1}{c|}{ ARI (yrs) } \\
\hline $\mathbf{1 9 7 5}$ & 59.5 & 27.7 & 58.9 & 20.2 & 41.3 & 9.7 \\
\hline $\mathbf{1 9 8 6}$ & 63.8 & 34.9 & 66.5 & 29.1 & 55.6 & 86.5 \\
\hline $\mathbf{2 0 0 0}$ & 45.0 & 12.0 & 57.8 & 19.0 & 46.0 & 18.5 \\
\hline $\mathbf{2 0 1 4}$ & 69.1 & 45.7 & 42.7 & 8.4 & 25.0 & 1.7 \\
\hline
\end{tabular}




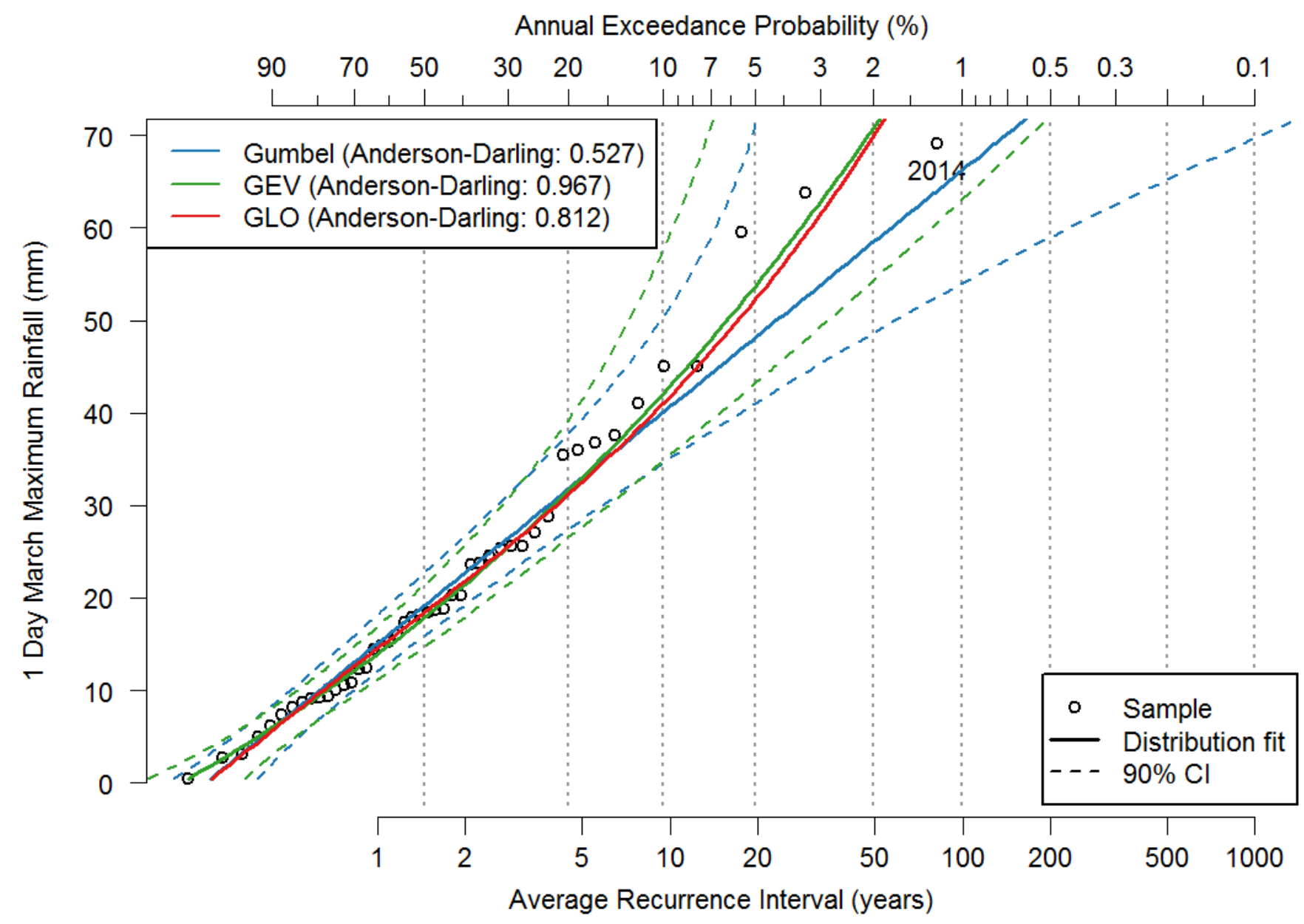

Figure 5.24: Extreme value Gumbel (blue), Generalised Extreme Value (red) and Generalised Logarithmic (green) distributions with 90\% confidence intervals (plotting $5^{\text {th }}$ and $95^{\text {th }}$ percentiles) for VCSN Chch1 March maximum RX1D rainfall. Anderson-Darling p-values are reported for how well each distribution fits the population of samples. 


\subsection{To what degree was this event influenced by global climate change?}

Given the considerable confidence in many aspects of climate change (IPCC, 2013), rather than starting from a conventional null hypothesis of no climate change and reestablishing the case for anthropogenic influence (Trenberth, 2015), here we seek to determine the degree to which climate change has altered the likelihood of RX1D events in Christchurch. In doing so we seek to avoid an inherently conservative approach which can be prone to underestimating the true likelihood of human influence (Trenberth, 2011; Trenberth, 2012). As illustrated in 5.3, changes can be difficult to detect - especially for extremes associated with circulation (i.e. precipitation) where signal-to-noise ratios are generally small. We present a storyline approach to examine the role of various factors that contributed to the March 2014 event as it unfolded. This includes a traditional probabilistic event attribution approach.

Fromw@h ANZ, large ensembles of simulations were generated to represent the factual world (ALL) and the counterfactual world (NAT) where the influence of anthropogenic activities have been removed. Figure 5.25-5.28 of March RX1D maxima show for a given total precipitation (y-axis), the associated return period from the ALL ensemble are nearly always shorter than those for the NAT. Additionally, for any given return-period (x-axis), the magnitude of the rainfall event in the ALL scenario is nearly always larger than in NAT. Thus, the four spatial domains provide consistent evidence for anthropogenic forcings, giving rise to both increased frequency and magnitude of RX1D events. However, the regions where the curves and the $90 \%$ confidence intervals separate differs depending on the scale of the domain under assessment and region of the curves under examination. Notably, Chch9L (Figure 5.28) does not exhibit the same degree of curve separation as the other three spatial domains, suggesting that anthropogenic forcings as simulated byw@h ANZ have not given rise to as large changes in March RX1D rainfall when the Southern Alps are included in the spatial domain. There is a tendency for separation to be more regularly observed across Chch1, Chch4 and Chch9 domains at short return periods yet Chch9, which includes the maritime cells, was the only domain to exhibit curve separation at longer return periods ranging from 1 -in-30 years to 1 -in180 years (Figure 5.27). 
After quantile-quantile bias correction, the observed VCSN event of $69.1 \mathrm{~mm}$ for Chch1 scale corresponded to $77.9 \mathrm{~mm}$ in w@h ANZ (Figure 5.22). This gives an annual return period for the ALL scenario of approximately 1 -in-81 years with the $10^{\text {th }}-90^{\text {th }}$ percentile confidence intervals ranging from 1-in-66 years to 1-in-100 years. In the NAT scenario, the return period is 1-in-112 years with confidence intervals ranging from 1-in-92 years to 1 -in-131 years. While the confidence intervals obtained from bootstrapping without replacement 10,000 times on $50 \%$ of each ensemble population still have a small degree of overlap, the $38 \%$ increase in likelihood $\left(\mathrm{P}_{\mathrm{A}} / \mathrm{P}_{\mathrm{N}} \times 100\right)$ in the ALL forcings scenario for an event of this magnitude strongly supports the increasing frequency of extreme March RX1D rainfalls in Christchurch. By comparison, the Chch1 $130 \mathrm{~mm}$ event bias corrected to $94.16 \mathrm{~mm}$ happens to be one of the only magnitudes in Figure 5.25 where the probability decreases (albeit by a very small amount) in the anthropogenic world. Such a result, in combination with the differences in degree of curve separation between spatial domains, demonstrates the sensitivity of attribution studies to the framing as indicated extensively in literature (i.e. Otto et al., 2012; Angelil et al., 2014; Stott et al., 2016). Bearing this in mind, quantification of the altered likelihoods under the ALL and NAT climate scenarios can be achieved using the FAR metric (Allen, 2003). 


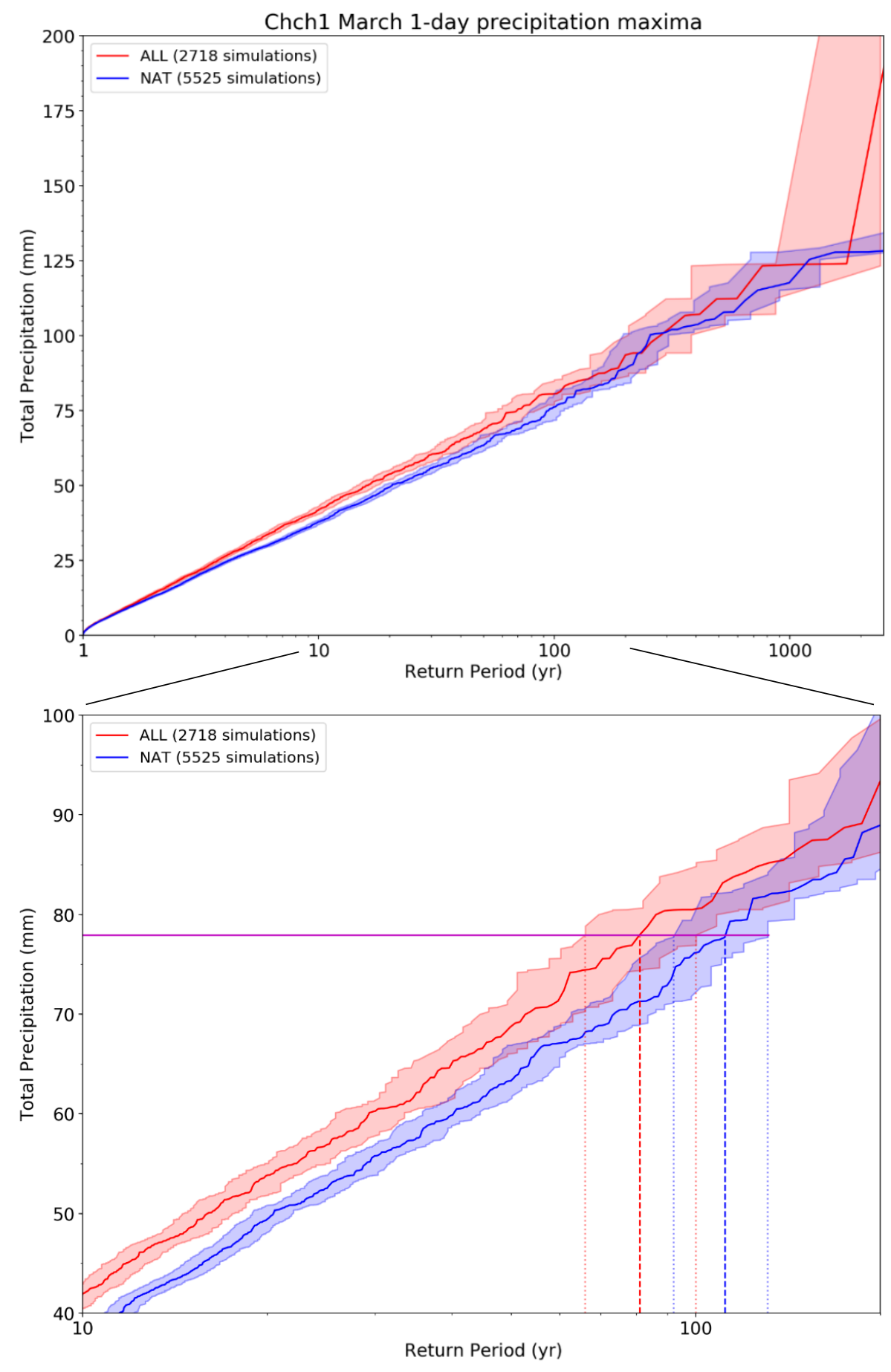

Figure 5.25: (a) Chch1 maximum RX1D rainfall for Christchurch, New Zealand from the w@h ANZ model, plotted against corresponding return periods (log scale). Each return period was bootstrapped (without replacement) 10,000 times on $50 \%$ of the respective ensembles to calculate the $10^{\text {th }}$ and $90^{\text {th }}$ percentile return period. (b) As in (a), but enlarged over region 1-in-10 years to 1-in-200 years with the total precipitation of $77.94 \mathrm{~mm}$ (as determined for VCSN after bias correction) plot as a horizontal line and vertical lines indicate the intersection with bootstrapped $10^{\text {th }}$ and $90^{\text {th }}$ percentile estimates of return period. 


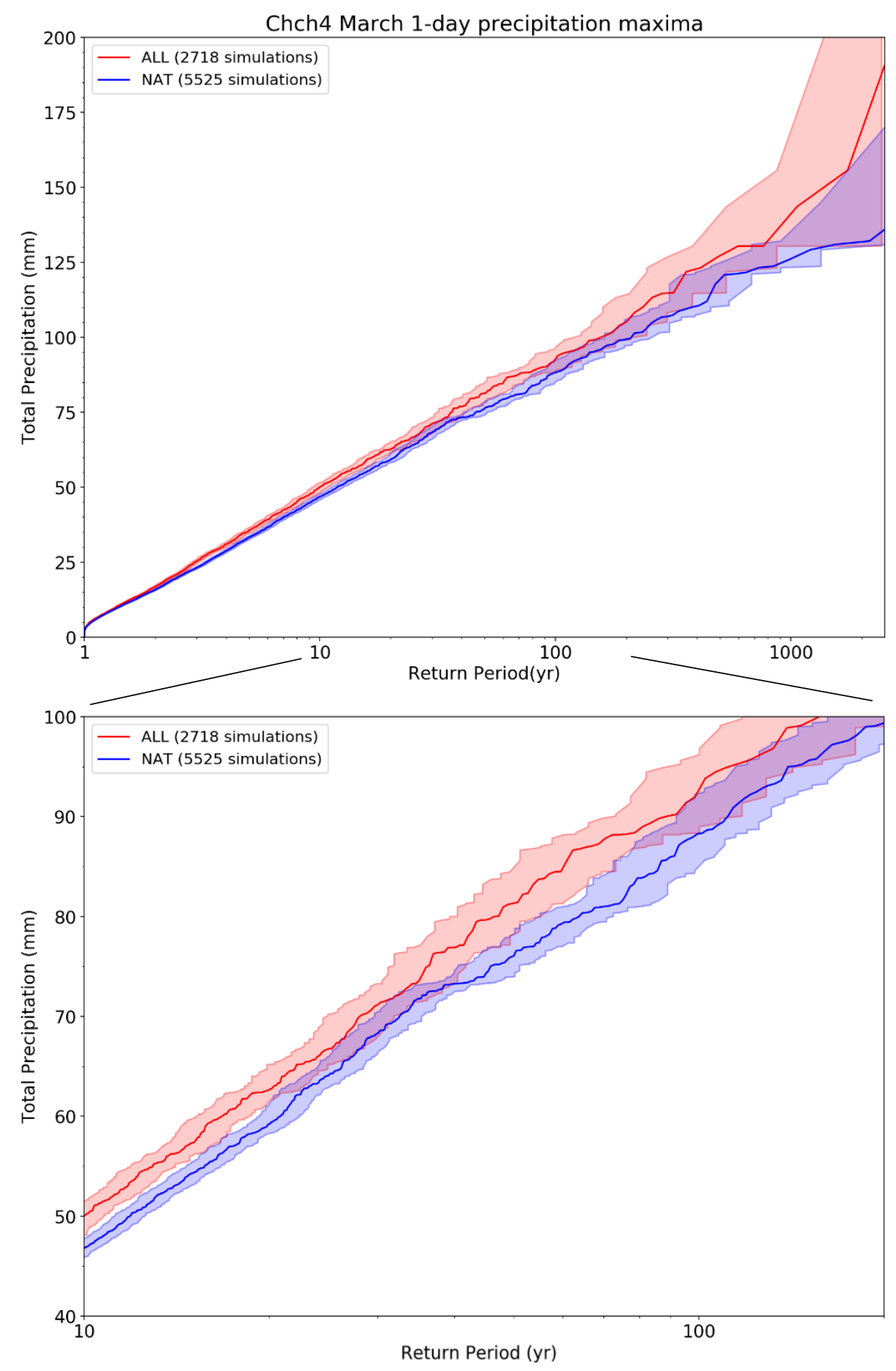

Figure 5.26: (a) Chch4 maximum RX1D rainfall for Christchurch, New Zealand from the w@h ANZ model, plotted against corresponding return periods (log scale). Each return period was bootstrapped (without replacement) 10,000 times on $50 \%$ of the respective ensembles to calculate the $10^{\text {th }}$ and $90^{\text {th }}$ percentile return period. (b) As in (a), but enlarged over region 1 -in-10 years to 1 -in-200 years. 


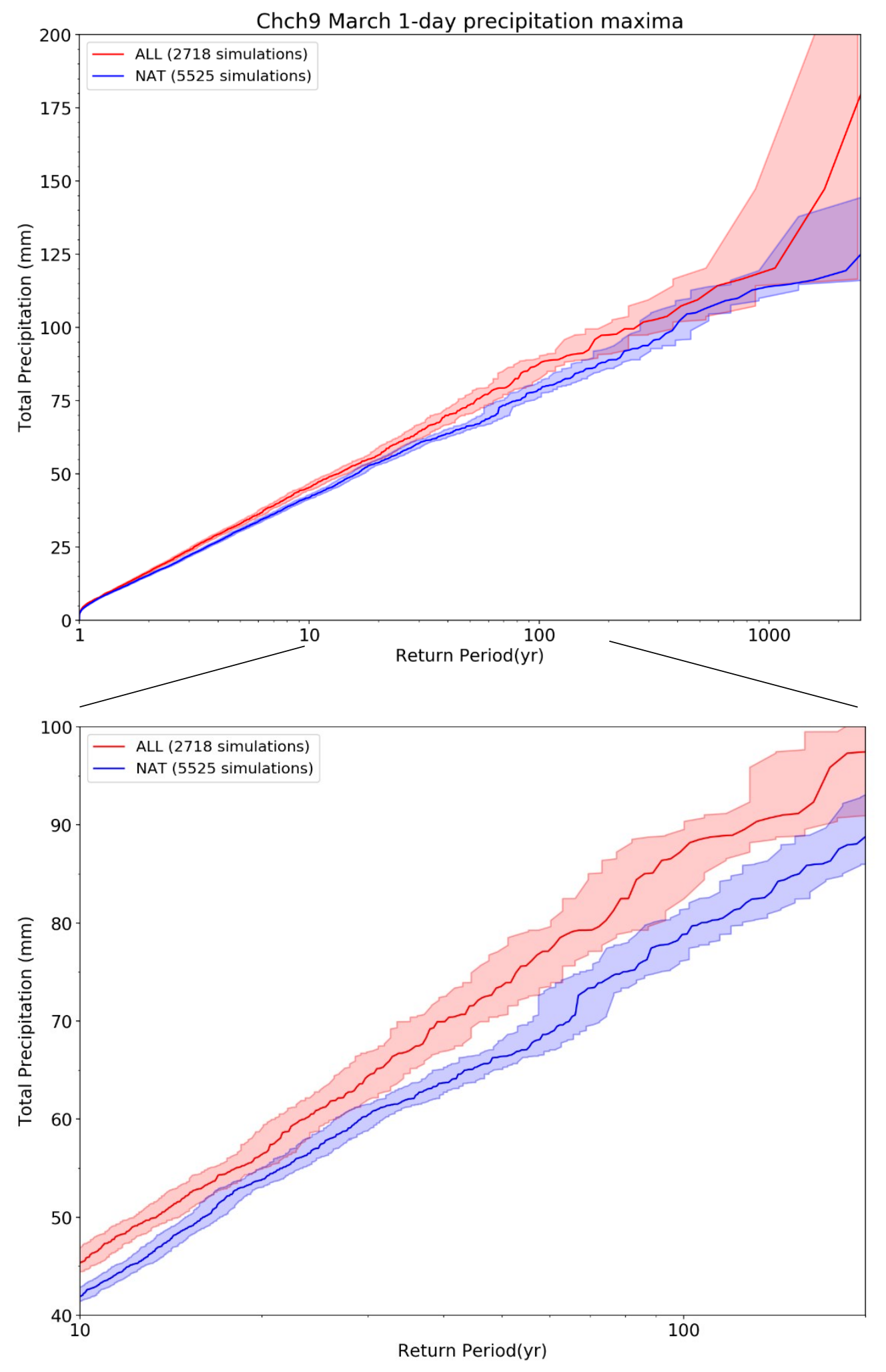

Figure 5.27: (a) Chch9 maximum RX1D rainfall for Christchurch, New Zealand from the w@h ANZ model, plotted against corresponding return periods (log scale). Each return period was bootstrapped (without replacement) 10,000 times on $50 \%$ of the respective ensembles to calculate the $10^{\text {th }}$ and $90^{\text {th }}$ percentile return period. (b) As in (a), but enlarged over region 1-in-10 years to 1 -in-200 years. 


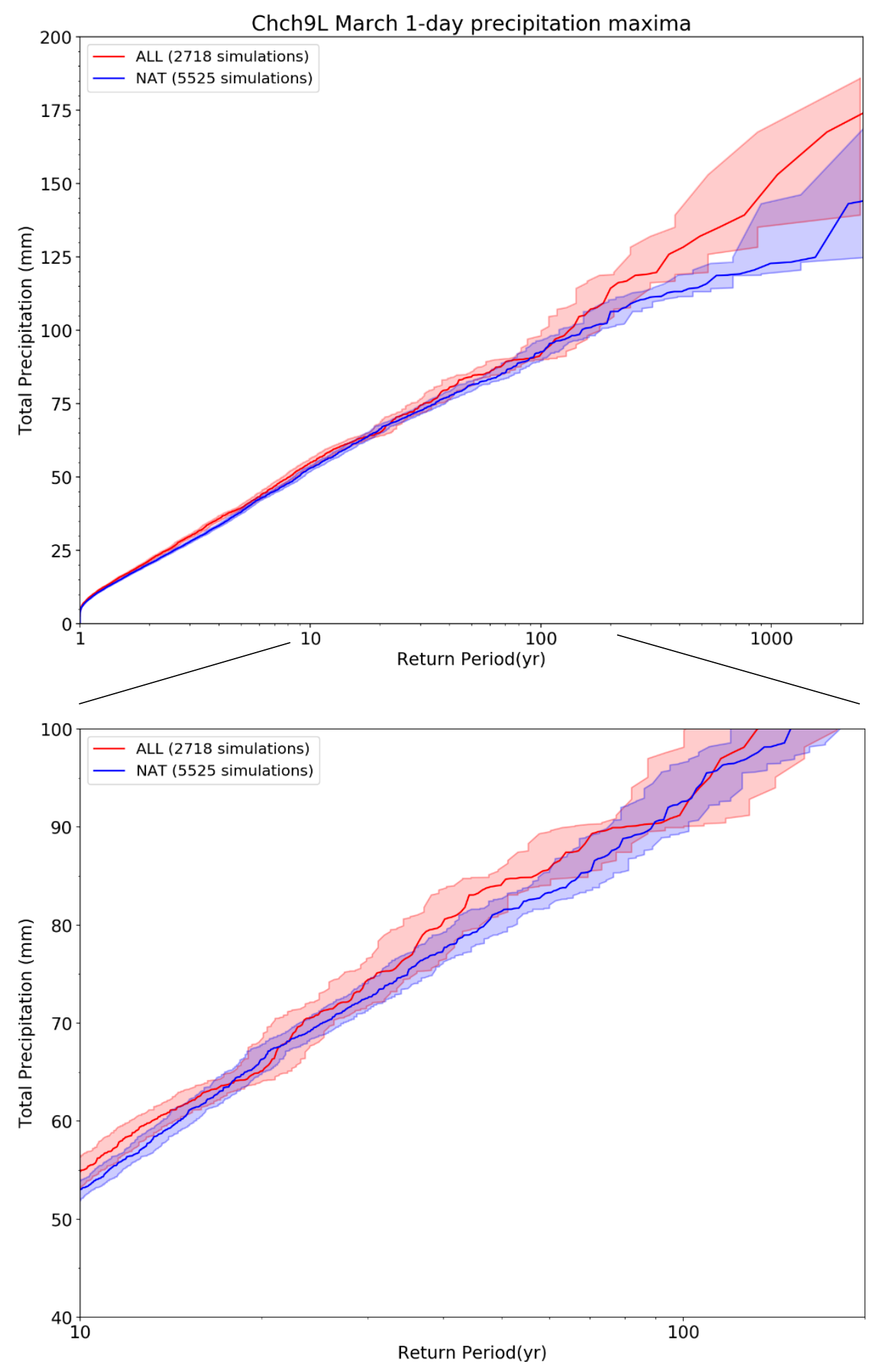

Figure 5.28: (a) Chch9L maximum RX1D rainfall for Christchurch, New Zealand from the w@h ANZ model, plotted against corresponding return periods (log scale). Each return period was bootstrapped (without replacement) 10,000 times on $50 \%$ of the respective ensembles to calculate the $10^{\text {th }}$ and $90^{\text {th }}$ percentile return period. (b) As in (a), but enlarged over region 1-in-10 years to 1 -in-200 years. 


\subsection{Assigning the fraction of attributable risk}

Bias correction of the model data suggested the $69.1 \mathrm{~mm}$ event to be modelled as 77.9 $\mathrm{mm}$ in the ALL ensemble with a return period of 1-in-81 years (Figure 5.25b). The corresponding return period for the NAT was 1-in-115 years. Utilising the bootstrapped $10^{\text {th }}$ and $90^{\text {th }}$ estimates of the return period and the corresponding ARI between these values, we can make a best guess of FAR for events of this magnitude. FAR values are calculated for each return period within the $10^{\text {th }}$ and $90^{\text {th }}$ percentile from which the mean is taken as the best estimate. The highest and lowest calculated FAR then provide the $10^{\text {th }}$ and $90^{\text {th }}$ percentile estimates. So for the $77.9 \mathrm{~mm}$ (i.e. $>97.8$ percentile class) event, the FAR is calculated to be 0.274 ranging from 0.237 to 0.283 . This may also be stated as $27.4 \%$ of the risk of extreme 1-day rainfalls during March in Christchurch is attributable to anthropogenic climate change. Using definitions set out by King et al. (2016), this result suggests a significant anthropogenic influence can be detected for this class of events and that human-induced climate change has very likely increased the likelihood of RX1D rainfall events in Christchurch.

When examined for a range of thresholds (Figure 5.29), we see the $50^{\text {th }}$ percentile FAR to vary between the different spatial domains, generally positioned around 0.15-0.20. Interestingly the FAR values for each spatial domain converges around the 105-110 mm threshold to give a FAR of approximately 0.29 . These values are similar to the findings of Fischer and Knutti (2015), who found 18\% of moderate daily precipitation extremes over land to be attributable to anthropogenic warming of $0.85{ }^{\circ} \mathrm{C}$. 


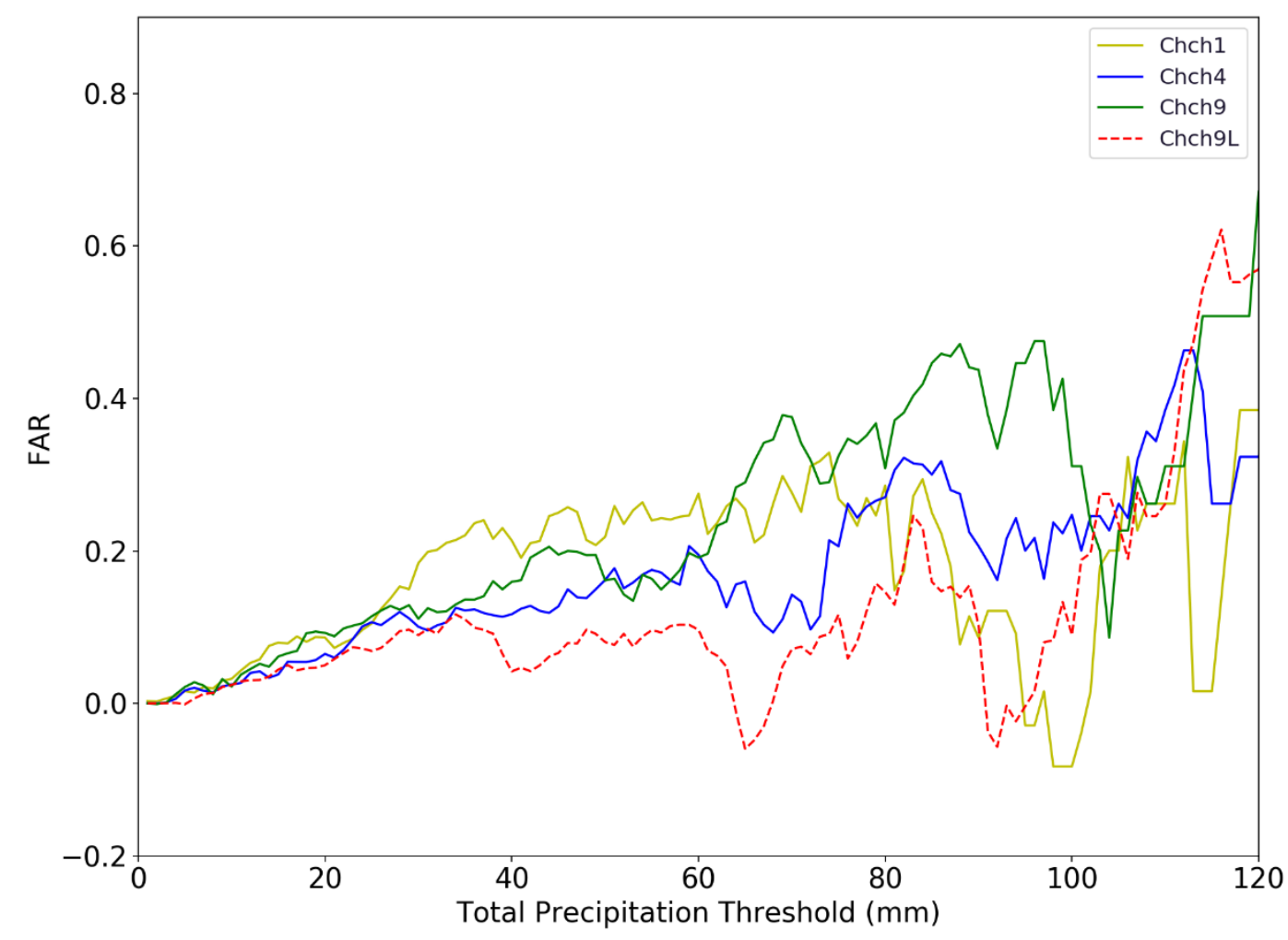

Figure 5.29: Estimates of the $50^{\text {th }}$ percentile fraction of attributable risk (FAR) values for March 2014 maximum RX1D thresholds ( $\mathrm{mm}$ ) after bias correction for spatial domains; Chch1 (yellow), Chch4 (blue), Chch9 (green) and Chch9L (red dashed).

Figure 5.29 above also shows a general increase in FAR with threshold, a result which was also found by Fischer and Knutti (2015) in their examination of the highest percentiles of rainfall extremes. This implies the rarest and most extreme heavy rainfall events are more attributable to human influence, as also found by Stott et al. (2004) in their study of heatwaves. While Figure 5.25-5.29 may appear as relatively straight and parallel lines, Figure 5.29 demonstrates that the actual value of the FAR threshold does matter, in contrast to the claim by Otto et al. (2015). This could be due to ever-decreasing sample sizes at higher thresholds affecting the statistics significantly but it may also indicate changes in extreme rainfall events are the result of dynamical circulation changes. Dynamical changes would be in addition to the thermodynamic change which affects all rainfall events (i.e. Clausius-Clapeyron 7\% increase in maximum atmospheric moisture availability per degree of warming) (Emori and Brown, 2005; Stott et al., 2016). As dynamical circulation changes have larger uncertainties and smaller signal-to-noise ratios (Trenberth et al., 2015), it may also explain why curve separation between ALL and NAT is greater for low rainfalls with smaller ARI (Figures 5.28-5.30). It is also important to bear in mind that climate models have historically underestimated observed 
increases in heavy precipitation with anthropogenic warming (Allan and Soden, 2008; Min et al., 2011), such that curve separation and corresponding FAR values could be even greater for high ARIs.

Comparison of probability density functions of March RX1D rainfall for the factual (ALL) and counterfactual (NAT) scenarios reveals where changes in the distribution are occurring. Figure 5.30 indicates there is a large decrease in the frequency of small $(\sim 10$ $\mathrm{mm}$ ) March maximum 1-day rainfall events compared to the corresponding counterfactual world, and that this is consistent for both Chch1 and Chch4 domains. This result supports Purich and Son's (2012) finding of systematic changes in light precipitation (1-10 $\mathrm{mm} /$ day) in response to ozone forcings and reiterates the importance of ozone forcings in Southern Hemispheric surface climate changes. Furthermore, Figure 5.30 indicates the frequency of events greater than $30 \mathrm{~mm}$ increases in the anthropogenic world with the Chch4 spatial domain observing a larger increase than the Chch1 domain. While the change in frequency for precipitation events above $100 \mathrm{~mm}$ is too small to discern visually from Figure 5.30, p-values from performing KS tests are both less than 0.01 , indicating the shape of the ALL and NAT distributions are significantly different for the Chch1 and Chch4 domains.

Median rainfall for the Chch1 domain increases significantly in the anthropogenic world by $8 \%(p<0.001)$, while a $29 \%$ increase is observed for the Chch 4 domain $(p<0.001)$. These increases are both larger than the 3.3\% increase in 1-day maximum rainfall attributed to human influence for Northern Hemisphere locations (Zhang et al., 2013). This difference is thought to be due to the focus of this study on March events which coincides with the majority of NZ's ex-tropical cyclone (ETC) interactions (Lorrey et al., 2014) that are also responsible for many heavy rainfall events. Thus it would be interesting to broaden the scope of this analysis to all months, and more Southern Hemispheric locations, both to assess the contribution of ETCs and to see if the changes in extreme RX1D rainfall are similar to those found in the Northern Hemisphere. Work by Bengtsson et al. (2009) estimated there to be a $27 \%$ increase in extreme precipitation for ETC tracks, close to the increase we saw in March for the Chch4 domain. They also stated the importance of accurately resolving synoptic-scale circulation for robust prediction of local precipitation extremes. As such we now evaluate the output 
simulations closer to ascertain the role of ETCs and the synoptic regime in the most extreme March RX1D rainfall events.

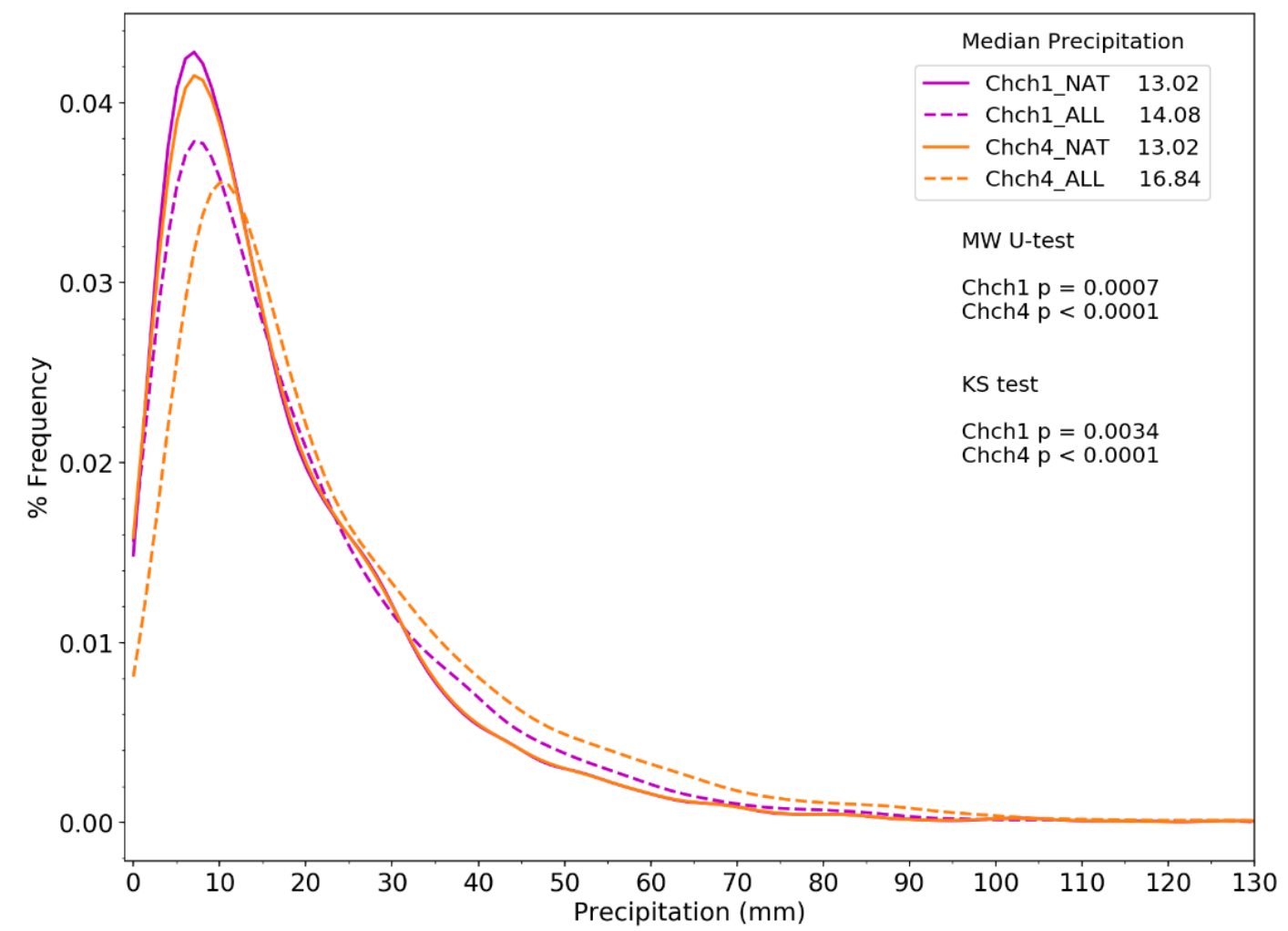

Figure 5.30: Probability density function of March 2014 maximum 1-day rainfalls for ALL and NAT forcings in Chch1 and Chch4 with the solid lines representing the Chch1 domain and dashed lines representing the Chch4 domain. Statistical results from Mann-Whitney (MW) and Kolmogorov-Smirnov (KS) statistical tests are reported for changes in the median value and distribution between for the ALL and NAT ensembles for the Chch1 and Chch4 domain. 


\subsection{Understanding the synoptic situation}

Large-scale atmospheric circulation is a key determinant of where rain falls, yet in contrast to the thermodynamic aspects of climate, forced circulation changes are not well established (Trenberth et al., 2015). Investigating the simulations that gave rise to the most extreme RX1D rainfall events can help with understanding the nature of such events.

Assessing the ALL forcing simulations from $\mathrm{w} @ \mathrm{~h}$ ANZ indicates common characteristics in the synoptic set-up for the largest RX1D rainfall events. Figure 5.31(a) depicts the largest simulated RX1D event for both Chch1 and Chch4 domains, while the simulation in Figure 5.32(a) is the third and second largest for the respective domains. Of particular note are the deep lows (Figure 5.31 and Figure 5.32) positioned north or north-east of Christchurch, with closely spaced isobars and strong onshore winds. These bear a striking resemblance to the synoptic situation observed on the $4^{\text {th }}$ and $5^{\text {th }}$ March (Figure 5.9). The synoptic depiction in Figure 5.31 also indicates that the position and breadth of the low may allow for extremely moist air to be drawn from the subtropics via 'atmospheric rivers' (AR). Prior research indicates such occurrences are not unlikely, with Waliser and Guan (2017) finding up to half of the extreme events in the top 2\% of precipitation distribution to be associated with AR across mid-latitude regions globally. Meanwhile in NZ, Rosier et al. (2015) suggested most extreme events to have arisen from AR.

In contrast, the top simulations for the NAT scenario (Figure 5.33-5.34) do not appear to show the same level of connectivity as the ALL forcings scenario with the sub-tropics. This may partly explain why the largest simulated 1-day rainfall event in the NAT ensemble is only $134 \mathrm{~mm}$ (contrasted with $308 \mathrm{~mm}$ for ALL) despite the larger number of simulations (5525 cf. 2718). Interestingly, the spatial extent of extreme rainfall appears to be smaller for the largest events in the NAT simulations. However, these differences in connectivity and extent may also be due to the data projection. As each simulation is the result of different initial condition perturbations, the exceptional $308 \mathrm{~mm}$ ALL forcing simulation and other extremes seen here are likely the rare coincidence of multiple contributing factors. 
a)
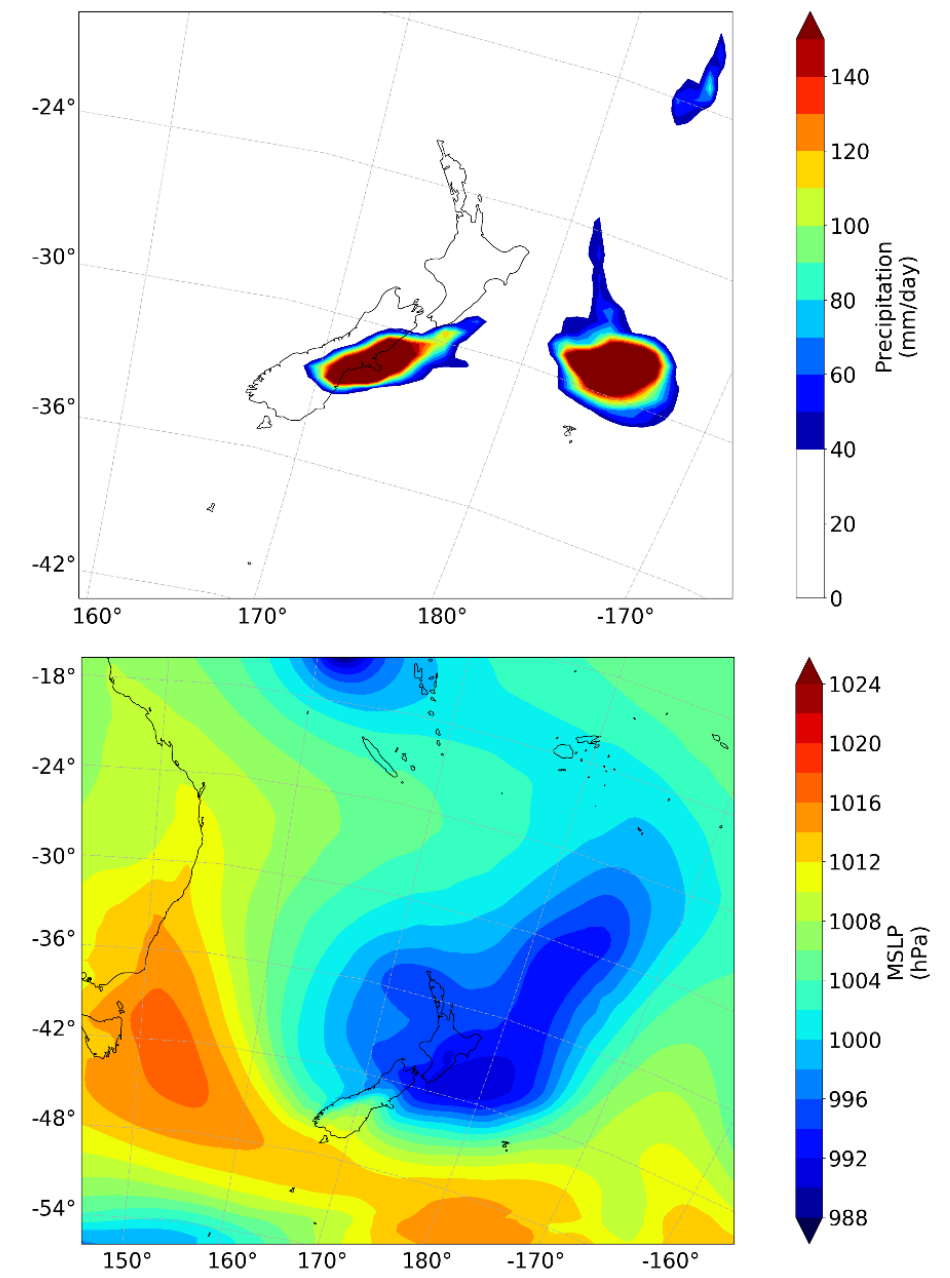

b)
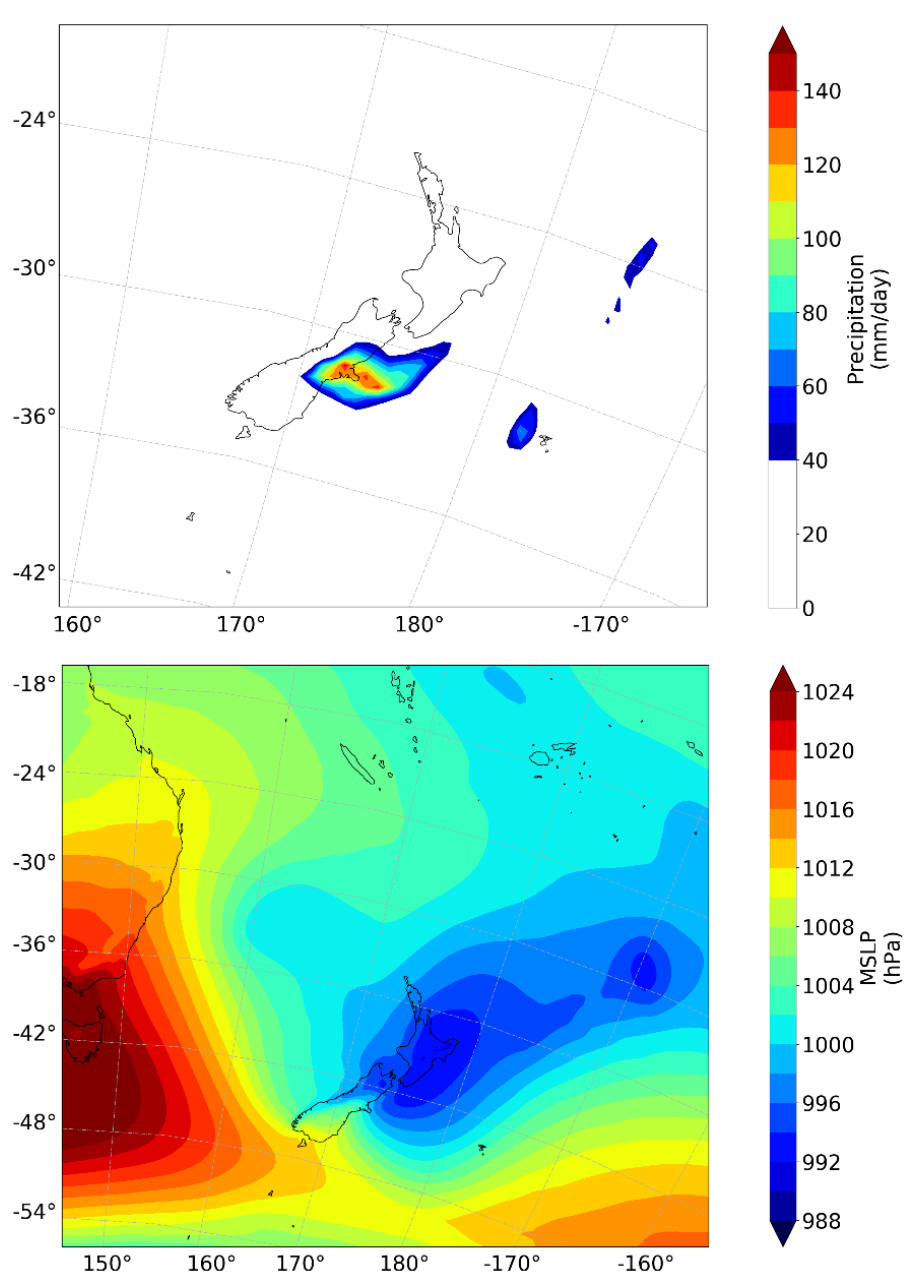

Figure 5.31: Precipitation and synoptic circulation as simulated within w@h ANZ for Chch1 ALL forcings (a) largest RX1D event (308 mm), (b) second largest RX1D event (124 mm). 
a)
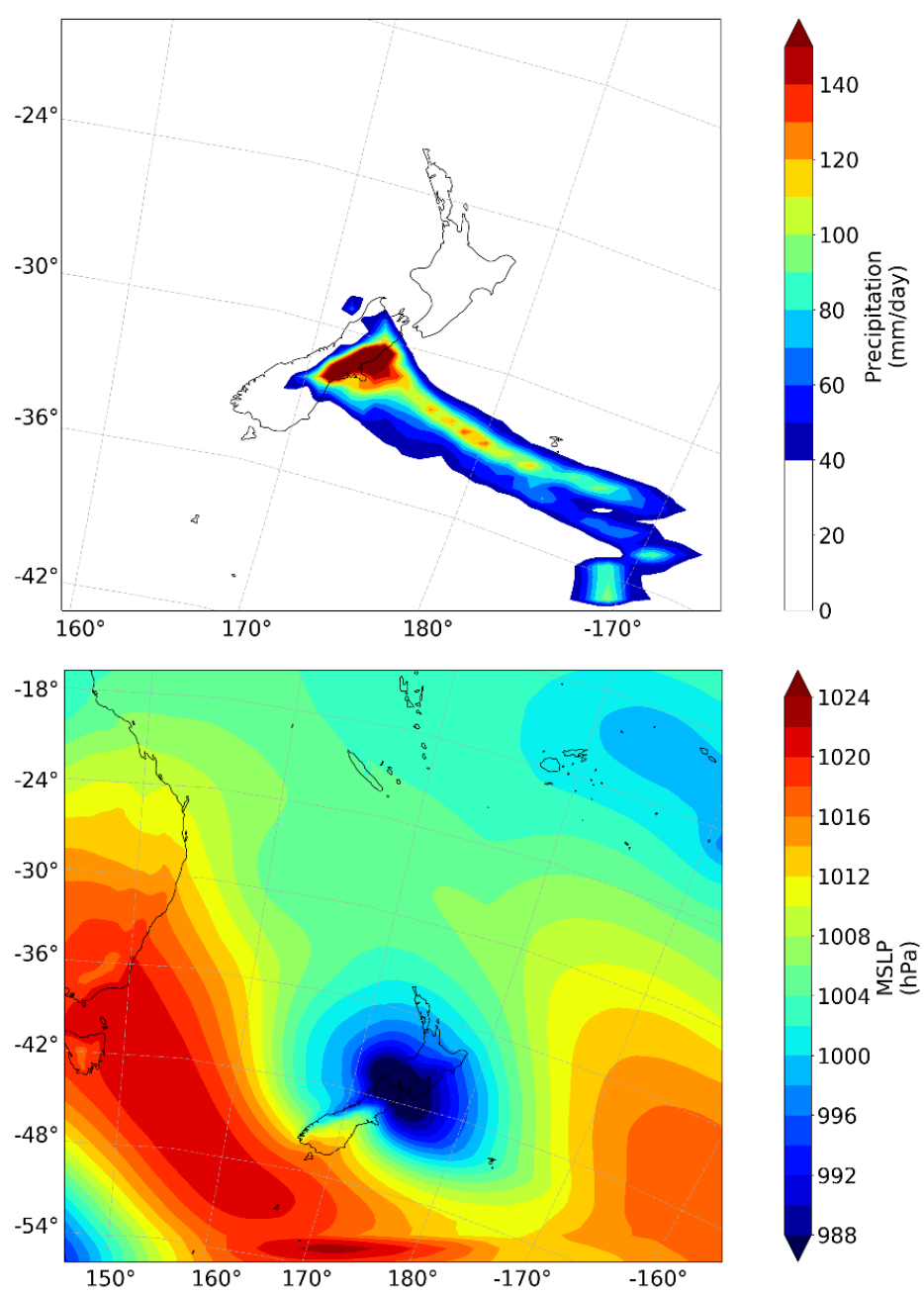

b)
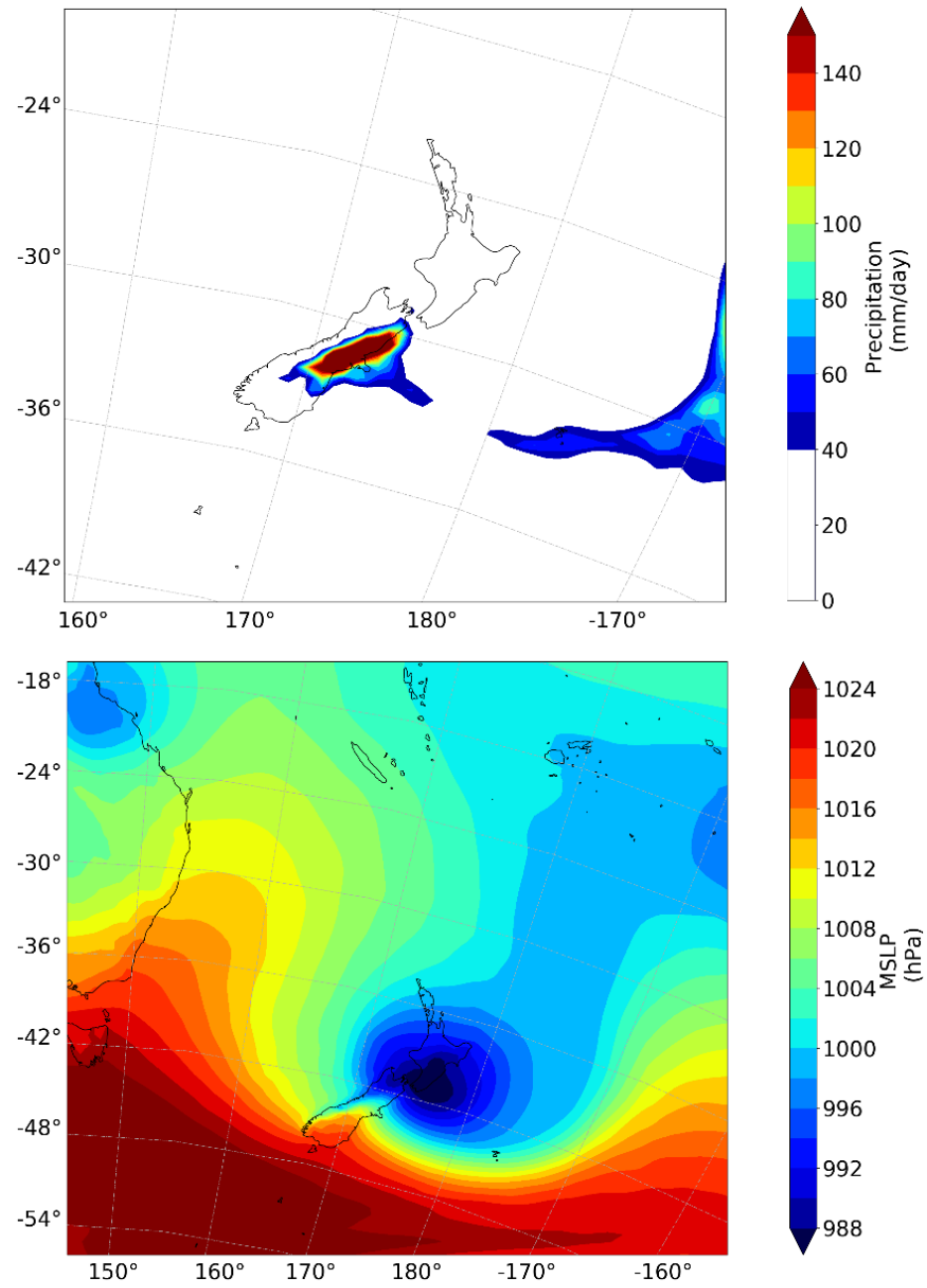

Figure 5.32: Precipitation and synoptic circulation as simulated within w@h ANZ for Chch1 ALL forcings (a) third largest RX1D event (123 mm), (b) $66^{\text {th }}$ largest RX1D event $(66 \mathrm{~mm})$ yet third largest event for Chch4 $(143 \mathrm{~mm})$. 
a)
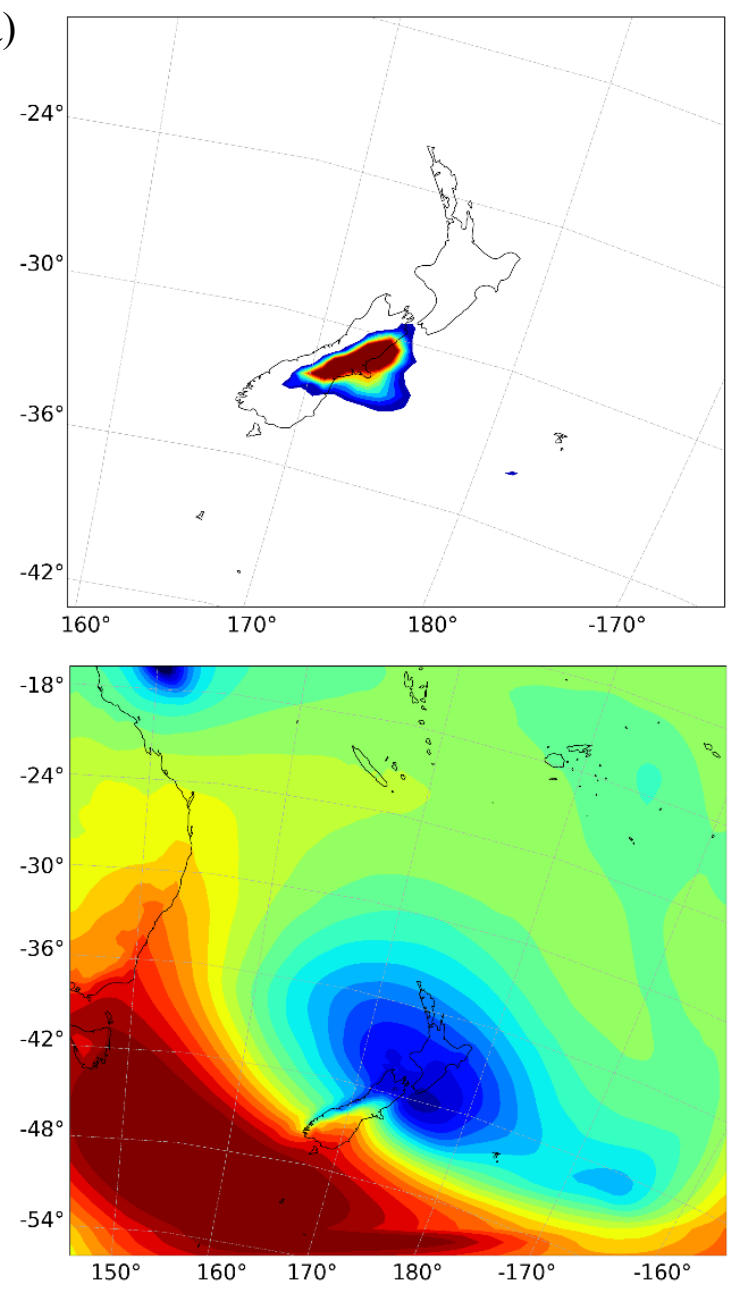

b)
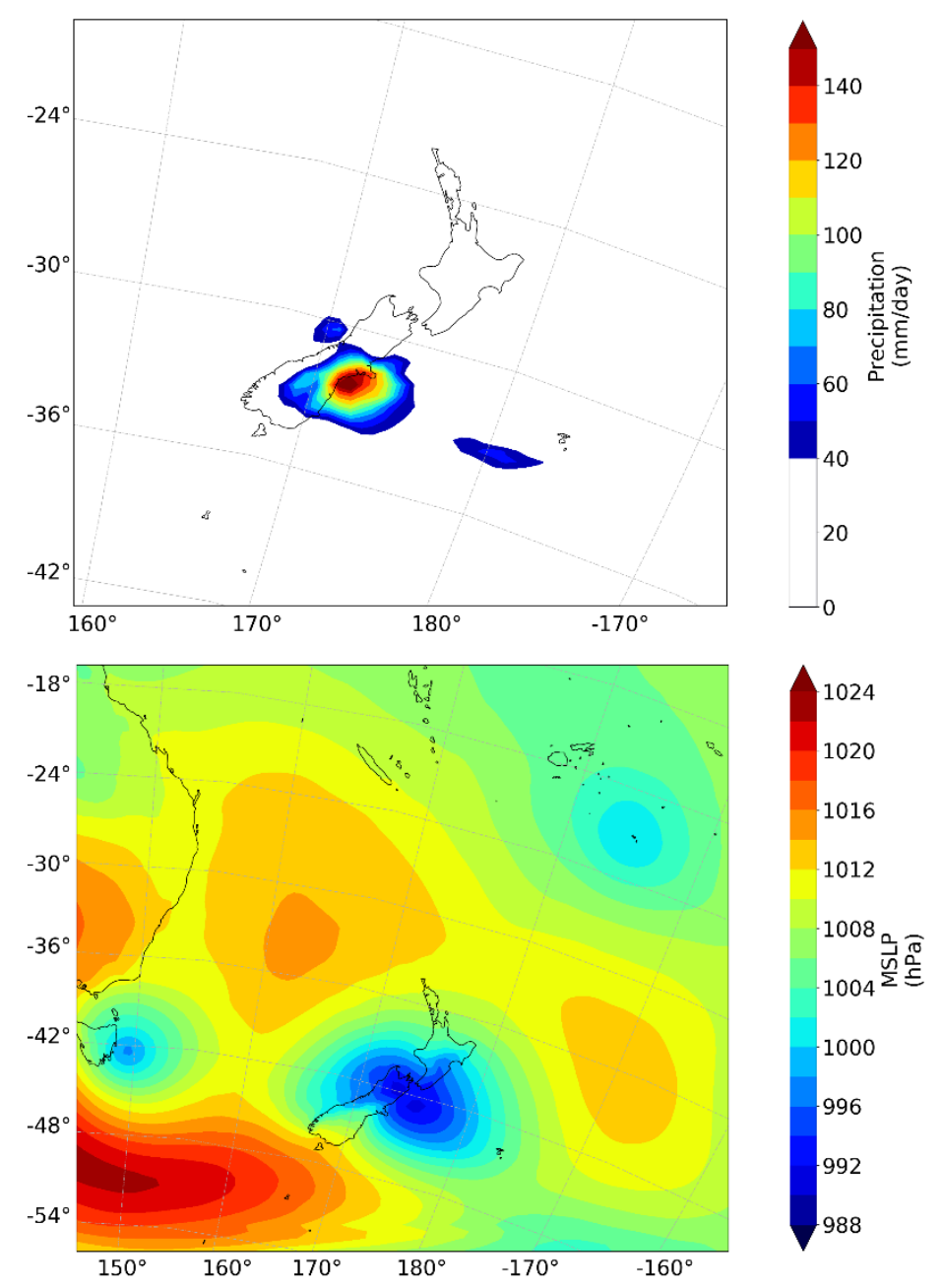

Figure 5.33: Precipitation and synoptic circulation as simulated within w@h ANZ for Chch1 NAT forcings (a) largest RX1D event (134 mm), (b) second largest RX1D event (129 mm). 
a)
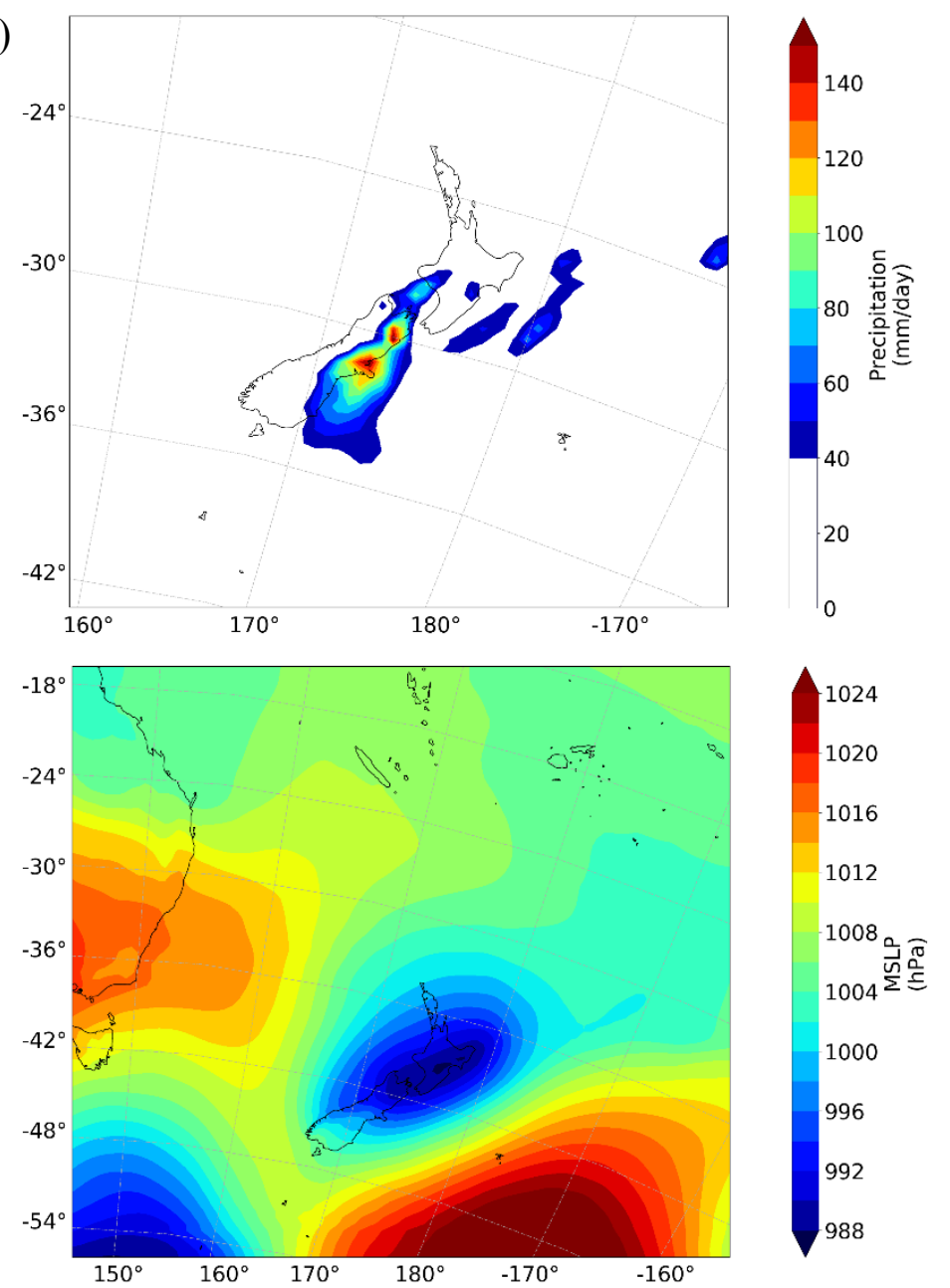

b)
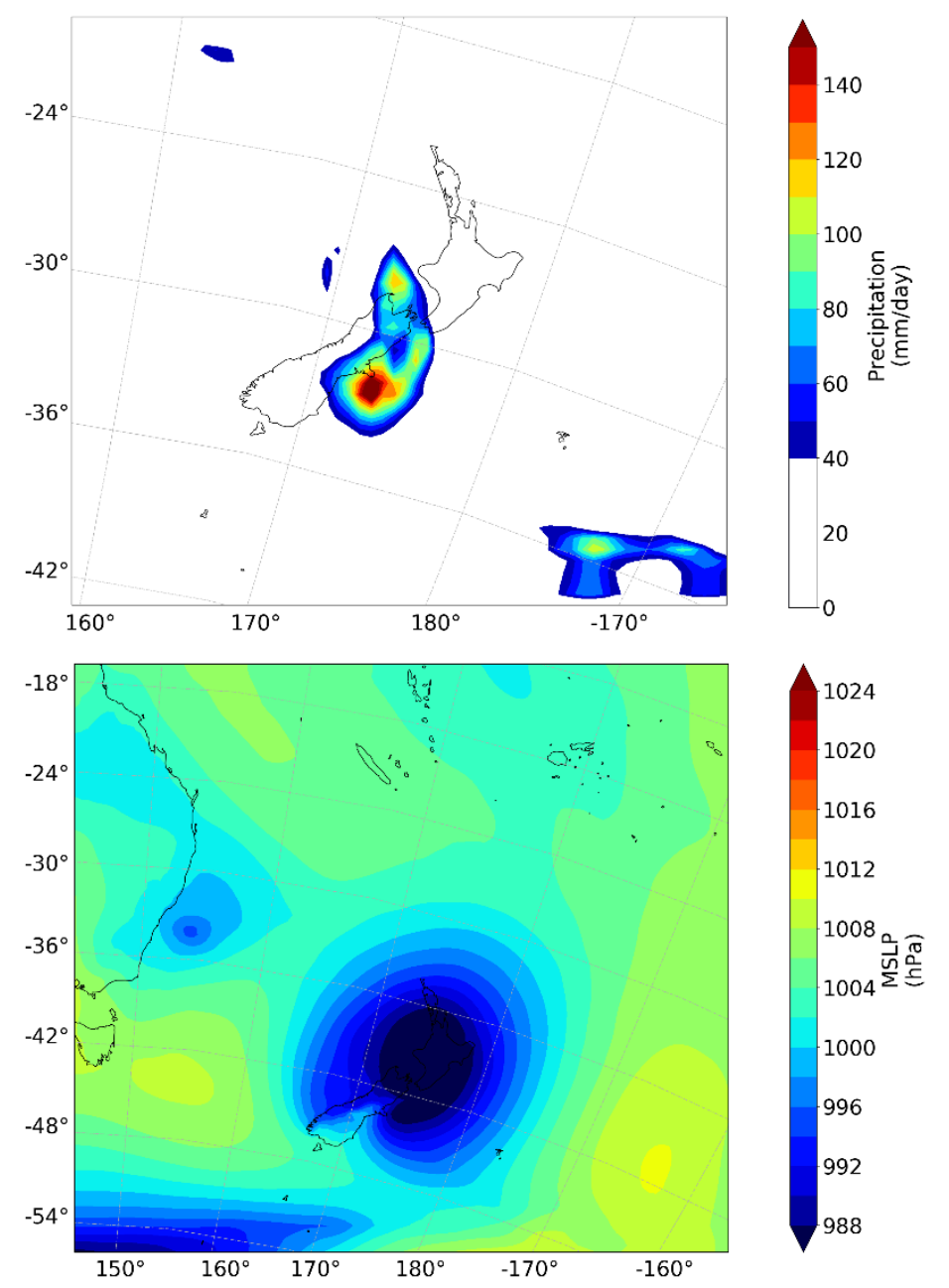

Figure 5.34: Precipitation and synoptic circulation as simulated within w@h ANZ for Chch1 NAT forcings (a) third largest RX1D event (127.86 mm), (b) fourth largest RX1D event (127.8 mm). 
Examination of the origin, pathway and speed of the ten largest 1-day rainfall events for Chch1 and Chch4 in the ALL and NAT scenarios show that many of the largest rainfall events are associated with tropical depressions (TDs) originating in the tropical South Pacific (Table 5.5). Only two events at the Chch1 scale are solely due to a Southern Ocean low (SOL) and are ranked in the $9^{\text {th }}$ and $10^{\text {th }}$ positions for ALL and NAT respectively. For the Chch4 domain, none of the 10 largest events are exclusively due to a SOL. There are however simulations where the arrival of a SOL coincides with a TD, much like the observed 4/5 th $^{\text {March }} 2014$ event. For Chch1 and Chch4 ALL forcings, this combination gives rise to an event much larger rainfall than from a TD alone, which in this case is nearly $250 \%$ greater than the second largest (Table 5.5). In Chch4, the pathway taken by these storms is evenly split between the west and east coast, yet for Chch1 these storms primarily approach from the west, which is documented to lead to more damaging events (Sinclair, 2002). These features would be interesting for future inquiry which could include the use of self-organising map techniques (Kohonen, 1990; Hewitson and Crane, 2002) to quantitatively examine the synoptic features of extreme events. 
Table 5.5: Descriptors of the top ten RX1D events in the ALL and NAT forcing ensembles for Chch1 and Chch4 as simulated in w@h ANZ for March 2014. Event categorisation as a Tropical Depression (TD) or Southern Ocean Low (SOL) is reported alongside total precipitation ( $\left.\mathrm{P}_{\mathrm{T}}, \mathrm{mm}\right)$ the origin and pathway where orange indicates an east coast pathway from the Pacific Ocean and blue a west coast pathway from the Tasman Sea.

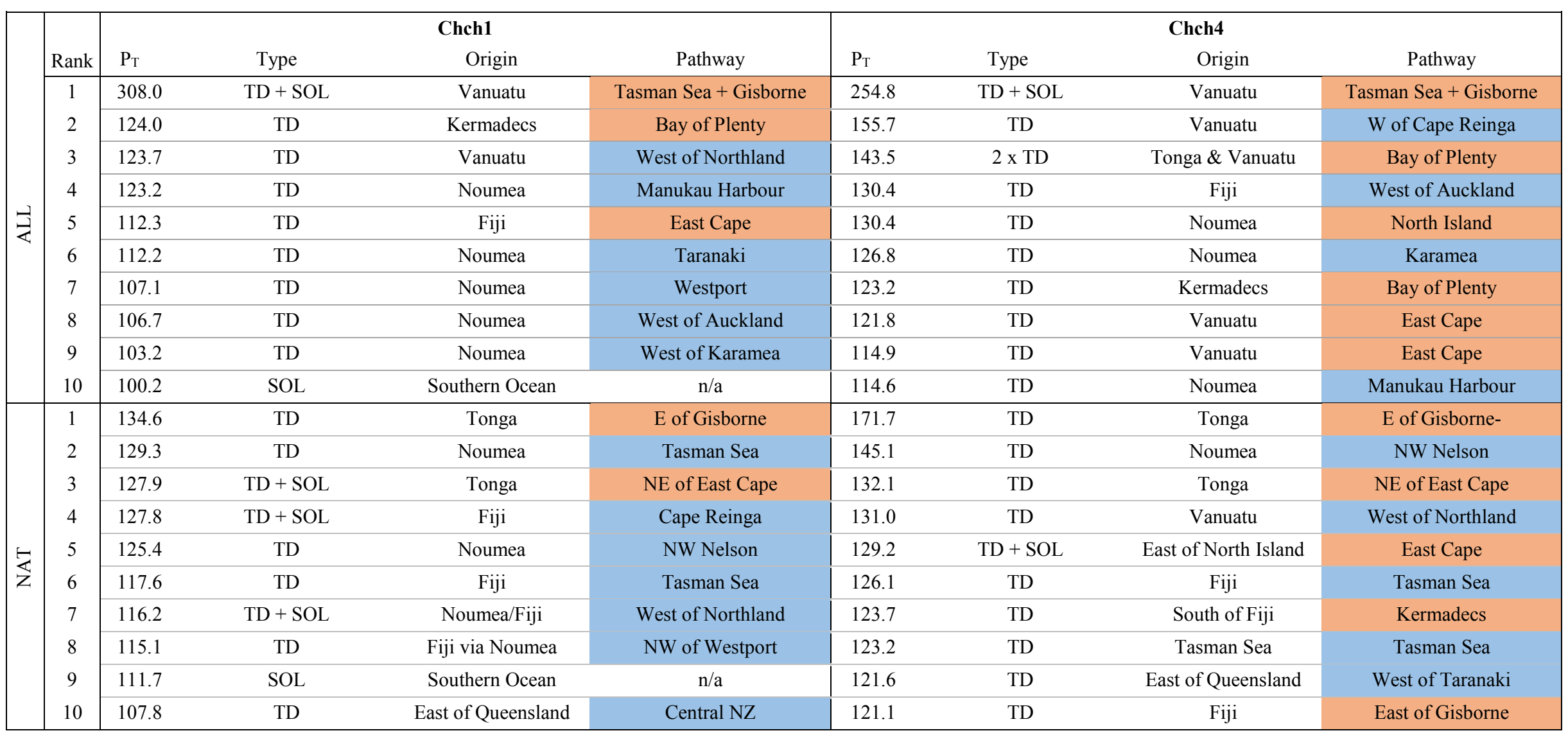




\subsection{The role of sea-surface temperatures}

A storyline approach examines the various factors which contributed to the event, principally the anomalous aspects of natural variability (Shepherd, 2016). Trenberth et al. (2015) advocate that more reliable statements regarding the role of anthropogenic climate change can be made when assessment of thermodynamics is conducted, given we have more confidence in observations of changing temperatures and the processes underlying these changes. We therefore assess this event on the basis of SSTs following the conditioned approach employed by Trenberth et al., (2015) in assessing the Boulder Colorado floods of September 2013.

Reanalysis estimates of total column water vapour (TCWV) suggest abundant moisture extending from the subtropics (Figure 5.11) to have contributed to the high rainfalls observed in Christchurch on the $4 / 5^{\text {th }}$ March 2014. However, for Christchurch, the March 2014 TCWV associated with this event of 17-21 mm was not exceptional (Figure 5.35). A more spatially extensive event nearly 11 days later had nearly double the TCWV, yet total rainfall at Christchurch Gardens was $33.7 \mathrm{~mm}$ across these two days. The small TCWV seen for Christchurch in ERA-Interim during the extreme event could be due to this event being highly localised and ARs generally being narrow (Waliser and Guan, 2017), yet ARs are generally sufficiently wide that they should be represented in reanalysis data sets. Trajectory analysis suggested the air associated with the event to have originated from the Southern Ocean (Figure 5.13), in contrast to what may be interpreted visually from the reanalysis data (Figure 5.9 and Figure 5.11-5.12). Here we examine the possible role of SST anomalies both north and south of NZ. 


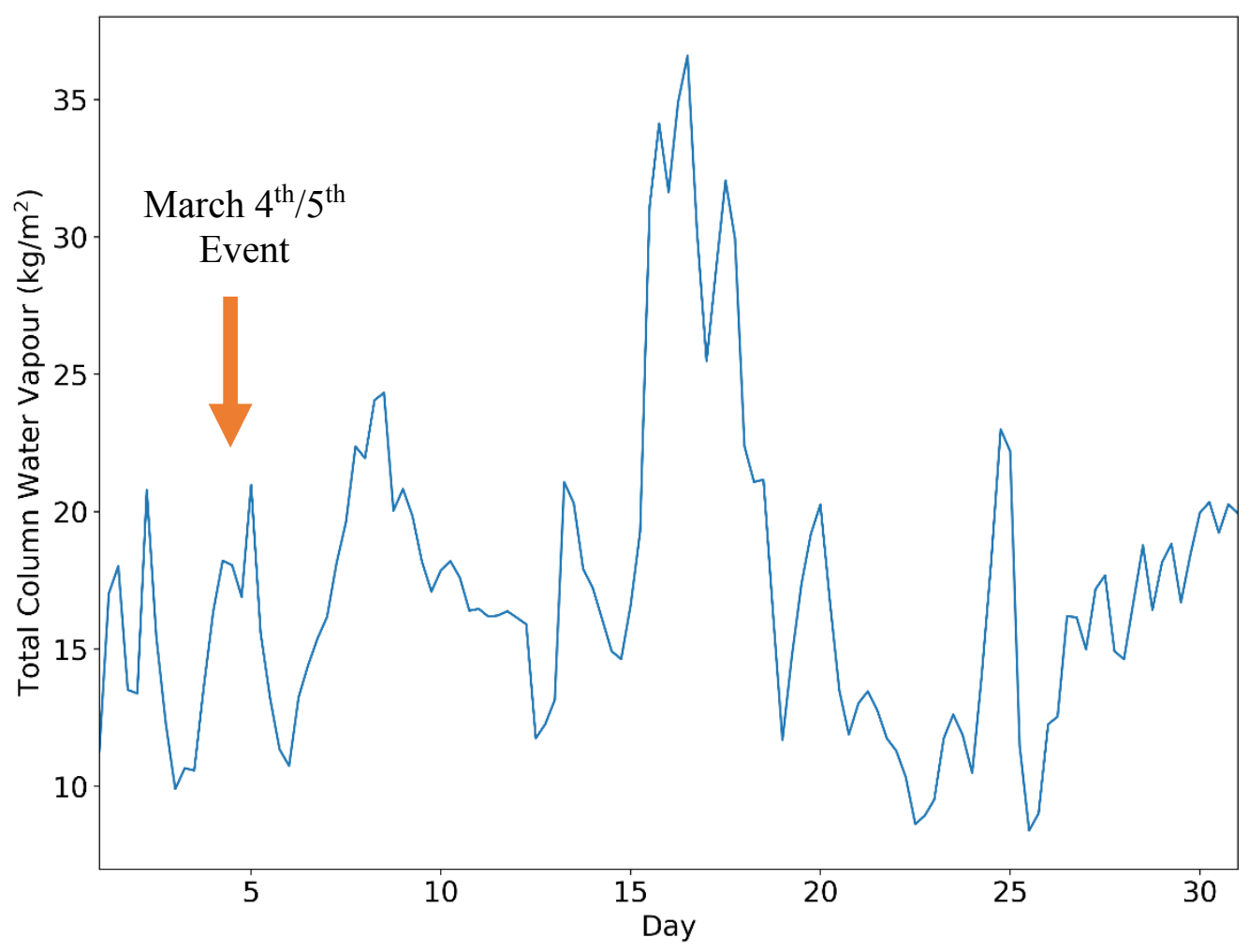

Figure 5.35: Time series of ERA-Interim 6-hourly reanalysis total column water vapour (TCWV, $\left.\mathrm{kg} / \mathrm{m}^{2}\right)$ for Christchurch $\left(43.5^{\circ} \mathrm{S}, 172.5^{\circ} \mathrm{E}\right)$ in March 2014.

SST anomalies from five domains were assessed throughout the South Pacific (Figure 5.36), both offshore from the South Island and in the Pacific Islands. As the Christchurch heavy rainfall event occurred in early March, we focus on the SST anomalies for February in the build-up to the event. 


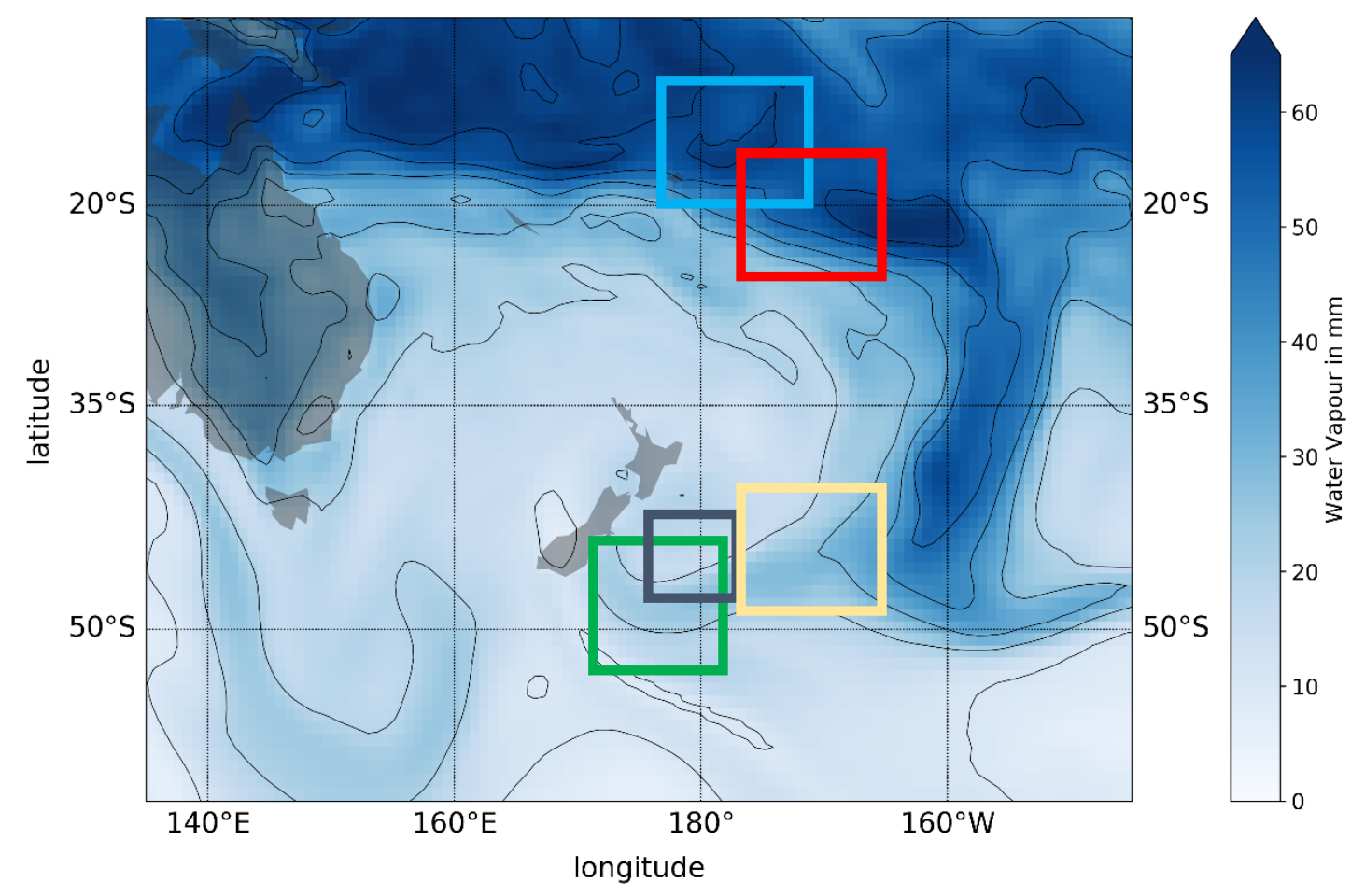

Figure 5.36: ERA-Interim total column water vapour at UTC 1200 on the $4^{\text {th }}$ March 2014. Fiji domain (blue), Tonga domain (red), Chatham Islands domain (pale-yellow), east of Christchurch (blue-grey) and south of Christchurch (green).

Notable distinctions were observed for the five ocean domains in SST anomalies. South of Christchurch, February SSTs for 2014 were only $0.2^{\circ} \mathrm{C}$ higher than the climatological average of $11.54{ }^{\circ} \mathrm{C}$ for $1981-2010$ (Figure 5.37). For the domain around the Chatham Islands, the February 2014 SST anomaly was $0.31{ }^{\circ} \mathrm{C}$ above normal (Figure 5.38). Contrastingly, SSTs near Tonga were $0.81{ }^{\circ} \mathrm{C}$ higher than normal for February (Figure 5.39). As such on the $1^{\text {st }}$ March, a few days prior to the Christchurch extreme rainfall event, very large total column water vapours of $72 \mathrm{~mm}$ were observed over the South Pacific. The high SSTs in combination with the presence of tropical cyclone Kofi and a SOL facilitated large-scale convergence of moisture which could then propagate south via an atmospheric river to make landfall at Christchurch (Figure 5.11). 


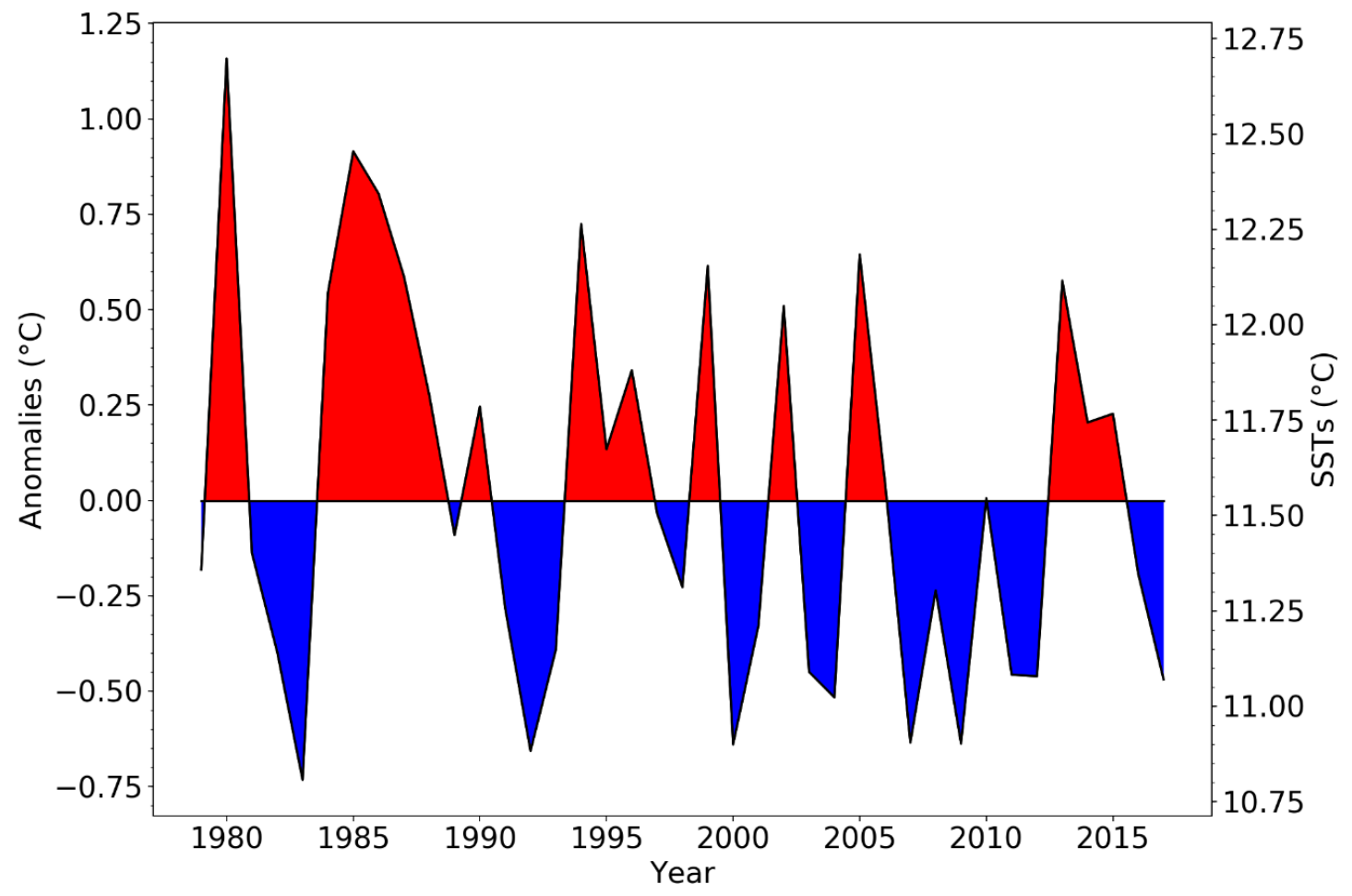

Figure 5.37: February SST anomalies for $44-54^{\circ} \mathrm{S}, 168-178^{\circ} \mathrm{E}$, south of Christchurch. The mean SST was $11.54{ }^{\circ} \mathrm{C}$ for $1981-2010$, the anomaly for 2014 was $0.2^{\circ} \mathrm{C}$ and the mean anomaly for $2000-2017$ was $-0.12^{\circ} \mathrm{C}$. The last value is for 2017 .

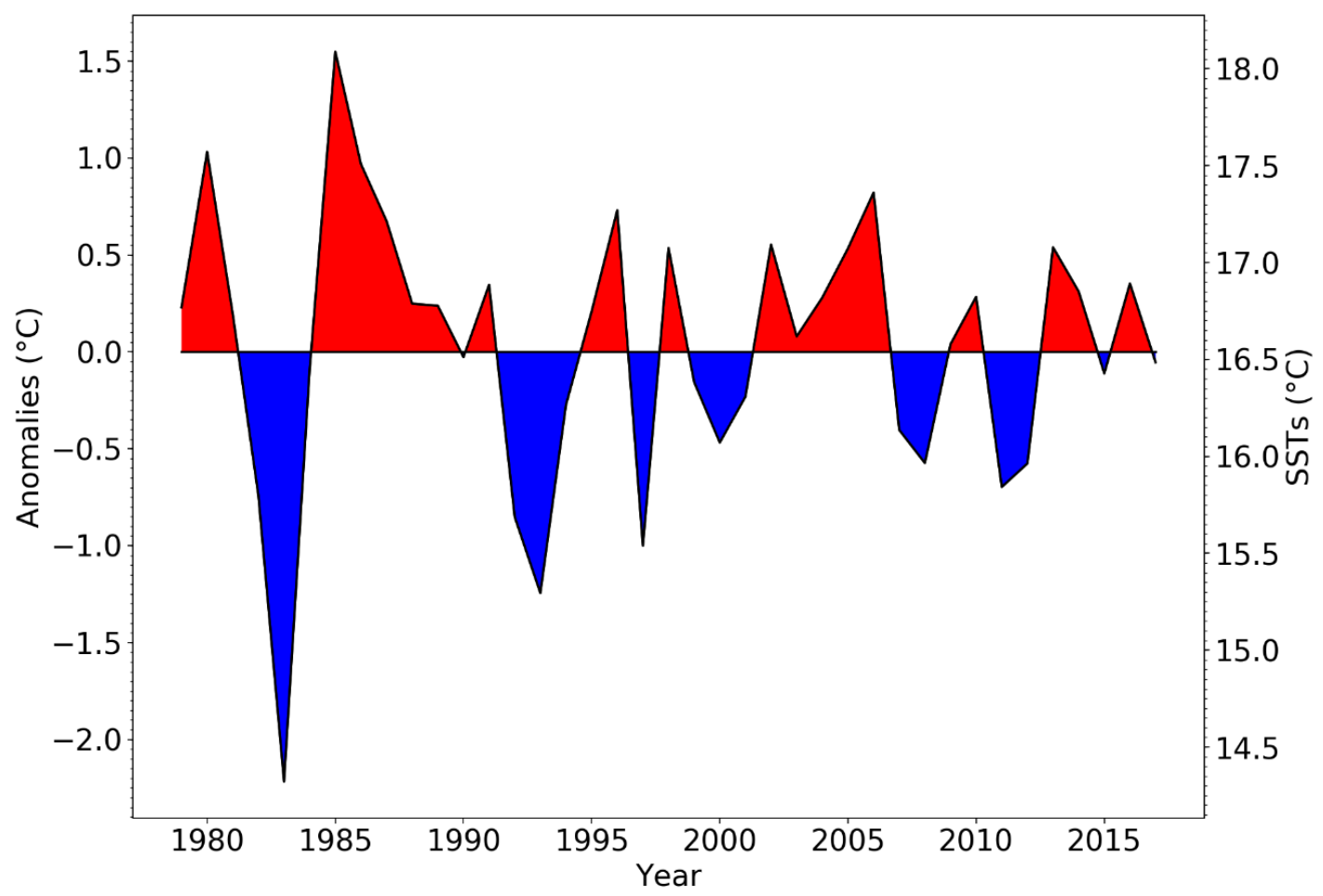

Figure 5.38: February SST anomalies for $39-49^{\circ} \mathrm{S}, 180-170^{\circ} \mathrm{W}$, near the Chatham Islands. The mean SST was $16.54{ }^{\circ} \mathrm{C}$ for $1981-2010$, the anomaly for 2014 was $0.31{ }^{\circ} \mathrm{C}$ and the mean anomaly for $2000-2017$ was $0.03{ }^{\circ} \mathrm{C}$. The last value is for 2017 . 


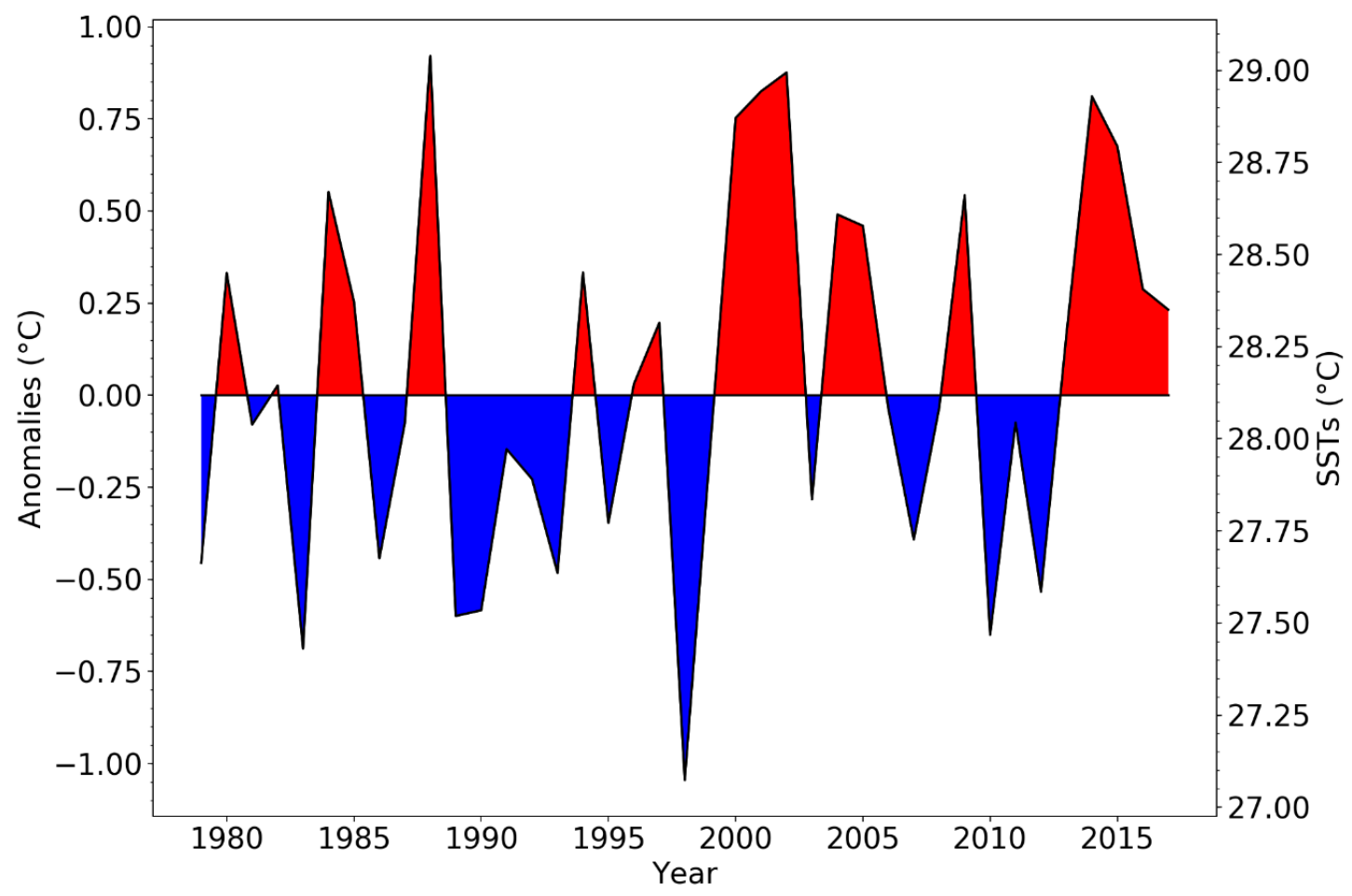

Figure 5.39: February SST anomalies for $15-25^{\circ} \mathrm{S}, 180-170^{\circ} \mathrm{W}$, near Tonga. The mean SST was $28.12^{\circ} \mathrm{C}$ for $1981-2010$, the anomaly for 2014 was $0.81{ }^{\circ} \mathrm{C}$ and the mean anomaly for 2000-2017 was $0.21^{\circ} \mathrm{C}$. The last value is for 2017 .

The high SSTs and quantities of water vapour content in the region of Tonga may have been important to the Christchurch rainfall event. As Trenberth et al. (2015, p.728) state "even a 10\% increase in moisture in the atmosphere becomes concentrated when focused by topography, and further amplified when on the ground as water drains into channels and rivers". While SSTs for the ocean domain near Tonga have been this high before (Figure 5.39), previous cases were generally part of much larger patterns associated with strong La Niña events as in 1988-1989 and 1999-2000 (Figure 5.40). During La Niña events, SSTs are usually warmer than normal across the western South Pacific. In 201314, the Oceanic Niño Index (ONI) was in a neutral phase such that neither El Niño nor La Niña conditions prevailed. Anomalously high SSTs in the region of Tonga may have played a role in feeding moisture into the Christchurch storm, via the passage of ETC Kofi. 


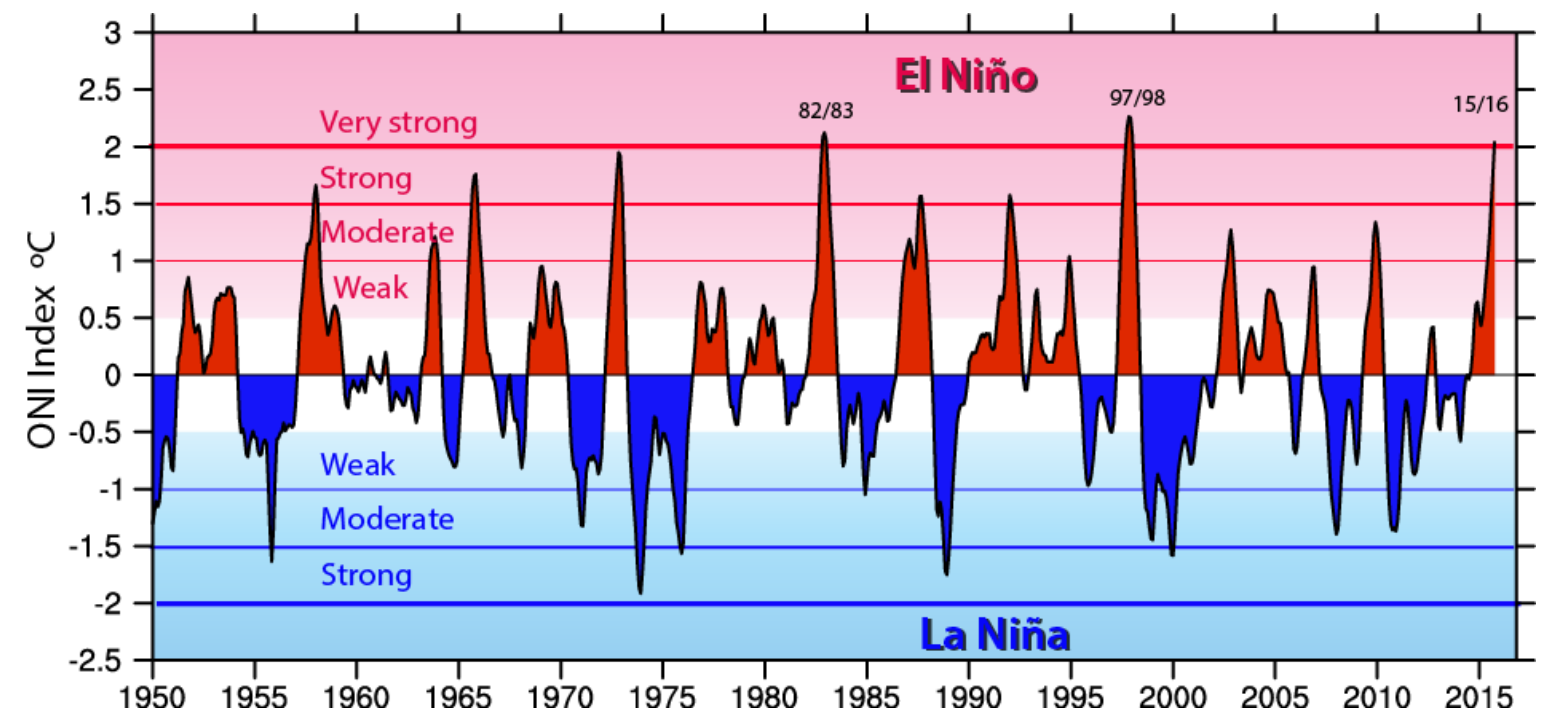

Figure 5.40: Time series of the Oceanic Niño Index (ONI, $\left.{ }^{\circ} \mathrm{C}\right)$ from 1950 to 2017. Very strong El Niño years are labelled (Trenberth, 2016). 


\subsection{Summary}

This chapter is one of the first New Zealand studies to incorporate a storyline approach to an attribution analysis, examining the role of various factors which contributed to the extreme 1-day rainfall event that occurred in Christchurch. Historical weather station observation trends, climate model simulations and reanalysis data support the idea of anthropogenic forcings increasing the likelihood and magnitude of March RX1D rainfalls.

This study has also been the first known NZ attribution study to embed sensitivity analysis within the study framework. In doing so it has provided insights by examining a highly localised (approximately $50 \mathrm{~km}^{2}$ ) and short duration (24-hr) class of extreme rainfall events which test the known capabilities of w@h ANZ. While previous attribution assessments have investigated longer RX3D - RX5D events over larger spatial domains, not many have assessed spatial sensitivity. This research found the use of larger spatial scales did not always generate larger FAR values. FAR was instead more sensitive to the designated threshold assessed. In our assessment, a significant FAR value of $27.4 \%$ was obtained for the extreme rainfall event of $4 / 5^{\text {th }}$ March 2014 in Christchurch.

Reanalysis data indicated SSTs to the south of the South Island were slightly below average in February/March, while to the north and east of New Zealand SSTs were up to $1{ }^{\circ} \mathrm{C}$ above average. Anomalously high SSTs in the tropical South Pacific are believed to have a played a role in feeding moisture into the storm that brought heavy rainfall to Christchurch in early March 2014. 


\section{CHAPTER 6 - CONCLUSIONS AND FUTURE WORK}

The focus of this thesis has been to assess the role of anthropogenic forcings in modifying New Zealand's weather and climate. A combination of observations, reanalysis fields and model output were examined using both a probabilistic event attribution and storyline framework to ascertain how weather and climate-related events have changed.

Very large ensembles of simulations from the global climate model weather@home Australia-New Zealand were compared under three different climate forcing conditions to ascertain how ozone forcings and anthropogenic forcings modified circulation and precipitation. Small $(<3 \mathrm{hPa})$ but significant changes in mean sea level pressure could be detected globally in response to altered ozone forcings. These changes were most pronounced during austral summer in the Southern Hemisphere and exhibited a clear seasonal response consistent with prior observation and model-based studies (Thompson et al., 2011). In high-latitude regions of the SH (approx. $60-65^{\circ} \mathrm{S}$ ), westerly winds were simulated to be $<1.0 \mathrm{~m} / \mathrm{s}$ stronger than otherwise due to ozone forcings, while in the midlatitudes $\left(\sim 45^{\circ} \mathrm{S}\right)$ westerly winds weaken by $<0.4 \mathrm{~m} / \mathrm{s}$. Rainfall patterns in NZ, as simulated for 2013, do not change significantly due to ozone forcings, though the first half of the year appears to be notably drier for the West Coast of the South Island before being wetter during the second half of the year. This is likely reflective of natural variability in the circulation (westerlies, storm track and the SAM) for the one year of simulation.

The event-specific attribution for an extreme one-day rainfall in Christchurch found multiple lines of evidence of increased likelihood for this class of events. The $130 \mathrm{~mm}$ March event of 2014 was unprecedented within the 134-year observational record and was estimated to have a March average recurrence interval of 1-in-300 years. The observational record suggests RX1D rainfall events greater than the $98^{\text {th }}$ percentile to have decreased $(-19 \%)$ in frequency, with the majority of this decrease occurring in austral summer (DJF) where a $-66 \%$ decrease in occurrence is observed. The very largest RX1D events in DJF meanwhile became significantly wetter $(+17 \%)$, despite decreasing magnitude and frequency for the entire population of DJF rainfall events. Such changes support documented trends associated with the SAM (Purich and Son, 2012) and a 
warmer atmosphere having greater maximum moisture holding capacity (Trenberth, 2015).W@h ANZ outputs detect a significant anthropogenic influence of increased risk for March RX1D rainfall events in Christchurch, a result which was seen across different spatial averaging areas and thresholds. The best estimate of the FAR for the class of event associated with this extreme event was 0.274 (ranging from $0.2-0.32$ ). However, the estimate of FAR was found to be sensitive to the attribution framing and choice of dataset as evidenced by differences between the Christchurch Gardens and VCSN estimates of FAR.

Simulations indicate a significant $8 \%$ increase in median March RX1D rainfall, though this was smaller than the $19 \%$ increase observed in historical records. The larger Chch4 spatial domain had closer agreement, predicting a 29\% increase in median March RX1D rainfall due to anthropogenic forcings. Most extreme rainfall events in Christchurch appear to be typified by synoptic conditions, much like those observed in early March 2014, with strong onshore winds and a deep low centred in close proximity. This provides further evidence of the ability of w@h ANZ to reproduce synoptic features of extreme rainfall events in NZ. Unique meteorological conditions in combination with anomalously high sea surface temperatures in the tropical South Pacific $\left(\sim 1{ }^{\circ} \mathrm{C}\right.$ warmer than climatological average) were likely important to the occurrence of this extreme event. Global warming may have been associated with the anomalously high SSTs, given they occur during a neutral phase of ENSO in addition to February/March SSTs consistently averaging more than $0.2{ }^{\circ} \mathrm{C}$ higher than climatological mean since 1999 . These results reiterate the importance of understanding the physical processes that give rise to individual extreme precipitation events given the challenges climate models have in robustly simulating the dynamical component of climate change (Diffenbaugh et al., 2017).

\subsection{Future avenues}

Given the challenges in our ability to detect, understand and model dynamical components of our climate system, future investigations should aim to constrain additional aspects of uncertainty. Incorporation of multiple lines of observational evidence in addition to SSTs via a storyline framework would help to ensure results are 
grounded in physical credibility, though as identified in this study, the framing and choice of dataset used for threshold designation are important considerations. Future analysis would benefit from having multi-year simulations for the identification and apportioning of multi-year trends related to the various components of anthropogenic forcings. This may help to better distinguish anthropogenic changes from natural variability. An interesting use of w@h ANZ's current capability would be to assess how extremes in 2013 respond to ozone forcings in isolation following similar procedures as performed in the Christchurch extreme rainfall event.

Future work may also seek to apply a quantitative framework to better understand the changing patterns of circulation regarding extreme precipitation events. This may include the use of self-organising maps to analyse the synoptic situations responsible for extreme rainfall events in the study region and how they are varying (both from observation and modelled data). Attribution studies are now exploring the application of higher resolution iterations of weather@home (Guillod et al., 2017) and/or coupled climate models in extreme event evaluation (Stott et al., 2016). Such studies are however constrained by computational processing requirements, particularly when attempting to resolve a fullydynamic ocean. While distributed computing has expanded opportunities for the creation of large simulation datasets, the drive to increasingly high-resolution simulations and increasing complexity in models may constrain the size of future ensembles that can be generated. 


\section{REFERENCES}

Abram, N. J., Mulvaney, R., Vimeux, F., Phipps, S. J., Turner, J., and England, M. H. (2014). Evolution of the Southern Annular Mode during the past millennium. Nature Climate Change, 4(7), 1-6. https://doi.org/10.1038/NCLIMATE2235

Ailliot, P., Thompson, C., and Thomson, P. (2011). Mixed methods for fitting the GEV distribution. Water Resources Research, 47(5), 1-14. https://doi.org/10.1029/2010WR009417

Alexander, L. V., Zhang, X., Peterson, T. C., Caesar, J., Gleason, B., Klein Tank, A. M. G., Haylock, M., Collins, D., Trewin, B., Rahimzadeh, F., and Coauthors. (2006). Global observed changes in daily climate extremes of temperature and precipitation. Journal of Geophysical Research, 111(D05109), 1-22. https://doi.org/10.1029/2005JD006290

Allan, R. P., and Soden, B. J. (2008). Atmospheric Warming and the Amplification of Precipitation Extremes. Science, 321(5895), 1481-1484. https://doi.org/10.1126/science.1160787

Allen, M. R. (1999). Do-it-yourself climate prediction. Nature, 401(6754), 642. https://doi.org/10.1038/44266

Allen, M. R. (2003). Liability for climate change. Nature, 421(6926), 891-892. https://doi.org/10.1038/421891a

Allen, M. R., and Stott, P. A. (2003). Estimating signal amplitudes in optimal fingerprinting, part I: Theory. Climate Dynamics, 21(5-6), 477-491. https://doi.org/10.1007/s00382-003-0313-9

Anderson, D. P. (2004). BOINC: A system for public-resource computing and storage. Proceedings - IEEE/ACM International Workshop on Grid Computing, 4-10. https://doi.org/10.1109/GRID.2004.14

Angélil, O., Stone, D. A., Tadross, M., Tummon, F., Wehner, M., and Knutti, R. (2014). Attribution of extreme weather to anthropogenic greenhouse gas emissions: Sensitivity to spatial and temporal scales. Geophysical Research Letters, 41(6), 2150-2155. https://doi.org/10.1002/2014GL059234

Angélil, O., Stone, D. A., Wehner, M., Paciorek, C. J., Krishnan, H., and Collins, W. (2017). An independent assessment of anthropogenic attribution statements for recent extreme temperature and rainfall events. Journal of Climate, 30(1), 5-16. https://doi.org/10.1175/JCLI-D-16-0077.1

Arblaster, J. M., and Meehl, G. A. (2006). Contributions of external forcings to southern annular mode trends. Journal of Climate, 19(12), 2896-2905. https://doi.org/10.1175/JCLI3774.1 
Arblaster, J. M., Meehl, G. A., and Karoly, D. J. (2011). Future climate change in the Southern Hemisphere: Competing effects of ozone and greenhouse gases. Geophysical Research Letters, 38(2), 1-6. https://doi.org/10.1029/2010GL045384

Arnell, N. W., Beran, M., and Hosking, J. R. M. (1986). Unbiased plotting positions for the general extreme value distribution. Journal of Hydrology, 86(1-2), 59-69. https://doi.org/10.1016/0022-1694(86)90006-5

Bandoro, J., Solomon, S., Donohoe, A., Thompson, D. W. J., and Santer, B. D. (2014). Influences of the Antarctic ozone hole on Southern Hemispheric summer climate change. Journal of Climate, 27(16), 6245-6264. https://doi.org/10.1175/JCLI-D13-00698.1

Bengtsson, L., Hodges, K. I., and Keenlyside, N. (2009). Will Extratropical Storms Intensify in a Warmer Climate? Journal of Climate, 22(9), 2276-2301. https://doi.org/10.1175/2008JCLI2678.1

Bergaoui, K., Mitchell, D., Otto, F., Allen, M., Zaaboul, R., and McDonnell, R. (2015). The contribution of human-induced climate change to the drought of 2014 in the southern Levant region [in "Explaining extreme events of 2014 from a climate perspective"]. Bulletin of the American Meteorological Society, 96(12), S66-S70. https://doi.org/10.1175/BAMS-D-15-00129.1

Bertail, P. (1997). Second-Order Properties of an Extrapolated Bootstrap without Replacement under Weak Assumptions. Bernoulli, 3(2), 149-179. https://doi.org/10.2307/3318585

Bindoff, N. L., Stott, P. A., AchutaRao, K. M., Allen, M. R., Gillett, N., Gutzler, D., Hansingo, K., Heger, G., Hu, Y., Jain, S., Mokhov, I. I., and Coauthors. (2013). Detection and Attribution of Climate Change: from Global to Regional. Climate Change 2013: The Physical Science Basis. Contribution of Working Group I to the Fifth Assessment Report of the Intergovernmental Panel on Climate Change [Stocker, T.F., D. Qin, G.-K. Plattner, M. Tignor, S.K. Allen, J. Boschung, A. Nauels, Y. Xia, 1217-1308. https://doi.org/10.1017/CBO9781107415324.028

Black, M. T., and Karoly, D. J. (2016). Southern Australia's warmest October on record: the role of ENSO and climate change [in "Explaining extreme events of 2015 from a climate perspective"]. Bulletin of the American Meteorological Society, 97(12), S118-S121. https://doi.org/10.1175/BAMS-D-16-0124.1

Black, M. T., Karoly, D., J., and King, A. D. (2015). The contribution of anthropogenic forcing to the Adelaide and Melbourne, Australia, heat waves of January 2014 [in "Explaining extreme events of 2014 from a climate perspective"]. Bulletin of the American Meteorological Society, 96(12), S145-S148.

https://doi.org/10.1175/BAMS-D-15-00097.1 
Black, M. T., Karoly, D. J., Rosier, S. M., Dean, S. M., King, A. D., Massey, N. R., Sparrow, S. N., Bowery, A., Wallom, D., Jones, R. G., Otto, F. E. L., and Allen, M. R. (2016). The weather@home regional climate modelling project for Australia and New Zealand. Geoscientific Model Development, 9(9), 3161-3176.

https://doi.org/10.5194/gmd-9-3161-2016

Black, M. T. (2017). An attribution study of southeast Australian wildfire risk (Doctoral dissertation). Retrieved on March 25, 2018 from https://minervaaccess.unimelb.edu.au/handle/11343/123669

Chou, C., Neelin, J. D., Chen, C. A., and Tu, J. Y. (2009). Evaluating the "rich-getricher" mechanism in tropical precipitation change under global warming. Journal of Climate, 22(8), 1982-2005. https://doi.org/10.1175/2008JCLI2471.1

Christidis, N., Stott, P. A., Scaife, A. A., Arribas, A., Jones, G. S., Copsey, D., Knight, J.R. and Tennant, W. J. (2013). A new HADGEM3-a-based system for attribution of weather- and climate-related extreme events. Journal of Climate, 26(9), 27562783. https://doi.org/10.1175/JCLI-D-12-00169.1

Coles, S. (2001). An Introduction to Statistical Modeling of Extreme Values. London: Springer.

Cook, N. (2011). Comments on "plotting positions in extreme value analysis." Journal of Applied Meteorology and Climatology, 50(1), 255-266. https://doi.org/10.1175/2010JAMC2316.1

Cubasch, U., Wuebbles, D., Chen, D., Facchini, M. C., Frame, D., Mahowald, N., and Winther, J.-G. (2013). Introduction in Climate Change 2013. Intergovernmental Panel on Climate Change 2013: The Physical Science Basis. Contribution of Working Group I to the Fifth Assessment Report of the Intergovernmental Panel on Climate Change, 119-158. https://doi.org/10.1017/CBO9781107415324.007

Cunnane, C. (1978). Unbiased plotting positions - A review. Journal of Hydrology, 37(3-4), 205-222. https://doi.org/10.1016/0022-1694(78)90017-3

De Noblet-Ducoudré, N., Boisier, J. P., Pitman, A., Bonan, G. B., Brovkin, V., Cruz, F., Delire, C., Gayler, V., Van den Hurk, B. J. J. M., Lawrence, P. J., van der Molen, M. K., and Coauthors. (2012). Determining robust impacts of land-use-induced land cover changes on surface climate over North America and Eurasia: Results from the first set of LUCID experiments. Journal of Climate, 25(9), 3261-3281. https://doi.org/10.1175/JCLI-D-11-00338.1

Dee, D. P., Uppala, S. M., Simmons, A. J., Berrisford, P., Poli, P., Kobayashi, S., Andrae, U., Balmaseda, M. A., Balsamo, G., Bauer, P., Bechtold, P., and Coauthors. (2011). The ERA-Interim reanalysis: Configuration and performance of the data assimilation system. Quarterly Journal of the Royal Meteorological Society, 137(656), 553-597. https://doi.org/10.1002/qj.828 
Deser, C., Phillips, A. S., Alexander, M. A., and Smoliak, B. V. (2014). Projecting North American climate over the next 50 years: Uncertainty due to internal variability. Journal of Climate, 27(6), 2271-2296. https://doi.org/10.1175/JCLI-D13-00451.1

Deser, C., Phillips, A., Bourdette, V., and Teng, H. (2012). Uncertainty in climate change projections: the role of internal variability. Climate Dynamics, 38(3-4), 527-546. https://doi.org/10.1007/s00382-010-0977-x

Diffenbaugh, N. S., and Scherer, M. (2011). Observational and model evidence of global emergence of permanent, unprecedented heat in the 20th and 21st centuries. Climatic Change, 107(3), 615-624. https://doi.org/10.1007/s10584-011-0112-y

Diffenbaugh, N. S., Singh, D., Mankin, J. S., Horton, D. E., Swain, D. L., Touma, D., Charland, A., Liu, Y., Haugen, M., Tsiang, M., Rajaratnam, B., and Coauthors. (2017). Quantifying the influence of global warming on unprecedented extreme climate events. Proceedings of the National Academy of Sciences, 1-6. https://doi.org/10.1073/pnas.1618082114

Dole, R., Hoerling, M., Perlwitz, J., Eischeid, J., Pegion, P., Zhang, T., Quan, X. W., $\mathrm{Xu}, \mathrm{T}$., and Murray, D. (2011). Was there a basis for anticipating the 2010 Russian heat wave? Geophysical Research Letters, 38(6), 1-5. https://doi.org/10.1029/2010GL046582

Dong, B., Sutton, R. T., Shaffrey, L. and Klingaman, N. P. (2017). Attribution of forced decadal climate change in coupled and uncoupled ocean-atmosphere model experiments. Journal of Climate, JCLI-D-16-0578.1. https://doi.org/10.1175/JCLID-16-0578.1

Donlon, C. J., Martin, M., Stark, J., Roberts-Jones, J., Fiedler, E., and Wimmer, W. (2012). The Operational Sea Surface Temperature and Sea Ice Analysis (OSTIA) system. Remote Sensing of Environment, 116, 140-158. https://doi.org/10.1016/j.rse.2010.10.017

Draxler, R. R., and Hess, G. D. (1998). An Overview of the HYSPLIT_4 Modelling System for Trajectories, Dispersion, and Deposition. Australian Meteorological Magazine, 47(February), 295-308.

Earth System Research Laboratory (ESRL) Global Monitoring Division, National Oceanic and Atmospheric Administration. (2017). The NOAA Annual Greenhouse Gas Index, published online April 2017, retrieved on March 26, 2018. https://www.esrl.noaa.gov/gmd/aggi/aggi.html

Easterling, D. R., Meehl, G. A., Parmesan, C., Chagnon, S. A., Karl, T. R., and Mearns, L. O. (2000). Climate Extremes: Observations, Modeling, and Impacts. Science, 289(5487), 2068-2074. https://doi.org/10.1126/science.289.5487.2068

Emori, S., and Brown, S. J. (2005). Dynamic and thermodynamic changes in mean and extreme precipitation under changed climate. Geophysical Research Letters, 32(17), 1-5. https://doi.org/10.1029/2005GL023272 
Feldstein, S. B. (2000). The timescale, power spectra, and climate noise properties of teleconnection patterns. Journal of Climate, 13(24), 4430-4440. https://doi.org/10.1175/1520-0442(2000)013<4430:TTPSAC $>2.0 . C O ; 2$

Fischer, E. M., and Knutti, R. (2015). Anthropogenic contribution to global occurrence of heavy-precipitation and high-temperature extremes. Nature Climate Change, 5(6), 560-564. https://doi.org/10.1038/nclimate2617

Fogt, R. L., Perlwitz, J., Monaghan, A. J., Bromwich, D. H., Jones, J. M., and Marshall, G. J. (2009). Historical SAM variability. Part II: Twentieth-century variability and trends from reconstructions, Observations, and the IPCC AR4 models. Journal of Climate, 22(20), 5346-5365. https://doi.org/10.1175/2009JCLI2786.1

Fyfe, J. C., Gillett, N. P., and Marshall, G. J. (2013). Human influence on extratropical Southern Hemisphere summer precipitation. Geophysical Research Letters, 39(23), 1-5. https://doi.org/10.1029/2012GL054199

Gillett, N. P., Fyfe, J. C., and Parker, D. E. (2013). Attribution of observed sea level pressure trends to greenhouse gas, aerosol, and ozone changes. Geophysical Research Letters, 40(10), 2302-2306. https://doi.org/10.1002/grl.50500

Gillett, N. P., and Stott, P. A. (2009). Attribution of anthropogenic influence on seasonal sea level pressure. Geophysical Research Letters, 36(23), L23709. https://doi.org/10.1029/2009GL041269

Gillett, N. P., and Thompson, D. W. J. (2003). Simulation of Recent Southern Hemisphere Climate Change. Science, 302(5643), 273-275. https://doi.org/10.1126/science.1087440

Giorgi, F., Im, E. S., Coppola, E., Diffenbaugh, N. S., Gao, X. J., Mariotti, L., and Shi, Y. (2011). Higher hydroclimatic intensity with global warming. Journal of Climate, 24(20), 5309-5324. https://doi.org/10.1175/2011JCLI3979.1

Gong, D., and Wang, S. (1999). Definition of Antarctic oscillation index. Geophysical Research Letters, 26(4), 459-462. https://doi.org/10.1029/1999GL900003

Greenwood, J. A., Landwehr, J. M., Matalas, N. C., and Wallis, J. R. (1979). Probability weighted moments: Definition and relation to parameters of several distributions expressable in inverse form. Water Resources Research, 15(5), 1049-1054. https://doi.org/10.1029/WR015i005p01049

Griffiths, G. A., McKerchar, A. I., and Pearson, C. P. (2014). Towards prediction of extreme rainfalls in New Zealand. Journal of Hydrology (NZ), 53(1), 41-52.

Griffiths, G. A., and Pearson, C. P. (1993). Distribution of high intensity rainfalls in metropolitan Christchurch, New Zealand. Journal of Hydrology (NZ), 31(1), 5-22

Griffiths, G., Pearson, C. P., and McKerchar, A. (2009). Review of the frequency of high intensity rainfalls in Christchurch. Report CHC2009-139, National Institute of Water and Atmospheric Research Ltd, Christchurch, New Zealand, 26 p. 
Gringorten, I. I. (1963). A plotting rule for extreme probability paper. Journal of Geophysical Research, 68(3), 813-814. https://doi.org/10.1029/JZ068i003p00813

Grise, K. M., Son, S. W., Correa, G. J. P., and Polvani, L. M. (2014). The response of extratropical cyclones in the Southern Hemisphere to stratospheric ozone depletion in the 20th century. Atmospheric Science Letters, 15(1), 29-36. https://doi.org/10.1002/asl2.458

Grise, K. M., Thompson, D. W. J., and Forster, P. M. (2009). On the Role of Radiative Processes in Stratosphere-Troposphere Coupling. Journal of Climate, 22(15), 4154-4161. https://doi.org/10.1175/2009JCLI2756.1

Grose, M., Black, M., Risbey, J., and Karoly, D. (2015). Attribution of exceptional mean sea level pressure anomalies south of Australia in August 2014 [in "Explaining extreme events of 2014 from a climate perspective"]. Bulletin of the American Meteorological Society, 96(12), S158-S162. https://doi.org/10.1175/BAMS-D-15-00116.1

Guillod, B. P., Bowery, A., Haustein, K., Jones, R. G., Massey, N. R., Mitchell, D. M., Otto, F. E., Sparrow, S. N., Uhe, P., Wallom, D. C., Wilson, S., and Allen, M. R. (2017). Weather@Home 2: Validation of an Improved Global-Regional Climate Modelling System. Geoscientific Model Development Discussions, 10(5), 18491872. https://doi.org/10.5194/gmd-10-1849-2017

Gumbel, E. J. (1958). Statistics of Extremes. Columbia University Press, New York, $375 \mathrm{p}$.

Gupta, A. Sen, and England, M. H. (2006). Coupled ocean-atmosphere-ice response to variations in the southern annular mode. Journal of Climate, 19(18), 4457-4486. https://doi.org/10.1175/JCLI3843.1

Harrington, L. J. (2017). Novel approaches to quantify the emergence of anthropogenic climate change (Doctoral dissertation). Retrieved on March 25, 2018 from http://hdl.handle.net/10063/6587

Hawkins, E., and Sutton, R. (2009). The potential to narrow uncertainty in regional climate predictions. Bulletin of the American Meteorological Society, 90(8), 10951107. https://doi.org/10.1175/2009BAMS2607.1

Haynes, P. H., McIntyre, M. E., Shepherd, T. G., Marks, C. J., and Shine, K. P. (1991). On the "Downward Control" of Extratropical Diabatic Circulations by EddyInduced Mean Zonal Forces. Journal of the Atmospheric Sciences. https://doi.org/10.1175/1520-0469(1991)048<0651:OTCOED>2.0.CO;2

Hegerl, G., and Zwiers, F. (2011). Use of models in detection and attribution of climate change. Wiley Interdisciplinary Reviews: Climate Change, 2(4), 570-591. https://doi.org/10.1002/wcc.121 
Held, I. M., and Soden, B. J. (2006). Robust Responses of the Hydrological Cycle to Global Warming. Journal of Climate, 19(21), 5686-5699.

https://doi.org/10.1175/JCLI3990.1

Hendon, H. H., Lim, E. P., and Nguyen, H. (2014). Seasonal variations of subtropical precipitation associated with the southern annular mode. Journal of Climate, 27(9), 3446-3460. https://doi.org/10.1175/JCLI-D-13-00550.1

Hewitson, B., and Crane, R. (2002). Self-organizing maps: applications to synoptic climatology. Climate Research, 22(1), 13-26. https://doi.org/10.3354/cr022013

Hoerling, M., Kumar, A., Dole, R., Nielsen-Gammon, J. W., Eischeid, J., Perlwitz, J., Quan, X. W., Zhang, T., Pegion, P. and Chen, M. (2013). Anatomy of an extreme event. Journal of Climate, 26(9), 2811-2832. https://doi.org/10.1175/JCLI-D-1200270.1

Holton, J. R. and Hakim, G. J. (2013). An Introduction to Dynamic Meteorology. Academic Press, Oxford, 519 p.

Hosking, J. R. M., Wallis, J. R., and Wood, E. F. (1985). Estimation of the generalized value distribution by the method of moments. Technometrics, 27(3), 251-261. https://doi.org/10.1080/00401706.1985.10488049

Hunter, J. D. (2007). Matplotlib: A 2D graphics environment. Computing in Science and Engineering, 9(3), 99-104. https://doi.org/10.1109/MCSE.2007.55

Intergovernmental Panel on Climate Change (IPCC). (2012). Managing the risks of extreme events and disasters to advance climate change adaptation. A special report of working groups I and II of the Intergovernmental Panel on Climate Change [Edited by Field, C. B., Barros, V. R., and Coeditors]. Cambridge University Press, Cambridge, United Kingdom, 585 p.

Intergovernmental Panel on Climate Change (IPCC). (2013). Climate Change 2013: The Physical Science Basis. Contribution of Working Group I to the Fifth Assessment Report of the Intergovernmental Panel on Climate Change [Edited by Stocker, T. F., Qin, D., and Coeditors]. Cambridge University Press, Cambridge, United Kingdom, 1535 p.

Intergovernmental Panel on Climate Change (IPCC). (2014). Climate Change 2014: Impacts, Adaptation, and Vulnerability. Part A: Global and Sectoral Aspects. Contribution of Working Group II to the Fifth Assessment Report of the Intergovernmental Panel on Climate Change [Edited by Field, C. B., Barros, V. R., and Coeditors]. Cambridge University Press, Cambridge, United Kingdom, $1132 \mathrm{p}$.

Jenkinson, A. F. (1955). The frequency distribution of the annual maximum (or minimum) values of meteorological elements. Quarterly Journal of the Royal Meteorological Society, 81(348), 158-171.

https://doi.org/10.1002/qj.49708134804 
Jensen, J. (2000). Remote sensing of the environment: An earth resource perspective. Upper Saddle River, N.J.: Prentice Hall.

Jones, R. G., Noguer, M., Hassell, D. C., Hudson, D., Wilson, S. S., Jenkins, G. J., and Mitchell, J. F. B. (2004). Generating high resolution climate change scenarios using PRECIS. Met Office Hadley Centre, Exeter, United Kingdom, 40 p.

Kang, S. M., Polvani, L. M., Fyfe, J. C., and Sigmond, M. (2011). Impact of Polar Ozone Depletion on Subtropical Precipitation. Science, 332(6032), 951-954. https://doi.org/10.1126/science.1202131

Kang, S. M., Polvani, L. M., Fyfe, J. C., Son, S. W., Sigmond, M., and Correa, G. J. P. (2013). Modeling evidence that ozone depletion has impacted extreme precipitation in the austral summer. Geophysical Research Letters, 40(15), 40544059. https://doi.org/10.1002/grl.50769

Karoly, D. J., Black., M. T., Grose, M. R., and King, A. D. (2016). The roles of climate change and El Niño in the record low rainfall in October 2015 in Tasmania, Australia [in "Explaining extreme events of 2015 from a climate perspective"]. Bulletin of the American Meteorological Society, 97(12), S127S130. https://doi.org/10.1175/BAMS-D-16-0139.1

Kharin, V. V., Zwiers, F. W., Zhang, X., and Hegerl, G. C. (2007). Changes in temperature and precipitation extremes in the IPCC ensemble of global coupled model simulations. Journal of Climate, 20(8), 1419-1444. https://doi.org/10.1175/JCLI4066.1

King, A. D., Black, M. T., Min, S. K., Fischer, E. M., Mitchell, D. M., Harrington, L. J., and Perkins-Kirkpatrick, S. E. (2016). Emergence of heat extremes attributable to anthropogenic influences. Geophysical Research Letters, 43(7), 3438-3443. https://doi.org/10.1002/2015GL067448

King, A. D., Black, M. T., Karoly, D. J., and Donat, M. G. (2015). Increased likelihood of Brisbane, Australia, G20 heat event due to anthropogenic climate change [in "Explaining extreme events of 2014 from a climate perspective"]. Bulletin of the American Meteorological Society, 96(12), S141-S144. https://doi.org/10.1175/BAMS-D-15-00098.1

Kohonen, T. (1990). The self-organizing map. Proceedings of the IEEE, 78(9), 14641480. https://doi.org/10.1109/5.58325

Le Coz, J., Patalano, A., Collins, D., Guillén, N. F., García, C. M., Smart, G. M., Bind, J., Chiaverini, A., Le Boursicaud, R., Dramais, G., and Braud, I. (2016).

Crowdsourced data for flood hydrology: Feedback from recent citizen science projects in Argentina, France and New Zealand. Journal of Hydrology, 541, 766777. https://doi.org/10.1016/j.jhydrol.2016.07.036 
Le Treut, H. (2007). Historical overview of climate change. Climate Change 2007: The Physical Science Basis. Contribution of Working Group I to the Fourth Assessment Report of the Intergovernmental Panel on Climate Change. Cambridge University Press, Cambridge, United Kingdom, 94-127.

Lee, S., and Feldstein, S. B. (2013). Detecting Ozone- and Greenhouse Gas-Driven Wind Trends with Observational Data. Science, 339(6119), 563-567. https://doi.org/10.1126/science.1225154

Lilliefors, H. W. (1967). On the Kolmogorov-Smirnov Test for Normality with Mean and Variance Unknown. Journal of the American Statistical Association, 62(318), 399. https://doi.org/10.2307/2283970

Lim, E. P., Hendon, H. H., Arblaster, J. M., Delage, F., Nguyen, H., Min, S. K., and Wheeler, M. C. (2016). The impact of the Southern Annular Mode on future changes in Southern Hemisphere rainfall. Geophysical Research Letters, 43(13), 7160-7167. https://doi.org/10.1002/2016GL069453

Lorenz, E. N. (1963). Deterministic Nonperiodic Flow. Journal of the Atmospheric Sciences. https://doi.org/10.1175/1520-0469(1963)020<0130:DNF $>2.0 . C O ; 2$

Lorrey, A. M., Griffiths, G., Fauchereau, N., Diamond, H. J., Chappell, P. R., and Renwick, J. (2014). An ex-tropical cyclone climatology for Auckland, New Zealand. International Journal of Climatology, 34(4), 1157-1168. https://doi.org/10.1002/joc.3753

Lucas, C., and Nguyen, H. (2015). Regional characteristics of tropical expansion and the role of climate variability. Journal of Geophysical Research: Atmospheres, 120(14), 6809-6824. https://doi.org/10.1002/2015JD023130

Madden, R. A. (1976). Estimates of the Natural Variability of Time-Averaged SeaLevel Pressure. Monthly Weather Review, 104(7), 942-952. https://doi.org/10.1175/1520-0493(1976)104<0942:EOTNVO>2.0.CO;2

Mahmood, R., Pielke, R. A., Hubbard, K. G., Niyogi, D., Dirmeyer, P. A., McAlpine, C., Carleton, A. M., Hale, R., Gameda, S., Beltran-Przekurat, , Baker, B., and Coauthors. (2014). Land cover changes and their biogeophysical effects on climate. International Journal of Climatology, 34(4), 929-953. https://doi.org/10.1002/joc.3736

Marshall, G. J. (2003). Trends in the Southern Annular Mode from Observations and Reanalyses. Journal of Climate, 16(24), 4134-4143. https://doi.org/10.1175/15200442(2003)016<4134:TITSAM>2.0.CO;2

Massey, F. J. (1951). The Kolmogorov-Smirnov Test for Goodness of Fit. Journal of the American Statistical Association, 46(253), 68. https://doi.org/10.2307/2280095 
Massey, N., Jones, R., Otto, F. E. L., Aina, T., Wilson, S., Murphy, J. M., Hassell, D., Yamazaki, Y. H., and Allen, M. R. (2015).Weather@Home-Development and Validation of a Very Large Ensemble Modelling System for Probabilistic Event Attribution. Quarterly Journal of the Royal Meteorological Society, 141(690), 1528-1545. https://doi.org/10.1002/qj.2455

Mayewski, P. A., Bracegirdle, T., Goodwin, I., Schneider, D., Bertler, N. A. N., Birkel, S., Carleton, A., England, M. H., Kang, J. H., Khan, A., Russell, J., and Coauthors. (2015). Potential for Southern Hemisphere climate surprises. Journal of Quaternary Science, 30(5), 391-395. https://doi.org/10.1002/jqs.2794

McKerchar, A. I., and Pearson, C. P. (1989). Flood frequency in New Zealand. Christchurch: DSIR Division of Water Sciences Hydrology Centre, 87 p.

McLandress, C., Shepherd, T. G., Scinocca, J. F., Plummer, D. A., Sigmond, M., Jonsson, A. I., and Reader, M. C. (2011). Separating the dynamical effects of climate change and ozone depletion. Part II: Southern Hemisphere troposphere. Journal of Climate, 24(6), 1850-1868. https://doi.org/10.1175/2010JCLI3958.1

Mitchell, D., Heaviside, C., Vardoulakis, S., Huntingford, C., Masato, G., P Guillod, B., Frumhoff, P., Bowery, A., Wallom, D., and Allen, M. (2016). Attributing human mortality during extreme heat waves to anthropogenic climate change. Environmental Research Letters, 11(7), 74006. https://doi.org/10.1088/17489326/11/7/074006

Min, S.-K., Zhang, X., Zwiers, F. W., and Hegerl, G. C. (2011). Human contribution to more-intense precipitation extremes. Nature, 470(7334), 378-381. https://doi.org/10.1038/nature09763

Moise, A., Wilson, L., Grose, M., Whetton, P., Watterson, I., Bhend, J., Bathols, J., Hanson, L., Erwin, T., Bedin, T., Heady, C., and Coauthors. (2015). Evaluation of CMIP3 and CMIP5 Models over the Australian Region to Inform Confidence in Projections. Australian Meteorological and Oceanographic Journal, 65(1), 19-53. https://doi.org/10.22499/2.6501.004

Mullan, B., Sood, A., and Stuart, S. (2016). Climate Change Projections for New Zealand: Atmosphere Projections Based on Simulations for the IPCC Fifth Assessment. Wellington: Ministry for the Environment.

National Academies of Sciences, Engineering, and Medicine (NASEM). (2016). Attribution of Extreme Weather Events in the Context of Climate Change. Washington, D.C.: National Academies Press, 186 p. https://doi.org/10.17226/21852

National Institute of Water and Atmospheric Research (NIWA). (2014). News \& publications: Flood in Pictures, published online May 2014, retrieved on March 25, 2018 from https://www.niwa.co.nz/publications/wa/water-atmosphere-10-april2014/flood-in-pictures 
Orr, A., Bracegirdle, T. J., Hosking, J. S., Jung, T., Haigh, J. D., Phillips, T., and Feng, W. (2012). Possible Dynamical Mechanisms for Southern Hemisphere Climate Change due to the Ozone Hole. Journal of the Atmospheric Sciences, 69(10), 2917-2932. https://doi.org/10.1175/JAS-D-11-0210.1

Otto, F. E. L., Massey, N., Van Oldenborgh, G. J., Jones, R. G., and Allen, M. R. (2012). Reconciling two approaches to attribution of the 2010 Russian heat wave. Geophysical Research Letters, 39(4), 1-5. https://doi.org/10.1029/2011GL050422

Otto, F. E. L., Rosier, S. M., Allen, M. R., Massey, N. R., Rye, C. J., and Quintana, J. I. (2015). Attribution analysis of high precipitation events in summer in England and Wales over the last decade. Climatic Change, 132(1), 77-91. https://doi.org/10.1007/s10584-014-1095-2

Pall, P., Aina, T., Stone, D. A., Stott, P. A., Nozawa, T., Hilberts, A. G. J., Lohmann, D., and Allen, M. R. (2011). Anthropogenic greenhouse gas contribution to flood risk in England and Wales in autumn 2000. Nature, 470(7334), 382-385. https://doi.org/10.1038/nature09762

Pearson, C. P., and Henderson, R. D. (1998). Frequency distributions of annual maximum storm rainfalls in New Zealand. Journal of Hydrology (NZ)

Peterson, T. C., and Manton, M. J. (2008). Monitoring changes in climate extremes: A tale of international collaboration. Bulletin of the American Meteorological Society, 89(9), 1266-1271. https://doi.org/10.1175/2008BAMS2501.1

Pielke, R. A., Pitman, A., Niyogi, D., Mahmood, R., McAlpine, C., Hossain, F., Goldewijk, K. K., Nair, U., Betts, R., Fall, S., Reichstein, M., and Coauthors. (2011). Land use/land cover changes and climate: Modeling analysis and observational evidence. Wiley Interdisciplinary Reviews: Climate Change, 2(6), 828-850. https://doi.org/10.1002/wcc. 144

Pitman, A. J., De Noblet-Ducoudré, N., Cruz, F. T., Davin, E. L., Bonan, G. B., Brovkin, V., Claussen, M., Delire, C., Ganzeveld, L., Gayler, V., van den Hurk, B. J. J. M., and Coauthors. (2009). Uncertainties in climate responses to past land cover change: First results from the LUCID intercomparison study. Geophysical Research Letters, 36(14), 1-6. https://doi.org/10.1029/2009GL039076

Polvani, L. M., Waugh, D. W., Correa, G. J. P., and Son, S.-W. (2011). Stratospheric Ozone Depletion: The Main Driver of Twentieth-Century Atmospheric Circulation Changes in the Southern Hemisphere. Journal of Climate, 24(3), 795-812. https://doi.org/10.1175/2010JCLI3772.1

Pope, V. D., Gallani, M. L., Rowntree, P. R., and Stratton, R. A. (2000). The impact of new physical parametrizations in the Hadley Centre climate model: HadAM3. Climate Dynamics, 16(2-3), 123-146. https://doi.org/10.1007/s003820050009

Previdi, M., and Polvani, L. M. (2014). Climate system response to stratospheric ozone depletion and recovery. Quarterly Journal of the Royal Meteorological Society, 140(685), 2401-2419. https://doi.org/10.1002/qj.2330 
Purich, A., and Son, S. W. (2012). Impact of Antarctic ozone depletion and recovery on Southern Hemisphere precipitation, evaporation, and extreme changes. Journal of Climate, 25(9), 3145-3154. https://doi.org/10.1175/JCLI-D-11-00383.1

Radio New Zealand (RNZ). (2014). Christchurch to speed up flood protection work, published online March 2014, retrieved on March 25, 2018 from http://www.radionz.co.nz/news/national/238054/christchurch-to-speed-upflood-protection-work

Rahmstorf, S., and Coumou, D. (2011). Increase of extreme events in a warming world. Proceedings of the National Academy of Sciences, 108(44), 17905-17909. https://doi.org/10.1073/pnas.1101766108

Randel, W. J., Garcia, R. R., Calvo, N., and Marsh, D. (2009). ENSO influence on zonal mean temperature and ozone in the tropical lower stratosphere. Geophysical Research Letters, 36(15), 1-5. https://doi.org/10.1029/2009GL039343

Reisinger, A., Kitching, R. L., Chiew, F., Hughes, L., Newton, P. C. D., Schuster, S. S., Tait, A. and Whetton, P., 2014. Australasia. In Climate Change 2014: Impacts, Adaptation and Vulnerability. Part B: Regional Aspects. Contribution of Working Group II to the Fifth Assessment Report of the Intergovernmental Panel on Climate Change [Edited by Barros, V. R., Field, C. B., and Coeditors]. Cambridge University Press, Cambridge, United Kingdom, 1371-1438

Renwick, J. A., and Thompson, D. W. J. (2006). The Southern Annular Mode and New Zealand climate. Water and Atmosphere, 14(2), 24-25.

Risser, M. D., Stone, D. A., Paciorek, C. J., Wehner, M. F., and Angélil, O. (2017). Quantifying the effect of interannual ocean variability on the attribution of extreme climate events to human influence. Climate Dynamics, 49(9-10), 3051-3073. https://doi.org/10.1007/s00382-016-3492-x

Rosenzweig, C., Karoly, D., Vicarelli, M., Neofotis, P., Wu, Q., Casassa, G., Menzel, A., Root, T. L., Estrella, N., Seguin, B., Tryjanowski, P., and Coauthors. (2008). Attributing physical and biological impacts to anthropogenic climate change. Nature, 453(7193), 353-357. https://doi.org/10.1038/nature06937

Rosier, S., Dean, S., Stuart, S., Carey-Smith, T., Black, M. T., and Massey, N. (2015). Extreme rainfall in early July 2014 in Northland, New Zealand - was there an anthropogenic influence? [in "Explaining extreme events of 2015 from a climate perspective"]. Bulletin of the American Meteorological Society, 97(12), S136S140. https://doi.org/10.1175/BAMS-D-15-00105.1

Seager, R., Naik, N., and Vecchi, G. A. (2010). Thermodynamic and dynamic mechanisms for large-scale changes in the hydrological cycle in response to global warming. Journal of Climate, 23(17), 4651-4668. https://doi.org/10.1175/2010JCLI3655.1 
Shepherd, T. G. (2016). A Common Framework for Approaches to Extreme Event Attribution. Current Climate Change Reports, 2(1), 28-38.

https://doi.org/10.1007/s40641-016-0033-y

Simmonds, I., Keay, K., and Bye, J. A. T. (2012). Identification and climatology of Southern Hemisphere mobile fronts in a modern reanalysis. Journal of Climate, 25(6), 1945-1962. https://doi.org/10.1175/JCLI-D-11-00100.1

Sinclair, M. R. (2002). Extratropical Transition of Southwest Pacific Tropical Cyclones. Part I: Climatology and Mean Structure Changes. Monthly Weather Review, 130(3), 590-609. https://doi.org/10.1175/15200493(2002)130<0590:etospt $>2.0$. co;2

Sippel, S., Otto, F. E. L., Forkel, M., Allen, M. R., Guillod, B. P., Heimann, M., Reichstein, M., Seneviratne, S.I., Thonicke, K., and Mahecha, M. D. (2016). A novel bias correction methodology for climate impact simulations. Earth System Dynamics, 7(1), 71-88. https://doi.org/10.5194/esd-7-71-2016

Sippel, S., Mitchell, D., Black, M. T., Dittus, A. J., Harrington, L., Schaller, N., and Otto, F. E. L. (2015). Combining large model ensembles with extreme value statistics to improve attribution statements of rare events. Weather and Climate Extremes, 9, 25-35. https://doi.org/10.1016/j.wace.2015.06.004

Sippel, S., and Otto, F. E. L. (2014). Beyond climatological extremes - assessing how the odds of hydrometeorological extreme events in South-East Europe change in a warming climate. Climatic Change, 125(3-4), 381-398. https://doi.org/10.1007/s10584-014-1153-9

Solomon, S. (1999). Stratospheric ozone depletion: A review of concepts and history. Reviews of Geophysics, 37(3), 275-316. https://doi.org/10.1029/1999RG900008

Son, S. W., Tandon, N. F., Polvani, L. M., and Waugh, D. W. (2009). Ozone hole and Southern Hemisphere climate change. Geophysical Research Letters, 36(15), 3-7. https://doi.org/10.1029/2009GL038671

Song, Y., and Robinson, W. A. (2004). Dynamical Mechanisms for Stratospheric Influences on the Troposphere. Journal of the Atmospheric Sciences, 61(14), 1711-1725. https://doi.org/10.1175/15200469(2004)061<1711:DMFSIO >2.0.CO;2

Stein, A. F., Draxler, R. R., Rolph, G. D., Stunder, B. J. B., Cohen, M. D., and Ngan, F. (2015). NOAA's HYSPLIT atmospheric transport and dispersion modeling system. Bulletin of the American Meteorological Society, 96(12), 2059-2077. https://doi.org/10.1175/BAMS-D-14-00110.1

Stephens, M. (1974). EDF statistics for goodness-of-fit and some comparisons. Journal of the American Statistical Association, 69(347), 730-737. 
Stott, P. A., Allen, M., Christidis, N., Dole, R. M., Hoerling, M., Huntingford, C., Pall, P., Perlwitz, J. and Stone, D. (2013). Attribution of weather and climate-related events. In Climate science for serving society [Edited by Asrar, G. and Hurrell, J.]. Springer, Dordrecht, United Kingdom, 307-337.

Stott, P. A., Tett, S. F. B., Jones, G. S., Allen, M. R., Mitchell, J. F. B., and Jenkins, G. J. (2000). External control of 20th century temperature by natural and anthropogenic forcing. Science, 290(5499), 2133-2137.

Stott, P. A., Christidis, N., Otto, F. E. L., Sun, Y., Vanderlinden, J. P., van Oldenborgh, G. J., Vautard, R., von Storch, H., Walton, P., Yiou, P., and Zwiers, F. W. (2016). Attribution of extreme weather and climate-related events. Wiley Interdisciplinary Reviews: Climate Change, 7(1), 23-41. https://doi.org/10.1002/wcc.380

Stott, P. A., Gillett, N. P., Hegerl, G. C., Karoly, D. J., Stone, D. A., Zhang, X., and Zwiers, F. (2010). Detection and attribution of climate change: A regional perspective. Wiley Interdisciplinary Reviews: Climate Change, 1(2), 192-211. https://doi.org/10.1002/wcc.34

Stott, P. A., Stone, D. A., and Allen, M. R. (2004). Human contribution to the European heatwave of 2003. Nature, 432(7017), 610-614. https://doi.org/10.1038/nature03089

Stott, P. A., and Tett, S. F. B. (1998). Scale-dependent detection of climate change. Journal of Climate, 11(12), 3282-3294. https://doi.org/10.1175/15200442(1998)011<3282:SDDOCC $>2.0 . C O ; 2$

Sturman, A., and Tapper, N. (2006). The weather and climate of Australia and New Zealand. South Melbourne, Victoria: Oxford University Press.

Tait, A., Henderson, R., Turner, R., and Zheng, X. (2006). Thin plate smoothing spline interpolation of daily rainfall for New Zealand using a climatological rainfall surface. International Journal of Climatology, 1(26), 2097-2115. https://doi.org/10.1002/joc. 1350

Tait, A., Sturman, J., and Clark, M. (2012). An assessment of the accuracy of interpolated daily rainfall for New Zealand. Journal of Hydrology (NZ), 51(1), 2544.

Taylor, K. E., Stouffer, R. J., and Meehl, G. A. (2012). An overview of CMIP5 and the experiment design. Bulletin of the American Meteorological Society, 93(4), 485498. https://doi.org/10.1175/BAMS-D-11-00094.1

Thompson, D. W. J., and Wallace, J. M. (2000). Annular Mode in the Extratropical Circulation. Part I : Month-to-Month Variability. Journal of Climate, 13(1999), 1000-1016. https://doi.org/http://dx.doi.org/10.1175/15200442(2000)013<1000:AMITEC $>2.0$. CO;2 
Thompson, D. W., Baldwin, M., and Solomon, S. (2005). Stratosphere - Troposphere Coupling in the Southern Hemisphere. Journal of Atmospheric Sciences, 62, 708715. https://doi.org/10.1175/JAS-3321.1

Thompson, D. W. J., Solomon, S., Kushner, P. J., England, M. H., Grise, K. M., and Karoly, D. J. (2011). Signatures of the Antarctic ozone hole in Southern Hemisphere surface climate change. Nature Publishing Group, 4(11), 741-749. https://doi.org/10.1038/ngeo1296

Thompson, D. W. J., Furtado, J. C., and Shepherd, T. G. (2006). On the Tropospheric Response to Anomalous Stratospheric Wave Drag and Radiative Heating. Journal of the Atmospheric Sciences, 63(10), 2616-2629. https://doi.org/10.1175/JAS3771.1

Thompson, D. W. J., and Solomon, S. (2002). Interpretation of recent Southern Hemisphere climate change. Science, 296(5569), 895-899. https://doi.org/10.1126/science.1069270

Trenberth, K. E. (1991). Storm tracks in the Southern Hemisphere subtropical oceans. Journal of Atmospheric Sciences. https://doi.org/10.1175/1520-0469

Trenberth, K. E., Dai, A., Van Der Schrier, G., Jones, P. D., Barichivich, J., Briffa, K. R., and Sheffield, J. (2014). Global warming and changes in drought. Nature Climate Change, 4(1), 17-22. https://doi.org/10.1038/nclimate2067

Trenberth, K. E., Fasullo, J. T., and Shepherd, T. G. (2015). Attribution of climate extreme events. Nature Climate Change, 5(8), 725-730. https://doi.org/10.1038/nclimate2657

Trenberth, K., and National Center for Atmospheric Research Staff. (2016). The Climate Data Guide: Nino SST Indices, published online February 2016, retrieved on March 2018 from https://climatedataguide.ucar.edu/climate-data/nino-sstindices-nino-12-3-34-4-oni-and-tni

Ummenhofer, C. C., and England, M. H. (2007). Interannual extremes in New Zealand precipitation linked to modes of Southern Hemisphere climate variability. Journal of Climate, 20(21), 5418-5440. https://doi.org/10.1175/2007JCLI1430.1

Ummenhofer, C. C., Sen Gupta, A., and England, M. H. (2009). Causes of late twentieth-century trends in New Zealand precipitation. Journal of Climate, 22(1), 3-19. https://doi.org/10.1175/2008JCLI2323.1

Waliser, D., and Guan, B. (2017). Extreme winds and precipitation during landfall of atmospheric rivers. Nature Geoscience, 10(3), 179-183. https://doi.org/10.1038/ngeo2894

Watson, P. A. G., Karoly, D. J., Allen, M. R., Faull, N., and Lee, D. S. (2012). Quantifying uncertainty in future Southern Hemisphere circulation trends. Geophysical Research Letters, 39(23), 1-6. https://doi.org/10.1029/2012GL054158 
Waugh, D. W., Randel, W. J., Pawson, S., Newman, P. A., and Nash, E. R. (1999). Persistence of the lower stratospheric polar vortices. Journal of Geophysical Research: Atmospheres, 104(D22), 27191-27201. https://doi.org/10.1029/1999JD900795

Weber, E. U. (2010). What shapes perceptions of climate change? Wiley Interdisciplinary Reviews: Climate Change, 1(3), 332-342. https://doi.org/10.1002/wcc.41

World Meteorological Organization (WMO). (2014). Scientific Assessment of Ozone Depletion: 2014. Report No. 55, Global Ozone Research and Monitoring Project, World Meteorological Organization, Geneva, Switzerland, 416 p.

Zender, C. S. (2008). Analysis of self-describing gridded geoscience data with netCDF Operators (NCO). Environmental Modelling and Software, 23(10-11), 1338-1342. https://doi.org/10.1016/j.envsoft.2008.03.004

Zhang, X., Alexander, L., Hegerl, G. C., Jones, P., Tank, A. K., Peterson, T. C., Trewin, B., and Zwiers, F. W. (2011). Indices for monitoring changes in extremes based on daily temperature and precipitation data. Wiley Interdisciplinary Reviews: Climate Change, 2(6), 851-870. https://doi.org/10.1002/wcc.147

Zhang, X., Wan, H., Zwiers, F. W., Hegerl, G. C., and Min, S. K. (2013). Attributing intensification of precipitation extremes to human influence. Geophysical Research Letters, 40(19), 5252-5257. https://doi.org/10.1002/grl.51010

Zwiers, F. W., Zhang, X., and Feng, Y. (2011). Anthropogenic influence on long return period daily temperature extremes at regional scales. Journal of Climate, 24(3), 881-892. https://doi.org/10.1175/2010JCLI3908.1 


\section{APPENDICES}

\section{Appendix A: Mean sea level pressure anomalies for 2013}

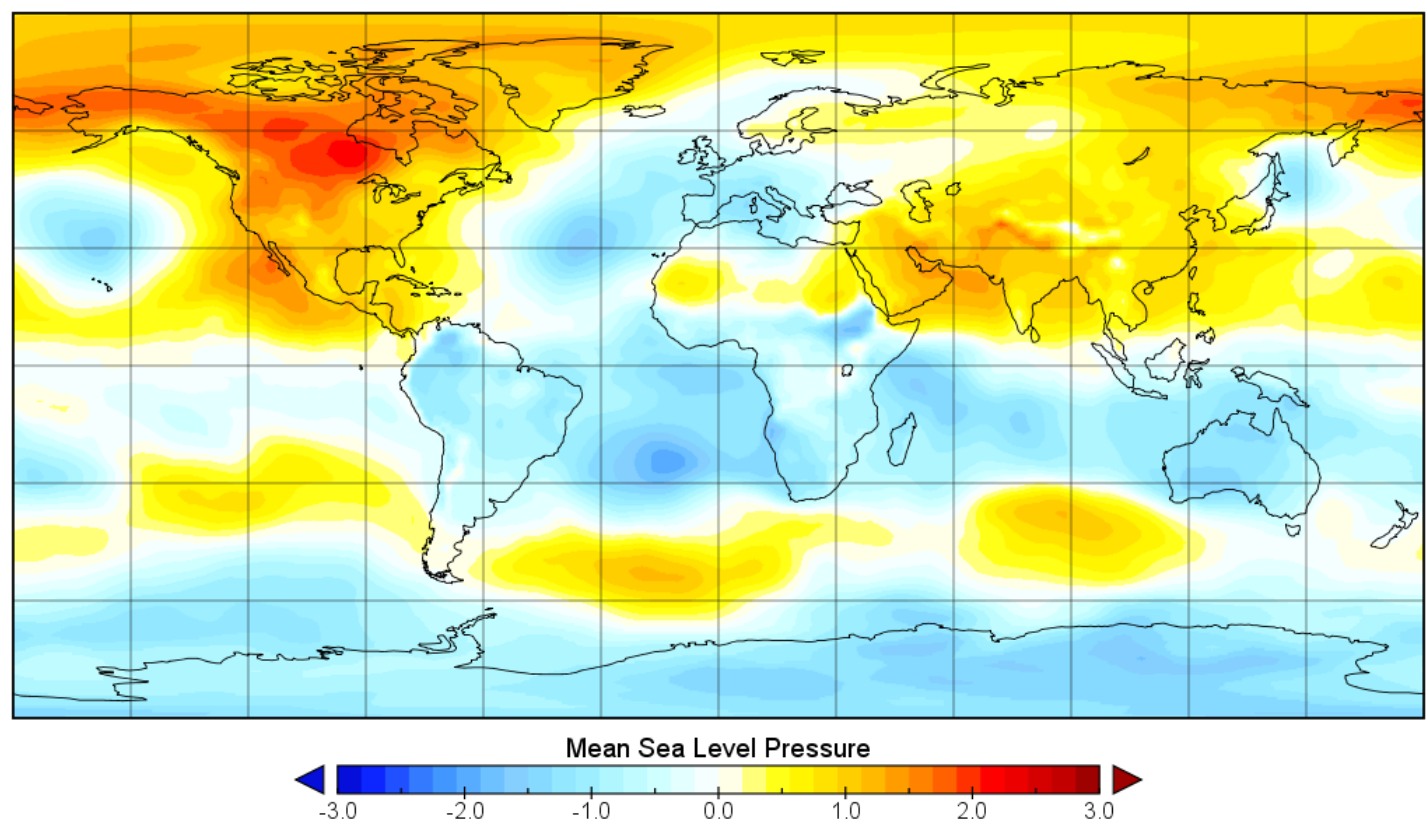

Figure A.1: MAM (Austral autumn) MSLP for 2013 compared to 1979-2017 climatology in ERA-Interim displaying standardised anomaly (dimensionless, units are standard deviations).

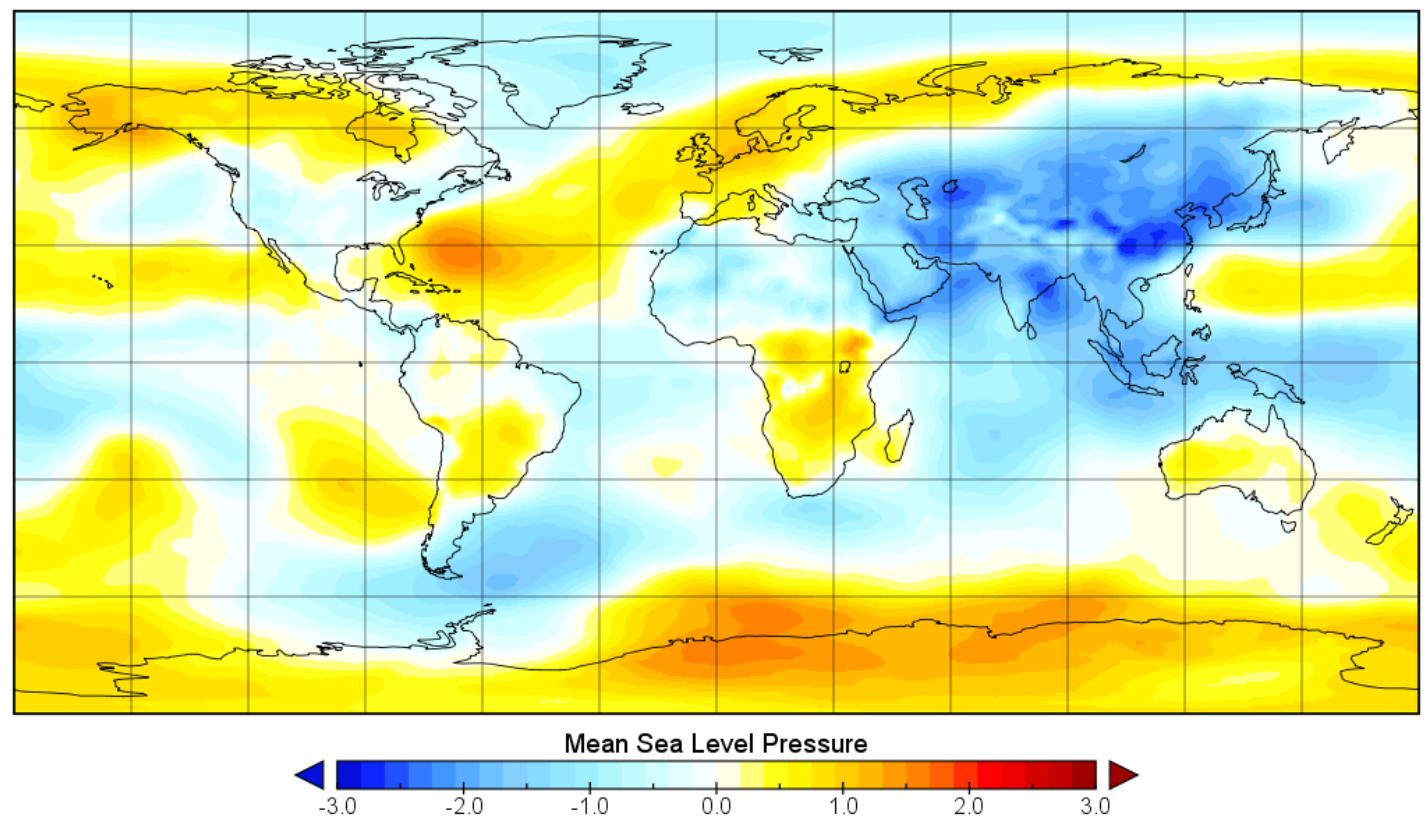

Figure A.2: JJA (Austral winter) MSLP for 2013 compared to 1979-2017 climatology in ERA-interim displaying standardised anomaly (dimensionless, units are standard deviations). 


\section{Appendix B: 1986 South Canterbury flood}

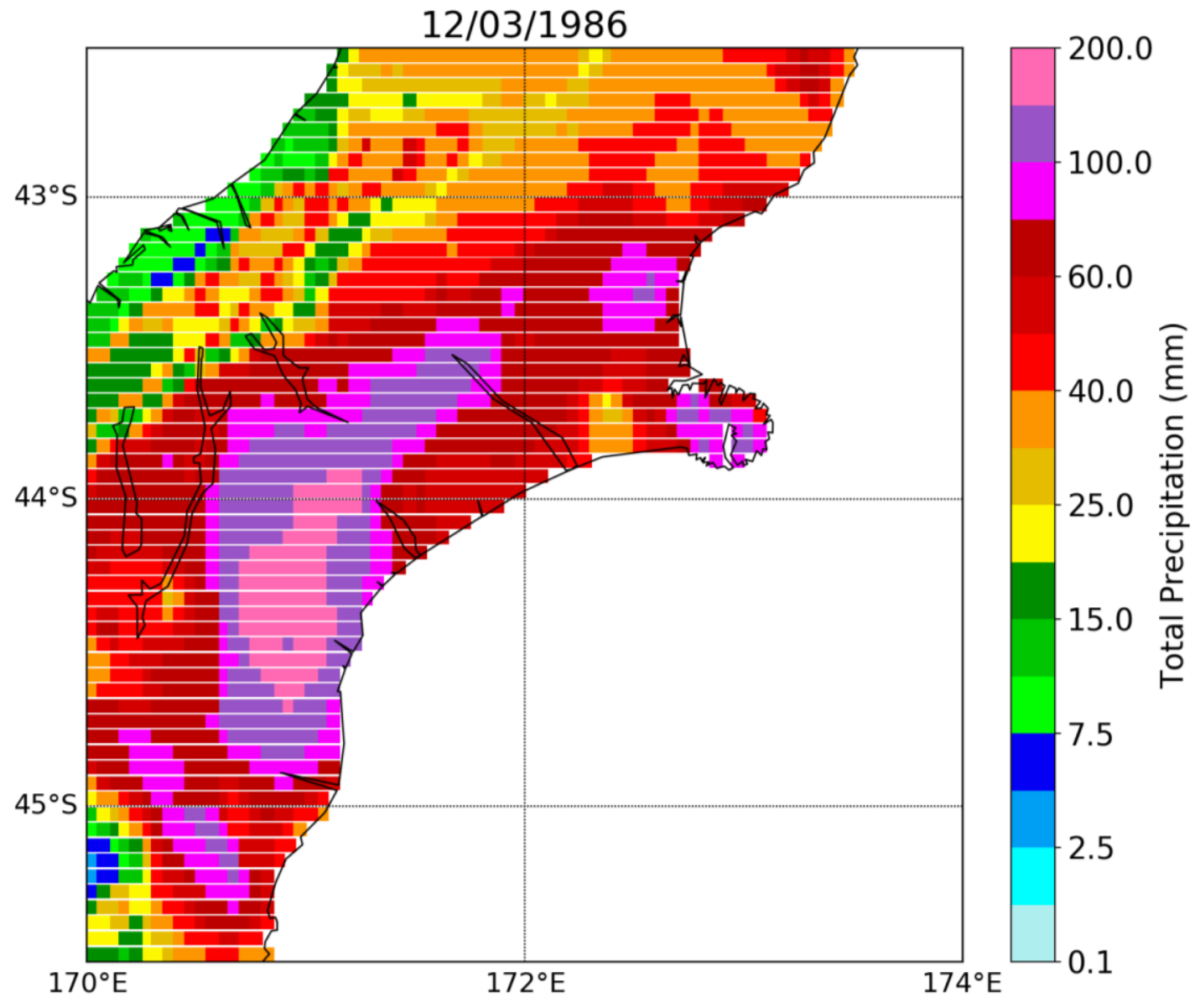

Figure B.1: Virtual Climate Station Network total precipitation (mm) on $12^{\text {th }}$ March 1986 which resulted in extensive flooding throughout South Canterbury determined to have an average recurrence interval of at least 100 years. 
